\title{
Sound science: recording and listening in the biology of bird song, 1880-1980
}

Citation for published version (APA):

Bruyninckx, J. L. M. (2013). Sound science: recording and listening in the biology of bird song, 1880-1980. [Doctoral Thesis, Maastricht University]. Maastricht University. https://doi.org/10.26481/dis.20130419jb

Document status and date:

Published: 01/01/2013

DOI:

10.26481/dis.20130419jb

Document Version:

Publisher's PDF, also known as Version of record

\section{Please check the document version of this publication:}

- A submitted manuscript is the version of the article upon submission and before peer-review. There can be important differences between the submitted version and the official published version of record.

People interested in the research are advised to contact the author for the final version of the publication, or visit the DOI to the publisher's website.

- The final author version and the galley proof are versions of the publication after peer review.

- The final published version features the final layout of the paper including the volume, issue and page numbers.

Link to publication

\footnotetext{
General rights rights.

- You may freely distribute the URL identifying the publication in the public portal. please follow below link for the End User Agreement:

www.umlib.nl/taverne-license

Take down policy

If you believe that this document breaches copyright please contact us at:

repository@maastrichtuniversity.nl

providing details and we will investigate your claim.
}

Copyright and moral rights for the publications made accessible in the public portal are retained by the authors and/or other copyright owners and it is a condition of accessing publications that users recognise and abide by the legal requirements associated with these

- Users may download and print one copy of any publication from the public portal for the purpose of private study or research.

- You may not further distribute the material or use it for any profit-making activity or commercial gain

If the publication is distributed under the terms of Article $25 \mathrm{fa}$ of the Dutch Copyright Act, indicated by the "Taverne" license above, 
Sound Science 
Copyright (C) 2013, Joeri Bruyninckx

Cover image: pour des dents d'un blanc éclatant et saines, (C) Jeroen Diepenmaat 2005

Cover design: Noortje Bruyninckx

Printed \& Lay Out by: Datawyse Maastricht

The printing of this dissertation has been financially supported by the Netherlands Graduate Research School for Science, Technology and Modern Culture (WTMC). 


\section{Sound Science \\ Recording and Listening in the Biology of Bird Song 1880-1980}

\section{PROEFSCHRIFT}

Ter verkrijging van de graad van doctor aan de Universiteit Maastricht, op gezag van de Rector Magnificus, Prof. dr. L.L.G. Soete volgens het besluit van het College van Decanen, in het openbaar te verdedigen op vrijdag 19 April 2013 om 14.00 uur

door

JOERI LOUIS MARIA BRUYNINCKX 
Promotor:

Prof. dr. K. T. Bijsterveld

Copromotor:

Dr. J. C. M. Wachelder

Beoordelingscommissie:

Prof. dr. ir. W. E. Bijker (voorzitter)

Dr. R. de Bont

Dr. A. Fickers

Prof. dr. ir. H. van Lente (Utrecht University)

Prof. dr. M. E. Lynch (Cornell University, USA) 


\section{Contents}

Acknowledgements

Chapter 1 Tuning in to Mechanical Ears

Introduction 11

Sound recording in field ornithology 13

Overview 18

Focus, methodology and analysis $\quad 21$

$\begin{array}{ll}\text { To the field } & 27\end{array}$

Chapter 2 Scientific Scores or Musical Ears

Sonic skills, diagrams and field work

Introduction 29

The attraction of the field 31

Learning to listen $\quad 35$

Naturalists, musicians, scientists $\quad 39$

Birds' music and graphic notation 46

Conclusion $\quad 51$

Chapter 3 Staging Sterile Sound

Producing and reproducing natural field recordings

Introduction $\quad 55$

Listening objectively 59

The complexities of field recording $\quad 64$

Two approaches to field recording $\quad 71$

Laboratorizing the field $\quad 75$

Conclusion 81 
Chapter 4 Samples, Assets and Trophies

Engaging networks of field recordists

Introduction $\quad 85$

New contexts of recording $\quad 88$

A community of recordists 96

A Moral Economy of Scientific Recording $\quad 100$

Authorship and shared listening $\quad 110$

Conclusion 114

Chapter 5 Patterned Sound

Inscriptions and the trained ear in bird song analysis

Introduction 119

Visible hearing $\quad 122$

Visual patterns $\quad 126$

Aural patterns $\quad 134$

Musical patterns? $\quad 137$

Visual inscriptions 143

Conclusion 147

Chapter 6 Sound Science

Conclusion

Introduction $\quad 151$

Changing patterns of listening $\quad 153$

New questions and knowledge 159

Legitimizing sound recordings 162

Conclusion 166

$\begin{array}{lll}\text { Appendix A Source collections consulted } & 169\end{array}$

$\begin{array}{lll}\text { Appendix B Interviews } & 171\end{array}$

$\begin{array}{ll}\text { List of illustrations } & 173\end{array}$

$\begin{array}{ll}\text { Bibliography } & 177\end{array}$

$\begin{array}{lr}\text { Samenvatting } & 199\end{array}$

$\begin{array}{ll}\text { Curriculum Vitae } & 205\end{array}$ 


\section{Acknowledgments}

In researching and writing Sound Science, first as a master thesis, then as a dissertation, I have accrued several debts of gratitude. While researching and writing this book, ornithologists, recordists, curators, editors and sound archivists have welcomed me in their homes, gardens, cabins, archives and offices. Invariably they granted me their time for interviews, dug up valuable documents, responded to ideas, and graciously coped with sometimes peculiar queries. In particular, I am grateful to Cheryl Tipp and Richard Ranft of the British Library, Jeffrey Boswall, the recordists of the British Society for Wildlife Sound Recording and the Dutch Club voor Natuurgeluiden Registratie, Hans Slabbekoorn, Greg Budney and his colleagues at the Cornell Laboratory of Ornithology as well as Randy Little, KarlHeinz Frommolt, Guenter Tembrock and his wife Sylvia at the Tierstimmenarchiv, the staff of the Cambridge and Cornell Macaulay Libraries. Listening to their stories has invariably enriched my understanding of the history of scientific recording.

My gratitude also extends to the people who have helped me to condense my argument. My promotor Karin Bijsterveld has exercised many a patient and enthusiastic ear. I am most grateful for her confidence in this project, for carefully sensing what I wanted this book to become and for helping me work towards that, draft by draft. I have also benefited much from having in Jo Wachelder a copromotor who invited me to re-open doors that I, sometimes inadvertently, had closed too soon. I am equally indebted to Trevor Pinch, who supported this project in more than one guise. As an editor and discussant on several occasions, he has pushed me to articulate my ideas more precisely. His enthusiasm for the field of Sound Studies has also been a persistent source of inspiration. Moreover, during the fall semester of 2010 Trevor and the faculty and graduate students of the STS department at Cornell University generously welcomed me in their midst, and they provided a wonderfully stimulating environment for me to tune into.

I was lucky to spend the long stretches of analysis and writing in room 1C.18, with its open views overlooking the perch of an insistently serenading blackbird in the garden, and with roommates such as Verena., Fabian, Marije, Tim and Vincent. They and many other colleagues at the Faculty for Arts \& Social Sciences have listened to, read and commented upon various versions of this dissertation. I have also tremendously enjoyed discussing, presenting and refining my work with col- 
leagues in the STS, Sounders and Sonic Skills groups. Outside of Maastricht, the Graduate Research School of Science, Technology and Modern Culture has brought together a wonderful mix of people in my field and I have learned from each training, workshop and dissertation-day. I offer my gratitude in particular to its academic coordinators, Sally Wyatt, Willem Halffman, and Teun ZuiderentJerak, as well as David Nye and Michael Lynch as anchor teachers, but also to everyone who took the time to dissect and discuss work in progress during muchvalued dissertation days. Likewise, co-panelists, discussants and audiences at various conferences have impacted this work in unmistakable ways.

Several colleagues and friends have made work ever so enjoyable and free time ever so stimulating. Among the people that I have enjoyed eating, cooking, walking, writing and singing with, Alexandra has been a generous commenter on ideas and drafts, up to the very last version of this book. Koen and Constance have been both critical colleagues and friends with whom I explored many a garden - and learned to negotiate safe ways for taking the inevitable stumbling stone. Finally, I am grateful to my family. My parents have been great advocates and supporters. Mom once wisely observed that a bird should not sit on its nest for too long and I believe I can safely say that for now at least, brooding is over. I also thank Noortje for her impromptu work on the wonderful cover of this book. Marijke, at last, now my wife, has been there all along. She has been an inexhaustible source of love, support and common-sense, reminding me, elegantly though relentlessly, of all those things that cannot be recorded. 


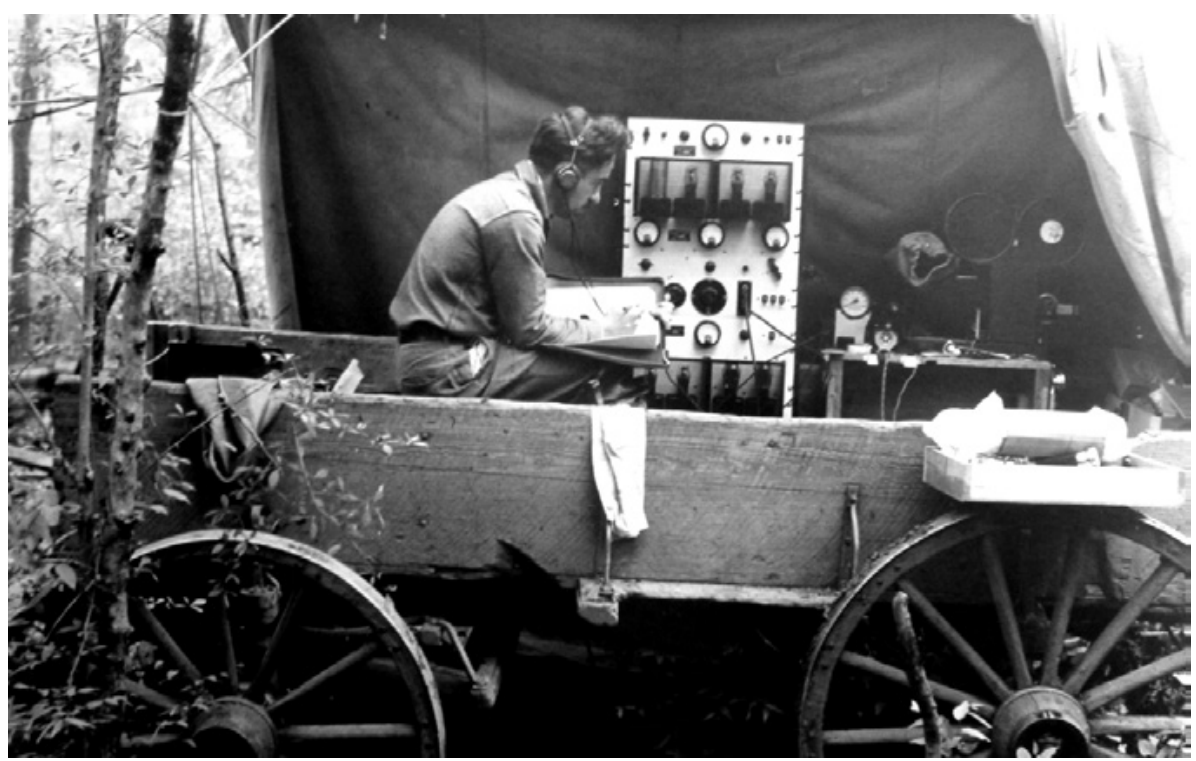

Figure 1.1

Cornell ornithologist Peter P. Kellogg on field expedition, in an improvised studio observing and recording a nest of ivory-billed woodpeckers, in 1935. 


\section{1 \\ Tuning in to Mechanical Ears Introduction}

\section{Introduction}

In the spring of 1935, an expedition of five ornithologists and one graduate field assistant perched on a spot deep in the heart of Louisiana swamp land. They had set out to study and collect the voices of American birds and had arrived there from New York on a five-month round-trip through the Eastern United States, organized by the American Museum of Natural History and Cornell University. The group's objective was to seek out and record the voices of birds rumored to be vanishing, and they had received reports that the crowning glory of these birds, the elusive ivory-billed woodpecker, had recently been spotted again. One decade earlier, head of the Louisiana expedition and leading field ornithologist 'doc' Arthur A. Allen had uniquely witnessed a pair of ivory-bills, but advancing loggers and eager shotgun collecting by fellow ornithologists had made such sights increasingly rare (Beyer, 1900). ${ }^{1}$ For several days, the party had waded through flooded bayous and muddy virgin forest, until they finally discovered a nest, "thanks to the keen ears and woodsmanship" of the local game warden who had guided them.

Once found, the excited scientists camped on a dry spot near the nest for almost a week. Taking turns on the ground and in a hide in a nearby tree, they kept their eyes and ears fixated on the birds. Along with binoculars, photo-cameras and film recorders, they also used a mule-drawn cart to wheel two truck-loads of sound recording equipment into the marshes and installed an improvised recording studio on top of the cart. In the preceding years, the ornithologists had perfected their recording technique and equipment in the woods and fields around the Cornell campus, but this kind of wilderness - remote, dirty and humid - exceedingly put it to the test. Nonetheless, they managed to make "the microphone and 'electric ear' stand within 50 feet of a tree which the birds frequent[ed] [ . . . ] so that the whole set-up for the study of America's rarest bird [was] about as perfect as could be hoped for."2 Sat there, bent over field notes and absorbed by their earphones, eavesdropping on the woodpeckers, ornithologist professor Peter Kellogg and his

\footnotetext{
${ }^{1}$ Voices of Southern Birds Recorded for Movie Films (May 18, 1935). The Science News-Letter, 27(736): p. 316.

2 Cornell University Library (hererafter: CUL), Brand papers, 1:42, letter Arthur A. Allen to Louis Bochever, 15 April 1935.
} 
colleagues made the species' first and only existing sound recordings (see figure 1.1).

The Cornell recordings still serve as the single authoritative reference for comparing recordings thought to be of the ivory-billed woodpecker. Even though the species has long been presumed extinct, over the past decades amateur and professional ornithologists have undertaken several (sometimes publicized, often secretive) expeditions in search for what scientists and birders alike have described as their "holy grail". 3 While most have been unsuccessful, some claimed to have spotted or at least believed to have heard the distinctive voice of the species that has been described as a "ghost bird". 4 In the densely forested tracts of Arkansas and Louisiana, visibility is severely limited. Hence recorded aural evidence of the bird's call has acquired a central role in the assessment of such claims. Much, however, has been at stake in the validation of these claims, and not just for the ornithologists. Over the twentieth century, the ivory-bill has been ascribed a large symbolic value, as its possible rediscovery seemed to signify 'a second chance' for nature restoration and conservation. Conclusive confirmation that the species had persisted would therefore have important consequences also for conservationists and policy makers in making a case for the legal protection of a large area in both states.

The recorded aural evidence available has, however, split the ornithological community. ${ }^{5}$ What had sounded convincingly like the original Cornell recordings and thus appeared as conclusive proof of the ivory-bill's survival to many of its discoverers, was received with skepticism by others. Critical ornithologists mobilized their own aural judgments, as well as various kinds of visual analyses (such as amplitude displays and audio-spectrograms), to contest the recordings' identification and thereby the evidence's irrefutability. They questioned for instance the earwitnesses' fielding skill and reputability, and advanced that the recordists might have mistaken the noises of nearby roads, gunfire, other bird species with oddly similar calls, or other humans, who mimicked the calls with clarinet mouthpieces or even broadcasted playbacks of the historic Cornell recordings in order to provoke the ghost bird's response (Fitzpatrick, 2006). Others complained that the signal was obscured by too much noise, and that this prohibited detailed analysis. Proponents and critics have each tried to enhance the recordings' intelligibility and debated the available evidence in prominent journals such as Science or The Auk. But although reputable institutes such as the Cornell Laboratory and the Nature Conservancy have repeatedly endorsed a number of recent sightings, to date ornithologists did not manage to authoritatively confirm the bird's much-expected tentative rediscovery, and the controversy has now again gradually faded from view.

\footnotetext{
${ }^{3}$ This description is used in some of the memoirs by ornithologists involved in the search, or popular scientific accounts of these expeditions. See for instance Bales (2010).

${ }^{4}$ See for instance Bales (2010) or Steinberg (2008).

5 See for instance Dalton (2005), Fitzpatrick (2006), Hardy (1975), Hill, Mennill, Rolek, Hicks \& Swiston (2006), Jones, Troy \& Pomara (2007).
} 


\section{Sound Recording in Field Ornithology}

As recent science studies scholarship has begun to show, the ivory-bill case provides an invaluable insight into the complex dynamics of a highly publicized scientific controversy (Barrow, 2011; Lynch, 2011; Walters \& Crist, 2005; Winn, 2009). But importantly, it also suggests the difficulty involved in mobilizing sound recordings to convincingly support scientific claims. However, that ornithologists did turn to sound recordings to substantiate their observations and claims in the ivory-billed woodpecker controversy was not a unique or isolated occasion. Even before the 1935 expedition, ornithologists had noted down sounds and claimed them as a suitable way of studying the life of birds. Since its first adoption, mechanical recording has variously been deployed as an investigative technique.

For instance, trained listeners, and recently also automated recognition recorders, have drawn on sound recording to monitor and census the distribution of species as well as individual birds where conventional techniques fail - in densely forested habitats or during nightly migrations (Baptista \& Gaunt, 1997). Recordings have also extensively been drawn upon to discern taxonomic relations between species, alongside more traditional markers of distinction (such as feather coloration or anatomy), and they have been crucial in the discovery of a list of 'new' species (Alström \& Ranft, 2003). Furthermore, sound recordings have been the methodological foundation for documenting and studying the processes by which birds learn, inherit or vary their songs, as well as to experiment with their social functions by playing back sounds to elicit vocal reactions in the field (Slabbekoorn, 2004). Such work has laid bare fundamental biological mechanisms that take place in the evolution of a species and have provided working models to explore questions of language acquisition by individual birds. Moreover, since the mid-century these investigations have been supported by several sound archives in North America, Europe and elsewhere, which collectively make hundreds of thousands of sound recordings available for bio-acoustic research, analogous to the collections of physical specimens such as eggs, skins or mounted exemplars that exist in other branches of natural history investigation (Kroodsma et al., 1996). In several respects, then, sound recordings have become a standard tool to document, study, understand and preserve the vocal behavior of birds, and, in specific branches of biological research, it has become a recognized approach to validate scientific claims about them.

It is against the background of such diverse scientific applications that this dissertation asks how sound recordings have been used and legitimized as a tool for scientific study in field ornithology. It seeks to show that such contemporary scientific applications of sound recording themselves unfolded over time in a much longer, complex and contingent history. Taking a perspective informed by scholarship in science and technology studies (STS), this book explores a history of how, over the long twentieth century, sound recordings have come to be regarded, crafted, acknowledged and contested as scientific objects, and how they have been em- 
bedded into a set of aural investigative techniques that field scientists relied on in their work. As I will argue, this was not a straightforward process. For sound recording to work and be accepted as a scientific technique, the instrument and its users had to be redefined technically, socially, culturally and even physically. Moreover, sound recordings were never exclusively scientific materials; they could be and were appropriated for other purposes too, and their use and legitimization as a scientific tool has hinged on ornithologists carefully negotiating the conditions under which recordings and its users could claim epistemic authority.

To the extent that historical scholarship has considered the role of sound recording in a scientific context, it has, however, tended to take for granted its legitimization as a tool of scientific work. Historian of science Gregory Radick's (2007) accomplished study of post-Darwinian primatology, for instance, illustrates how already by the late nineteenth century, phonograph recordings have been used in biological field research and how they quickly took center stage in a debate on the concept of animal mind and the related problem of animal language. He analyzes the circumstances under which biologists around 1890 and 1980 explored what primate vocalizations could reveal about the theory of evolution. But like related historical work dealing with the scientific applications of sound recording technologies, Radick presents this history above all as an intellectual history that examines shifts in conceptions of animal language, rather than a history of the methodological legitimization of sound recording practices. ${ }^{6}$ While such work has in many ways usefully highlighted how sound recording began to serve as a lever in unleashing and resolving recurring controversies over animal vocalization, my own focus in this book, instead, lies with the cultural life as well as the material practices that have spun around these sound recordings themselves.

Recent work in media history as well as folk and literary studies has begun to do just that, by tracing the various histories of the cylinder phonograph, especially in ethnographic field work (Ames, 2003; Hochman, 2010; Rehding, 2000; Stangl, 2000; Sterne, 2003). Literary scholar Brian Hochman (2010) has shown, for instance, how ethnographers' adoption and legitimization of the phonograph had been motivated by a desire to capture auditory differences without the cultural bias of the human listener. As such, he notes, the mechanical recorder seemed to comply with what Lorraine Daston and Peter Galison (2007) have termed 'mechanical objectivity': the desire to eliminate human influence from the processes of observation and representation so as to maximally avoid the distortions of subjectivity such as personal taste, judgment and cultural bias. Such discourses surrounding mechanical recording provide an important reference point for understanding why and how listening has been delegated to 'mechanical ears' in the first place. However, in so emphasizing ethnographers' apparent epistemic confidence in the mechanical objectivity of the apparatus, these studies also tend to oversee the alternative mean-

${ }^{6}$ See for instance, Thomas (2005) and Zon (2007). 
ings that this technology might embody and the sustained practical work that has been involved in achieving such assurances of scientific authority.

In fact, as the woodpecker controversy above has demonstrated, the evidentiary value of mechanically recorded sound should not at all be overestimated (Lynch, 2011). Folklorist Erika Brady (1999) has suggested that unlike their American linguist colleagues, several British musicologists fiercely opposed adopting the phonograph in their studies of folklore songs because they preferred original notations transcribed by trained musicians instead. These recordists had trained their ears such that the observer herself became an instrument of observation. Moreover, the recent historiography of phonographic recording has shown that such recordings were not by themselves stable entities (Sterne, 2003). Julia Kursell (2012) for instance demonstrates that phonographs did not simply suppress the observers' own auditory experiences in favor of mechanic representations. In fact, for some they shifted the focus of the observer instead towards the processes of hearing. Mechanical recording instruments thus did not just simply close, but also repeatedly open the black box of sound recording processes, as well as the role of human perception therein. In addition, Kursell argues, the deployment of phonograph records in scientific contexts has variously been influenced by commercial interests and cultural settings. Ethnographic recordists' at the Berlin and Viennese phonographic archives preferred different instruments; Berlin recordists used a light, mobile yet vulnerable phonograph in the field, while Viennese recordists preferred a heavy, immobile gramophone instead. Although this prevented the instrument from leaving the rooms of the Austrian Academy of Sciences and being taken on field expeditions, it did allow commercial duplications and thus suggested a selfsustaining potential for the ethnographers' archival work.

Hence if we are to gain a better understanding of how sound recording has actually acquired epistemic currency, we must turn our focus also to its material existence and the specific social, cultural and technological contexts in which it circulated. This will be the focus of this book. For ornithology, these contexts primarily resulted from its status as fieldwork. Historians of science have recently begun to address scientific work in the field (Kohler, 2002c; Kohler, 2006; Kuklick \& Kohler, 1996; Vetter, 2011), and the history of scientific sound recording folds into many of the social and cultural transformations through which the field-site has been described to have emerged as a place of scientific investigation. When ornithology became established as a specialized field of study in the middle of the nineteenth century, its province was largely confined to museum collections of mounted specimens. The specimens were being shot and collected in the field, but authoritative academic work itself focused on ordering taxonomies of specimens indoors. Due to shifts in conceptions of nature and the increasing popularity of bird watching around the turn-of-the-century, a growing group of amateur naturalists turned to actually observing and listening to birds in the field. These naturalists collected sounds by transcribing them on paper in the field, using musical or other graphic scores for later reference, or 'hunting' the birds with a microphone. Such 
work granted sound to varying degrees a material presence that had been expected of traditional ornithological work. Yet the professional guard of museum academics remained deeply divided over what value should be ascribed to such field reports. Even though the field-site has gradually acquired professional acceptance - due in part to the study of animal behavior gaining strong foothold in biology before the middle of the twentieth century - its status has long remained compromised by comparisons to museum and later laboratory work, which has also impacted the scientific use and legitimization of sound recording.

Even when academic professionals adopted mechanical recording technologies to provide an assurance of objectivity when they shifted their focus to the field, these tools also amplified the variability and particularities of the field-site. Different field disciplines relying on field recordings put different demands to their recorded specimens. Moreover, unlike the laboratory, access to the field-site could not be restricted; it remained an integral part of a public space that could be traversed and acted in by different kinds of people, and thus could never be an exclusively scientific domain (Alberti, 2001; Kuklick \& Kohler, 1996; Lachmund, 2003; Vetter, 2004). Because field recordists conducted their research in the nature reserves, forests and city parks that were also frequented by hunters, tourists, commuters and laborers, encounters with non-scientists and their social activities were simply inevitable. The trust-inspiring exclusivity of the laboratory was often absent in field work, which underlined its deeply ambiguous epistemic status (Kohler, 2002b; Shapin, 1988). Scientific field recordists therefore not only had to safeguard their recordings against the elements and the changing material conditions of fieldwork such as dirt or humidity, but also against some of the social and especially acoustical interferences that seemed to compromise their authority. The skeptical reinterpretations of the ivory-billed woodpecker recordings as anthropogenic noises do suggest that particular field-sites come with their own complex soundscapes and that these do in effect influence how recordings are listened to and how they are trusted to validate specific knowledge claims.

In part due to this physical accessibility, scientific field work has also often involved a more socially diverse group of laborers. Particularly in ornithology, amateur ornithologists and birdwatchers have had a vital and pervasive influence (Ainley, 1979; De Bont, 2009b; Mayfield, 1979). In comparison to other natural subjects, birds are widely and generally distributed, as well as relatively easy to encounter and spot in the wild, and as such have generally captured the attention of individuals with limited resources. Moreover, as an animal vocalization traditionally qualified as song, bird sound has enjoyed a strong cultural resonance. Hence recording and listening to them has engaged a diverse lot of people. When biologists turned to the field to record the sounds of birds, they thus shared this space with a heterogeneous community of other recordists - if 'community' is at all the right word to describe such varied and tenuously defined networks. What may above have been conveniently collected under the rubric of 'ornithology' actually fans out in a wide range of field identities that included 'amateurs', dedicated naturalists and 
recreational birdwatchers, as well as 'academic professionals', ornithologists next to ethologists, ecologists, systematists or bio-acousticians. They were often accompanied by hobby recordists, sound hunters, musicians and composers, as well as radio and television broadcasters, movie producers and their teams of recording engineers, operators and assistants.

Although these groups' involvement may have variously been obscured in inventories of recorded specimens or scientific articles, they did have a profound influence on the development of ornithological field recording into a scientific practice. Due to the geography and scale of field research and the technical sophistication of recording practice, professional biologists often found themselves relying on the embodied experience of local amateur recordists, the technical expertise of recording engineers or even the listening skills of musicians. Because of these alliances, the identity of the scientific recordist did not remain fixed either, but while such dependencies could reflect positively on the scientific observer they also threatened to compromise the credibility and authority of both biologists and sound recordings. After all, if scientists depended on musically trained listeners or movie broadcasters, could they detach themselves from their overly aesthetic and emphatic engagements with nature and instead guarantee the distance and reliability required of their observations, identifications and recordings?

This was even more the case because sound recordings were never exclusively scientific specimens: amateurs, composers, broadcasters, ornithologists and ethologists did not only bring different skills to the job, but also recorded bird vocalizations for their own particular intellectual, practical or economic motives. Even when the Cornell recordists set out on their endeavor in 1935, they anticipated that their recordings might be beneficial also beyond their scientific study. Recordings have since been used as teaching tapes and didactical tools in classrooms and the domestic sphere, to entertain and to train the ears of aspiring naturalists. They have also been used in local and national wireless broadcasts and with the advent of sound motion pictures in the 1920 s, wildlife recordings with scientific relevance also became of much use as background sounds to accompany commercial broadcasts as well as nature films. Even if mechanical recordings had seemed to dissociate the observation from observers' skill, their success as scientific objects could vary with each of the ways in which their producers' motives had shaped how recordings were made, identified, authorized, processed, exchanged and circulated.

Therefore, in transforming sound recordings into scientific specimens, scientific recordists did not simply depend on other groups in the field, but also had to grapple with the various social and cultural contexts in which sound recordings customarily circulated. For that reason, sound recorders' suggestion of objectivity and reliability was to be carefully constructed and balanced with other interests, by reconfiguring existing artifacts, practices and conventions. This involved rearticulating notions such as those of aestheticism, authenticity and fidelity that surrounded recorded sound in other realms, in accordance with their own ideals in scientific work. Capitalizing on them as scientific specimens also involved negotiat- 
ing prosaic issues such as ownership and authorship of recordings. Moreover, the deployment of recording technologies as scientific instruments even required modifying and adjusting the technologies themselves to fit recordists' scientific ambitions and their notions of what the ideal listener entails. To deploy recording technologies in a certain way also implied a specific understanding of aural perception. The appropriation of sound recording in scientific practice has thus been the result of a complex process in which scientists and recordists too strategically opened up and closed the black-boxes of sound recording processes and aural perception.

The question that this dissertation ultimately sets out to answer, then, is how, under these conditions, ornithologists have employed sound recording as a scientific technique to make sense of what they studied in the field. This involves asking: how have ornithologists employed their ears in making sense of what they studied and how and with help of which tools did they listen to their objects of study? How have such practices of mediated and unmediated listening generated new kinds of questions or findings? And how have these kinds of listening come to be legitimized as authoritative and reliable scientific practice? Tracing the history of scientific sound recording inevitably involves attending to the shifts and continuities in relations between embodied listening and mediated recording, between amateurs and professionals, experts and laypeople, the field and the laboratory, the acoustic and the musical as well as the auditory and the visual.

\section{Overview}

In pursuing these questions, this book unfolds a particular history of ornithological sound recording. These chapters trace the gradual development of sound recordings as scientific objects chronologically as well as thematically. The chapters cover this history first of all by focusing on successive periods of between two and five decades, in the century-long period between 1880 and 1980. This chronological thread aims to allow insight into the historical development of the field of bird song biology, its inhabitants and its listening techniques. But rather than aiming for a comprehensive historical coverage, each chapter at the same time seeks to illuminate that history from a different vantage point. In each chapter, therefore, a technological innovation in bird song recording practices serves as a lens through which a different set of theoretical issues is explored. Each thematic chapter thus highlights to different degrees the respective material, social and representational technologies that have been developed in order to reproduce sound recordings as scientific objects. These chapters moreover follow a conceptual sequence in which sound recordings are processed from the field to their analysis in the laboratory and into publication.

Chapter 2 "Scientific Scores or Musical Ears: Sonic skills, diagrams and field work" focuses on a half-century period between 1880 and 1930. Since 1878, mechanical sound reproduction had become a practical reality. But although naturalist 
work had begun to turn to the field-site to study the lives and behavior of wild birds, technical issues prevented the application of the phonograph in field work. This 'prologue' to mechanical recording provides an ideal starting point to introduce some of the issues that concern me in this book. It traces how a dispersed group of amateur naturalists and ornithologists sought to establish musical notation as a workable and authoritative scientific technique in field observation. Such field observation had been the province of (amateur) naturalists as well as recreational birdwatchers, and slowly gained recognition by professional ornithologists. This, I show, was a complex process in which field observers were not only to bolster their own epistemic authority in the face of professional skepticism, but also reached out to a very heterogeneous group of naturalists, birdwatchers and professionals. Scientific listening thus took shape between efforts to standardize on the one hand, and the multiplicity of interests, competencies, and local practices of listening on the other. In understanding how sound recordings became grounded as scientific objects, it is thus important to consider how they operated not only as mimetic inscriptions, but also afforded alternative didactic, mnemonic and alluring functions.

As I show in Chapter 3, "Staging Sterile Sound: Producing and reproducing natural field recordings", mechanical recordings integrated all four functions when they were first successfully produced in the field from 1930 onwards. Moreover, they promised to replace inherently subjective impressions with objective registrations. Although this had seemed to discard the need for specialized listening skills, it also restricted field recording to those with access to expensive and technically demanding equipment. Between 1930 and 1950, small groups of ornithologists in Britain and the United States emerged alongside the 'artisanal' naturalist recorder, who ventured into field recording through various alliances with the recording industry. But these gramophones and microphones also came with their own practical and epistemological problems. Analyzing the problems of recording in the field and recordists' solutions for dealing with them, this chapter shows that in order to usefully serve as both scientific and commercial objects, sound recordings themselves were to be artfully crafted. This involved not only appropriating existing notions of fidelity and realism and harmonizing those with scientific notions of objectivity or authenticity. It also involved the re-construction of the field-site itself into a place of scientific and technological control, a process that I have termed the laboratorization of the soundscape of the field. Drawing on scholarship on the history of fieldwork, the sociology of place in science and of visual representation, I argue that this enabled recordists to strategically mediate between the acoustic and epistemic properties of the field, the laboratory and the sound studio.

In Chapter 4, "Samples, Assets and Trophies: Engaging networks of field recordists" I show how the reconfiguration of these recordings into a scientific object was not only a material intervention, but also a social process. Between the late 1940 s and late 1960 s, magnetic tape recordings provided an alternative that was less expensive and less complex to handle than the gramophone. This not only granted a new mobility to the field recordists, but indirectly also to the recordings. 
As recording became cheaper and easier, academic ornithologists relied on a growing group of recordists to supply them with extensive libraries of sampled natural sound. However, in this chapter I show that building a stable stream of recorded sound and transforming them into reliable specimens for scientific research and reference did require considerable social negotiation. Drawing on work in the history and sociology of scientific collaboration within science and with industry, I argue that ornithologists' success in aligning birdwatchers, amateur recordists, broadcasters, and diversely motivated biologists, has been grounded in their recognition of recordings' heterogeneity. In collecting and exchanging recordings, ornithologists purposefully traded on their alternative monetary, social and symbolic currencies outside the scientific domain. By refining the notion of moral economy to signify the establishment of a normative frame through the bartering of goods, this chapter shows how in strategically trading sound records under various regimes of ownership, status and access, recordings reified a moral frame of mutual obligation, responsibility and authority.

Chapter 5, "Patterned Sound: Inscriptions and the trained ear in bird song analysis" focuses on the subsequent analysis of sound recordings. While magnetic tape instruments had opened up sound recording for a diverse group of field workers who contributed their recordings to dedicated sound archives, sound analysis itself became increasingly dissociated from this type of fieldwork. By the early 1950s, academic biologists adopted the sound spectrograph, a Bell Laboratories device that visualized short sound fragments, as their standard instrument of choice to investigate the animal vocalizations 'objectively'. Spectrography performed sound analysis as part of a mechanic, visual and expert authority that allowed additional control over the acoustic phenomena. Yet, as I argue in this chapter, a meaningful interpretation of the visual language of sound spectrograms has to varying degrees also been informed by the sonic skills and aural experiences of recordists and analysts. Trained judgment - visual as well as aural - thus supplemented the mechanical registration of sound. As I show, however, the trained ear served only to facilitate the spectrographic analysis of sound, not to replace it. As such, this trained ear was qualitatively different from that of musician-naturalists. Drawing on sociological work on scientific imaging and visualization strategies, this chapter explores the strategies that these biologists developed for the conversion of hearing into reading and image into sound. Analytically, it closes the circle by evoking the opposition between authoritative inscription and accessible conscription addressed in Chapter 2. Chapter 6 "Sound Science", finally, concludes with a synthesizing discussion that cuts through these chapters and takes up again the theme of mediated and unmediated listening as a mode of authoritative scientific observation. 


\section{Focus, Methodology and Analysis}

In tracing the use and legitimization of sound recording as a scientific tool, this book takes a historical approach, focusing on the period between 1880 and 1980 . These dates bracket a period in which ornithologists gradually came to grips with the notion of recording sound in the wild. The beginning of this period is marked by the first incarnations of commercial mechanical sound reproduction in the Edison cylinder phonograph, and closes off with the emergence of digital audio technologies. Edison's cylinder phonograph has been credited for being the first device to record and reproduce sound and attract massive popular interest with it (Chanan, 1995; Morton, 2004). Since 1878 the phonograph has widely and publicly fostered a notion of audible sound reproduction. At the other end, the first commercial instances of digital audio recording and editing represent a natural end-point to a century-long history of 'analogue' recording in the field (Fine, 2008). Digital technology has initiated a new era in animal sound recording. Archivists and field recordists were initially cautious in their adoption of digital tools and techniques (Interviews Boughton, Budney, Medler). Yet since more than a decade, digital technology has begun to affect everything from how sound is obtained to how it is stored, documented, examined and circulated (Gaunt, Nelson, Dantzker, Budney, \& Bradbury, 2005)..$^{7}$ Such observations suggest that digital recording represents a new type of intervention that nevertheless may draw from the analogue tools and routines that have made up twentieth century field recording culture.

Geographically, this study focuses on a selection of institutes in three key countries that have played pivotal roles in the history of ornithology and shaped the frames within which ornithological recording practices have developed: the United States, the United Kingdom and Germany (Birkhead, 2011; Davis Jr. \& Jackson, 1995; Haffer, 2008a). While recordings of bird vocalization have been produced in other national contexts too, such attempts have generally remained isolated and

\footnotetext{
${ }^{7}$ Lighter and specialized recording equipment and formats have afforded sound recordists a much wider range of possibilities to manipulate or restore sounds and to accelerate their distribution. These developments do impact fieldwork. Recent articles report the uptake of new digital audio technology, such as iPods that carry entire aural reference works, are carried along on expedition and may even help to identify species automatically by the sound they produce (LaVallee, 2007; Ouellette, 2012). For STS-related work on the ways in which new technology influences the practices of birdwatchers and ornithologists, see Watson (2010). In the past decade, wildlife Sound Archives have not only begun to digitize their collections to circumvent the material decay of the original magnetic tape records, but also started to place these at the online disposal of users (Interviews Budney, Fischer, Medler, Ranft). Moreover, specialized online repositories with global coverage also complement those established sound institutes with user-generated collections that serve as reference points for (amateur) scientists of all sorts (see for instance the website xeno-canto.org). At the same time, digital audio has stirred ongoing discussions about the value of authenticity and a distrust of signal compression, see Budney \& Grotke (1997). The digitalization of sound spectrography, moreover, has made the method easier to use and affords a greater number of users the possibility to analyze their recordings visually. But the analysis of sound as chunks of digital data came with its own problems, such as sampling rates. On the metaphysics and cultural lives of analogue and digital audio, see also work by Jonathan Sterne (2006a, 2006b).
} 
usually went unnoticed in the scientific realm. ${ }^{8}$ In comparison, American, British and German recordists not only have a more extensive active history in bird sound recording and its scientific usage, but also displayed much wider and denser networks of users. A good indication for this is the establishment of publicly and privately funded sound archives in these countries. While not always established specifically to assist scientific research, these institutes served as a collection point for recorded wildlife sounds and thus fostered the exchange and circulation of recordings between scientific and other cultural contexts, such as broadcasting, amateur recording or art. The Macaulay Library at Cornell University in New York and the British Library of Wildlife Sounds Archive in London each originated as the first, largest and fastest growing archives of recordings of bird sound, in their respective countries as well as globally (Ranft, 2004). ${ }^{9}$ These cases, and the specific contexts within which they emerged, form the backbone to my story. The resulting AngloSaxon focus is complemented by German material where possible, some of which has been collected among others at the Tierstimmenarchiv at the Humboldt University in Berlin, which originated as a private academic collection of Professor Günter Tembrock but developed into the third largest natural sound archive in the past decades. This dimension has served as an occasional counterpoint in my analysis, for instance in the first decades of the twentieth century when German ornithologists were significantly internationally active. ${ }^{10}$

I have taken these institutes as a starting point, empirically as well as analytically, to follow people, technology and recordings as they circulated through a wideranging, heterogeneous and generally informal network of recording actors. These involved individual amateur recordists, commercial and public bodies as well as specialized scientific laboratories. For the sake of clarity and in order to be able to present local practices with sufficient detail, I have chosen to foreground in my analysis some of the most prominent among these actors. While many scientific and non-scientific actors might occasionally have made use of sound recording, the British Broadcasting Corporation, the Cornell Laboratory of Ornithology and the Cambridge University department of Zoology and its Madingley Ornithological Field Station have been prolific producers and consumers of wildlife sound record-

\footnotetext{
${ }^{8}$ Radio engineer Carl Weismann, for instance, began recording wild bird sounds for Danish Radio near Copenhagen in 1934, while Gunnar Lekander and Sture Palmér pioneered bird sound recording in Sweden for Radiotjänst AB (Swedish Radio) in 1936, and the Japanese Tsuruhiko Kabaya published bird sound recordings in 1954 (Interviews Weismann, Palmér). In France, scientist Claude Chappuis has been recording avian sounds, for his own scientific use, but apart from publishing an album of bird sounds he deposited his recordings with the wildlife section of the British Library Sound Archive (Copeland, Boswall, \& Petts, 1988).

${ }^{9}$ The Macaulay Library was formerly called Library of Natural Sounds. The British Library of Wildlife Sounds Archive emerged as part of the British Recording Institute, which was built in part on an extensive recording collection of wildlife sound by the British Broadcasting Corporation and the personal collection of recordist Ludwig Koch.

${ }^{10}$ In the period after the Second World War, Tembrock and his fellow DDR ornithologists were left much more to their own devices in keeping track with the development of sound recording as a scientific technique, which at this point took place primarily in British and American bio-acoustics (Interview Tembrock).
} 
ings that have been deployed for scientific purposes. My focus on these institutes in the subsequent chapters has been motivated by their pioneering adoption and application of widely-used techniques of sound recording and analysis. This, as well as their mutual interconnectedness, has allowed me to trace how recorded sound, but also technologies, people, knowledge and skills have been allowed to circulate across various cultural, professional and geographical borders, and how these innovations and their mobility may have contributed to the contestation and legitimization of sound recording as a scientific tool.

While these choices represent a specific geographical coverage, this dissertation does not operate in a comparative matrix, nor do I organize its narrative on the basis of respective national contexts. Rather, I have chosen to show that sound recordings travelled between field-sites, laboratories, archives and readers, and that in doing so, they have crossed geographical and social boundaries that were not always just national in kind. By attending to the development of widely adopted recording and listening practices, I have sought to establish a historical account that, in the words of historian of science Jim Secord (2004), "keeps the virtues of the local but operates at a unit of analysis larger than a single country" (p. 668). Secord advocates this approach as part of a historiographical program for understanding knowledge as communication and focusing on its circulation among different publics, to which the present work is sympathetic. In this context, however, this perspective is specifically fit to study how sound recordings have travelled between dispersed locales and how they stabilized there as accountable and epistemically meaningful carriers of information. This involves attending both to the local conditions of producing and interpreting sound recordings, as well as to the building and maintenance of the regional, national as well as trans-Atlantic networks in which they circulated.

Following the recordings also means attending to the ways in which recording technologies have been appropriated and reconfigured, and the scientific practices that they thus opened up. This dissertation therefore takes up Trevor Pinch and Karin Bijsterveld's suggestion of following the instruments in the same way that conventional STS studies have followed the actors (Pinch \& Bijsterveld, 2004). Media historian Jonathan Sterne has argued that sound technologies may be regarded as "social, cultural, and material processes crystallized into mechanisms" (2003, pp. 1, 8). Following technologies, and thereby the practices, ideas and constructs that they embody, thus becomes a heuristic to highlight the social, cultural and epistemic issues that are at stake for different users. This is most evident, as media historian Lisa Gitelman (2008) has argued, during the "novelty years, transitional states and identity crises" of a recording technology (p. 1). Tracing a recording culture over the period of a century, I have therefore focused specifically on those phases in which new technologies are adopted and subsequently expose themselves as sites of ongoing negotiation. It is in these initiating phases that such technologies may become integrated into existing practices, be modified and tinkered with or simply invite entirely new applications. By following the trajectories of 
these technologies particularly in phases of transition and appropriation thus provides unique windows into their reconfiguration as scientific instruments.

This heuristic of following the instruments through phases of transition moreover provides a second class of insights that is particularly relevant to the questions that this thesis has set out to answer. At the same time that technologies breach existing practices or are themselves being reconfigured, they also expose most explicitly the embodied skills that are required for handling these technologies most efficiently. Such skills may be difficult to trace, as they ordinarily are part of the tacit and embodied choreographies between users and their tools. However, in periods in which these users, tools and applications themselves are in the process of being mutually re-defined, such skills are applied most self-reflexively. As historian of science and technology Lissa Roberts and others have noted, embodied skills' active presence may be mapped most concretely by examining "the changes in meaning, significance and use that [a technology] underwent as its examples circulated among a number of sites" (Roberts, Schaffer, \& Dear, 2007).

I use these heuristic strategies of following both technologies and recordings across their sites of application to highlight from the expansive field of birdsong studies those controversies, routines and material interventions that significantly bring into relief the practices through which recordings have been articulated as scientific objects. Although this dissertation's broad chronological scope does not allow for a systematic anthropological account, its approach is in part ethnographic in its theoretic reference as well as in its concern with the material foundations of practice and the diverse meanings that these acquire within changing sociological and cultural contexts. As Jonathan Sterne (2003) again has pointed out, social and physical 'practice' is not invisible to the historian's viewfinder per se: "the ethnographer can go somewhere to learn about cultural practices through participation and observation; historians and genealogists must reconstruct domains of physical practice from documents and artifacts" (pp. 91-92). Indeed, while material objects and historical sources may not open up sensory and embodied experiences in the same way as for their original users, they do open an interpretative space in which physical practice, skill and routine can productively be encountered. In that sense, my own approach has to some extent been grafted onto sociologist Diane Vaughan's account (2004) in which she describes the historical ethnographer's reliance on documentary records to "elicit structure and culture" and help to "understand how people in another time and place made sense of things" (Vaughan, 2004, p. 316). Like Vaughan's decidedly historical ethnographic enterprise, tracing a history of scientific listening has involved making strategic use of different genres of documentary sources and contemporary observations. To this I have brought an analytical apparatus that is as much ethnographic as it is historical in its "centrality of culture and the [...] theoretically informed writing" that it attempts to put forth (ibid, p. 321).

In considering the bulk of empirical material that I collected, I have attempted to subtract especially the practice of dealing with recordings as scientific objects. I 
have examined individual sources for the ways in which recordists have dealt with and developed ways of recording and analyzing the sounds of wild birds. I have focused specifically on the problems that they encountered and the ways in which they arranged to overcome those problems. Doing so has led me to investigate how both these problems and the material, social and representational solutions formulated to them, ultimately impacted their legitimization as scientific specimens. This has opened up a wide array of issues. How have actors concerned themselves with human hearing and other sonic skills - listening skills as well as the skills needed to employ the tools for listening (Pinch \& Bijsterveld, 2012a, p. 11). How have these skills and listeners' identities intersected with non-scientific practices such as composing and listening to music? How have such sonic skills been learned and transferred by different actors and which professional roles did they imply? Finally, they have also led me to consider different standards of representation and how these have been negotiated by different actors.

To this end, this dissertation draws upon a variety of empirical material that is broadly classifiable in three categories: archived sources and published biographical material (such as recordists' autobiographies); published academic and popular work; and oral history interviews which I collected and analyzed between 2008 and 2011. Archival sources provided the most substantial share in the empirical material and were collected at the British Library and its Sound Archive Wildlife Section, the Humboldt University's Tierstimmenarchiv, Cambridge University Library, the BBC Written Archives Centre, Cornell University Library and the Cornell Laboratory of Ornithology. ${ }^{11}$ These archived sources cover a large body of primary documents, among which correspondence between scientists, archivists, amateur recordists, technicians, recording engineers and broadcasters, as well as their diaries, manuscripts, leaflets, news clippings, field- and laboratory records, editing forms, administration and the recordings themselves. Items in the latter category have not been analyzed systematically for their acoustic make-up. But in juxtaposition with other relevant sources, such as administration, leaflets or recording notes they have been considered as particularly informative of the audiences implied and the epistemic claims being made. Combined, these sources provided a particularly thick trace of recordists' ongoing activities, problems, concerns and solutions.

In addition, memoirs and other published (auto-) biographical accounts by the actors have been considered in the analysis. As a genre that was much more public than many of the archived private notes and correspondence collected, these narratives have usually been more stylized. Yet these memoirs nevertheless provide an important insight in their authors' working conditions. With sufficient caution, such sources may be used strategically: often these autobiographies and popular histories develop a motive of 'scientific heroism' in which the individual scientist overcomes the challenges that nature has set on him. Little wonder to find that especially for field recordists, the memoir has been a widely appreciated genre. Therefore, when

\footnotetext{
${ }^{11}$ See Appendix for a list of archival sources consulted and their abbreviations used in referencing.
} 
contrasted with sources that are publicly undisclosed, the scientific personae fashioned in each of these sources provide sharp insight into a prevailing scientific habitus and customs (Daston \& Sibum, 2003).

Secondly, a corpus of published and publicly available academic material has been collected. This corpus consists of published journal articles in nine journals that have featured relevant ornithological, ethological and bio-acoustical studies, especially (though not exclusively) for the period between 1880 and 1980. As historians of biology have shown, tracing the developments in content and style of a scientific journal may reveal the processes by which new ideas and methods enter a particular community of naturalists (Battalio, 1998; Johnson, 2004; Nyhart, 1991). In fact, as historian Douglas Futuyama has noted, the analysis of journal articles is an important means to learn about the concepts and convictions of a general community of naturalists throughout a longer period of time (Futuyama, 1986, p. 310). The journals examined include The Auk (published since 1884), The Condor (since 1899), The Wilson Bulletin (since 1889), Journal of Field Ornithology (since 1930), Ibis (since 1859), British Birds (since 1907), Journal für Ornithologie (now Journal of Ornithology, published since 1853), Animal Behaviour (since 1958), and Behaviour (since 1947). I have selected these journals through literature searches and by following the references and publication trajectories of the researchers and recordists involved. These journals thus represent important developments in the field - specifically ethological journals became more important, alongside the traditional ornithological journals - and the major outlets for the researchers and recordists considered in this dissertation. In addition, articles in non-selected outlets have been considered when explicitly referred to in writings by the authors considered.

For each of the selected journals an electronic archive has been available, which enabled advanced full-text searches for key terms. ${ }^{12}$ This resulted in a body of 756 elements. These have been considered per journal initially, and hand-coded individually. Within this body of texts, no a priori distinction has been made between full academic papers or shorter contributions under entries such as 'communications', book and record 'reviews', editorials or more general essays and field notes. In fact, such headings have been particularly relevant entries to trace the trajectory of sound recording techniques from their initiative phases; many innovations in notating or recording, methods of study or interpretation have not usually been introduced first in full-bodied research articles, but rather in short notes and communications or as part of a field report, and initially led to discussion or controversy by just a relatively small group of (amateur) contributors. In addition to these article sources, fifty field-guides and handbooks have been included in the collected source material, consisting among others of works that have been reviewed in these journals for the period specified and including at least the works that were (co-) authored or used by the actors that figure in this study. While handbooks provided an overview of changes in the state-of-the-art of bird song biology,

12 These key-terms consisted of: “*sound*”, “*song*”, “*record*”, “*audio*”, “*listen*”, “*vocalization*”. 
field-guides, recording manuals and song books have been good sources to get insight into changes in the organization of observation and recording in the field as well as the habitus of the recordist. Wherever available, these academic and didactic sources have also been supplemented with popular science magazine articles and other public sources reporting on the actors' recording work.

Finally, this dissertation draws on a selection of oral interviews with naturalists, recordists, sound archivists and ornithologists, collected in part by archival institutes as part of oral history programs on the development of field recording, and in part by the author himself. Both categories concerned semi-structured qualitative interviews that lasted between one hour and three hours. Interviews carried out by the author have been based on the same topic list which was handled flexibly and would be adapted according to the specific expertise of the interviewees. While the majority of these interviews concerned the interviewees' experiences with contemporary recording and archiving practices, several interviewees also had substantial experience with historical recording practices, which is reflected in the content of the interviews. The majority of the interviews conducted by the author have therefore also included demonstrations or participatory observation of the operation of specific (historic) recording equipment and techniques. These experiences had a particular analytical value, in that they added texture and sensitivity to routine or complex technical aspects of recording practice that were occasionally absent from regular accounts in scientific papers or biographical memoirs. From my time spent with various Cornell Laboratory of Ornithology sound editors I brought home a haptic memory of the fragility of original reel-to-reel tapes and wax discs, that even when carefully handled in the protected and climate-controlled space of the sound archive proved their vulnerability to the realities of the field. It also brought into focus some of the specialized handling and listening skills that have been involved in splicing, editing and annotating tapes. A wax cylinder recording demonstration by artist and researcher Aleks Kolkowski at the Science Museum in London illustrated some of the difficulties involved in capturing bird sound on wax. At the Humboldt University, a demonstration of sound spectrography has impressed me with the importance of careful calibration and the multitude of standard settings between which the operator must decide to produce the kinds of useful sound spectrographic visualizations that have been widely used across laboratories in Britain, the United States and Germany since the 1950s.

\section{To the field}

Among the many experiences in sound archives, gardens, nature-reserves and summer-cottages, one in particular stands out. In spring 2010, I was being awaited at the Ennerdale train station by my host Roger Boughton to be driven in his jeep to a campsite in the heart of the stunning Lake District. I had arrived there to meet the field recordists of the British Wildlife Sound Recording Society, a small but 
industrious troupe of birdwatchers, technology-enthusiasts and ornithologists who had flocked to the district for its peace and quietude, and I would spend a good three days with them in the field. It was only there that I realized that for these people, 'days' began way before the actual light of day. We would rise from our bunk beds an hour before dawn, the only comfort a cup of black tea before each disappeared into the dark and the dew to find a perch before the birds would start their chorus. Roger had kindly provided me with a microphone of his own, attached to a parabolically shaped plaster form to reflect and concentrate the sounds of the microphone, and he had taught me how to hold and focus it and optimize any sound levels. Yet in the inky darkness between the foggy fells, stumbling through the thickets along the actual trails, trying to get the equipment working proved a dear challenge. I aimed my sonic gun at the shadows of indistinct brushes and trees and at birds I did not even know the name of. Often I would hear a song bursting into my earphones, crystal clear, only to find the singer to have flown as soon as I had my gear in place and pressed the record button, leaving me with the faint echoes of cows, distant tractors and splashing waves at the lakefront.

My fellow recordists were evidently more successful, even though the unsure footsteps of their novice companion had scared off many of the precious birds they set their eyes or mechanical ears on. Their experience of the surrounding landscapes was clearly different from mine; already on our reconnaissance walks on the first evening, I later learned, they had mapped the area not by its tracks and trails, but by the perches of individual birds and the territories that they occupied. While I had been eager to hear about their stories, these recordists had only had ear for the birds. By lunchtime on the following days, all recordists would trickle in and dump their gear onto the large kitchen table in our camp. Afternoons were reserved for more tea and a diligent process of identifying, annotating and editing the recordings that had been made in the morning, while their proud owners played and compared samples and debated themselves into an informal competition for the weekend's most superb recording.

A good seventy-five years after the Cornell recordists camped in the Louisiana swamps, my own expedition astounded and confronted me with the uncompromising materiality of recording technique, the tacit skill and fieldmanship of any practice taking place in the unpredictable and unforgiving realm that is the field, and above all, the thrill and excitement of a stealthy hunt. 


\section{Scientific Scores or Musical Ears: Sonic skills, diagrams and field work}

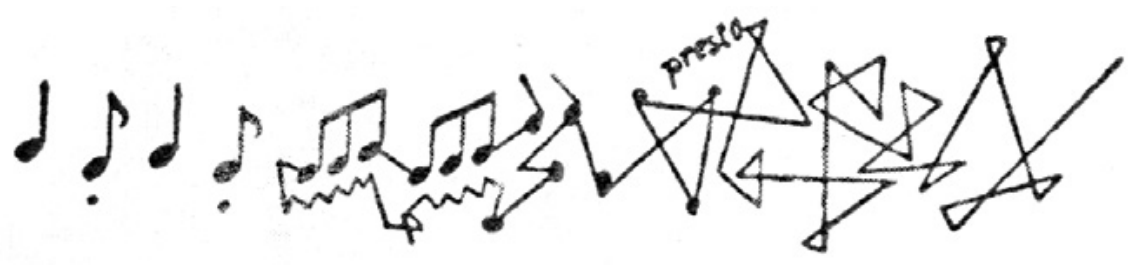

Figure 2.1

Transcript of Bobolink song by Ferdinand S. Mathews.

\section{Introduction}

It is a mad, reckless song-fantasia, an outbreak of pent-up, irrepressible glee. He begins bravely enough with a number of well-sustained tones, but presently he accelerates his time, loses track of his motive, and goes to pieces in a burst of musical scintillations.

(Mathews 1904, 49)

When writing this in 1904, naturalist Ferdinand S. Mathews was not reviewing an artistic composition. In fact, he was describing a motif of "musical fireworks" he once observed being brought forth by a bobolink, an American songbird. This was music, he explained, and in character easily comparable to some of Chopin's musical fantasias. In his Field Book of Wild Birds and Their Music (1904), the author of field guides such as 'Familiar Life of Field and Forest' had compiled impressively detailed transcripts of the songs of almost 130 wild bird species native to the Eastern United States. He had transcribed them all by ear and had rendered them in a conventional musical notation. This was necessary for them to be 'scientific', he explained: "When the bird sings G sharp we will put it on the musical staff where it belongs!" (Mathews, 1904, p. vii).

However, in a twist of irony the parts of the Bobolink song that inspired Mathews' powerful prose also proved resistant to the musical approach he advocated: "I have never been able to 'sort out' the tones as they passed at this breakneck speed," he explained, and "the difficulty in either describing or putting upon 
paper such music is insurmountable" (Mathews, 1904). He eventually made do in the drawing pictured above (figure 2.1). He sketched the notes as they had appeared to him, wildly bouncing and receding back in time. His written record had started off in a traditional grid of quarter and eighth notes but quickly oscillated beyond the conventional dimensions of relative time and pitch. In all its unconventionality, this score might be read as an unsuspected predecessor of avant-garde notational experiments by composers such as Stravinsky or Stockhausen (Pryer, 2002; Taruskin, 2005). But however evocative this diagram may appear to the present-day reader, to some of Mathews' contemporaries it suggested rather musical notation's inadequacy for representing natural sounds accurately and intelligibly.

Mathews' failure to take down the Bobolink song in musical notation marks a period between 1900 and 1930 in which ornithologists widely debated the possibility of taking down birdsong on paper with sufficient precision and accuracy for scientific study. Musical notation had long been the technology of choice for recording of animal sounds. This had been the province of unpaid naturalists - amateur natural historians who had turned to compiling detailed accounts of animal life, based on long-term observations of animals in their natural surroundings (Crist, 1999). Scientific, professional ornithology, on the other hand, had long concentrated on armchair taxonomic work in museum collections. Yet by the turn-ofthe-century, growing numbers of both naturalists and professional ornithologists had begun to turn to the field to study the behavior of living birds in their natural surroundings. Conservative ornithologists' skepticism concerning field observations, however, raised important questions among these ornithologists: what was the value of such aural observations, who should be allowed to listen authoritatively, and how were they to listen and record their observations as scientifically as possible?

This chapter thus explores how over the first decades of the twentieth century, students of birdsong sought to position listening and recording work as part of their field observation practices. In doing so, they proposed a variety of new diagrammatic technologies. These, I will argue, became important sites of negotiation. As students of birdsong began to define in different ways what kinds of professional literacy, perceptual ability and listening technique should be expected of field observers, they also outlined and negotiated the boundaries of an emerging community of students of bird song. Much work in the history and sociology of science has shown that new forms of codification may be powerful factors in shaping and consolidating local scientific or technical communities (Clarke, 1992; Hannaway, 1975; Kaiser, 2005a, 2005b; Lachmund, 1999). At the same time, they and others have also shown that before certain research tools can be usefully applied at all, various forms of non-textual transfer of skills may take place within highly localized training regimes (Collins, 2001; Kaiser, 2005a; Kohler, 1994; Warwick, 2003). Likewise, in the first decades of the twentieth century, ways of listening to birdsong largely took shape between efforts to standardize on the one hand, and the multiplicity of interests and competencies of listeners in local practice on the other. 
Notations thus revealed themselves in very different roles. This chapter draws on the notion of 'conscription device' to distinguish between different purposes of recording and listening. Musical notation, for instance, accommodated at the same time very different disciplinary identities, different conceptions of bird vocalization, as well as different listening skills and competencies. Moreover, different users often listened and recorded bird songs with very different intents. As such, I claim, notations did not only have a mimetic purpose - inscriptions that suggested exact recording - but also served mnemonic, didactic and alluring roles, as they were supposed to help memorizing bird song for field recognition, teaching them to novices and inspiring new users to take up field observation. But before this chapter turns to the self-construction of a community of observers and listeners, the next section outlines the historical context in which ornithologists and naturalists turned to the field and began to listen to their subjects.

\section{The attraction of the field}

In the half-century period between 1880 and 1930, the practices and interests of ornithologists shifted. Until the late nineteenth century, scientific ornithology had above all been focused on faunistic and taxonomic description and classification. Yet over the course of more than fifty years following 1880, practices of shooting animals and collecting and conserving specimens, bird eggs and skins for cabinet study gradually began to make way for field studies and observations of behavior and ecology (Barrow, 2000; Bircham, 2007; Burkhardt Jr., 2005; Mearns \& Mearns, 1998). Within the historiography of ornithology, this shift has been recognized as one in which the field transformed into a recognized branch of professional biology. This history has been traced by following the discipline-formation and conceptual transformation by several key protagonists (Burkhardt Jr., 2005; Haffer, 2007b, 2008b; Junker, 2003). However, the negotiation of a new, decidedly 'professional' identity for ornithology has not only concerned academic zoologists, but has also impacted the realm of amateur naturalist study. A lot of ornithological fieldwork had, after all, initially been the province of naturalists, in the sphere of local natural history societies, school teachers and pastors that Lynn Nyhart (2009) has described as the 'civic realm'(Ainley, 1979; Allen, 1976; De Bont, 2009b). But while field studies of living birds in the field had emerged at the margins of academic science, in the first decades of the twentieth century they became also gradually appropriated by professional ornithologists finding their way to biology departments and state surveys (Barrow, 1998; Burkhardt Jr., 2005). Around the late 1920s and 1930s, professional biologists began to reconfigure local 'amateur' observers to become part of national networks whose activities would have scientific and social significance (MacDonald, 2002; Toogood, 2011). But as this chapter will go on to show, even before 1930 had birdwatchers, amateur naturalists and professional ornithologists together begun to negotiate the scientific status of records of their 
field observations and to calibrate these through methodological discussion papers, field-guides and keys.

Several historians of ornithology and conservation have related this late nineteenth-century turn to the field to a profound change in the attitude of man towards nature (Doughty, 1975; Lutts, 1990; Orr, 1992; Ritvo, 1989). In his social history of bird watching, Stephen Moss (2004) points out, for instance, that many amateur naturalists in Britain and North America had begun to promote a less exploitative and more harmonic relation with nature. Urbanization and industrialization had made the presence of unexploited nature less self-evident than ever, and the field study of live exemplars for recreation and pleasure seemed to provide an answer to that yearning. ${ }^{13}$ Changing leisure patterns for the middle-class had created a void to be filled with a meaningful pastime, while the wider availability of bicycles and automobiles increased the mobility of new country-dwellers and their ability to penetrate even farther into the country-side. This changing attitude also saw expression in the emergence of several successive bird protection movements in the last quarter of the nineteenth-century (Allen, 1976). The history of this protection movement and related changes in conceptions of nature go a long way in explaining the attractions of the field for a large group of naturalists.

For one, as historian of ornithology Mark Barrow (1998) has pointed out, these changing attitudes toward nature put an increasing strain on the traditional divisions of work between professional specialists and a growing community of diversely motivated 'amateur' bird enthusiasts. By the early 1880s, scientific ornithologists had begun to foster a professional disciplinary identity through the clustering of various local bird clubs into specialized national societies, such as the Deutsche Ornithologen Gesellschaft, the British Ornithologists' Union and the American Ornithologist Union, and through the organization of annual meetings and the publication of periodicals (Barrow, 1998; Bircham, 2007; Haffer, 2007b). ${ }^{14}$ But in doing so, scientific ornithologists had also begun to differentiate between themselves and the motley of teachers, foresters, clergymen and schoolboys who collected their own assortments of mounted specimens and eggs in their spare time. In principle, the societies' respective journals were open to any kind of contribution, but in the United States for instance, the Union's restrictive membership policy and its members' focus on technical discussions of nomenclature or faunistic descriptions of bird species did in practice establish a two-tier distinction within the profession between professionals and amateurs (Barrow, 1998).

Moreover, in the 1880 s and 1890 s the emerging bird protection movement achieved a stricter regulation of bird shooting. The movement identified not only common practices such as hunting and commercial millinery as the main culprits

\footnotetext{
${ }^{13}$ For an early and fuller exploration of the 'back to Nature' movement, see Peter Schmitt (1990). On the motives of field collectors and their relation with leisure and outdoor recreation, see Robert Kohler's work on naturalist collecting (2006).

${ }^{14}$ In 1850, 1858 and 1883 respectively. Note that the German Gesellschaft was deemed mainly a society for museum collectors (even though its objectives were never so obviously stated). See Haffer (2007a).
} 
for the rapid decline and possible extinction of several populations. They also blamed the collecting practices of professional ornithologists and their various counterparts in the civic realm (Barrow, 1998; Moss, 2004; Orr, 1992). In an attempt to protect their objects of study from careless shooting, ornithological societies such as the American Ornithologists Union themselves advocated stricter permit policies. However, to leave their own collecting privileges out of shot, they tried to exempt especially 'proper scientific work' from increasingly restrictive state legislations. As a result, however, these professional ornithologists also began to deny the amateur ornithologist, collector and dealer a role in traditional ornithological practice (Barrow, 1998).

As opportunities quickly diminished for amateur naturalists to collect and study as they had done before, they began to focus more systematically on collecting and publishing records of the species they encountered in the wild (Barrow, 1998; Burkhardt Jr., 2005). John Battalio (1998) notes for instance that in the last decades of the nineteenth century, contributions on technical (taxonomic) and field ornithology were equally divided in American ornithology. In the first decades of the twentieth century, however, published work became clearly dominated by field reports. Such field-studies were initially the province of 'amateur' naturalists, producing extensive descriptions through patient monitoring of breeding habits, migration patterns, mating or singing behavior, and even exploring their implications for problems of Darwinian evolution (Barrow, 1998). In the same vein, British bird-watching shifted from a fascination with rare species to common birds, and detailed studies of their habits and life histories (Burkhardt Jr., 1992)

Such field studies were carried out with increasing confidence, as is exemplified by the Wilson Bulletin editor's call to readers to "prove that the slur often aimed at amateur field work is not applicable in your case at least. Such work needs to be done" (n.a., 1905, p. 22). But well until the 1920s, that slur was still premised on the conviction that "popular ornithology is the more entertaining, with its savor of the wildwood, green fields, the riverside and seashore, bird songs and the many fascinating things connected with out-of-door-Nature" and that "systematic ornithology [on the other hand], being a component part of biology - the science of life - is the more instructive and therefore more important" (Ridgway, 1901). ${ }^{15}$ Indeed, many naturalists considered birds less as narrowly defined scientific objects of study than as individuals in their own right. One prominent field ornithologist, Frank Chapman, commented in this regard that birds "have not only a beauty which appeals to the eye, but often a voice whose message stirs emotions to be reached only through the ear ... they further possess humanlike attributes which go deeper still, arousing in us feelings which are akin to those we entertain toward our fellow-beings" (Chapman, 1915, p. 348). ${ }^{16}$ Similarly, the amateur field observer O. T. Miller declared to be perfectly satisfied to "let those who will spend their days killing, dissecting and

\footnotetext{
${ }^{15}$ Quoted in Birkhead (2011, p. 205).

${ }^{16}$ Quoted in Barrow (1998).
} 
classifying; I choose rather to give my time to the study of life [ . . . ] I study the beautiful, the living, the individual bird, and to my scientific confreres I leave his skin, his bones and his place in the Temple of Fame" (Miller, 1894, p. 86). Clearly, to understand the appeal of singing birds in the field it does not suffice to cite just the politics of professionalization. The engagement with birds in the field resonated also with an existing need for a more intimate knowledge of animals and experience of nature.

As noted, by the beginning of the twentieth century, some professionals too began to embrace field observation, although within the bounds of their employment they were still often pressed to assemble collections of tangible specimens rather than intangible observations. These field observers - birdwatchers, naturalists as well as professionals - benefited from the upsurge of optical and representational aids such as identification guides, prismatic binoculars and well into the twentieth-century also more technically advanced cameras (Barrow, 1998; Dunlap, 2011; Wachelder, 2009). But although these innovations greatly facilitated the organization of observation, they did not by themselves legitimate sight and hearing records as scientific material of equal standing to a preserved specimen. As Mark Barrow (1998) and others have pointed out, ornithologists and naturalists remained long divided over the scientific value of such records, especially when they had been registered by amateur naturalists and birdwatchers. For conservative professionals, the acceptance of unverifiable and often dubious identifications by inexperienced and potentially overzealous birdwatchers threatened to undercut the authority their discipline had carefully established. Some ornithologists still refused to accept such sight records when they were not substantiated by a preserved specimen well until the late 1920s. By that time, however, graduate training in ornithology at places such as Cornell University had begun to produce a new generation of professionals. These new professional ornithologists were crucially different from their technical predecessor of the 1890s, because they worked not only in museums but also established positions at universities and in state-organized biological surveys. Hence they were pressed by different institutional and methodological demands than the typical nineteenth-century ornithologist. With ornithologists' methodological interests now leaning towards questions of ecology and systematics, they were increasingly willing to rely on field identification themselves and accept observational records by others.

The existing historiography of ornithology has focused in particular on these politics of vision. But naturalist observers and bird-watchers did not only watch - they also listened, and it is against this background of a gradual shift in the relations between amateur naturalism and professional ornithology that both the emergence of birdsong studies and its quest for scientific legitimacy need to be considered. Of course, specimen collectors had always relied on their ears when in the field, if only to detect and identify wanted species on their expeditions. Yet now, amateur naturalists, birdwatchers and professional ornithologists had begun to emancipate as scientific field-workers that relied on visual and auditory experience to investigate 
bird life. But whereas taxonomic study had long relied on a fixed protocol for the validation of claims, through systematic comparison with carefully annotated and preserved specimens in hand, no such agreement existed yet with regard to the perceptual standards according to which visual and auditory observation could function as scientific specimens. Nor did the existing scientific establishment offer much institutional support or an educational infrastructure through which such social and cognitive standards could proliferate easily. Hence (amateur and increasingly professional) field ornithologists' quest for scientific legitimacy hinged in considerable part on individual naturalists' coalescence around a new community of practice, the development of a joint enterprise and a repertoire of shared routines, vocabulary and techniques for listening that defined what exactly to listen for and how to do so 'scientifically'. In the next sections, I explore how individual naturalists defined their 'ear-work' and the listening skills they required, as well as the ways in which they articulated their status as scientific listeners and recordists.

\section{Learning to listen}

For many amateur naturalists and civic bird enthusiasts, listening to birdsong in the field had not been primarily a scientific practice, but was simply part of the attraction of being outdoors. In a typical turn of phrase, British ornithologist Charles Dixon acknowledged for instance that "the music of the fields and woodlands is one of the most gratifying pleasures of the country. The variety of these songs is great, their beauty a refreshing and perennial one. [They] attract the least sentimental among us, arouse our sympathies, and charm the majority of us to a degree unapproached by any other living form” (1897, p. i). Similarly, German teacher and amateur naturalist Ulrich Ramseyer, explained that his study of bird life might not bring any material profits, but "when I walk through field and forest, I am never alone. A little bird sings me with ininimitable joy its lovely luck" (1908, p. 1). ${ }^{17}$ Another American naturalist observed that "there is happily a wide-spread impression that birds are something more than mere "specimens" [ . . . The woods, fields, mountain-sides and river-valleys tell another and a charming story" (Abbott, 1896, pp. 14-5). For many naturalists, then, listening to bird songs outdoors provided the promise of a short glimpse of the deep structures and meanings of nature (Dunlap, 2011).

Indeed, several late nineteenth-century popular monographs and field-guides on bird song celebrated these romantic and aesthetic associations. They were written for a growing market of civic bird enthusiasts, often novice observers, to familiarize themselves concretely with the habits and lives of birds whose song they admired, but knew nothing about. Descriptions and notations of birdsongs also

\footnotetext{
17 Translated by author from: "[w]enn ich aber durch Feld und Wald wandre, bin ich nie alleine. Da verkündet mir ein Vöglein mit unnachahmlichen Jubel seiner Liebe Glück.”
} 
featured, for instance, in several children's books as, according to one of their authors, "the actual bird-melodies thus unconsciously absorbed should inevitably lead to a keener delight in the singing of birds, and a better understanding of their songs [ . . a as well as] the promotion of a deeper interest in the whole subject of bird-life, and the need of its preservation" (Olds, 1914). In different guises then, the aestheticism of listening to bird song also encouraged aspiring observers to engage more systematically with the subjects of their fascination. Likewise popular field-guides cultivated an understanding of aural cues as a way to recognize, appreciate and describe the behavior of a wild bird. As such, popular monographs as well as fieldguides alike articulated the popular pastime of observing birds outdoors in the field as a thoroughly multi-sensorial and deeply embodied experience.

But listening did not remain a leisurely business only. By 1879 already, naturalist Xenos Clark observed bird song to have "almost exclusively been treated of in the world of sentiment, where poet-naturalists and nature-poets have culled a wealth of fancies" (1879, p. 209). His attempts to compile notes on bird song from the literature and from observations by himself and fellow naturalists to "make inductions of scientific value" had therefore very much been a pioneering job. By the turn of the century, that distinction was drawn even more sharply. As one American naturalist noted, "there are usually two methods of procedure open to the observer. The more common [is to] go into rhapsodies over the enchantment of some bird's songs, the soul stirring melodies of others [ . . ] exactly as we do with human singers. [ . . ] This is the simpler method of treating the subject, but there is a more thorough way which gives better results even if it is a little more intricate. In the first place bird songs are not the meaningless warblings and twitterings they may seem to the casual observer" (Williams, 1902, p. 12). And by 1916, British biologist Julian Huxley listed bird songs as one of the fields the field observer should attend to if he wished to make observations of scientific value. A vast group of enthusiastic bird-watchers, he noted, was readily available to be mobilized to "provide all-important material for the fundamental problems in biology" (Huxley, 1916, p. 142). The gap between amateur naturalists and birdwatchers on the one hand and the trained professional biologist on the other only had to be bridged - what amateur naturalists needed was knowledge of what to search for and a method to guide their search. Field observation was to be learned. For these students of bird life, listening did not just add to the enjoyment of doing field research; as much as it could give delight to the birdwatcher, it was also to be practiced as an intrinsic part of the new field observers' babitus.

Naturally, naturalists relied on acoustic cues when they were in the field. The naturalist J. Schafer described, for instance, how he let his ear guide him through the landscape: "while going through a thicket of hazel brush, briars and vines, a bird was heard singing so softly that it was some time before I could locate the exact place where the song came from. After listening a short time I recognized the song to be that of a Catbird, but to make sure of the identity of the singer, it was driven from its hiding place" (Schafer, 1916, p. 42). Biologist Henry Oldys, described an 
instance of Wood Pewee's musical song "that seems generally to have escaped observation," based on a chance-encounter he had had in 1894 but which he heard "not again, although I was carefully listening for its repetition, until 1899" (Oldys, 1904, p. 271). ${ }^{18}$ In each of these instances, listening was part of an active exploratory attitude with which the observer navigated the surrounding landscape. The point was that in order to enlist listening as part of a scientific attitude to observation, such 'sonic skills' of exploring and diagnosing had to be learned.

Whether the field observer was on the alert for yet unobserved odd behavior, a species outside of its usual geographic range or for confirmation of reported and previously noticed phenomena, such listening was predicated on patience and naturalistic skill - based, therefore, not only on good listening skills but also on a ready knowledge of what to expect. Trevor Pinch and Karin Bijsterveld (2012b) have elsewhere defined several modes of listening. One of these they term 'exploratory listening', by which the listener attends to sound to discern potentially relevant phenomena from background noise. These field observers' listening for the 'expected unexpected' may thus be compared to what radio historian Susan Douglas (2004) described as the listening routines with which hobbyist radio operators scanned the ether for radio transmissions amidst atmospheric interference. Moreover, as the first quote by Schafer above indicates, listening was not only employed as an exploratory faculty, but could also be mobilized as a diagnostic complement to the often visual identifications made in the field. Field observers depending on their ears to identify species by their sounds relied on a mode of 'diagnostic listening', in Pinch and Bijsterveld's (2012) terms. This they had in common with physicians listening through a stethoscope to identify pathologies in the patient's body, car mechanics listening to detect the origin of technical problems in the engine or engineers amplifying the sounds of computers to detect mistakes in calculation (Krebs, 2012). In doing so, the listener attended to sound not so much to discover new phenomena, but to identify sounds by comparing their features with idealtypical examples from memory and experience.

The ability to distinguish the features of particular sounds only came with practice. As Winsor Tyler explained: "One is at first impressed by the fact that most of the call-notes which he hears over and over again, often in great variety, are notes which he has never heard before, and consequently can ascribe to no known bird. Again, after a few years of observing, one realizes that each year the notes (at first strange and unfamiliar, but finally perfectly recognizable from one another) occur in a definite order" (Tyler, 1916, p. 133). Naturalist Jno Williams concurred that "[it is] very hard for a beginner to imitate accurately, mentally or orally, even the commonest bird notes [ . . ] To listen to the ups and downs of a bird's song is easy for anyone to do but to mentally photograph all or any of these variations, so that the mind can partially recall them later on, is a task for even a

\footnotetext{
${ }^{18}$ Emphasis mine.
} 
practiced observer" (Williams, 1902, p. 12).19 For Williams and others, learning to diagnose different species by their songs implied acquiring the ability to listen analytically, to appreciate, recall and distinguish sounds by their acoustic structure and variations. Others suggested that the best way to learn still was to "visit the wilds in company with experts" who could teach apprentices to appreciate specific differences based on only the "quality or style" of their song (Summers 1916, pp. 79-80).

But however it was learned, acquiring diagnostic listening skills did not require a natural virtuosity or exclusively specialist knowledge but practice, training, and possibly the insight and experience of others. This point, that observation - visual or aural - was not a specialist skill was also explicitly endorsed by ornithologist Ludlow Griscom, one of the first American ornithology graduates at Cornell and a professional systematist at the American Natural History Museum. Despite his professional orientation, he believed that a discussion of field identification and diagnostic traits could be beneficial to both amateur and professional ornithologists (Griscom, 1922, p. 31). Griscom campaigned for the acceptance of field identification and repeatedly tried to strengthen relations between academic ornithology and hobbyist bird-watching, among others in his own book Birds of the New York City Region (1923). He trained a new generation of amateur and professional ornithologists and promoted among them a more holistic method of 'instant identification' that did not rely exclusively on distinct visual patterns (Dunlap, 2011). Based on his own field experiences he noted that, with some exceptions, so-called difficulties or inaccuracies of identification are due to the defects of the individual student and not the bird. Granted, a very small portion of what he termed "the human equation" could be related to physical defects of the eye and ear. But these were greatly outnumbered by what he considered an unscientific attitude and the persistent lack of study by a minority of 'amateur' field students. Griscom considered care, dedication, modesty and a scientific attitude much more important than virtuosity.

Aspiring scientific ornithologists were to learn by heart the diagnostic characters of the birds in their locality, getting to know them in the field and train themselves in a proper routine of identification and report. Sight and hearing records would have to be judged according to the reliability and reputation of the observer, rather than his professional status. "If the bird student really wishes to make observations of scientific value, he must needs [sic] become a trained field ornithologist" (Griscom, 1922, p. 39). But, he urged his readership, "to attain these qualifications calls for no special gifts or capabilities" and "granted no physical defects and some aptitude for the study, this is well within the reach of anyone" (1922, pp. 39-40). Indeed, several ornithologists at the time displayed similar belief in the equal distribution of observational qualities. Naturalist J.P. Burkitt (1922) invited British naturalists to send him their observations on the song-periods of common birds. And when professional biologist Wallace Craig began losing his hearing around the age of 46 while still engaged in an extensive field study of wood pewee song, he recruit-

${ }^{19}$ Emphasis mine. 
ed a network of volunteer observers via a call in The Auk (Burkhardt Jr., 2005). ${ }^{20}$ The ear-work he expected of them in documenting the song variations of woodpewee song would not be a difficult assignment, he assured his readers; recording song variations could "be done by any person who is careful and accurate and can follow a tune" (1926, p. 152). ${ }^{21}$

Around the turn of the century, listening had become an important aid in field observation for both amateur naturalists and professional ornithologists. They relied on listening to locate, identify and analyze a species' song. As part of field observation, listening was also a skill that had to be learned. This was firstly so because recognition and affinity with a bird's song came with practice in the field or instruction by local experts. But secondly, this was also the case because, as Griscom suggested, it required the adoption of a distinctively scientific habitus. But however much listening relied on experience, these naturalists and professional ornithologists considered it a skill that was generally part of the field observers' habitus and moreover, generally accessible to all.

\section{Naturalists, musicians, scientists}

These field observers were not, however, only to attend to birds' vocal behavior to identify them for their own good or enjoyment, but also to study and describe them for others. And whereas professional ornithologists such as Griscom had declared themselves prepared to accept the potential of amateur field observation, and thereby granted an observational authority to amateur naturalists, others tried to lift the scientific status of their field studies by establishing new criteria of expertise. They stressed instead the need for a trained judgment that they dubbed a 'musical ear'. Around the same time as Julian Huxley advised closer cooperation between biologists and birdwatchers, biologist Henry Oldys suggested in The Auk that "because of its difficulty, [the study of bird-notes] should be undertaken only by trained musicians". Of course, he admitted "much excellent work has been done by naturalists who lack musical training," but "the final word must be spoken by the musician, whose education fits him to observe important features that are quite certain to escape the attention of one whose musical ear has never been cultivated" (1916, p. 20). Such qualifications defined musical listening as a distinctive expertise.

At the end of the nineteenth century, musical listening had for many naturalists been the default mode of appreciating and studying bird song. The adoption of a musical frame often seemed self-evident and not exactly in need of justification,

\footnotetext{
20 Although Craig's call was answered by more than 80 volunteers, only nineteen ultimately succeeded in doing so - taking down some 125 records of about 55 individual birds, containing a total of more than 80.000 phrases (Craig 1933). Craig leaves us only to guess at the reasons for the inability of three-quarters of his network in taking down the straightforward pewee song.

${ }^{21}$ I have adopted the term 'ear-work' from Cyrus Mody's (2005) ethnography of sound and listening in a contemporary material science laboratory.
} 
even though its limitations were obvious and readily acknowledged by many of its practitioners. The American naturalist Simon Cheney, for instance, had simply drawn on his extensive musical experience as a singing-master to render his collected recordings in regular notations, even though he was "well aware that not all of their music can be written" (1892, p. 7). The British ornithologist Charles Witchell (1896) completed his study on the evolutionary role of imitation in birdsong with just a few pages of musically annotated vocalizations. He too had exercised his 'musical ear' "in various musical pursuits since his childhood", but still often found himself "puzzled in attempts to follow the intricacies of bird-music, [ . . . ] sometimes actually impossible to record in their natural order" (1896, p. 231). By repeatedly listening to and carefully writing down phrases simple enough to be captured in music, Witchell had been able to "obtain records which, although not perhaps scientifically accurate, were as true as musical notation would allow" (ibid., p. 231).

The modesty of these late nineteenth-century qualifications contrasts, however, with the confidence with which naturalists came to define musical listening as a distinctly scientific technique, a mere two decades later. Composer Cornell Schmitt and naturalist Hans Stadler introduced their musical notations in a series of German and English papers as "a precise and scientific way of comparison" (Schmitt \& Stadler, 1913, p. 394). Likewise, the editor of ornithological journal The Auk and council member of the American Ornithologist Union, Witmer Stone blamed the failure of ornithology to advance along true scientific lines to a lack of fundamental musical knowledge. In his view, musical notations constituted the "specimens for this line of investigation" and as such they were "absolutely essential, just as mathematics is essential in computing averages and percentages of error in bird migration, or chemical notation in recording the composition of pigments or other products of the bird's structure" (Stone, 1913, p. 473). Just like complex formulas, he explained, these notations might well be unintelligible to one who is ignorant of them, "but a knowledge of them is necessary to investigation". For these musicianornithologists, listening skill was not necessarily based on acquired intimacy with species' sounds, but a distinctively scientific technique. It presented auditory observation as structured by convention - not by subjective and artistic judgment but by precise notation, in kind at least comparable to notations that were used in commonly accepted practices of ornithological study.

Musical listening implied considerable technique. Stadler and Schmitt (1919) provided extensive guidelines, for instance, for how naturalists should listen to and record bird vocalizations musically. They did so, for instance, for the simple call of a blue-tit: "Several times we hear the call note, then we imitate the whistle. It consists of two tones. The second descending somewhat [ . . . N Now we establish that the lower tone is continuous with the higher tone. This is what the musician calls 'Legato' and captures graphically with a bind sign above the notes' (p. 3). 22 Such

${ }^{22}$ Translated by the author from: "Einige Male hören wir den Lockruf, dann pfeifen wir nach. Es sind zwei
Töne. Der zweite sinkt etwas abwärts [ . . . N Nun stellen wir fest, dass der tiefere Ton mit dem höheren 
guidelines taught the naturalist reader to hear sounds as musical structures. Musical notations provided listeners with a standard lexicon and an interpretative frame that should enable them to coordinate and calibrate their aural experiences. They further encouraged the naturalist to follow a suggested routine of listening, imitating, checking and analyzing sounds as part of the process of recording, underlining the systematicity of musical listening. Such systematicity, they claimed, was what distinguished scientific listening from artistic listening. "The need of rigid accuracy and unbiased judgment must ever be kept in mind", Witmer Stone assured his readers, if they were to "guard against the enthusiasm of the musician which like that of the artist is sometimes inclined to run away with him when dealing with such problems" (Stone, 1913, p. 474). To that end it was important to test their musical records for accurate results. Instead of recording from memory, valuable records "must be made by actual tests of each note with a graded pitch pipe, as is done by our best observers, while the time must be correctly gauged by some metronome contrivance." The standard tone of such a pitch pipe might even aid those without a professionally trained hearing.

The scientific listener was thus to become what one contemporary musicologist characterized in the context of concert listening as an "intellectual listener": "many varieties of listening are purely intellectual - listening for form, or for technique of performance or of composition. To the purely intellectual listener, music is not necessarily an art at all; it is a craft or a science" (Gibling, 1917). This persona of the scientist-musician captures the field worker as a methodical and detached listener - one who does not get involved in bird music emotionally or aesthetically as an artist would.

This reconfiguration of musical listening as a methodical and explicitly scientific technique for collecting and analyzing sound represented an attempt to establish the scientific authority of aural field observations. Reference to a musically trained ear, after all, seemed to attribute to the field naturalist some form of competence and expertise in listening, suggesting in other words what Thomas Porcello (2004) has termed 'professional audition'.23 The term, following anthropologist Charles Goodwin's (1994) notion of 'professional vision' developed to describe discursive practices of expertise in archaeology and court witnessing, denotes the auditory artifacts, techniques, discourses and expertise that establish its possessors and users as professionally competent members of a community. Porcello has been concerned with the linguistic practices of professional studio engineers to show that their status as a professional was deeply tied to their competence with linguistic (as well as other, more tacitly embodied) resources. The notion alerts us to the ways in which such technical-musical discourse was intended to establish a body of shared terminology and meaning for listeners to draw upon when describing or

lückenlos, pausenlos zusammenhängt. Das nennt der Musiker Legato und setzt als Zeichen über die Notenfigur einen Bindebogen“.

${ }^{23}$ For an insightful discussion of 'professional audition' in another scientific context, that of the sonification of data, see Supper (2012). 
interpreting birds' acoustic behavior efficiently and authoritatively in the field. At the same time, Porcello notes that such technical discourse may also be exclusive for others who do not (yet) possess knowledge and even the embodied experience implied by these codes. Some authors of field-guides attempted to remedy the lack of musical competence among ornithologists through extensive lay introductions or glossaries and musical keys. But even those who, like Stadler and Schmitt (1919), anticipated that laypeople would be able to grasp the basics of musical notation in only a few hours, acknowledged that a reasonably good musical hearing remained important. As we will see in the following section, the assertion that naturalists could acquire a musical ear and sufficient competence for reading and writing musical notation was received skeptically.

Moreover, despite the suggestion that musical notation would have a standardizing effect, the musical score also provided the naturalist with a resourceful and versatile frame for interpreting bird behavior that was far from homogenous. Although musical notation served a formulaic and scientific mode of comparison to some, opinions diverged on the exact rules of the game, both as to the perceived accuracy and readability of musical notation and to what such notations purported to demonstrate at all. Schmitt and Stadler for instance had drastically modified musical notation for it to represent animal sound; they invented new symbols for non-musical sounds, added syllabic elements to represent timbre and abolished the musical bar (thereby also abandoning precise notations of pitch) (figure 2.2). Other recordists adopted a more traditional approach in writing down bird sound; they did fix the notes on a bar, thus suggesting the possibility of representing the sounds in absolute pitch, and added an absolute, metronomic measure of tempo as well (figure 2.3). Alwin Voigt (1913), finally, applied basic musical notation for simple songs, but found that it did not render more complex songs with small toneintervals recognizable at all. He thus complemented musical notation with a shorthand, Morse-like script for short, long and vibrating tones that highlighted rhythm but dismissed other parameters (figure 2.4). A mutual understanding between researchers was thus not only complicated by differences in the recordists' grasp on the fundamentals of music, but also by differences in the way recordists chose to arrange their own musical recordings. 


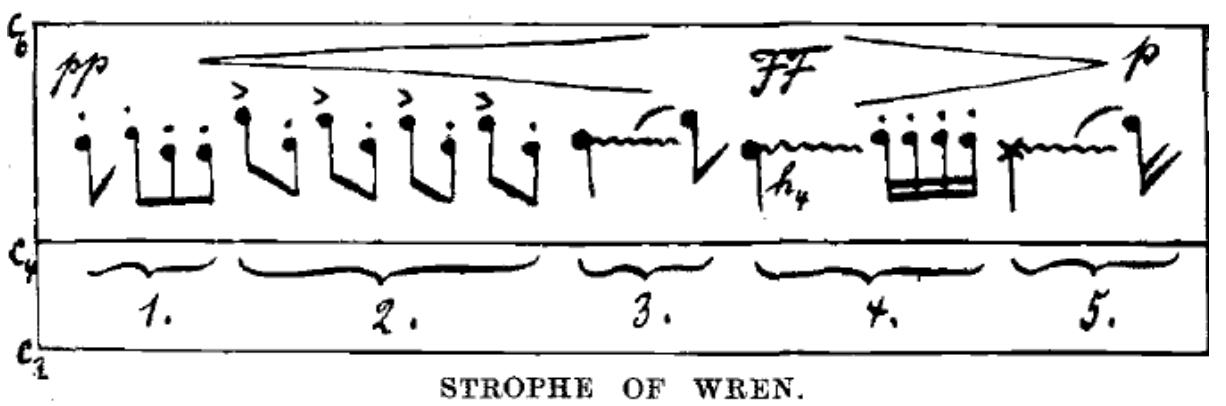

Figure 2.2

Adapted 'scientific' musical notation by Stadler \& Schmitt (1915). The notation situates pitch in a range of octaves - a range that is particularly difficult for human listeners to appreciate.
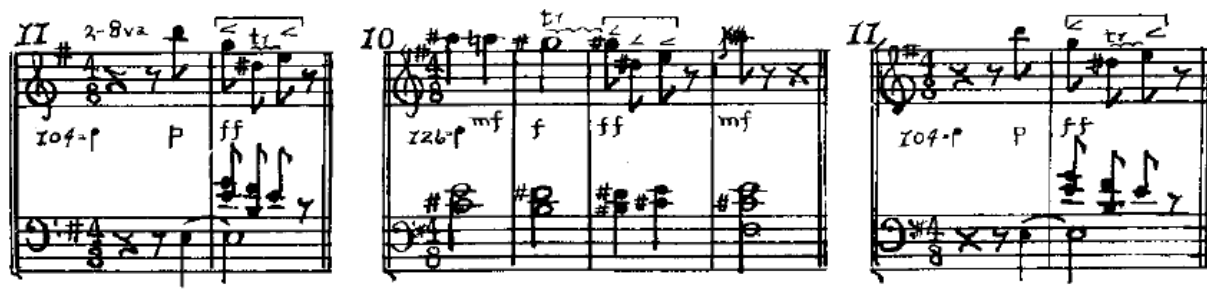

Figure 2.3

Musical notation by Moore (1913). This orchestrated notation suggests a harmonic arrangement for performance.

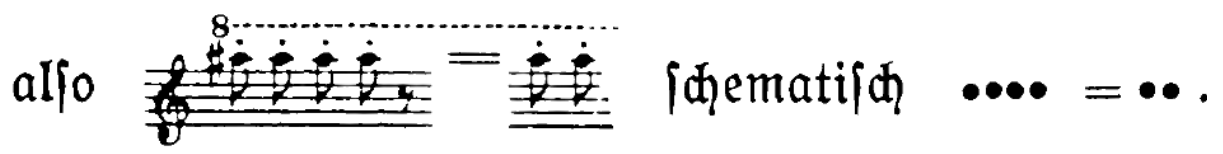

Figure 2.4

Musical notation by Alwin Voigt (1913). The equal sign separates two song strophes.

Such tinkering with musical notation tools often reflected practical concerns (for instance, to make recording in the field less complex and burdensome) or served to accommodate methodological emphases (to highlight certain parameters over others). For some recordists, musical notation also served different theoretical assertions than for others. The American state biologist and amateur ornithologist Henry Oldys (1913, 1916), quoted above, drew for instance on musical notation to demonstrate that the Thrush and Veerie songs he observed had rhythmical arrangements that were particularly pleasing to the human listener. He considered this proof that there was a universal appeal to musical appreciation among both birds and men and that this developed teleologically. "The bird expresses itself in human music. The notes were sung with great accuracy of intonation - my ear is very keen to detect variations from the true pitch." This could not be coincidence, Oldys noted: "astonishing and revolutionary as it may seem, there is no escape 
from the conclusion that the evolution of bird music independently parallels the evolution of human music and that, therefore, such evolution in each case is not fortuitous, but tends inevitably toward a fixed ideal" (1913, p. 541). In a comparable vein, German professor of ornithology Bernard Hoffmann had adopted in his 'Kunst und Vogelgesang' (1908) what he himself called a "natural scientificmusical" approach. By rendering the songs of talented individual birds in musical notation and syllabics, he aimed to demonstrate that their song matched criteria for human music (figure 2.5). ${ }^{24}$

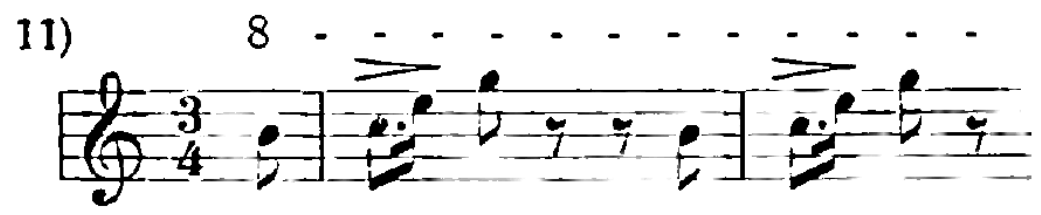

Figure 2.5

Musical notation by Hoffmann (1908)

Oldys' and Hoffmann's work is by no means unique. Instead, it exemplifies a rich and multi-faceted discourse on the evolution of music that had developed in the last quarter of the nineteenth century. It had found a particularly fruitful ground in Darwin's Descent of Man (1871). Darwin spent a great deal of attention to instances of non-human music, which he considered to have emerged through a mechanism of sexual selection. By attributing the function of aesthetic sensibility, like plumage or human art, to mate-selection and courtship, he also blurred the boundary between man and animal. ${ }^{25}$ Moreover, such investigations into the evolution of animal and human music were not confined to biology alone. Historians of musicology have recently shown that this discourse found broad appeal also in turn-of-thecentury musicological and anthropological scholarship (Ames, 2003; Mundy, 2010; Rehding, 2000; Zon, 2007). These musicological explorations of a common source for 'primitive' folk music and 'advanced' Western polyphony are in many ways

\footnotetext{
${ }^{24}$ Translated by the author from German: "naturwissenschaftlich-musikalischen Standpunkte”. For an elaborate discussion of Hoffmann's premises, see Kursell (2003).

${ }^{25}$ For an accessible explanation of Darwin's take on the function of birdsong, see Birkhead (2011, pp. 266-7). The importance of Darwin's work for the study of animal music, and reversely, the study of birdsong to the origin of melody was made explicit early on. For an exploration of the roots of this discourse and its function in musicological scholarship, see Rachel Mundy's (2010) doctoral dissertation. Darwin's assertion that birds and other animals displayed a comparable disposition towards the production of (aesthetically) pleasing sounds was received critically by Herbert Spencer, whose scala natura presented a hierarchy in the advancement of mental and musical capacities from animal to human. By situating music low on the scale of evolution, Darwin suggested that the faculty of language evolved much later. Spencer instead maintained that music developed from language (Kivy, 1959; Mundy, 2010). Oldys remark that his observations of hermit thrush music could seem revolutionary may be considered against the background of this debate, which was revived by a critical commentary of Spencer in 1890 and its continued discussion, for instance in Wallschek (1893) and Stumpf (1911).
} 
analogous to the ways in which naturalists promoted the study of birdsong as an exploration of the origins of human music. In ornithology, British professor of zoology Walter Garstang for instance concluded that "birds, aesthetically, are probably somewhere near the level of primitive man, and that by the study of bird-song we may be enabled to retrace some of the steps by which the primitive emotional cries were transformed into the beginnings of artistic music" (1922, pp. 16-7). Exploring this thesis, Garstang complemented his academic discussion on the evolution of birdsong with musical renditions and artistic interpretations.

Some of these approaches might seem strikingly tautological, anthropomorphist or speculative when compared to contemporary notions of animal behavior, but not necessarily so by those of turn-of-the-century naturalist study. As Eileen Crist (1999) has shown, some naturalist work since Darwin has described a conceptual continuity between the behavior of animals and man, or conceived of this behavior as inherently meaningful to the animal subject itself. ${ }^{26}$ This would only begin to change profoundly by the late 1920s, when the pioneers of classical ethology such as Konrad Lorenz and Nikolaas Tinbergen, began to adopt a more technical and objectifying idiom, which conceptualized animal behavior instead as compulsive, functional and automatic (Burkhardt Jr., 2005). Naturally, this ethological perspective left little room for animal subjectivity and notions of 'aesthetic consciousness'. But different to contemporary debates on linguistic theory and the concept of animal language, for instance, at least until the 1930s such notions formed part of a broad spectrum of behavioral interpretations that seemed to be reconcilable with evolutionary thought among naturalists as well as ornithologists.

This is illustrated by repeated controversies in several ornithological journals. Around 1910, several prominent British naturalists quarreled for instance over the precise behavioral role of birdsong, debating whether its function was one of sexual selection, a mere instinctive ebullition of superfluous energy or a matter of singing, as one ornithologists phrased it, "to please himself" (Kirkman, 1910, p. 121). This comment provoked another ornithologist to declare, however, that "it is surely going too far to grant aesthetic tastes to birds when the most generous of us cannot allow them in by far the greater number of our own species [of man]" (Stubbs, 1910, p. 156). In the United States, comparable discussions on the evolution of birdsong unfolded, in which the explanatory power of sexual selection would be weighed against the alternatives of imitation or natural selection. Again, one ornithologist brought the factor of aesthetics into the equation: "how can we escape imputing the origin and development of this beauty in bird-song to an aesthetic sense in the birds themselves?" (Allen, 1919, p. 531). In a similar vein, assistant curator and collector at the Museum of Vertebrate Zoology in California Richard Hunt advocated that musical taste was to be considered seriously as a factor in

\footnotetext{
${ }^{26}$ For a good example of this in terms of the study of bird life, see Dixon (1917): "This is the secret of all worth-while nature study. We must look upon a bird as we do upon a man - not merely to learn the Latin names of bones and muscles, but to study its disposition, character, emotions, and thought processes. In other words, we must treat a bird as a friend and not as a scientific specimen" (p. xii).
} 
evolution. He had observed that birds seemed to want to 'improve' their song, clearly preferring those sounds that to the human observer had sounded "absolutely superior" over others. Musical taste had a universal appeal. As a result, he said, "I believe that herein lies the explanation of the evolution of bird song. The songster is an esthete" (Hunt, 1922, p. 196).

Interestingly then, music provided naturalists and ornithologists with a versatile frame for the analysis of bird song. Recordists did not only draw on music as a lexicon for discussing and representing natural sound in a technical and structured way. Some also tended to ascribe it a much more literal role in the representation of bird song or to use it as a conceptual analogy in their theories of behavior. After all, if bird song was inherently aesthetic or musical, it was also to be represented as such. Hence musical notation became positioned as a scientific technique as well as an interpretative frame for birds' singing behavior, often even at the same time, by both professional ornithologists and amateur naturalists. But at the same time, the 'professional jurisdiction' (Abbott, 1988) of self-declared scientist-musicians, as well as the representational and explanatory powers of musical notation, were not unequivocally accepted by all of their peers. In the 1910s and 1920s, musical notation was received with growing skepticism, both for its apparent lack of documentary precision in representing birdsong and for its manifest inaccessibility to musical laymen.

\section{Birds' music and graphic notation}

Criticism and standpoints concerning the adequacy of musical notation to frame the study of birdsong found expression in many handbooks, articles, notes and other journal contributions between 1900 and 1930, but in this context the positions are clarified best by zooming in on a brief controversy in 1915, when amateur naturalist Aretas Saunders dismissed the scientific relevance of musical notation in The Auk:

[Musical notation] has been made primarily for the recording and rendering of human music and birds do not usually sing according to such standards. [ . . . ] Its standards of time do not allow the record of a song that does not follow the rhythmic beat of its measures. Do birds sing in any given key? Do they recognize any fundamental notes? Can one beat time to a bird's song? In the majority of cases these questions must be answered in the negative. [ . . . The great majority of birds sing in a free, non-mechanical, natural manner that cannot be recorded on the musical scale with the exactness that it deserves. (Saunders, 1915, pp. 173-4) 
His ridicule prompted a bitter public correspondence with Robert Moore, an active promoter of musical notation in the American Ornithologist Union (see figure 2.2 for an example of his work). Saunders had suggested an alternative that represented pitch and duration graphically, but not in a musical score, which he believed was "much simpler, and much more easily used and mastered" (figure 2.6). His alternative involved not just a different way of representing but also a re-classification of the points concerning which ornithologists should desire to add to their knowledge of bird vocalizations. Both the classification and definition of each of these points went against the grain of most musical recordists. For one, Moore objected that Saunders' concept of 'duration' was obviously of little use for ornithologistmusicians, because it obscured important elements such as 'metre' and "the extremely important factor of "rhythm"' (Moore, 1915, p. 535). Saunders, however, insisted that "we must realize that it is our intention to study bird songs, not from the standpoint of a musician but from that of a scientist" (Saunders, 1916, p. 103). "Shall we change such a song in order to make it fit our method? Is such a proceeding scientific accuracy? [sic] Or is it the conception of a musician, so trained in the rules and necessities of human music that he is unable to conceive of music that is not rhythmic?” (ibid, pp. 104-5).

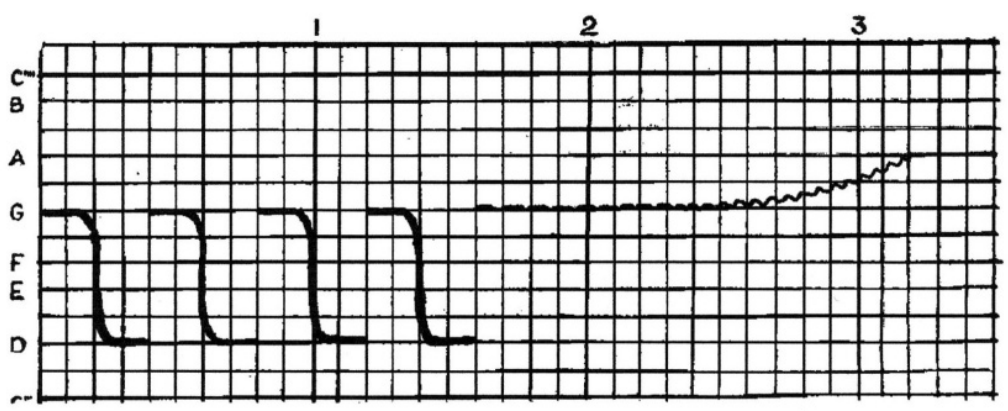

Song of the Field Sparrow. West Haven, Conn., April 18, 1914, 9 A. M.

Figure 2.6

Graphical recording by Saunders (1915).

For Saunders, an understanding of music and its terminology did not guarantee scientifically accurate results; in fact, he stated, "too much musical knowledge in some cases is liable to result in too little along other important lines" (ibid, p. 106). That does not mean Saunders was dismissive of anything musical. Even though the fidelity of musical notation was to be distrusted, he valued the skill of musical listening and the given of a musical ear: "records made by a person not possessed of such an ear for music would be of no more value than descriptions of plumages made by one who is color blind" and still, he added, "a knowledge of music is es- 
sential also, but it need not be great" (Saunders, 1915, p. 182). While Saunders was concerned that too much of an understanding of music jeopardized objective interpretation, he also shared with scientist-musicians the conviction that scientific listeners required a certain level of skill and natural ability, which obviously required practice. Acknowledging that graphic records might be made without exact indications of pitch and time, he added that these might be efficient only to teach field students. For detailed study of scientific relevance, however, "the records should be as exact as it is possible to make them" (Saunders, 1924).

Saunders' questioning of the documentary fidelity of musical notation paralleled an ongoing debate in the fields of comparative musicology and anthropology. Already by the late nineteenth century, anthropologist Franz Boas had argued that ethnographic observers might be unable to listen to the sounds of cultural groups outside of their own without filtering them through their own cultured set of perceptual biases (Hochman, 2010). By the turn of the twentieth century, ethnographers in the US and Europe increasingly acknowledged what they conceived as the problem of perception and the incongruence between aural perception and its representation as written text. Ethnomusicologist von Hornbostel, for instance, repeated Boas' concern when in his article 'Musikpsychologische Bemerkungen über Vogelgesang' he invited his colleagues to consider the musicological interrelations between human and bird music. Musical notation, he argued, risked "the worst possibility of deception to which also the most practiced musical observer time and again falls prey: intervals of the mind, that is, familiar musical intervals that we hear in the objectively given tone steps [hineinhören], even when these deviate considerably from them" (Hornbostel, 1911, p. 119). ${ }^{27}$ In response to this problem, Hornbostel had turned to phonographic recordings which, he suggested, "might otherwise also benefit the study of birdsong" (ibid.1911, p. 120). ${ }^{28}$

For sure, Saunders' and Hornbostel's concerns with the demands of their recording technology also resonated in the work of fellow ornithologists. Their alternatives did not, however, always depart so resolutely from the musical track. Realizing that "the natural scale and rhythm of the bird is not the tempered scale of the piano nor the conventional rhythm of our written music", amateur ornithologist Lucy Coffin suggested that "perhaps a new system of musical notation may be necessary - possibly the Chinese, with its center 'four-square,' with four internotes or the Gregorian five-tone scale" (1928, pp. 97-9). Moreover, even when considering the alternative of phonographic recordings, musical notation remained the default analytical tool for both musicologists and ornithologists. When Ferdinand Mathews announced in 1904 that in order to take down the bobolink bird

\footnotetext{
${ }^{27}$ Translated by the author from original German, “die gefährlichste Möglichkeit der Täuschung, der auch der geübteste musikalische Beobachter immer wieder zum Opfer fällt: die Gedächtnisintervalle, d.h. die gewohnten Intervalle unserer Musik, die wir in die objektiv gegebenen Tonschritte hineinhören, auch wenn diese von jenen sehr erheblich abweichen".

28 Translated by the author from original German, "möchten übrigens auch dem Studium des Vogelgesangs zugute kommen".
} 
accurately, ornithologists would have to "wait for some interpreter with the soundcatching skill of a 'Blind Tom' and the phonograph combined," he did not expect his musical notation work to be replaced by the joined effort of the exceptionally skilled listener and a phonograph, but simply to have it facilitated by mechanical means (Cheney, 1892; Mathews, 1904, p. 49). ${ }^{29}$ These ornithologists anticipated that musical notation and the phonograph would complement each other: repeating and slowing down the phonographic record would enable listening to be more systematic and undistracted. ${ }^{30}$

Moreover, the actual phonographic reproduction of bird songs in the field remained a distant promise for a long time. While ethnologists, comparative musicologists and zoologists had begun to incorporate phonographic recording techniques in their practice since the 1880s, phonographs became part of ornithology less rapidly (Ames, 2003; Brady, 1999; Radick, 2000; Shelemay, 1991). The phonograph's limited mechanical means for amplifying the signal required the source to be in the immediate vicinity of the recording horn, which limited recording largely to caged animals. Such recordings of a captive bird had been presented to the American Ornithologists' Union congress in 1898 already, where this "new and unique feature" suggested "great possibilities to be looked for in the future" (Judd, 1899; Sage, 1899, p. 53). In Germany, the amateur scientist and bird-breeder Karl Reich had collaborated with an engineer from the Deutsche Grammophon Gesellschaft to record the songs of caged nightingales by 1911 as a means to train the canaries in his aviary to sing (Birkhead, 2003; Copeland, et al., 1988). Reich presented his recordings at the fifth International Ornithological Congress in Berlin. Scheduled during the break along with a film-screening, the recordings were much enjoyed, although their scientific value reputedly was scarcely recognized at the time (Birkhead \& Balen, 2008; Schalow, 1911).

Most amateur naturalists picked up on the possibilities of the phonograph after electro-acoustical amplification was introduced in 1925. Saunders, for instance, became alerted by the possibilities of the phonograph only in 1929, and only in the vaguest sense. Likewise Lucy Coffin (1928) suggested that since the development of a written record had proven a failure in ornithology, it would be best to investigate the possibilities of the newly 'electrified phonograph'. And at the International Ornithological Congress in 1930, Hans Stadler invited his peers to consider the practicalities of electrical field recording, as well as the establishment of a scientific library, comparable in kind to the voice recordings of 'primitive people' at the Psychological Institute in Berlin. As chapter three will show, by the 1930s the phonographic ear would begin to outshine the musical ears of many of

\footnotetext{
29 And so did pioneering anthropologist Jesse Fewkes in 1890 when he arranged for his phonographrecordings to be transcribed for analysis in musical notation, incidentally by another pioneering amateur and skilled bird-recordist (Brady, 1999; Cheney, 1892). 'Blind Tom' refers to an African American musical savant who lived in the second half of the nineteenth century. In this context, he exemplifies the exceptionally skilled listener.

30 This was the case also in comparative anthropology, see particularly Hochman (2010).
} 
Saunders' contemporaries; a new group of professional ornithologists and recording engineers pitched the gramophone, as an embodiment of faithful and objective reproduction, against the subjective, physically flawed perception of field ornithologists.

Saunders' late recognition of the phonograph's advantages to his cause may seem surprising to a modern-day reader. But by 1915, his concern with musical notation did not only concentrate on its putative documentary infidelity. He also, and especially so, took issue with its manifest unintelligibility to inexperienced readers of music. His interest was therefore not so much in abolishing notation, but in developing an alternative notation that was not only less constraining and more accurate, but also 'intelligible to musicians, and a little less 'like Greek' to those whose knowledge of written music is slight" (Saunders, 1915, p. 183). Similarly, naturalist Ewing Summers advanced that "but few people, one in a hundred or more, perhaps, are musicians far enough advanced to be able to perceive clearly what would be meant by some of the characters that would have to be employed, even when explained at length" (Summers, 1916, p. 79). Other ornithologists, amateur as well as professional, developed effective teaching and recording methods that explicitly did not require any musical proficiency at all (Strong, 1918; Wheeler $\&$ Nichols, 1924). Yet such effectiveness in communicating and teaching birdsongs to as widely an audience of students as possible also seemed to come at the prize of the degree of accuracy that could be expected. At least, not all proponents of alternative notation techniques made as strong a claim to accuracy as Saunders did.

William Rowan (1925), himself embarking on a career as an experimental zoologist but also a gifted amateur musician and ornithologist, objected to Stadler and Schmitt's simplified musical notation that "the use of this too is confined entirely to musicians [,] it is therefore ruled out for the layman." And since even "trained musicians" were often not able to judge an interval correctly, he found, musical notation was of not much use anyway. His alternative, a short-hand script that combined graphics and syllabics, even surrendered accuracy completely, in favor of its intelligibility (figure 2.7): "its scientific value may be nil, but its practical value is very great". The notation, in Rowan's words, had the advantages of "simplicity, plasticity and adaptability" and especially that "everyone can read it but write it as well" (ibid., pp. 16-8). With this emphasis on readability, Rowan not only abandoned a claim for the accuracy of recording. His focus on the ability to read the notation also ignored, as it were, the listening competencies that many of his contemporaries had considered to be problematic in the first place. With Rowan, then, a growing group of ornithologists dismissed musical knowledge as a representational technology that was too complex, exclusive and unintelligible to be of use for a broader population of ornithologists, amateur naturalists and birdwatchers.

Opposition to musical notation was thus not only grounded in an understanding of birdsong, but also implicated in the configuration and possible selfconstruction of a very heterogeneous group of aspiring field observers. Because of the competencies and technical skills that different notations presupposed, such 
tools did not only mediate standards of accuracy and precision but also questioned the 'professional jurisdiction' of professional ornithologists and expert listeners as well as the exclusivity of their formalized skills to the study of birdsong. These ornithologists' denunciation of musical skill in favor of a simplified recording scheme should of course not obscure the fact that for these recordists too, listening remained an essential element of the recordists' toolkit. A skill also that needed to be trained and developed. And while musical notation did indeed gradually disappear from public representations of birdsong after 1930, the graphic, syllabic or phonetic recording schemes that ornithologists adopted in their articles remained extremely diverse. The standard, efficient, theory neutral and easy representational tool that ornithologists had so frantically been looking for in the first decades of the twentieth century did not come about at least until 1950, when the sound spectrograph seemed to provide a universal language for recording and analyzing bird vocalizations. However, as chapter five will show, even then some ornithologists remained deeply dissatisfied with the balance between objective analysis, efficiency and intelligibility that the instrument seemed to offer.

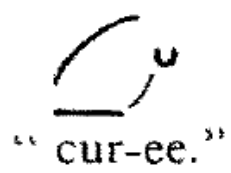

Figure 2.7

Graphical - syllabic recording by Rowan (1925).

\section{Conclusion}

This chapter has explored some of the ways in which the first investigators and admirers of bird song have organized their listening experiences and given shape to the notation of sound as a scientific technique around the turn of the twentieth century. In the late nineteenth-century, listening to birdsong had become the domain of civilian birdwatchers and amateur naturalists. By 1910, ornithologists, in their professional capacities or still as amateur enthusiasts, had begun to associate themselves with field studies of bird behavior. But while leisurely birdwatchers had generally been content with the wordy descriptions and musical impressions of bird song, professionals and amateurs alike now highlighted the importance of accurate and precise notation, both to guide their identifications in the field and to document the study of birds' vocal repertoires. Notation fixated and circulated an understanding of bird sound that naturalists often acquired locally and tacitly in the field. As such, it also invited a calibration of listening practices. But in calibrating and standardizing listening and recording techniques, these methods also became tangled up in the self-perception and self-construction of an emerging community of field listeners. 
I have focused on the fate of musical notation within this emerging community of field observers and its alternative, graphic notation. This is not to suggest that they could be neatly divided into two opposing camps, each pursuing its own contained agenda. As this chapter has attempted to show, their strategies were deeply diverse. They covered a spectrum with on the one end, the self-proclaimed scientist-musician who presented listening work as a calculative, systematic and precise technique. On the other end of the spectrum stood the musical layman, for whom specialized musical notation appeared exclusive and inaccessible - in spite of the assurances of some scientist-musicians that musical notation could easily be learned. Instead, its critics advanced an entirely different graphical lexicon that was much less centered on the sonic skill of the recordist (and his or her ability to identify musical structures and read or write them in a score) than on its intuitive visual understanding. In between these ends, naturalists struggled to devise a notation that could be found accessible and accurate at the same time, and that mediated sound meaningfully between analysis and their embodied experience in the field.

Importantly, this chapter shows that bird song notations were not only intended to function as what Bruno Latour and Steve Woolgar (1986) have termed 'inscriptions'. Often they also functioned at the same time as what Katherine Henderson (1991) and Wolff-Michael Roth (2003) have each described as 'con-scription devices'. 'Inscriptions' generally function as visual instances of knowledge that represent and package information, and that by processes of refining, filtering, coding, comparing and mathematizing help to narrow down its interpretative flexibility. They 'harden' claims and attempt to close off subjective interpretation through a process of cascading self-contained representations. The notion of 'conscription device,' on the other hand, alerts us to alternative social functions that inscriptions may have, other than that of a rhetorical tool for producing docile objects to establish the credibility of its authors' claims. As conscription devices, notations and diagrams act as symbolic places that bring together and engage collectivities to construct and interpret them. They provide, in Roth's words (2003), "the material grounds over and about which sustained interactions occur, and which serve in part to coordinate these interactions" (ibid., p. 18). As this chapter has shown, musical notations and graphic diagrams have also served as a means to calibrate, enact and focus listening practices, to distribute tacit knowledge, and to engage participation of a diverse and dispersed group.

In the context of this chapter, the notion of conscription device alerts us to the multiplicity of functions that a notation may assume in the practice of ornithological field recording. There are numerous historical examples of scientific representations assuming diverse functions for different users. Based in part on this literature, the examples described in this chapter may be categorized as (a combination of) mnemonic, mimetic, didactic, and alluring. As David Kaiser (2000) has shown, for instance, the Feynmann diagram had originated as a convenient mnemonic tool in physics but acquired a new (initially unintended) sense of realism for a new generation of academic users. Likewise, Ursula Klein (2001) has shown how 
Berzelian formulas in organic chemistry transcended their original mnemonic function as a representation of chemical reactions to acquire an unsuspected conceptual use. ${ }^{31}$ In the same way, one may grasp how sound recordings assumed both mimetic and mnemonic roles. As mimetic devices, recordings assumed a direct connection with the sound phenomena that they referred to, and articulated a heightened sense of realism. These notations, such as musical scores, were predicated on the successful negotiation of their writing conventions as standing in for the real thing, and they evidently did so to different degrees: a musical lexicon could at the same time serve as the most realist visual representation of a sound event and be considered as literal evidence of a musical sensibility in birds. But as criticism by Saunders and others has demonstrated, this relation was also precariously unstable.

This is different with mnemonic devices, which did not make visual claims to realism. Instead, they emerged as part of an often highly individual and rather adhoc scheme of perceptual signposts. As such, they were not to serve analysis per se, but recognition, memorization and self-instruction. Mathews' bobolink recording, for example, remained unintelligible to those without a notion of the actual sound, but could have considerable value for those who did.

Recordings might not only help the recordist himself to orient in the field, but also help to instruct bird song to lay readers, as in Rowan's visual script. As didactic devices, such representations were often directed by similar demands of ease-of-use and intelligibility. Yet to aid printed instruction and the standardization of naturalists' auditory perception, they also required a codification that was more fixed and rule-based than intuitive. Like mnemonic devices, however, these recording depended on iconicity rather than detail. As Saunders explained, without the defining axes of time and pitch, his system was to lose much of its alleged precision, but it might still be used for teaching field students bird's acoustic signatures. The same recordings might thus be used to study and to teach bird song. Moreover, as part of popular field-guides, as well as song or poetry books, such bird song records were not only didactically functional; they also ascribed a subtly alluring element. Anne Secord's (2002) work on nineteenth-century British botany is instructive in this regard. She demonstrates that as botany turned to engage the amateur participant, expert naturalists began to see botanic plates no longer exclusively as a means to convey scientific truths to a specialist audience. The aesthetic and cultural appeal of these illustrations enabled them to be deployed also as a means with which middleclass novices could be taught and recruited to extend their interest and participation in scientific botany. By appealing to popular notions of pleasure and entertainment, these field scientists managed to complement the images' mimetic functions with didactic and alluring elements. Similarly, in order to appreciate how a community of practice might begin to gravitate and cluster around ways of listening to bird song in the field requires attending not only to their scientific functionality. The diagrams and descriptions that naturalists and professional ornithologists deployed often

\footnotetext{
${ }^{31}$ See also Cambrosio, Jacobi and Keating (1993) and Rudwick (1976).
} 
followed similar visual schemes (such as musical notation) that also featured prominently in birdwatchers' field-guides, musical scores, poetic re-interpretations or children's nature-books. Their visual form placed these diagrams in a continuous series of scientific and popular records, which allowed them to embody a variety of functions for very different audiences.

The multiplicity of these roles may explain some of the difficulty that these birdwatchers, amateur naturalists and professional ornithologists encountered in establishing a single comprehensive diagram. Such multiplicity was, after all, both problematic and inevitable. It was inevitable because this was a heterogeneous group with very different interests in listening to and recording bird song, with different levels of competence. Moreover, for this dispersed group of naturalists, no educational infrastructure was yet available through which tacit skills and knowledge might be transferred and listening practices could be stabilized. As such, representations carried the burden to comply with diverging demands for accessibility, flexibility, accuracy and precision, readability and didactic potential. These proved conflicting at times, and particularly difficult to integrate in a single standardized and optically consistent scheme. As we will see in the following chapters, from 1930 onwards, mechanical recording instruments promised to solve some of these apparent tensions. These functions, and the negotiation of their relative importance, continued to influence, however, the ways in which bird song biologists organized their listening and recording practices. 


\section{3 \\ Staging Sterile Sound: \\ Producing and reproducing natural field recordings}

\section{Introduction}

"There is little question that if it were possible to produce satisfactory phonograph records of birds' songs and calls, the study of bird voices would be greatly stimulated. All previous methods, while useful in their way, were, at best, merely makeshifts, awaiting the time when science should have advanced sufficiently so that faithful reproductions of actual singing birds could be made" (Brand, 1932). The failure to devise a satisfactory notation for the study of birdsong had clearly raised ornithologists' expectations of new mechanical means of recording. But when electrical amplification turned those hopes into a practical reality by the late 1920s, the phonograph did not necessarily simplify the process of field recording. In fact, the electrical microphone, phonograph and sound-camera introduced new actors, new techniques, as well as new problems to overcome. In this chapter, I will analyze how electrical recording changed the conditions of sound recording in the field, and how it has been implicated in the reproduction of the field as a place where natural sounds can be observed.

I will explore such changes in techniques of scientific recording and listening by attending more closely to the field's soundscapes. The concept was first coined by Murray Schafer (1977), who influentially documented and studied the sonic elements that defined an environment. The term 'soundscape' has since been variously appropriated in the interdisciplinary field of sound studies, which gradually stripped it of its moralistic undertones. In recent years, historians such as Alain Corbin (1998) and Emily Thompson (2002) have defined a soundscape as an aural landscape that is not just a physical environment, but also a cultured way of perceiving that environment; not just a collection of acoustical events, a soundscape is also a result of the material and social contexts within which listeners may attend to and interpret those sounds. Moreover, soundscapes are not only experienced culturally, but also constructed and ordered technologically, conceptually and discursively (Greene \& Porcello, 2005).

This has been illustrated by several historical and anthropological cases of scientific work. Historian Sabine Höhler $(2002,2003)$ has shown for instance how by the early 1920s, oceanographic technique came to rely on acoustic deep-sea soundings. As the technique of sounding depth changed "from the tactile operation 
of groping in the muddy ground to an operation involving the sense of hearing", the conception of the oceanic field also transformed from an opaque depth into a technologically and scientifically sounding volume (2002, p. 131). However, this shift from a tactile to an aural apperception of the field was not wholly unproblematic by itself. Discontinuities within the ocean volume and on the bottom greatly complicated the job, as they tended to reflect, diffract, scatter and absorb the emitted sounds. Anthropologist Stefan Helmreich (2007) makes a related point in a plea for a transductive ethnography, when he describes the complex intersection of multiple, technologically mediated soundscapes that structured his submarine experience. Studies such as these, which focus on the ways in which 'natural' landscapes are experienced by scientists, are thus far relatively few. Yet they underline the importance of attending to the ways in which mediated sound conditions experience, as well as its ability to define, demarcate and structure space.

It resonates also in the work of Emily Thompson, who describes the emergence of what she terms a 'soundscape of modernity' (Galison \& Thompson, 1999; Thompson, 2002). She shows how in the first three decades of the twentieth century, scientists, engineers and technicians developed a new language for describing the behavior of sound, new tools and techniques for measuring, as well as new materials to design and control it. Moreover, within the new sound-engineered buildings that these engineers designed, new electro-acoustic technologies, such as the microphone and loudspeakers, had begun to redefine what counted as signal and noise, allowing their manipulation into a clear, controlled, direct and nonreverberant sound. With this, also the spatialization of sound was being radically transformed. As Thompson points out, the new soundscape was decidedly modern, because it displayed a technical and scientific mastery over the acoustical environment. The acoustic behavior of sound became dissociated from its spatial context, architecturally and technologically, which allowed the soundscapes of the recording studio, the auditorium or the office space not only to be engineered with much more precision and care, but also to be increasingly standardized in the process.

Other recent studies have shown that these intertwining issues of design, isolation and control were not just in place in corporate and cultural America. They also figured in many spaces of scientific research. Historian of science Henning Schmidgen (2003) has demonstrated for instance how nineteenth century astronomical observations and psychological experiments were found to be heavily disturbed by noise outside the research sites as well as inside the isolated rooms of subject and experimenter. In both cases, scientists tried to exclude such acoustic disturbances through material interventions: by constructing their sites far from possible sources of interference and by adapting existing infrastructure to protect against surrounding noise. In fact, as Schmidgen (2008) further demonstrates, there is an interesting annex to be found in the history of the laboratory, in the development of the so-called camera silenta; a sound-proof - sometimes even anechoic room that was used for scientific research. A lack of what could be termed sonic sterility in these laboratory contexts seems disruptive of what scientists usually re- 
gard as an efficient, faithful and reliable operation. This point is confirmed by more contemporary ethnographic work on the ways in which sounds condition observation and experiment in nanotechnology research (Mody, 2005; Roosth, 2009). As Cyrus Mody (2005) demonstrated, it "often is the soundscape of a place that shapes what knowledge can be treated there" (p. 184). This is among others the case in places where sound acts as a sonic contaminant that potentially disturbs scientists' experimental setups. Droning infrastructure or outside traffic noises thus challenge the conviction that laboratories not only look and perform alike but also sound alike.

This is potentially problematic for the production of scientific knowledge. As Steven Shapin has pointed out, "the wide distribution of scientific knowledge flows from the success of certain cultures in creating and spreading standardized contexts for making and applying knowledge" (Shapin, 1998, p. 7). Indeed, several decades worth of science studies have highlighted the peculiar success with which the twentieth-century scientific laboratory has standardized such contexts. This has been achieved in part through the homogenization of its spaces (Henke \& Gieryn, 2008). Despite the historical diversity in function, design and appreciation of 'the laboratory' since the nineteenth-century (Gooday, 1991), it has been fashioned into a universal cultural space that thrives on at least the belief in its "generic placelessness" (Kohler, 2002a) and an ensuring "presumption of equivalence" (Gieryn, 2002). In these generic places, natural phenomena are thought to become detached from their context so they can be examined, measured and manipulated at the observer's own terms, independently of the natural conditions and contingencies of local situations (Knorr-Cetina, 1992). Sonic standardization has been one, thus far however slightly overlooked, part of this desire for contextual equivalence.

This chapter deals not so much with the soundscapes of the built environments of science, but with those of actual, natural landscapes and the sites of scientific fieldwork therein. Within the history and sociology of science, the field-site and the laboratory have often figured as two ends of a wide-ranging spectrum of ways in which scientific knowledge has been legitimized. Field and lab have each been associated with different occupants, discourses, epistemic virtues and degrees of accessibility (Gieryn, 2006). Between the lab and the field there exists, therefore, a clear methodological tension (Kuklick \& Kohler, 1996). As Karin Knorr-Cetina (1999) writes, the power of the laboratory "resides precisely in its enculturation of natural objects" (p. 118). It is by transforming them that the observer is granted an unprecedented control over them. In contrast, natural scientists have presented the field-site as a place where they encounter their objects of study in their most natural and unadulterated state and environment (Burkhardt Jr., 1999; Gieryn, 2006; Rees, 2005). At the same time, however, the phenomena encountered there have been much more multivariate, fleeting, complex and unrepeatable than laboratory objects (Collins \& Pinch, 1993; Kuklick \& Kohler, 1996). After all, scientific research in the field depended on the conditions of specific open places, which were not only highly contingent, changeable and often uncontrollable, but also had to be shared with other actors (Henke \& Gieryn, 2008; Lachmund, 2003). 
These differences in cultural topography also implied differences in soundscape. Recent work in environmental history, cultural geography and history of technology has shown that such communal nature spaces have been intersected by different, often contested moral geographies that regulate different interests in the sonic environment (Bijsterveld, 2003; Coates, 2005; Matless, 2005). Hence if we take seriously the assertion that scientific practice is indeed surrounded by a multitude of sounds that laboratory scientists have, with varying degrees of success, tried to filter, segregate, or control, one needs to ask how field-scientists have come to deal with the acoustics of a complex environment that, like so many other aspects of fieldwork, has in fact been particularly hard to establish control of. I will argue in this chapter that while ornithologists drew extensively on the epistemic virtues of the field and direct observation of phenomena in their natural context, they developed techniques through which they not only took control of the soundscapes of the field, but ultimately also domesticated their subjects.

It is in this, admittedly limited sense, that I will argue the field-site has actually been 'laboratorized', and I use the term here as a nod to a thesis by historian of science Robert Kohler (2002b). Kohler argued that the history of particular biological sciences displays an interesting convergence of the apparently distinct idealtypes of field and laboratory, with plenty of hybrid forms emerging between them naturalized labs as well as laboratorized nature. This thesis has not remained wholly unqualified though; others have rightfully pointed out that other branches of field research were less impacted by the premises of laboratory work and that many other field stations were never merely the 'placeless laboratories' one might take them for (De Bont, 2009a). Accordingly, I do not wish to argue that the field-site was ostensibly supplanted by the laboratory. Rather, I have in mind a more subtle 'laboratorization' that involved analogies between strategies adopted in the laboratory and the field to complement the epistemic legitimization of work situated in the field. This implies not necessarily an element of experimentation - although as chapter 4 will make clear, field studies of animals' acoustical behavior did sometimes involve experimental programs that relied on recordings. Instead, I argue, field recording came to involve particular epistemic interventions that resemble those adopted in the laboratory and that also facilitated the transfer of these sound recordings into the laboratory. The result, I argue, was a convergence between the acoustic conditions of the field and those of the studio, as well as the laboratory.

In conceptualizing these dynamics between laboratory and field, this chapter draws in particular on an argument made by sociologist Thomas Gieryn (2006) in which he demonstrates that the urban sociologists of the Chicago School presented their work in the city of Chicago at the same time as an experimental laboratory practice and as an observational field practice, which allowed them to strategically evoke the epistemic authority of either place where they deemed it appropriate. To schematize how these researchers ascribed such properties of the urban landscape and how they shuttled back and forth between these constructions, Gieryn identified three dimensions that are relevant to this chapter's argument. First, as Gieryn 
points out, objects of study are found naturally at the field site, while in the laboratory they are necessarily made and crafted first into suitable objects of research. Secondly, at the field site, the objects and phenomena of research also connect intimately with and are part of the place of research, while laboratory practice intentionally constructs environments and objects that are generic, by virtue of which their universality is suggested. Finally, field and lab position their analysts in different ways vis-à-vis their objects of study. At the field site, researchers get immersed their research object is everywhere around - while the laboratory creates distance between researcher and object. In the words of Gieryn, "with the white coat comes a detached objective view from nowhere. Elements [ . . . ] are manipulated in a passionless, mechanical, and antiseptic way" (Gieryn, 2006, p. 11).

Gieryn presents this shuttling emphatically as a rhetorical mechanism that takes place within discourse. In this chapter, however, I will show that these dimensions may also have a material influence that is no less important. It should be noted at this point that I do not offer these dimensions as definitive and exclusive standards to measure degrees of 'laboratory-ness' or 'field-ness' by, but as a starting point in my analysis for coming to terms with their complex dynamics and a way to focus and crystallize the many differences that have been distinguished between lab and field in some of the scholarship quoted above. These dimensions (ready-to-use, specific context, and immersion versus craft-to-use, generic context, and detachment) may thereby help to grasp how nature recordists situated their work in the field - which has been an explicit factor in establishing its credibility and authenticity - and at the same time reproduced that field as a new phenomenal domain that, by reducing place and context as much as possible to a generic and mute backdrop, invites comparison with such other modern spaces of sonic control as the sound studio and the laboratory. It is through the mechanical mediation of recording, I argue, that such apparently stable distinctions between field work site, laboratory and studio may begin to leak into each other.

\section{Listening objectively}

How then did the field come into the focus of these ornithologists as a place where recordings of bird vocalizations were to be made? In this section I introduce two groups of recordists, located in the United States and Europe respectively, who pioneered recording of bird vocalizations in the field. For sure, as the previous chapter has shown, the very idea of recording birds in the wild had occupied the minds of a number of naturalists already since the late nineteenth-century, but it would only materialize concretely by the late 1920s. Ornithologists in North America and Australia each had toyed with the idea of recording birds in the wild, using wax cylinders and later also an electrical microphone. However, they typically had found "the matter hopeless" or suspended their initial ventures into recording after 
it proved difficult to obtain, afford or maintain suitable machinery for field work. ${ }^{32}$ Ultimately it would be the entertainment business that initiated these ornithologists into the practicalities of field recording. Their interest was raised when improved phonographic techniques enabled sound accompaniment to the silent film around 1926 (Kellogg, 1955). By spring of 1929, a movie production company appealed to the expertise of Dr. Arthur A. Allen, then an eminent ornithologist and photographer of bird behavior at Cornell University. The Fox-Case Movietone Corporation sought to record wild birds to include in the soundtrack of one of their films but had failed miserably in their attempts, and they requested the experience of the ornithologists at the Cornell department of Conservation to help approach their subjects. Eager to collaborate, these ornithologists found themselves confronted with a recording truck equipped with state-of-the art microphones, electrical amplifiers and a "sound camera" that recorded sound on movie film. Introduced by Western Electric, the sound camera proved particularly useful for the movie industry, because like the film itself sounds could be cut and pasted to fit the scene. Moreover, sound-films might also again be recorded on phonograph disc for commercial distribution. After a week of experimenting, Allen and his colleague Peter Kellogg had become very excited about the possibilities of this instrument for their own field studies (Kellogg, 1938).

In Germany and Great Britain, the recording of birdsongs outdoors took flight after 1930, and there too, it initially was heavily reliant on the entertainment industries to match zoological experience with technical expertise and equipment. By 1935, EMI record producer and amateur birdwatcher Ludwig Koch had published a series of records of animal sounds, together with the director of the Berlin Zoo Lutz Heck and with assistance of the established ornithologist Oscar Heinroth, whom Konrad Lorenz would later count among the founding fathers of ethology. Within the changing German political climate, Koch soon felt compelled to move to London, where his recording work was welcomed with much enthusiasm by the British Broadcasting Company. In addition, Koch became acquainted with leading British ornithologists Max Nicholson and Julian Huxley. They were the right people to be around at this time. Nicholson was a well-known conservationist who had been instrumental in the establishment of the British Trust for Ornithology, a national council that fostered coordinated research by British birdwatchers. Together with Julian Huxley he campaigned to foster more biologically literate citizens, and re-fashioned the birdwatcher in Britain as an amateur citizenscientist who formed part of an organized network of observation (MacDonald, 2002; Toogood, 2011). Julian Huxley, who had earlier proposed closer integration of biology and bird-watching, was now Secretary of the Zoological Society of London, a keen and prolific science popularizer and especially interested in the possibilities of new technologies (Kevles, 1992; Waters \& Helden, 1992). In 1934, for in-

\footnotetext{
32 William V. Vogt to Arthur A. Allen, 12 July 1928, Brand Papers (CUL), 1:25. Brand to Vogt, 5 March 1931, Brand Papers (CUL), 1:25. R. Littlejohns to Brand, 14 February 1933, Brand Papers (CUL), 1:27.
} 
stance, Huxley had begun to produce a popular nature film that was to combine entertainment and documentary (Boon, 2009; Mitman, 1999). Koch also became introduced to established natural history publisher and a prominent figure in British ornithology Harry Witherby as well as the British Parlophone record company (Koch, 1955). These actors jointly endorsed Koch's idea of a sound-book - a combination of text and images with gramophone records - to spread the gospel of ornithology among a wider audience.

While Koch went on to record the voices of wild birds for the publication of his sound-books and numerous broadcasts with the BBC, the contacts between the Cornell department and the movie industry were rather short-lived. With the financial crash only a few months after their first collaboration, recording companies could not be enthused to embark on costly and time-consuming expeditions. Importantly, when these contacts ended, not only their access to the mobile and expensive sound-camera equipment waned, but also the expertise of specialized recording engineers and technicians. ${ }^{33}$ While this had set them back in their enterprise, the former stock trader turned amateur ornithologist at the American Museum of Natural History named Albert M. Brand offered a solution. As a part-time student at Cornell University, Brand had become part of the inner circle of field ornithologists at the department of conservation and offered to invest his time and private funds in organizing a small-scale portable recording outfit. After all, Brand had come to believe, "many of the secrets of avian life are hidden in an understanding of the meaning of the song." And phonographic records, he expected, will "become almost as indispensable to the ornithologist of the future, as the camera has become to the present generation, and as the gun was to earlier workers" (1932, p. 439$) \cdot{ }^{34}$

Indeed, these ornithologists and recordists anticipated that sound recordings were to have a significant impact on ornithology, with regard to both its didactics and its potential for scientific research. ${ }^{35}$ Julian Huxley made clear in his introduction to the first British publication that "to both [bird-lovers and amateur scientists] as well as to professional ornithologists, this book will be of great interest and value" (Nicholson \& Koch, 1937b, p. xiii). In a follow-up publication that Huxley coauthored with Koch on animal language in general, he projected that with recordings of animal vocalizations "students of animal behavior will be able to make experiments on the differences between related species, on the share of what is innate and what is learnt in determining reaction [ . . . In any case, it is clear that an interesting field, with both practical and theoretical sides, is here opened up by the ad-

\footnotetext{
33 Peter Kellogg blames in part the financial crash in October which meant that "[p]lants and studios were closed, executives came and went, and promises unsecured meant nothing” (Kellogg, 1938). After contacts with Fox-Movietone disappeared, they tried unsuccessfully to enthuse other recording companies such as RCA Victor Company.

${ }^{34}$ For a discussion of the role of new media in attracting public interest in bird-watching, bird behavior and bird protection, see Wachelder (2009).

35 CUL, Brand Papers, 1:26, Letter Albert R. Brand to P.B. Coffin, 28 January 1932.
} 
vance of technique" (Huxley, 1938, p. 6). Albert Brand, in turn, expected that "the casual bird lover would find identification much easier if he could study the songs and calls at his leisure," and "classes of bird students would find bird song records extremely useful". As with notations, sound recordings would have several different functions at the same time. The sound books and field-guides that both Cornell and British recordist-ornithologists published in the course of the 1930s were thus to be considered as mediated scientific observations, as aural identification guides, as well as tools for learning to identify them, and even as a novel way to allure the casual birdwatcher and -listener into more concrete scientific observation work.

To that end, Nicholson had included an appendix in their sound book with guidelines to the reader about methods of listening and recording bird sound. Of course, field observers were to have a "tolerably good hearing" but for finding out in what ways particular songs differ from each other regarding their duration, intervals, rate of delivery, pitch and the notes of which they are composed, "one may quickly develop a surprisingly good ear," provided that the listener keeps in practice (Nicholson \& Koch, 1937b, p. 191). "Anyone of reasonable intelligence" would then be able to contribute to answering important outstanding questions in ornithology: if listeners studied and reported differences in the song periods or of regional, seasonal and individuals patterns of song variation, he outlined, "we can gradually find out more about the relationship and possibly the origin and significance of songs" (ibid., p. 193). As such, Koch and Nicholson's 1937 Songs of Wild Birds book and gramophone record readily fed into a BTO (British Trust for Ornithology) organized nation-wide bird-song inquiry that ran from 1937 to 1940 (Alexander, 1943). ${ }^{36}$ The census included over eighty volunteer observers, who were asked to chart the development of song of specific species throughout the seasons. The network was temporarily suspended because of war conditions but, as it turned out, also due to unsatisfactorily inaccurate results. The data collected suggested that either birds' song periods or the methods of taking down data and the reliability of observers varied enormously. Amateur ornithologist Horace Alexander concluded pessimistically that in reality "not every observer is trained to have an ear that records bird-song heard each day without a good deal of deliberate concentration. The birds may be singing, but the recorder, though within earshot, may not be listening - though he may think he is. Also, some people are much deafer than they think they are" (Alexander, 1943, p. 67). ${ }^{37}$

\footnotetext{
36 Such surveys were also carried out elsewhere. Hans Slabbekoorn notes a similar wide-ranging ear-based survey of Great tit in Finland between 1947 and 1950. The research was repeated again in 1981, which revealed a dramatic shift in the ratio of song-types (Slabbekoorn, 2009).

${ }^{37}$ Indeed, the demographics of the community made deafness a real problem for the field observer. In 1934, for instance, British ornithologist Howard Saunders (at the age of 60) read a paper before the American Ornithologists Union meeting to warn his peers that with age their hearing might diminish: "This year I had an ear test and while I was found to have a competency of about $90 \%$ on the lower vibrations, when the tones went up into the thousands, my ability to hear them dropped towards zero very fast." Yet Saunders' account of the regression of his hearing abilities remained optimistic. There had been many occasions, he noted, in which his hearing despite its apparent deficiencies had proven to be surprisingly effective: "It was
} 
Apart from teaching field observers to listen and allure them to contribute to scientific research, ornithologists such as Brand expected that their recording work would also open "the way to a multitude of scientific experiments [and] an entirely new field to the ornithologist", as now the "serious student of ornithology could study song in a way that has been impossible heretofore" (1932, p. 436). Many preWar studies of birdsong had focused on the statistical analysis of singing behavior as part of species' life history descriptions - they quantified and charted the timing and duration of the dawn chorus, average song output per hour or fluctuations in seasonal song periods. While sound recordings were of not much use to compile such long-term data, they could, however, potentially aid studies that documented and analyzed the composition and acoustical variation of specific songs. In light of the shift from species to population in ornithology, such studies had now slowly begun to gain currency among field observers, and the sound-camera and phonograph potentially provided these studies with new dimensions within which such variation might be shown. Brand's (1935) own scientific work with sound recording in ornithology for instance highlighted differences in the average frequency of different species families, and confirmed that birds produced many more individual notes in a song than what a human listener might actually be able to perceive.

In a 1937 paper titled 'Why listening cannot be adequate', Brand explained that "hearing differs, in all probability quite markedly, from person to person". He pointed out that this usually went unnoticed by the average listener, "but in bird sound the range of frequency is quite different from other common sounds" (1937, p. 11). Brand had personally witnessed a series of experiments at Cornell that demonstrated that considerable "fading points" existed in the hearing spectra of most people. Moreover, listening was shown to have a significant psychological factor: "[W] hear what we are listening for and what we expect to hear," for "it is impossible to separate the hearing apparatus from the thinking mechanism" (1937, p. 12). But this fundamental problem with the human faculty of hearing, he argued, could now be undone. As he himself had maintained, "heretofore, the bird song student has had to rely entirely on auditory impressions [but] with mechanical devices such as the sound camera, an objective medium of study is now available" (Brand, 1935, p. 192). On sound film, he explained, "extremely short notes and those of very high pitch, often inaudible to the ear, can be clearly seen and studied" (1935, p. 40). Another Cornell student, Harold Axtell, found that "there is tremendous variation in the inherent capacity of different people to count notes when delivered rapidly [or] to determine changes in pitch." And "there is the simple psychological factor of suggestion or first association [ . . : : because of this initial prejudice, we cannot understand how other people can say that [a song] sounds more like something still different". As a result, "bringing our hearing under scien-

difficult to believe one's ears, especially with such unreliable ones as mine, but it showed that poor ears have been able to detect nuances that had never been noted, or at least never recorded, by better ones [ . . . I am sometimes the first of a group to catch the 'tick' of the purple finch, a note which I have always been inclined to regard as rather difficult to hear” (1934, p. 504). 
tific control seems to be at best an especially difficult accomplishment" (Axtell, 1938, pp. 482-3).

Indeed, Albert Brand noted, his experiments had shown that listeners were usually unable to correctly estimate the number of notes an ordinary bird song consisted of. Even an accomplished musician and trained listener had required several rounds of listening to estimate that number correctly (Brand \& Axtell, 1938). For sure, Brand still relied on the trained ear of the professional musician, his assistant Harold Axtell, to study these songs in the field, but as he had shown, such observations seemed much less accurate than the machine. This resulted in an uneasy straddle for the field ornithologist who was led to acknowledge, in Axtell's words that what a bird sings does not equal what can be heard by a human observer. Axtell for instance published a detailed description of song features (and their variations) that might help the listener to recognize the Kirtland warbler in the field. But he also complemented his own graphic notation, based on his own hearing, with a graph based on sound-film recordings of the same song. In Axtell's words, this demonstrated that although "the human ear is a relatively imperfect recording device and misses many details, it does pick out the essentials. At the same time, the juxtaposition of both graphs also highlighted the distinction between a mechanical registration of a song's acoustical make-up and its perception by a human listener in the field.

For Brand, the recorder enabled the kind of objectivity that historians of science Lorraine Daston and Peter Galison (2007) have described as 'mechanical objectivity'. That seemingly universal marker of truthful knowledge - objectivity they explain actually has a complex history. Up and until the mid-nineteenth century, Daston and Galison argued, scientific workers aspired to an ideal of what they call 'truth-to-nature', whereby the individual idiosyncrasies that nature brought forth were mildly abstracted, 'corrected' to fit its ideal underlying form. Yet in the middle decades of the nineteenth century, they observed, a self-consciously 'objective' approach took flight that came to discard such practices of selection and idealization as mere subjective projections of the observer. Following an imperative of minimal intervention, in the nineteenth and twentieth century, scientists began to delegate their tasks as much as possible to mechanical procedures and automatic registration techniques, which were believed to be impartial and infallible.

\section{The complexities of field recording}

But although recordists in both Britain and at Cornell now had professional equipment at their disposal for field recording, making it run smoothly in place proved to be a daunting task. As I will demonstrate in this section, mobilizing the mechanical recorder into the field not only required more than usual improvisation and make-do of the recordists, it also greatly transformed their conception of both the field-site and of natural sound. 
When their collaboration with the movie industry waned, the recordists at Cornell soon experienced that they lacked sufficient practical knowledge to assemble the right equipment and make it work properly. Calling upon their colleagues of the electrical engineering department, they realized that "the whole thing seemed so complex we didn't know where to begin. Like an octopus it seemed, and each of its tentacles reached out into a different field of technology: mechanics, electrical engineering, sound and acoustics, photography [ . . . ] all seemed hazily intermingled in this new machine to which we were being introduced" (Kellogg, 1938, p 78-9). Only after a full year of testing and tinkering, the engineers and ornithologists eventually managed to redesign their "rather amateurish" outfit in such a way that it would be able to withstand hard usage in the field, and "be capable of being operated by ornithologists who knew little or nothing about engineering" (Kellogg, 1938 , p. 84). But although this had reduced the technical complexity of the recording enterprise, actually recording in the field remained a logistic tour-de-force.

"A layman might think it easy, and might imagine setting out with a small apparatus and a microphone like an amateur photographer with his camera, having no more to do than to take a snapshot," Koch explained (Nicholson \& Koch, 1937b). But in reality, field recording was much more complicated. This was so, not just because of the diverse staff - a group of around five drivers, technicians, engineers and ornithologists in the case of the British recordists, and a team of at least two operators for the recording outfit at Cornell - that were required for the recording expedition to run smoothly. With his artisanal notation techniques of pencil and notebook, the field naturalist had been able to depart easily from the tracks to follow his subjects to their perches. These ornithologists, however, were much less mobile. Field recording after all required a load of heavy equipment that was to be transported in a truck or large delivery wagon.

Historians Jeremy Vetter (2004) and Robert Kohler (2006) have observed that commercial and military infrastructure such as railroad lines impacted the practice of scientific field work in significant ways, by expanding access to distant field sites and facilitating the transport of equipment, specimens and personnel between center and periphery. This has certainly been the case for sound recordists. Whether they ventured into the cultured environment of town parks or the relative wilderness of nature reserves, roads, paths, trails and other infrastructure formed a network of mobility that became vital to the logistics of nature recording. Some were able to employ this infrastructure creatively - Danish radio engineer Carl Weismann set up his first recording outfits next to a railway ten kilometers out of Copenhagen and used the telegraph wires to send the recording signal of a singing bird to a wax disc recorder in his radio headquarters (Interview Weismann). But as often, when following their subjects, the naturalist-recordists would have to leave those networks of mobility and infrastructure and venture into a lot more wild terrain. During the expedition by the Cornell ornithologists and the American $\mathrm{Mu}$ seum of Natural History described in chapter one, the ornithologists were forced to transfer their sensitive recording equipment from the studio truck onto mule-drawn 
carts. It took them two days to dismantle the equipment from the truck and mount it on the cart. This turned out to be the only possible mode of transportation to navigate, guided by hired locals, through the extensive Florida swamplands.

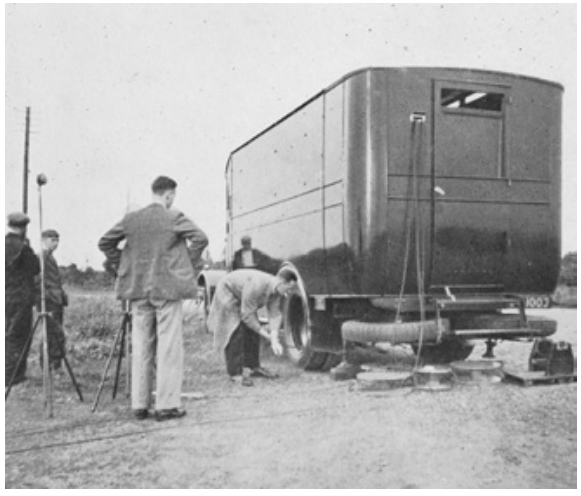

Figure 3.1

Preparing the recording-van in the field.

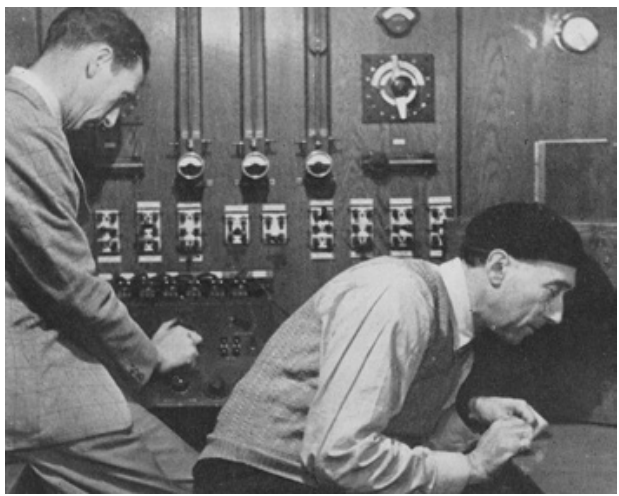

Figure 3.2

Listening at the loud-speakers in the mobile studio.

To prepare for such difficult field conditions, the equipment had to be built ruggedly to withstand rough terrain. The van was outfitted such that recordists referred to the improvised control paneling in the trucks as their own mobile studio. Except in size, they found, it was exactly similar to the professional studios on Abbey road (Nicholson \& Koch, 1937a). For both groups, their sound vans carried the amplifiers and multiple microphones, as well as a great number of dry cell batteries or a noisy dynamotor for power supply (Pulling, 1949). This did not, however, preclude regular failures. Power supply was often short, and humidity would regularly cause short circuits. Brand and his Cornell colleagues moved a large and extremely sensitive sound camera and testing equipment around, amounting in total to a weight of roughly 1500 pounds, which accounted for dangerous sways of the van. Koch and his British recording engineers instead worked with a phonograph recorder that would cut the recordings on wax discs. Recording on wax had the disadvantage that the recording could not be played back under the conditions of mobile recording, but had to be processed in the studio first, which required recordists to ensure that they would not break in the meantime. Moreover, wax could not be recorded on in its original state, so that these discs had to be softened first to a critical point in special wax-heaters or large electric ovens. And to make the needle run smoothly on the wax, the recording vans also had to be precisely leveled so the equipment would stand perfectly upright. Moreover, field recordists would operate often in the dark or around dawn, to catch the dawn chorus around sunrise, when birds are most active and vocalize most repetitively. The British team of drivers, ornithologists, and operators would thus venture into the field to check up 
on the microphones they positioned there the day before, to allow the bird to return to its perch overnight. With their equipment connected, checked and prepared, the operators would have to wait for the bird to begin its song. At this exact moment, the recordist would have to lower the stylus onto the recording medium. Often, however, the disturbed bird would have flown elsewhere, often too far out of reach of the stationed microphones.

Catching a bird therefore often meant a trial of patience lasting for days or weeks. Why, then, one must ask, did these recordists go through so much effort to record wild birds outdoors? After all, Albert Brand pointed out, "recording the caged wild bird appeared the simpler option" to the ornithologist with an interest in bird vocalizations. However, recording caged birds, he explained, had one major drawback: "most birds will not sing normally in captivity. Some will not sing at all; others, only in subdued and restrained tones" (Brand, 1934, p. 17). "We know that molt, willingness and ability to mate, and even incubation are seriously disturbed by confinement; there is every reason to believe that song and song development are also affected." It would therefore be "rather dangerous to make generalizations on bird song from observations of captive specimens" (Brand, 1936, p. 49). Likewise, his Cornell colleague Kellogg concluded that "it is doubtful that such recordings [of caged birds] would receive wide acceptance, especially from ornithologists, because it is well known that captive birds behave differently from free birds of the same species" (Kellogg, 1938, pp. 175-6).

But however 'well-known' this might have been among field naturalists, many of the self-consciously 'ethological' studies that had begun to appear in the preceding two decades had been based specifically on captive animals. Several of these ethologists had been animal keepers, whose long-term and repeated engagement with the animal, as Konrad Lorenz pointed out, had special advantages over the experimentalist or the field naturalist (Burkhardt Jr., 1999). In Germany, for instance, Ludwig Koch had also made an argument for recording wild birds for his first record, but he had found it welcomed with derision by his collaborator, ornithologist Oskar Heinroth. Like other pioneers of behavioral study at the time, Heinroth had spent large parts of his professional career at the Berlin zoo and in his own aviaries, and he persisted that "caged birds always have the same song as members of their own species in their natural surroundings" (Burkhardt Jr., 2005). In Koch's recollection, Heinroth maintained that "my attempt to record birds in the open was merely a sort of circus performance" (Koch, 1955, p. 25-6). ${ }^{38}$ Koch eventually managed to convince Heinroth by demonstrating the misleading mimicries that encaged animals might produce, with such success that Heinroth would

\footnotetext{
38 Albert Brand must have been aware of these ethologists' ideas. During a round trip in Europe in 1938, Brand and Allen met Konrad Lorenz as well as Oskar Heinroth. In a report (CUL, Brand Papers, 1:40, Bird hearing experiment, 9 March 1938) he noted that "[Heinroth] has recently recorded bird songs and is especially interested in working up individual species, recording their calls and songs completely. As he says, song can be gotten in Nature, but calls are different and more difficult. He suggests hand-reared birds and recording mainly from birds of the second captive generation."
} 
emphasize in the introduction to their record Gefiederte Meistersänger that "in no case does it concern here caged animals. This kind of recording guarantees a flawless, I might even say, location-specific fidelity" (Heinroth \& Koch, 1935, p. 13). ${ }^{39}$

Koch went on to assure his readers that "such recordings cannot be made in a zoo, but also not in a room or a recording studio, if they are really to become trueto-life" (ibid, p. 1). ${ }^{40}$ But curiously, what made these places so different from the field to this recordist was not only determined by Koch's desire to observe and record authentic behavior. He would initially explain that "attempts with caged birds have proved a failure, [also] since the acoustics of a building distort the sound, sometimes beyond recognition“" (Nicholson \& Koch, 1937b, p. xx). Recordings of enclosed individuals were not only prone to distortions in the birds' behavior, but also in its acoustic representation on record. In the hands of the naturalistrecordist, then, the qualifications that accompanied their records, such as the German "Naturtreue" or the English "natural" turn out to be doubly layered notions. Of course they underlined that the recording had been produced in nature and after real-life specimens. This was certainly no superfluous assertion in an era in which whistling bird imitators still had an important share in the amusement and recording business, and in which the consumer had been familiar only with recordings of caged and trained animals, often as an accompaniment to musical arrangements. ${ }^{41}$ The qualification of authenticity and naturalness thus set the recordings clearly apart from the popular or aesthetic in its didactic and scientific aspirations. But in the context of this move outdoors, the term referred as much to the reproduction's acoustic exactitude and fidelity.

For these recordists, recordings were to be both naturally and acoustically correct. As Emily Thompson (1995) and Jonathan Sterne (2003) have shown, by the late 1920s consumers had been shaped into critical listeners who had become accustomed to expect an increasing authenticity to go with phonographic reproductions. And these recordists readily fed into that discourse. Bird song was very delicate, Albert Brand (1936) pointed out, and although the songs had been recorded with great care, ordinary commercial phonographs might easily distort its highpitched sounds. For that reason, the authors had omitted higher pitched bird songs from the record, but listeners would do good to invest in a good phonograph as well. Moreover, he pointed out, the acoustics of the salon in which the recordings

\footnotetext{
39 Translated by the author from original German, "es handelt sich hier also in keinem Falle um gekäftigte Tiere. Diese Art der Aufnahme verbürgt eine tadellose, ich möchte sagen, eine standortsgemässe Naturtreue". 40 Translated by the author from original German, "Derartige Aufnahmen nicht in Zoologischen Gärten, aber auch nicht im Zimmer oder im Aufnahmeraum einer Schallplattenfabrik gemacht werden konnten, sollten sie wirtlich naturgetreu ausfallen“.

${ }^{41}$ Originally a vaudeville performance, many whistling artists made themselves a successful career by impersonating the songs and calls of common birds. In the first decades of the twentieth century, bird song imitators also filled the catalogues of prominent record labels such as Victor, Columbia and Brunswick, often to accompany small orchestras or opera singers. For more on the art of whistling, see Tipp (2011a, 2011b). Likewise, well until the 1930s caged canaries and nightingales were being recorded for entertainment purposes, often in combination with musical arrangements of classic tunes such as 'The Blue Danube', see Bevis (2010), Birkhead (2003) or Tipp (2011c).
} 
were played were equally important to its fidelity, as they might dampen or magnify certain frequencies to the extent that "when sound is so distorted, the reproduction is unnatural" (Brand, 1936, p. 30). It would pay to experiment to find the phonograph's most favorable place in the room. For that reason, the Cornell recordists often liked to demonstrate their recordings out-of-doors. Clearly, then, objective, authentic and undistorted sound mattered for these field recordists. But while the naturalness and fidelity of a sound recording might seem evidently interlocked in this discourse, they proved difficult trade-offs in practice.

After all, while the field conditions were usually not optimal for such recording expeditions, the field was also never as much a wilderness as it might appear. As Albert Brand warned his readers, "it is not as simple as it would seem to get a location where there is absolute quiet [ ... ] Too great proximity to a traffic road, for instance, makes recording impossible" (Brand, 1932). Hence, the recordists' reliance on infrastructure to reach distant areas for recording had an ironic effect: it produced noisy surroundings. The Cornell recordists experienced this the hard way, for instance when several recordings turned out useless because their microphone had picked up static from nearby power lines. Both Brand and Koch complained that their recordings of bird sound were often interrupted by a passing airplane or turned out to be unfeasible because of the hum of a distant highway (Brand, 1932; Koch, 1955). British conservationist Max Nicholson accompanied Koch on several expeditions into the British countryside, and vividly recalled his impressions as:

Aeroplanes, motor-cars, lorries, trains, and motor-bicycles combined to shatter the tranquility which had been so perfect a few hours before. Just as smoke pollution helps to swamp a town under fog, so the natural peace of the country was drowned under the indefinable hum of distant engines and wheels. ... Until one has listened objectively to all these sounds coming through the loud-speaker, in what counts still as a peaceful retreat from the bustle of London, it is hard to realize what a noise-ridden world we have managed to make ourselves live in. (Nicholson and Koch, 1937, p. 38)

The analogy between noise and smoke pollution is a strong one here. Not just because it evokes some of these noises' ungraspable omnipresence, but also because it was a trope more commonly employed in noise abatement campaigns since the late nineteenth century. Indeed, these recordists' public aversion towards noise fitted with a more general resistance to all kinds of mechanically generated noise, which, as historians of technology Emily Thompson (2002) and Karin Bijsterveld (2001, 2008) have shown, became increasingly organized in American and European cities between 1910 and 1940. In New York, for instance, officials of the Noise Abatement Commission monitored sound levels in the street since 1929, while in London, an Anti-Noise League was formed in 1933 (Matless, 2005; Thompson, 2002). The League had coined noise as a threat to citizen health and, with the es- 
tablishment of the decibel as a unit of loudness in 1925 and technical instruments such as acoustic meters, relied on a more "systematic and objective measurement" of city noise levels. But the battlefield against sonic exhaust was not restricted to the clamor of the city only. Noise became a point of concern in the English countryside too. In 1933, for instance, the geographer Vaughan Cornish argued on behalf of the Council for the Protection of Rural England (CPRE) for better regulation of the Norfolk Broads region, deploring the vulgarity of anthropogenic noises: "It is well to remind ourselves of the fact that quietude and harmony of sound are among the amenities of the natural scene" (Matless, 2005, p. 752). Nicholson's complaint about advancing noise levels in the country fits, therefore, with a sentiment that was felt more generally.

But Nicholson's experience of the field was not only sentimental. The soundscape of this mechanical age had obviously changed. This was not simply the case because mechanical artifacts and machinery generated more noise, but also because mechanical measuring devices and recording technologies made noise increasingly audible. Technological mediations had thereby begun to structure the sonic landscape in a way completely different than the human ear had. For the recordists, this was due especially to the unselective sensitivity of the microphone. As Ludwig Koch explained, "the sensitive microphone takes up all noises, often within several miles' radius, and exaggerates them" (Nicholson and Koch, 1937, p. 20). As a result, it would be common for an observer like Nicholson to find that "although I did not realize it at the time, an aeroplane [sic] was cruising about too far away to be seriously noticeable to the human ear, but quite near enough for the microphone with its acute sensitivity to pick up the sound" (Nicholson \& Koch, 1937, p. 36). Microphones, Brand explained, picked up so-called 'ground noises':

These are the sounds that are always present, but which our ears with the aid of our brain shut out from our consciousness. The ticking of a clock in our bedroom does not disturb our sleep - we say we become accustomed to it. Our brain does not transmit to us all the sounds which our ears pick up. But though man has been able to invent a mechanical ear - the microphone, and it is an extremely sensitive one, too - he has not been able to equip it with a brain. It transmits all the sounds it hears, without discrimination.

(Brand, 1934, p. 19)

Hence the 'mechanical ear' did not just function as a simple prosthesis to the human ear; it did not just amplify what a human ear would normally perceive. It also structured the listeners' acoustic experience in a new way through an indiscriminate, unselective registration. Indeed, as Daston and Galison (2007) noted, mechanical objectivity also came at a price. Without selection and idealization, images become cluttered with context and artifacts. Similarly, then, for these naturalist- 
recordists, objective registration techniques also introduced an unpleasant byproduct: noise.

It was especially this technique of data visualization that made field noise particularly problematic - not just an aesthetic (as it had been for Koch and his colleagues) but also an epistemic issue. After all, as these recordists had found, the human ear would usually be able to select and distinguish a bird sound relatively efficiently from its noisy surroundings. Once represented visually, however, that distinction between sound and noise was potentially harder to make. Although specific sounds would be distinguishable by their visual shape, particularly the higher pitched sounds appeared as very thin hair lines that were "hardly visible to the eye". When these overlapped with the frequencies of other noises, they were particularly difficult to distinguish. Such techniques of visualizing sound will be taken up again in more detail in chapter 5. At this point it is important, however, to note already that although the inscriptions of sound-on-film allowed ornithologists new ways of comparing and a claim to objectivity, the process of visualization also determined more narrowly what kind of sounds one was able to record and study at all. Mechanical recording thus had seemed to outline the beginning of a solution to the problem of faithful reproduction of sound. But at the same time, it had created a new problem too: the acute perception of noise which, to the Cornell recordists, possibly complicated the visual inspection of their sounds for scientific study.

\section{Two approaches to field recording}

The recordists in Britain and at Cornell University were faced with a similar challenge: a noisy environment that complicated the recording process. Their approaches and solutions to these challenges, however, differed quite markedly. Koch and his British recording team tackled the realities of field recording by employing a strategy that was common in the studio recording practice of the day. They would engineer the desired sound by adjusting sound levels through a strategic placement of microphones and the singing bird. Historian of sound technology Susan Horning (2004) has argued that much recording work in the first half of the twentieth century was based on trial and error and gradually acquired experience. Before electrical systems could amplify the recording signal, studio recordists relied on their intuition to position the vocalist and the various instruments around the recording horn in perfect balance. But this remained the case even when the condenser microphone and the vacuum tube amplifier replaced the recording horn in the 1920 s, and sound quality drastically improved. By the late 1930s, the 'recording engineer' had been granted much more control over the process of recording which, however, still required a lot of skill and experience to place the increasingly sensitive microphones in relation to the sound source - an expertise that was acquired only through trial and error. 
It was this particular skill that the recording engineers and technicians in Koch's unit had learned to make their own in the studio and, except for Koch, who had been recording in zoos, these men had little or no experience in recording wildlife outdoors. Koch and his team outlined an approach similar to that used in studio recording when he explained that a real birdsong hunter must "with skill and much patience go about the job of bringing the songster as near as possible to his microphone, or rather the microphone as near as possible to the songster" (Koch, 1955, p. 3). At all times, Koch arranged the microphone to be near the bird "as if he were a performer in a studio" (ibid., p. 73).

Yet the technique was also different from those employed in studio recording in at least one important aspect; if the space of the sound studio before 1940 had begun to be operated as a 'dead room', an acoustically sterile backdrop for musical performance, these British recordists elevated the natural environment to an important aspect of their kind of nature recording (Horning, 2002; Thompson, 1997). As Julian Huxley repeatedly stated in his laudatory introduction to Koch's first British sound book, Koch's records had "the quality for evoking the bird's environment": "when I first heard his records I was immediately struck by the way in which they called up the natural environment of the singers. As the nightingale's voice escaped from its ebonite prison under the touch of the needle and the scientific magic of the sound-box, I felt myself transported to dusk in an April copse wood" (Nicholson \& Koch, 1937b, pp. xiii-xiv). This 'natural' sound, the evocation of an environment, was indeed what Koch was after: "in my nature recording I invariably observe the principle of getting the bird-notes in question in the foreground by all means, but always with their natural background" (Nicholson \& Koch, 1937b, p. 21).

However, under such noisy circumstances, evoking a sense of naturalness required a number of crucial interventions. Most importantly, the team had to make sure to distinguish between the bird's voice in the foreground and the interfering and sometimes noisy environment in the background. To do so, the recordists would arrange up to six different microphones to enclose the bird's song perch, thus improvising a large-scale recording room outdoors. Each of these microphones was linked to a control panel in the van several hundred yards away, where an incoming sound to one of these microphones would be cut straight into the wax disc. ${ }^{42}$ Occasionally the bird would fly away, and then the whole set-up of microphones would have to be changed, including tests to make sure the microphones "cut out as much as possible of interfering noises" (Nicholson and Koch 1937b, p. 37). With their sensitive omni-directional microphones, the disturbance could be caused by anything: the low frequencies of anthropogenic and mechanical noises, electrical interferences, as well as the constant or sudden interference by rain, wind,

\footnotetext{
${ }^{42}$ To be sure, this set-up with several microphones could not be used to produce a stereophonic recording of the field by combining multiple signals and thus localizing the listener within it. Instead, it was a way to enhance the chance of encountering a bird 'performing' close enough to pick up its signal at the expense of a potentially disturbing ambience.
} 
water, rustling leaves or other species. While the recordists considered noise part of the reality of field recording, the intended purpose of the recordings - reproduction on low-tech gramophones or broadcasts over radio - also dictated that interference was to be reduced as much as possible by obtaining a close-up recording of the bird. Of course, as Jonathan Sterne (2003) has stressed, the very act of recording always implies mediation and selection. But in this context, a "natural sounding" recording was dependent on the technical restrictions enforced by its reproduction as well as an implicit preference for how nature should sound ideally - clear and tranquil (Altman, 1992; Helmreich, 2011).

As we have seen, the recordists at the Cornell Laboratory of Ornithology faced similar problems, but eventually they took a rather different approach. After experimenting for some months, the ornithologists had experienced some success with their equipment. Yet they also found that many of the recordings they had produced with ordinary microphone set-ups had significantly been drowned out by noise. Of course, they had learned, with some tinkering and re-recording, lowfrequency sounds could to some extent be filtered out. Yet this would often result in a high-pitched and squeaky tone from which it became immediately obvious that the sound had been 'worked'. The group found inspiration for a solution in a cover story of Radio News on a parabolic reflector and a demonstration by their colleagues at the physics department. 'Sound concentrators' in the spherical shape of a parabola had been patented for radio pick-up only a few years before and were being used extensively in sports broadcasting and movie productions (Dreher, 1931; Elway, 1932; Thompson, 2002). After the group had cast their own from an old mold that had been used for war-time airplane detection, Kellogg concluded enthusiastically that this "parabola for picking up and concentrating bird songs on the microphone was probably our greatest piece of good fortune. Recording would have been possible without a reflector, but the results with it were so superior as to make the instrument a universal tool in this field" (Kellogg, 1962a, p. 39).

What then, made the parabolic reflector so superior for these Cornell ornithologists? The principle was such that the surface of the parabola reflected sound waves to a dynamic microphone at its focal point. Focusing the sound waves like this drastically increased the input to the recording equipment and concentrated it to at least twenty decibels louder than the sounds not caught by its narrow shape, which amounted to an amplification of about fifteen times (Sellar, 1976). As a result, the reflector would help to record sound at a much greater distance than microphones in an ordinary setup. Consequently, bird sounds could be recorded at a distance, in flight or in to the traditional recordist inaccessible places - an obvious added advantage to students increasingly reflective of studying animal behavior in the wild. Since microphones would not have to be set up and retrieved stealthily, recording was much more efficient too. Equally important, however, was that the parabolic reflector only focused the sound energy from the direction in which it was pointed, which permitted a greater selectivity and directionality in recording. Unlike the common carbon or condenser microphones that were used by record- 
ists more generally and that recorded omni-directionally, this microphone design had the effect that "the outside noises are very nearly shut out, while the sounds wanted are greatly increased" (Brand, 1934, p. 23).

These advantages led Kellogg, Brand and their colleagues to compare the concentrator "with the magnifying power of a field glass, reducing the apparent distance to about $1 / 20$ th the actual distance" (Kellogg, 1938, p. 181). The analogy to this quintessential field naturalists' tool was particularly apt, and not just because the reflector had a small telescope attached to bring the individual bird 'into focus'. It was particularly fit because just as with a pair of binoculars, the concentrator would eliminate part of the (aural) landscape but zoom in and produce a close-up of parts of it. As with a visual lens, the result of this aural lens was, therefore, a close-up recording: a sonorous sound with a high signal-to-noise resolution that provided, however, very little information on the spatial behavior of its source signal - it cut out, for instance, part of the reverberation.

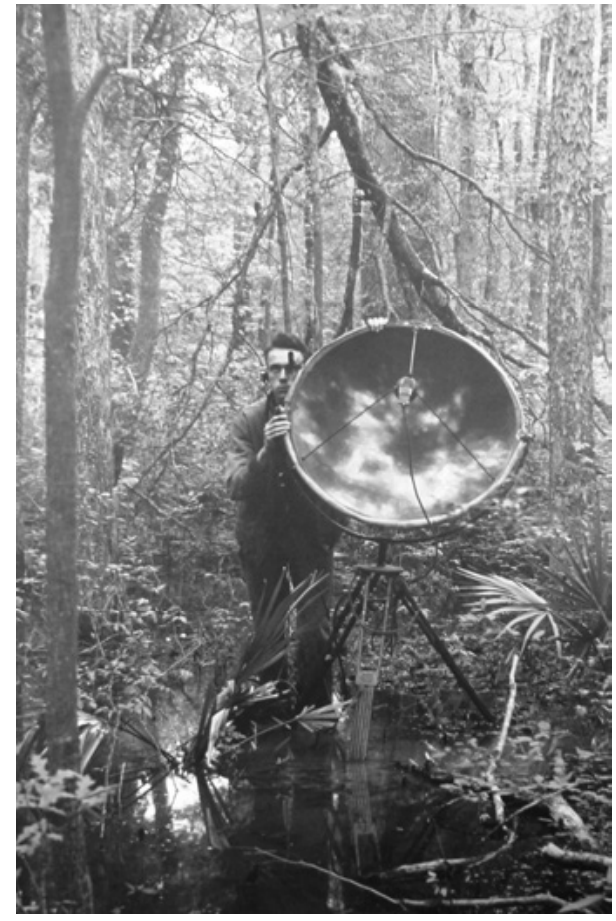

Figure 3.3

Cornell ornithologist James Tanner 'aiming' parabolic reflector.

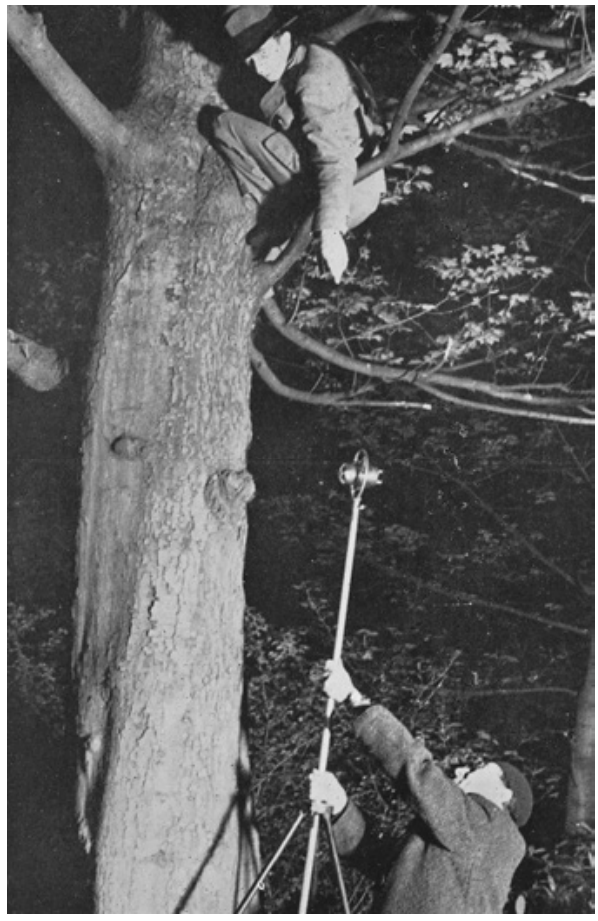

Figure 3.4

British recordists fixing up a microphone near a song-perch.

In that sense, such close-up sound was much alike in kind to the 'sterile' sounds that were increasingly being produced in the studio of the 1930 s - by capturing the 
sound and nothing but the sound. Of course, unlike the professional studio engineer, the ornithologist-recordist did not have such modern means of architectural control of sound at his disposal, but he did share a desire to produce an attractively intelligible sound which, to paraphrase film theorist Rick Altman (1992), privileged the listener as a consumer of sounds. But despite this similarity in kind between the studio and field recording technique, announcements that the sound concentrator had "overcome much of the handicap imposed by lack of soundproof studios where the wild birds sing" do come across as somewhat hyperbolic. ${ }^{43}$ While it was certainly true that the parabolic microphone was much more effective in the field than any other type of microphone, the recordings that were considered most satisfactory by the Cornell ornithologists were achieved especially on quiet days and at relatively short distance. In acoustically less favorable surroundings interferences might still occasionally leak through.

Moreover, the application of the sound concentrator in field recording was never self-evident, for although it excluded most ambient noises and distortions, it was itself a source of new ones as well. Since the parabolic recordist was an operator who did not monitor the microphone in a fixed position but had to focus it manually, the large spherical plaster occasionally picked up unintentional body and handling noises. An additional disadvantage was that because of its design, the concentrator structurally suppressed lower frequencies. This effect was responsible for the exclusion of lower-noise levels, but it also changed the quality of the recorded sound. This was not immediately obvious to all listeners though. Recording technicians unfamiliar with birdsong usually preferred to cut out a wide band of lower frequencies to reduce noise levels, yet this, Peter Kellogg complained, seriously detracted from the songs for more experienced listeners, as it made them thin and squeaky. With bird sounds, therefore, "the absence or suppression of the low frequency components is not noticeably detrimental except to the sensitive ears of those very familiar with bird songs" (Kellogg, 1938, pp. 183-4). Ornithologistrecordists were thus faced with a difficult trade-off between a demanding recording routine that produced slightly more noisy recordings of a more realistic quality and a more efficient approach that produced pleasantly-sounding, yet subtly distorted acoustics. Although it was agreed that in principle not all noise would by definition detract from the scientific and aesthetic potential of the recordings per se, extensive listening tests by and among the Cornell recordists ultimately decided in favor of the latter as their standard tool of choice.

\section{Laboratorizing the field}

These recording techniques had been developed and used independently by different groups of recordists to face comparable challenges in the field. Yet their actual

\footnotetext{
43 'Reflectors like Airplane Detectors Catch Bird Songs.' Science News Letter November 10, 1934.
} 
effect on the reproduced experience of the field was substantially different. One important difference in the way in which these recording techniques were conceived is captured in two schemes in a recording manual for aspiring recordists (see figure 3.5). It places the ordinary dynamic microphone within a circular recording range, which is suggestive of the microphone's unselective reproduction of the aural events within its perceptual scope. The parabolic microphone, on the other hand, is portrayed as exclusively capturing the sounds a single bird emits, and nothing else. As becomes apparent from these two schemes, both recording techniques constitute different topographies in the representation of the field-site. Because directional microphones amplified especially those sounds at which the reflector was aimed, they did not permit the presence of much local context. Nor did they evoke the bird's environment in the way that British biologist and science popularizer Julian Huxley appreciatively described as the "fullness, immediacy, and emotional completeness" of an aural immersion he experienced when listening to Koch and Nicholson's British bird recordings (Nicholson and Koch 1936, xiv).
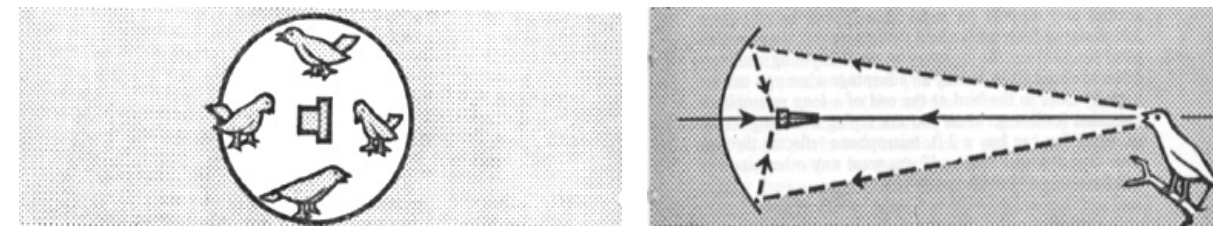

Figure 3.5

Schemes illustrating the recording range of an ordinary crystal microphone (left) and the parabolic reflector (right).

This is not to suggest that other types of recordings could not sound sonorous or close-up. Yet the point is that the parabolic recorder had been designed to create close-up recordings with which instances of acoustic behavior could be organized and sampled within a panoramic, enveloping and noisy aural ecology. ${ }^{44}$ In this section, therefore, I attend more closely to the ways in which these techniques of mechanical recording sonically articulated the field-site. Such articulations are not neutral, and they bring into relief some of the processes of selection that science studies have shown to be at work when crafting observations into scientific objects. These processes, I argue, associate with what I call a laboratorization of the aural landscape in the field.

In spite of the available historical and anthropological work that is quoted in section two, few analytical tools are as of yet at hand to investigate how exactly

\footnotetext{
${ }^{44} \mathrm{My}$ interest here is not so much with a critique of how recorded reproductions relate to the original soundscape they purport to portray, by holding a 'distorted representation' against a putative naked 'reality'. Rather, I will try to articulate some of the transformations of auditory perception that take place through technological mediation and their functionality within scientific practice.
} 
scientists have engaged with the soundscapes of their workspaces. Recent work on visual technologies of scientific investigation may, however, provide a suitable point of reference. As historian of science Gregg Mitman (1996) has pointed out with regard to cinematic techniques in science, the roles of such visual technologies could be multiple in kind. He demonstrates, for instance, how for one generation of research the camera had been a unique way to engage with the individuality and emotional essence of nature, while for the next it constituted a wide-angled, panoramic field of observation that distanced the researcher from his subjects. As such, the camera has been flexibly employed to construct a space in which nature might be confronted and engaged with in very different ways, and by very different audiences. Another, in this context very much related, distinction is being addressed in Chunglin Kwa's (2008) exploration of pictorial conventions in the representation of landscape. Kwa shows how the medium of aerial photography has been employed to reproduce the landscape both as a panoramic view from above, and, alternatively, as a much more fragmented collection of analyzable 'units'. The point here, Kwa insists, is that this is neither a property of the landscape itself nor merely the theoretical presupposition of the viewer. The medium of photography stands in between the landscape and its representation here, and it does so with its own history of innovations and associated ways of looking. Through the photographic techniques of angle, distance, and scale, this medium shapes a particular notion of the landscape that is, however, not fixed. Mitman and Kwa's work thus underlines the role of a representational medium in establishing spaces through which landscapes can be represented, experienced or reproduced in different, yet equally controlled ways; by way of a transcendental, distanced panorama, a set of fragmented analytical units taken from above, or even expressive illustrations that convey a more intimate bond with nature.

An evocative essay by art historian Svetlana Alpers (1998) also illuminates how landscapes may be re-produced and controlled at the same time. Alpers explores analogies between the painter's studio and the scientific laboratory, which she regards not only as physical workplaces, but also as instruments and a condition of working. Her discussion of the representation of landscape as studio matter is especially helpful here. In an accepted historical account of nineteenth-century landscape painting, she argues, painters had freed themselves from studio conventions and began painting "real landscapes" instead. However, Alpers claims, whether painted outside or inside the studio, their work was not necessarily free of a studio approach. Even in landscape painting, she finds, a landscape found and painted outdoors could still be transformed into what appeared to be an object composed in the studio. She quotes Cézanne, for instance, as an artist who represented his vistas as a still-life motif and reduced the expanse of the landscape to the static and frontal presence of a nearby object. Alpers' deliberately speculative style may invite criticism, yet I do not intend to evaluate this essay on its art historical merit. Rather, it may be used to highlight how yet another visual technology permits different modes of representation through which a landscape may be experienced. In trans- 
ferring a three-dimensional surrounding onto a flat canvas, painters have variously opted to translate the field without the illusion of expanse outside the studio. They have altered its realities in a studio way - a way in which phenomena were being experienced as if they were before the beholder in the confines of a room.

Similarly, such recordings reproduced their subjects to the likeness of conventional images in bird-watcher's field-guides; as frontal depictions of the species in action, situated against an opaque, hazy or otherwise cropped backdrop (Law \& Lynch, 1988). Indeed, like the images, these sound recordings do purport a certain sense of realism still. But its version of realism is one that strongly idealizes what may be heard in the field itself. In fact, as one contemporary recordist of bird vocalization describes it, the perspective that such sound recordings purport to convey is that of the singing bird itself, rather than that of the birdwatcher in the field (Interviews Robb, Boughton).

These visual strategies for representing, reproducing and ordering a complex natural environment, artistically as well as scientifically, provide some useful analytical analogies with which we may begin to understand the ways in which directional recording re-produces the landscape. The effect of directional recording techniques is first of all a double one. Physically, the parabolic reflector situates the recordist at a distance from the bird and potentially minimizes intervention with its behavior as much as possible. Yet aurally, it generates a frontal and perspective-less recording that seems to bring the listener extremely close to its subject. The technique thus eliminates the spatial and physical awareness of immersion, of presence and of being in the middle of the field, and replaces it instead by the detached, objectifying point of view of an observer that is situated very close to, but always inevitably outside the scene of action.

As such, the parabolic microphone associates with a much broader set of modern techniques of listening that crystallized around new technologies of sound mediation such as the stethoscope and the telegraph. According to media historian Jonathan Sterne (2003), in order for listening to become useful as a tool of rationality, listening has been separated from other sensory activities, which allowed it to be intensified and focused. Such, as Sterne calls them, audile techniques reconstructed the shape of acoustic space by segmenting it and re-assembling it and thus transforming it into a private auditory space. This reconstruction of the acoustic ecology of the field echoes several of the ordering strategies described by Mitman, Kwa and Alpers above. The effect of parabolic selection and amplification is, after all, an aural recording perspective that reproduces the field as a set of fragmented analyzable units. By focusing and intensifying particular segments of a soundscape, it enforces, more than any other conventional recording technique, an aesthetic of the individual. It is this property by which sounds may effectively be sampled just as other types of natural history specimens, because it allows them to be collected, labeled and ordered. At the same time, directional recordings do suggest an intimate closeness to the individual bird. Sounds are being reproduced as if they were experienced by a detached, transcendental aural gaze from nowhere. Without a 
fixed point of hearing and the suggestion of perspective, it is this aural gaze that fixated the bird, in Alpers' terms, as a still-life motif in a clearly demarcated acoustic landscape.

These visual strategies for landscape representation and Alpers' notion of the studio frame have an acoustic pendant in the parabolic microphone. Yet at this point we may also take up Alpers' suggestion to explore further the analogies between the 'frame of mind' of the studio and that of the laboratory. The studios of the painter or the sound engineer provide suitable analogies to understand the control they allow their inhabitants over visual or acoustic phenomena. Yet in contrast to the 'studio' techniques applied by Koch and the British field recordists, I suggest that it may be productive to regard the parabolic audile technique of the Cornell recordists instead as applying a 'laboratory' frame. Just as the studio approach has not been restricted to the space of the studio, conditions of the laboratory are not exclusive either only to experimental cultures within laboratory walls. I propose to think of directional recording as enforcing a 'laboratory' condition to the field. Bringing to mind the schematic distinctions that Thomas Gieryn used in his study of urban sociologists' discourses, bird sound recordings may thus associate with and shuttle between constructions of the field and the laboratory.

The field-site emerges first of all as a place where animals may be studied in their natural environment. As such, it is thought to permit access to their vocal behavior in what is perceived as an unadulterated state, where it can be encountered as it is found, in contrast to the perceived artificiality of the prepared, tamed, caged or otherwise domesticated bird. Indeed, for that reason birds could not be recorded in the studio. But although the natural environment has been thought to produce natural behavior and acoustical conditions, these were not so easily controlled either. Hence in order to make bird song amenable to recording, measurement and analysis, they were tamed - not so much physically as they were acoustically, by crafting close-up specimens from the complexity of a landscape. That does not mean that locality and context did not matter at all; in fact, as Chapter 4 will continue to show, the context of a place came into view and was being ordered through extensive field-note taking, which privileged and demanded descriptions of the unique local circumstances of the field and recording site. Its acoustic conditions, however, were effectively being crafted into a generic and homogenized background, promoting a detached perspective over the experience of aural immersion.

Consequently, the field may be understood to be 'laboratorized' in several ways. First, directional recording techniques reproduced the vocalizations of the bird against the generic background sound that is, at least ideally, similar to the expectance of a generic soundscape within the isolated laboratory that Cyrus Mody (2005) and Henning Schmidgen (2008) among others have described. Even in an acoustic environment that is more complex than that of the laboratory, then, the field presents itself as a place of science in which a sterile and mute backdrop provide the conditions within which knowledge production may take place. In a se- 
cond way, the laboratory also stands in for a particular set of epistemic techniques with which, as a number of classic laboratory studies in the sociology of science have shown, scientists produce 'docile objects' (Amann \& Knorr Cetina, 1988; Latour, 1986, 1997; Lynch, 1985, p. 43; Lynch \& Woolgar, 1988). What Michael Lynch (1988) for instance observed to be sequential transformations of an original image into a representation applies also to the process of recording. Like illustrations, diagrams and pictures, aural inscriptions too are being selected, filtered, isolated and reduced, which reproduces the field-site as a very specific phenomenal field.

Thirdly, Lynch has shown how a landscape may be transformed into a graphic space by imposing the plane geometry of paper onto the field-site: "a graph is impressed into the very natural terrain with which the observation begins" (Lynch, 1988, p. 225). This, as he and others have argued, makes phenomena in the fieldsite amenable to later mathematization, calculation and a further cascade of inscriptions (Latour, 1986; Lynch, 1988; Roth \& Bowen, 1999). Of course, these audible inscriptions are not subjected to mathematization in the field yet, but they will be eventually, as Chapter 5 will go on to show in more detail. Hence additionally, the field is also being 'laboratorized' in the sense that these techniques facilitated the integration of field recordings into laboratory processes that would produce a further chain of inscriptions. The demands of laboratory techniques of analysis thus shaped the ways in which recordings are being produced in the field. For instance, Cornell's microscopic analysis of sound-film clearly benefited from focused, compartmentalized and sound sterile recordings. Recordings with simultaneous voices by multiple individuals or species did not translate well visually, especially when covering the same frequency band. Enforcing a new topography on the field has therefore also helped to ensure the subsequent intelligibility of recordings as visual inscriptions in later laboratory analysis.

This section thus shows that the 'laboratorizing' strategies for recording soundscapes of the field variously intersect with visual strategies that have been adopted for ordering landscapes. Visual metaphors, such as 'close-up', 'focus', or 'panorama' have presented themselves easily, especially for developers and users of the parabolic reflector themselves. This observation should not be interpreted as another instance of the dominance of the visual in Western culture, its language and its science per se (Classen, 1993; Levin, 1993). In fact, this position has been repeatedly rejected for its essentialist reductionism of sensory experience (Ihde, 1976; Ingold, 2000; Sterne, 2003). Media historian Jonathan Sterne has criticized this essentialism in what he considers an 'audiovisual litany'. This takes the form of an ideological dichotomy drawn up between sound and vision, in which each of these sensory faculties usually assumes a trans-historical and trans-cultural essence (Sterne, 2003, p. 18). In this customary conception, he notes, only hearing is said to place the individual in close contact with the world; sound is found to penetrate, fill space, to be immersive, subjective and affective. This has been contrasted in turn to a dominant conception of vision which, by its very nature, has come to be regarded 
as generally outwardly directed, hence directional, distancing, abstracting, isolating, indifferent and by those virtues, ultimately also objectifying. Instead, recent historical and anthropological work provides strong examples of audile techniques that cut across such supposedly fixed dichotomies, and demonstrate instead how hearing too may be isolating, distancing, directional and objectifying (Rice, 2008; Sterne, 2003).

In that same vein, then, the reading of directional recording that I offer above, suggests that visual and audile techniques are not to be regarded as essentially different from each other. Instead of its inevitable and ahistorical dominance, this 'visual' discourse suggests something else: visual and audile techniques may organize perception in comparable ways and can have similar epistemic effects on a phenomenon under study. Rather than underlining the constraints of a visually biased vocabulary in describing acoustic phenomena, then, the example of the parabolic reflector highlights an affinity between certain cognitive actions at work across presumed sensory divides. As such, the parabolic reflector too should be read as a warning against any conception of sound and vision that emphasizes its putative trans-cultural and trans-historical features over the historical, local, and practical organization of perception (Grasseni, 2007; Smith, 2012).

\section{Conclusion}

In this chapter I have explored how new technologies of electrical recording and its advantage of amplification have implicated changes in the practices of field recording as described in Chapter 2, and in particular how it has re-articulated the fieldsite as a place of scientific research. I have done so primarily by contrasting the field techniques developed by two pioneering teams of ornithological field recordists; one team of technicians in Britain, formed around former recording industry man Ludwig Koch, who published books and records and recorded for the British Broadcasting Corporation; another group in the United States at the Cornell Laboratory of Ornithology, where ornithologists Albert Brand and Peter Kellogg devised a new technique of recording in collaboration with the university's electrical engineering department.

In this chapter, I have tried to show how electrical technologies of sound reproduction have changed fieldwork in a practical sense. It did so, first of all, socially as well as materially. Instead of the lone naturalists with a good musical ear and notebook, fieldwork now involved a specific set of costly and complex equipment, as well as a number - at least two - of skilled recordists to operate it. As a result, the recorder was less mobile in the field and the process of recording had become much more labor-intensive: registering a particular song on record could take anything between one morning and several weeks. But as Ludwig Koch announced in the introduction, due to the cost and technical complexity of the recording instruments, the practice of electrical wildlife recording was also privileged 
to an entirely new community of recordists, consisting of producers, engineers and technicians, along with professional biologists who spotted new opportunities and could afford the time and resources. They created among others a market of gramophone records and books published on the topic of bird song, sustained in part by an audience of amateur naturalists who necessarily persisted with more artisanal techniques of transcription in communicating their findings.

But electrical recording also transformed the aural experience of the recordist in the field. What to the human listener had been a natural and mostly unconscious process of filtering the ambient sounds of the field was less evident to the mechanical ear. Bird sounds were suddenly drowned out by the hum and drones of traffic, industry, radios and vacationers, qualifying the field as a particularly noisy and somewhat uncontrollable environment. Moreover, mechanical devices redefined the understanding of a sound recording into mechanically mediated content. What made a good recording was no longer what Saunders and Moore had termed the 'accuracy' of a human observer, but what Brand and Nicholson perceived as the 'objectivity' produced by the recording device. Both aimed to reduce subjective interpretation from the act of recording, but whilst the scientist-musician would rely on the disinterested and trained listener and his systematic attention, Brand disqualified that trained observer in favor of a mechanically 'neutral recording machine'. Along with this shift in the authority of trained listeners, the new community of recordists also exchanged the musical vocabulary of most amateur naturalists for a technical idiom of physics and acoustics, which led them to characterize bird songs no longer in terms of harmonics and rhythm, but to frame them according to their approximate frequency in cycles per second, as this forms one criterion by which recordists could assess the suitability of a particular song for its mechanic reproduction.

However, the second part of my analysis has highlighted that despite these general shifts, recordists in Britain and at Cornell University entertained different notions, practices and techniques of field recording. While Koch's team of British recordists allied closely with publishing companies and broadcasters and incorporated their approaches into their field recording routines, Brand and Kellogg developed their recording techniques in relative independence from the recording industry. This chapter has shown that these recording techniques conceptualized and reproduced the field in different ways. Both were geared to optimize the recordists' control over the soundscape and acoustical conditions of the field. As such, they blurred the boundaries between the field-site and the studio, for instance by introducing a mobile studio as well as recording techniques into the field. My analysis has focused on one recording instrument in particular, the parabolic microphone, as a material intervention by which the soundscape of the field was being reproduced as a crisp, controlled and context-ridden sound. These features may well be associated with the sonic control of the 1930s studio model, but as this chapter advances, they may also be regarded as part of the "passionless crafting" and generic universality of the scientific laboratory. Exploring further the analogy between the studio and 
the laboratory, I have argued that scientific recordists did not just take control over the soundscape of the field but, as I have called it, 'sterilized' it. This process is ultimately antiseptic, in that it disassembles and segments the soundscapes of the field into a collection of distinct analytical units or cuts. This technique of listening enabled selection, focus and filtering, and as such it also compared to the techniques of visualization with which scientists take control of their objects of study. As I have argued and as we shall find in the chapters to come, this technique had been prompted by visual inspection of recorded sound in the laboratory. But the sonic close-up of the parabolic microphone was also helpful in other ways. Sound recordings were not only recorded for analysis in the field, but were also compiled in sound identification guides - even if such close-up experiences would be rare in the field, the close-up sample provided an effective didactic tool for aspiring naturalists to learn to identify bird songs.

Like the laboratory model did in the nineteenth century, the parabolic reflector travelled fast beyond the historical and local context of the Cornell Laboratory of Ornithology in the 1930s. Even though Koch and his fellow recordists persisted with gramophone recorders and 'studio' techniques, a change of curator in the BBC natural sound archive established the parabolic microphone also among British recordists and some bird song biologists by the early 1950s (Marler, 1956; Simms, 1953). Indeed, Cornell ornithologist Peter Kellogg did not exaggerate much when in 1962 he described the reflector as a "universal tool" in the field (Kellogg, 1962a). By then, the parabolic microphone had been adopted as a part of the standard outfit of almost every amateur and professional recordist engaged in nature recording. In subsequent decades, British archivists promoted the parabolic reflector among recordists as the most efficient way of engaging with nature recording (Margoschis, 1977; Purves, 1962; Sellar, 1976). More recently, the clumsy parabolic reflector design has been complemented with other, sometimes more effective, types of directional recording, such as the so-called 'shotgun' microphone models (Catchpole, 1995). The success of the parabolic reflector in becoming a 'universal tool' in the field was due in part to the relative simplicity of the technology and its maximal effect. But its success (particularly in North America) was due also in large part to Kellogg's own doing, and the strategic exchange policies that he instituted in building a library of recorded specimens. As chapter 4 will go on to explore, this enabled archivists and biologists to promote the parabolic microphone and the listening techniques associated with it to become part of standard recording practice. 



\section{4 \\ Samples, Assets and Trophies: Engaging networks of field recordists}

\section{Introduction}

In April 1956, Pennsylvania State University hosted some forty-five international scholars who had convened on the initiative of professor Hubert Frings to form an International Committee of Bio-Acoustics (ICBA). These scholars of sensory physiology and animal behavior represented the few laboratories throughout the world that had recently become engaged in studies of animals' acoustical communication and Frings had invited them to think about the future. The past two decades had brought significant advances in electronics and acoustics, and while this had resulted in powerful tools for the production, analysis and recording of sounds, little exchange of such material had taken place among their users (Busnel, 1963, p. ix). ${ }^{45}$ As a result, recordings remained almost exclusive to the 'private' sphere of the recordists' laboratories and field-sites.

To solve these problems, the Committee proposed to establish two new institutes: an International Library of Publications in Biological Acoustics, as well as an Animal Phonography Collection, a collection of biologically significant samples recorded by professional bio-acousticians. Especially the latter became subject of discussion. After all, how was one to define biological significance anyway? With physiologists, ecologists, taxonomists and ethologists around the table, no one seemed quite certain which sounds were significant or just who could judge. ${ }^{46}$ Cornell professor of ornithology and bio-acoustics Peter Kellogg tried to convince the assembly that the infrastructure for such a truly international center for biological acoustics was there already. Together with a group of dedicated recordists, Kellogg had built a Library of Natural Sounds at Cornell, specializing in bird vocalizations. But his vision did not catch on with the others, and Kellogg eventually sought to increase its scientific relevance with other means. In turn, the International Committee of Bio-Acoustics itself never really acquired sufficient administrative support to realize its ambitions. ${ }^{47}$ But for whatever reason the idea did not materialize, the

\footnotetext{
${ }^{45}$ CUL, Kellogg Papers, 3:39, Report 'International Committee on Biological Acoustics'.

${ }^{46}$ Written Archives Center (henceforth, WAC), BBC Records, R46-365-2, Peter Paul Kellogg to Eric Simms, 2 May 1956.

47 A similar initiative, the International Bio-Acoustics Council (IBAC) materialized between 1967 and 1969 and was embedded in the Danish Natural History Museum in Århus (retrieved February 15, 2011 from
} 
concepts of both the Animal Phonography Collection and Cornell's own Library of Natural Sounds exemplify an ambition to preserve and make available a wealth of recorded sound that had been accumulated over two decades. The same idea stimulated also the Berlin Tierstimmenarchiv, the Borror Bioacoustics Collection and the British Institute for Recorded Sound, to be established and expanded in the following years.

In important respects, however, the initiatives of ICBA and the Cornell Library of Natural Sounds were also very different. The ICBA had envisioned a research collection exclusive to all professional bio-acousticians, while the Cornell ornithologists had focused their efforts on bird species but had opened their collection to a diverse group of users and contributors. Chapter 3 has shown that due to the expense and technical complexity of recording equipment, mechanical recording initially remained the exclusive domain of a relatively small group of ornithologists only. Yet by the late 1940s, magnetic tape recorders had become available that simplified and cheapened the recording process. This enabled a more diverse group of biologists, amateur recordists and 'sound hunters' to take up field recording (Bijsterveld, 2004; Morton, 2000). ${ }^{48}$ Where the Tierstimmenarchiv or the Bioacoustics Collection emerged initially as smaller collections assembled by one researcher, Günther Tembrock and Donald Borror respectively, the Cornell Library of Natural Sounds actively sought collaborations with these new groups of biologists, recordists and sound hunters. By 1956, it had received and exchanged recordings with researchers from dozens of scholarly institutes, movie corporations, publishers as well as a host of amateur recordists. While such recordings had often been made with very diverse intentions, biologists would be able to draw on them as potential scientific objects.

In the past two decades, the scientific archive for sharing (non-auditory) data has received significant attention in science studies, both as a site and a technology for heterogeneous groups to coordinate complex activities of knowledge production (Bowker, 2000; Hilgartner, 1995; House, 2002). Susan Leigh Star and James Griesemer (1989) for instance have influentially described the museum archive of the Museum for Vertebrate Zoology as a 'boundary object', whose weak structure in common use but strong structure in individual use allowed amateurs, collectors, administrators and museum professionals to achieve coherent action despite their inherent diversity. Star and Griesemer's work goes a long way to explain how scientists manage to translate elements of different worlds into a collective resource, for which they rely in part on the standardization of method through standard forms. This work is less explicit, however, in elucidating why collaborators may choose to

ibac.info/history.html). This platform still exists but was transferred to the British Library section of Wildlife Sound in 1996.

48 In fact, its wide appropriation among scientists and others even prompted several field practitioners to ascribe to the magnetic tape-recorder and the spectrograph combined what they perceived as a dramatic boom in the substance of bird song biology since 1950 (Baker, 2001; Falls, 1992; Marler \& Slabbekoorn, 2004; Thorpe, 1961a). For other applications of magnetic tape recorders, see Morton (2000). 
comply with such professionals' demands in the first place. In this chapter, therefore, my interest will be less in further exploring the actual mechanics of collaboration and translation, then in demonstrating how potential collaborators may be enticed to meet the demands of professional scientists, and how the continuation as well as the reliability and authority of their collaboration may be ensured.

Recent work, after all, has shown that the sharing of data encounters lots of difficulties, such as high costs, abundance of standards, and importantly a lack of incentives to share data (Hine, 2006; Zimmerman, 2008). More than for other types of specimens, such as skin and bones, sound recordings were not only of interest to the professional scientists. These 'specimens' also had different monetary, social and symbolic currency outside the scientific world, among sound hunters, movie corporations, record companies and broadcasters. Secondly, as scientists draw from systems of collective knowledge production, they may not have the ability and resources to verify every knowledge claim on their own (House, 2002). Particularly when faced with diverse contributors, this may be accompanied with uncertainty about the data and whether they are complete, let alone correct (Zimmerman, 2008). While mechanical recording techniques had seemed to introduce a new degree of objectivity, the actual identification and description of data often still came down to the virtue, competence, and skill of the recordist. And precisely these abilities still involved to a large extent the embodied experience of the field, auditory perception and other sonic skills. As the previous chapters have variously shown, twentieth-century ornithologists remained deeply suspicious of identifications and aural records by non-professional scientists, and their value was often still evaluated by the "record and ability of the observer" (Barrow, 1998, p. 179).

How, then, this chapter asks, have ornithologists ensured access to sound recordings that circulated in a variety of contexts, and how have they ensured such recordings' reliability and epistemic robustness? In doing so, it adopts a 'datastreams' perspective, which conceives of data not as finished packages (Hilgartner \& Brandt-Rauf, 1994). Instead, data forms are seen as being part of evolving heterogeneous flows of "information and other resources, produced by or needed for scientific work" such as people, skills, techniques and instruments (ibid., p. 359). Understanding how sound recordings come to work as data within a heterogeneous community, thus requires us to investigate not only how they may accommodate different interests, but also how they may be used to ensure a continuous flow of reliable resources towards scientific work. Recordists had to be taught how to record, edit and annotate vocalizations, while researchers had to become convinced of the reliability and credibility of the ways in which recordings were produced, identified and processed, in order to count as 'scientific data'. This perspective focuses our attention to what recordists and researchers distribute to whom and under what terms and conditions, and how this matters to the flow of data.

As I argue in this chapter, scientists managed to establish and maintain a stable flow of data by using parts of their data-streams, sound recordings, in a strategic exchange of recognition and access, significance and credibility. I will argue that 
exchanges of sound recordings, its copyright and authorship, were important because they constituted what historians have called this community's 'moral economy' (Daston, 1995; Kohler, 1994; McCray, 2000; Rasmussen, 2004; Shapin, 1994). The concept has its roots in Marxist economic history, but it has been appropriated by students of modern science to describe the interplay of implicit norms, values and conventions in local communities. But because sound recordings did not qualify exclusively as scientific objects, their moral economy was not exclusively local. Establishing a sustained flow of recordings obliged scientists to engage with different customs of ownership, credit, priority, access and evidence. This moral economy and a flow of scientific recordings, I will show, was established among scientists, amateurs and other users, by trading the recordings as local currencies with which societal and scientific values, morals and loyalties could be brokered (Atikson-Grosjean \& Fairley, 2009, p. 169).

\section{New contexts of recording}

\section{Technology-fascinated sound hunters}

By the late 1940s, a group of techno-enthusiasts became especially active in developing grassroots applications of taping birdsongs outdoor. Tape-recorders made recording also accessible to the consumer, but recording was by no means a casual business. Some of these recordists had a professional background, or an amateur interest, in radio or electrical engineering and would assemble their own tape recorder from a kit of parts. ${ }^{49}$ Others acquired their device when the first moderately priced portable tape recorders came on the market. Most of these recordists report to have gone through a typical phase in which, like every consumer at the time, they recorded the voices of their acquaintances or copied programs from their radio receiver to play them back at leisure (Bijsterveld \& Jacobs, 2009). As they got bored by the common applications and were on the lookout for another challenge, these amateur recordists generally fell back on an interest in amateur naturalism. ${ }^{50}$ Typically, they had not been occupied with the actual study of song before, but many of the new recordists did, however, report a long-held active interest in wildlife. Whether some of them retrospectively fashioned themselves as naturalists in function of their new persona or not, bird song gave them the opportunity to furnish their experiments with recording the air of a new pursuit: hunting sounds with a microphone.

Early in the 1950s some tape correspondence clubs had emerged (Bijsterveld, 2004, p. 616), but nature recordists were not typically associated in wildlife record-

\footnotetext{
${ }^{49}$ Edwin Boyes is an example. He was chief engineer of Radio station WWJ in Detroit, as well as past president of the Audubon Society.

${ }^{50}$ See Stillwell (1964, p. 3) and (Interview Kirby).
} 
ing societies until the late $1960 \mathrm{~s}^{51}$ Many of the recordists, however, quickly found their way to the British Broadcasting Corporation and the Cornell Lab of Ornithology. Because of the publicity these organizations managed to generate around their trade, they had become highly visible and widely renowned as institutes with expertise in field recording. The ornithologists at the Cornell Lab in particular maintained casual relations with dozens of nature recordists, and advised aspiring recordists on how to make potentially valuable contributions. A number of these recordists developed a more long-term and formal attachment to the Cornell Lab of Ornithology and its bioacoustics program. Indeed, for much of the recordings it assembled in its library in the next two decades, the Lab was dependent on contributions by these individual recordists.

By the middle of the 1950s, over half a dozen projects were operative, adding several hundreds of cuts from Africa and the American continents to the collection. Retired businessman Jerry Stillwell and his partner Norma, for instance, had left their home for a trailer and travelled the entire United States for several years to collect American bird species. Dr. George Reynard, a geneticist by profession, focused his study and recording work on species in the American East coast and the Caribbean. Retired civil engineers Irby Davis focused on Mexican species and taxonomic relations. Colonel Donald McChesney and his partner Marian specialized in ducks and geese and led recording expeditions to Florida, Kenya and Canada, while chemist Paul Schwartz established a satellite library of natural sounds for South America in Venezuela. In Britain, the British Myles E. North studied and recorded African bird vocalizations during his detachment and retirement as a district commission in Kenya (Kellogg, 1962b). Because of their respective specializations in the field, these sound hunters occasionally collaborated with full-time academic biologists on publications or conference presentations. It was the record collections, however, that were often recognized as their major ornithological achievement (Thorpe, 1968). These sound hunters had not usually embarked first on such recording projects only to collect 'scientific data' or to engage in an alternative academic career. They had typically become curious about field recording after hearing recordings that had been distributed by Cornell Laboratory of Ornithology, Koch and Nicholson or that had been broadcasted on the radio. Indeed, a great deal of recordists published their own album of field recordings on various occasions in the 1950s and 1960s, often assisted by the Cornell Laboratory of Ornithology, which mediated with the Houghton Mifflin Company that began to distribute most of the Laboratory's records.

Because of these recordists' fascination with high fidelity, and their desire to exploit their recordings commercially, they were especially keen on producing technically outstanding records. Among such recordists, the extent to which they could

\footnotetext{
51 The predecessor of the International Bioacoustics Committee, the French Enregistrements et Etudes des Chants et Cris d'Oiseaux (ECHO) was presided by two amateur ornithologists and recordists, the Canadian EDH Johnson and the British John Kirby.
} 
eliminate distortion, static and noises was recognized as their ability to select and operate the equipment, which counted in turn as a clear marker of technical craftsmanship. Yet for the ornithologist, technical craftsmanship alone did not suffice. As Peter Kellogg laid out his plans to preserve and distribute natural history sound recordings for the American Ornithologists' Union, he stressed the equal importance of field craft: "In addition to identifying the sounds recorded, the naturalist must know what species inhabit a given locality and when they may be expected to perform." 52 For an ornithological record to be of scientific significance, these recordists seemed well aware of the importance not only of good quality recording but also of competent identification: "otherwise you can be sure that we will have a good crop of perfectly fine recordings that will be useless because we don't know who they belong to, and since much of this work may be done far afield we can ill afford to return to make that final identification." 53

It was particularly important to make good identifications because identified recordings were likely to become future points of reference, even if the recordist himself intended to use the recording but for personal consult or to merely relay the record to a lay-audience. But whether they remained in personal collections or were circulated as publications, sound recordings were often used to introduce other ornithologists to specific songs and calls. Amateur recordist Irby Davis, for instance, used his recordings to prepare ornithologists for the avifauna they could expect in Central American habitats: "I play the record for them here and explain the different types of calls to the visitor. This results in most people getting many birds on their trips into new areas that they would have otherwise missed. [ . . . They] have little or no more difficulty with the tropical birds than they have on a field trip in this country. ${ }^{54}$ As such auditory observations became part of a collective that many actors directly or indirectly came to rely on, bad identification risked getting tangled up in a kind of 'observational regress'. 55

Therefore, like high fidelity recording displayed technical craftsmanship, good naturalistic records depended on their producers' field craft. High fidelity recording and ornithological observation were two very different skills and good recordists were expected to master both. These skills did have at least one thing in common though. In both ways, recordings could be an aid in building up a record of demonstrated competence. With the establishment of wildlife sound recording societies in the late 1960s, the symbolic value of recordings as markers of competence was further formalized by establishing recording competitions. Such competitions, exclusive to society members or international natural history recording contests, awarded recordings that were particularly well crafted, technically as well as natural-

\footnotetext{
52 CUL, Kellogg Papers, 1:15, Manuscript “A new proposal for preserving and distributing natural history sound”, manuscript by Peter Paul Kellogg presented on 11 October 1951 at the AOU Meeting, Minneapolis Minnesota, p. 15.

${ }^{53}$ CUL, Kellogg Papers, 7:24, Letter Paul Schwartz to Peter Paul Kellogg, 3 October 1960. Emphasis mine.

${ }^{54}$ CUL, Kellogg Papers, 3:4, Letter L. Irby Davis to Peter Paul Kellog, 26 September 1951.

55 CUL, Kellogg Papers, 3:32, Letter Peter Paul Kellogg to William Fish, 1 November 1961.
} 
istically speaking, which underlines the dual importance of these recordings. For recordists, a technically superb recording or a uniquely documented call of a rare species were as much a trophy as they were a scientific sample.

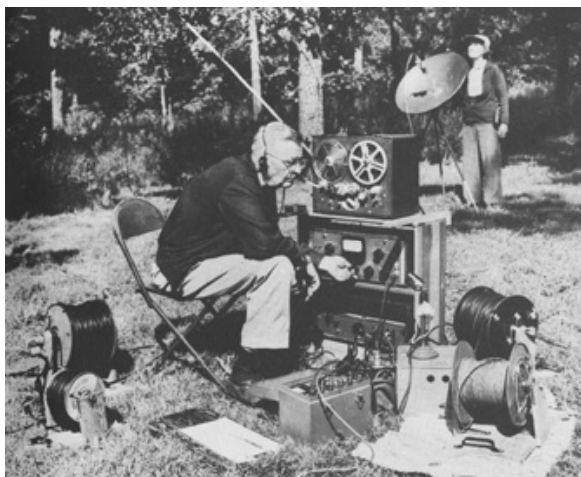

Figure 4.1

Amateur recording couple Jerry and Norma Stillwell in the field.

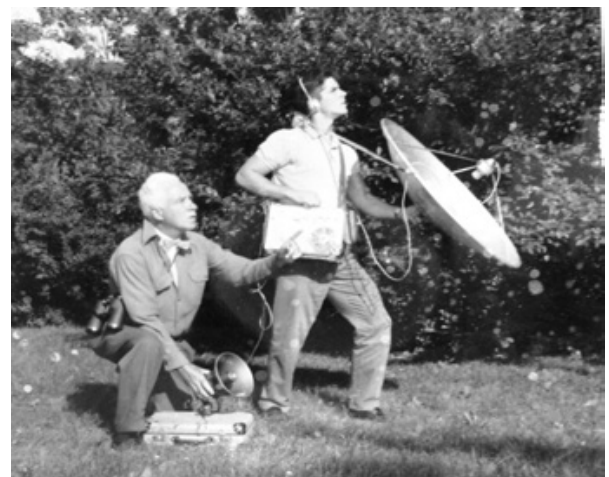

Figure 4.2

Kellogg (left) testing a mobile recording unit with parabolic reflector.

\section{Broadcasting, Entertainment and Science popularization}

Within the recording and broadcasting industry, it was especially the British Broadcasting Corporation that considered nature sound recording of paramount importance. The $\mathrm{BBC}$ was in a unique position to establish a natural history sound recording collection. As a publicly funded organization, the BBC had a strong tradition of public service content and attention to science (LaFollette, 2008, p. 90). Because of this tradition, it could afford to act upon a UNESCO resolution to oversee the preservation of Koch's collection of animal recordings. ${ }^{56}$ As a public broadcasting organization it allied itself to the newly established British Institute of Recorded Sound, where the collection was used to establish a wildlife sound department. But the recordings also served their own library of sound effects and could be exploited in BBC productions - another public service, but more beneficial to the organization. The recording efforts of the $\mathrm{BBC}$ could, in other words, be justified and amplified because they intersected with public interest, such as the permanent preservation of wildlife sound or its "possible scientific interest" (Burton, 1969). Hence, while its sound curators had to keep potential program use in mind, especially in the 1950s, the BBC's recording expeditions were also motivated by naturalistic interest. ${ }^{57}$ In fact, from 1951 onwards, its curator of wildlife sound

\footnotetext{
${ }^{56}$ Of which at the time Julian Huxley, Ludwig Koch's intellectual patron, was Director-General.

${ }^{57}$ By 1957, the collection was assigned to the new Natural History Unit, where it further developed, with the number of contributing amateur recordists steadily increasing. From 1962 onwards, its new curator shifted priority more to "programme needs than to their zoological interest" by adding substantially more habitat or 'atmosphere' recordings (Burton, 1967, p. 109). The initial curator's ability to attend scientific conferences
} 
Eric Simms strengthened relations with the ornithological world. He and his successors solicited recordings from amateur recordists and radio organizations in Britain and abroad. He also presented his recordings on behalf of the BBC at ornithological venues such as the International Ornithological Congress in Switzerland in 1954, where he connected to prominent ornithologists such as Erwin Stresemann, who offered his help in appealing to his own networks. ${ }^{58}$ Such connections helped to identify species of scientific interest, acquire records from amateurs or to locate particular populations when organizing recording expeditions.

Despite their different interests, the recording efforts at Cornell and the BBC had one thing in common. Both the scientific institute and the public broadcaster applied their recordings widely for purposes of science popularization. Importantly, these institutes approached bird songs not merely as sound effects, but as registrations worthy of their audience's attention. By 1960, the Cornell group had published about thirteen full and well-selling gramophone records. In addition, Kellogg and Allen had a weekly half hour on a regional radio show (Interview Little). Likewise, the BBC licensed its recordings for purchase by the general public and used them in natural history programs such as The Naturalist, Birds in Britain and Masterpieces of Bird Recording. The very content of bird song biology also featured on air, in sporadically scheduled talks by scholars that were illustrated with recordings, such as behaviorist Peter Marler's 'The Language of the Chaffinch' or philosopher Charles Hartshorne's 'Music in Bird Song'. ${ }^{59}$ By the 1950s, science popularization on the radio was a tested format (LaFollette, 2008). And although these professional students of bird song were involved in broadcasting only on occasion, it provided an opportunity to improve the understanding of their field and alert the public to the implications of a more systematic attention to bird song.

Probably even more powerful in their address to the public were long running series such as Birds in Britain on the Sunday afternoon program (Interview Hawkins). On the radio, vocalizations were virtually the only means to capture the public's imagination of a bird invisible to them, but as such the medium also disseminated the perception of birds as sounding species. The actual influence of such disseminations on the public is of course hard to ascertain. As David Goodman (2010) and Susan Douglas (2004) point out, listening to the radio may have happened routinely, as a background to family life or in-between stretches of attentive listening. But although not all listeners will have been as attentive, among those who were, such series will have instilled an appreciation or enthusiasm for, or even a passive knowledge of, the songs of common British bird species. In addition, the Cornell and $\mathrm{BBC}$ gramophone records too reached a large group of interested

\footnotetext{
itself was limited. The BBC had not allowed Simms to attend the conference on bio-acoustics organized in 1956 at Penn State, mentioned in the introduction of this chapter. The official reason was that discussion would be too technical, and not specifically on bird sound.

58 WAC, BBC Records, R46-366-1A, Manuscript Address to XIth International Ornithological Congress in Basle from $2^{\text {th }}$ May to $5^{\text {th }}$ June 1954.

${ }_{59}$ Broadcasted on 20/01/1957 and 01/04/1962 respectively.
} 
listeners. Such recordings were widely consumed and they connected, indirectly though intricately, their producers in science and broadcasting to a diverse audience of citizens and amateur naturalists with a keen ear for bird song. Moreover, such recordings also served as a bench-mark for amateur recordists (Interview Kirby). Since such gramophone records selected what were considered "typical" and "technically best" excerpts, they also standardized a discourse on the accepted behavior of each species as well as the accepted norms of recording.

\section{Bird song biologists}

In the 1950s, the academic ornithologist community grew increasingly attentive of the new possibilities that taping bird voices afforded. In 1951, Professor Peter Kellogg organized a small symposium on bird sound as part of the annual meeting of the American Ornithologist Union, to enable twelve beginning recording ornithologists to demonstrate their work. Among them were a number of amateur recordists such as Jerry Stillwell, Myles E. North and L. Irby Davis, as well as several ornithologists and biologists who had taken up tape recording alongside their main interests. ${ }^{60}$ An Ohio entomologist, Donald Borror, for instance, had started to tape bird songs to teach in his ornithology classes. Another biologist, Dr. William Fish, presented his analysis of a taped song of Californian Bewick's wren, with accompanying slides of an oscilloscopic analysis. This combination of recording and analyzing, he argued, held "great promise as tools not only for the taxonomists but also for those engaged in studies of avian life histories". ${ }^{61}$

Indeed, within five years, the focus of such "biological studies based on recorded bird sound" would shift significantly. When Fish organized a similar symposium again in 1956, its contributors all seemed to concentrate on a specific problem: the role of song in shaping distinct populations. Ohio ornithologist Wesley Lanyon presented his research into the differences between the songs and calls of Eastern and Western meadowlarks. Kellogg's student Robert Stein presented the role of song as a mechanism with which different species in the genus Empidonax isolated themselves, while his colleague William C. Dilger discussed a behavioral study of how species recognize each other by voice in the Thrush family (Mayfield, 1957 , p. 86). Clearly, these studies had birds as their objects of study. But this work also displayed a more general concern with fundamental mechanisms in biology, such as variation and speciation.

This concern with the biological implications of bird vocalization research followed a more general trend that had begun to take place in ornithology since the 1930s. In 1959, British ornithologist Moreau argued triumphantly that a revolutionary change had taken place in ornithology since the 1940s. While such developments seemed to have taken place already earlier in American and German journals

\footnotetext{
${ }^{60}$ CUL, Kellogg Papers, 1:16, Manuscript "Introductory notes on speakers at AOU Sound Symposium" by Peter Paul Kellogg, 10 October 1951.

${ }^{61}$ CUL, Kellogg Papers, 3:34, Letter William R. Fish to Peter P. Kellogg, 19 September 1951.
} 
such as The Auk and the Journal für Ornithologie, by 1950, he argued, British ornithology too no longer seemed "inbred and isolated from the main currents of biological science", but reflected ornithologists' turn towards "biological papers" including work on migration, territory theory, population dynamics, behavior and new systematics (Johnson, 2004; Moreau, 1959, p. 29). According to the existing historiography of the field, in Britain this shift was effected by a small group of young ornithologists who pressured the field to transform from a natural history discipline that had traditionally been divided between systematics (taxonomic studies) and field ornithology into a broad-based biological discipline that became concerned with answering questions of evolution and speciation (Haffer, 2008a; Johnson, 2004). With these transformations of ornithology new fields concerned with species evolution (new systematics), the relation of birds to their habitats (population ecology) and development and behavior (ethology) took prominence. Within these fields, biologists thankfully began to make use of recorded bird vocalizations as a means to explore biological mechanisms of variation, selection and development.

The magnetic tape recorder obviously had not instigated that shift, but it did aid in its completion. The interests of these new avian biologists provided a particularly receptive intellectual context for studies of bird song. Field ornithologists had observed for some decades how bird song varied individually and geographically, but little had been done to sonically conserve that diversity. By now, however, a light-weight and mobile instrument as the magnetic tape-recorder allowed recordings to be made much more easily in geographically distinct areas, and more consistently in successive seasons as individuals practiced and developed their song. As in the USA, German and British students of bird song incorporated sound recording in their work from 1950 onwards. In Germany, Guenter Tembrock at the Berlin Humboldt University and Gerard Thielcke at Freiburg University each acquired a tape recorder by the late 1950s, and applied it to behavioral studies of chaffinch and tree-creepers respectively (Interview Tembrock; Thielcke, 1961). In Britain, William H. Thorpe also exchanged the cumbersome phonograph disc cutter for tape recorders, and applied these in the investigations of song learning of his newly assembled research group at Cambridge University (Marler, 1985). For these Cambridge ethologists, bird song became a prime site to study mechanisms of animal behavior. Thorpe, for instance, isolated young birds to varying degrees from their parents' tutorage, to conclude that the birds have an inborn template for their song but that the refinement of this template at a later stage is learned by example (Thorpe, 1954). Thorpe's doctoral student Peter Marler used a tape recorder to document variations in the calls of chaffinches around their Madingley field station (Marler, 1955). In a series of papers, Marler linked the acoustic properties of chaffinch calls to their specific functions in the social life and habitat of the birds (Marler, 1956).

By the early 1950s tape recordings also became adopted for more experimental purposes in the study of bird song. Researchers discovered that by playing back pre-recorded songs in a given habitat, they could elicit particular behavior which 
could then be observed (Niethammer, 1955). Population ecologists, for instance, used the technique to map the extent of a bird's territory, by studying the reach of its defensive behavior in response to songs played back from neighboring territories. In 1956, one of them, the Canadian bio-acoustician Bruce Falls, demonstrated by playing back ovenbird songs that the birds are generally capable of discriminating between neighboring birds and visiting strangers. By recording in turn the birds' reactions and editing them into artificial sequences, he also sought to determine the exact song components that birds relied on to recognize each other (Falls, 1992, p. 14). Others used playback experiments to try to distinguish the auditory cues with which herring gulls communicate the availability of food (Frings, Frings, Cox, \& Peissner, 1955). Such proved useful to design sonic techniques for dispersing roots of birds, for instance around airports. Tape recordings might also serve experimental work in another way. As Hubert Frings and his colleagues pointed out, humans have a tendency to focus their attention on some phase of the environment to the exclusion of others. Recording the experiment and playing back the tape recording later on, "without visual distractions, quickly reveals the true situation" (Frings, et al., 1955, pp. 168-9). Similarly, tape recorders were used to survey nightly migration patterns of species by their vocalizations, when visual identification was simply impossible (Graber \& Cochran, 1959). With tape cheap enough to run at a stretch, the recorder documented not only fragments of specific behavioral sequences, but could also be deployed to monitor the field experience as a whole. Here again, the tape recorder was thought to convincingly meet the putative fallibility of human auditory capacity, and helped to establish auditory experience as a method of observation.

These examples demonstrate the diversity of projects that began to make practical use of the magnetic tape recorder in documenting, observing and monitoring sound. In fact, by 1962 the Cornell ornithology group applied at the National Science Foundation with the projection that these applications of sound recording would have long-term intellectual benefits to the study of systematic, ecological and behavioral problems. ${ }^{62}$ Recorded sounds, they argued, were to function in "parallel to morphological specimens, but have other advantages: [ . . . they] provide documentary material about behavioral sequences and [ . . . ] the ontogeny of individual sound patterns can be documented." 63 In other words, sound recordings seemed not only compliant with a tradition of specimen collecting, but could as easily be incorporated in an ethological approach. But despite these projections by ornithologists at Cornell, not all biologists were as eager to rely on sound recordings as scientific specimens. For unlike for instance morphological specimens that systematists could hold in hand and check for themselves, for sound recordings they

\footnotetext{
${ }^{62}$ Similarly, in an introduction to tape recording nature sounds, Kellogg located their use in Identification, Taxonomy, and Behavioral and Psychological Studies (Kellogg, 1950).

${ }^{63}$ CUL, Kellogg Papers, 6:16, Manuscript "An investigation of the sound patterns of birds and their application to systematic, ecological and behavioral problems" research proposal for NSF, by Peter Paul Kellogg and Robert C. Stein, 1 June 1963.
} 
were very much reliant on the auditory and visual identifications and descriptions of others. As one biologist advised Kellogg, "speaking as a systematist, it occurs to me that the usefulness of your work to other ornithologists may be limited by the amount of data that you can supply with each recording [ . . . If the bird is unusual, I am sure a systematist would want to have a bird in the hand to go with the voice. At least he would not be satisfied to have one of your foreign collaborators making the identification for him." 64 This, of course, presented recordists with a challenge. The tape recorder had greatly increased the ease with which biologists might independently collect data, which meant that larger bodies of data became available. Such data was of potential interest to bird song biologists, interested in the geographic variations, evolution and social functions of bird song and calls. But in order for these recordings to become available and relevant to these biologists, they also had to be produced, edited and annotated to fit their demands.

\section{A community of recordists}

Despite the diverse meanings that recordists had ascribed to their recordings, by the early 1950s these groups nevertheless came to cluster around tape recording as a research tool in what with Cyrus Mody $(2006,2011)$ we could describe as an 'instrumental community'. Instrumental communities take shape whenever "a porous group of people convene to build, develop, use, sell and popularize a particular technology" (2006, p. 59). Crucially, this group takes shape through a number of alliances that typically span institutional, disciplinary and social contexts. Within these contexts, participants may well have conflicting projections of the technology, but nevertheless develop a degree of coherence. Instrumental communities thus represent the diffuse give-and-take that occurs between different social worlds. Evidently, the academic institutes, broadcasters, movie corporations, and amateur recordists that were involved in sound recording did not necessarily share a practice, nor were their actions necessarily coordinated. But this loosely tied community did foster a (largely informal) circulation of techniques, goods and recordings, and this (often indirectly) stimulated the use of sound recording as a scientific tool. Incidentally, this also strengthened the position of professional scientists. For that reason, an instrumental community is not only 'instrumental' because, as Cyrus Mody suggests, it facilitates the transfer of technologies from academic to corporate worlds, or vice versa transforms tools into scientifically relevant devices. In some ways, the community will also have served as an instrument for scientists (Clarke, 1992).

As we have seen in chapter 3, initial alliances between the worlds of academia, broadcasting and industry provided a technical infrastructure for the scientific aspirations to record bird song. Similar exchanges took place elsewhere, for instance in

${ }^{64}$ CUL, Kellogg Papers, 6:16, Letter David D. Keck to Peter Paul Kellogg, 15 April 1960. 
Berlin, where ethologist Guenter Tembrock obtained his first professional recording equipment and instructions on how to operate it through the world of German radio broadcasting (Interview Tembrock). When the relations between Cornell's Laboratory of Ornithology and Movietone had dwindled (see chapter 3), the institute had called upon the help of the electrical engineering department to modify equipment and solve fundamental technical problems. Kellogg gladly recruited biologically-minded engineering graduates in his own projects. From the late 1940s onwards, he also maintained close corporate links, for instance to Bell Labs and the Amplifier Corporation of America, for advice on technical issues, to test prototypes or to brainstorm over ambitious projects such as the experimental 'Synthetic Bird Song Generator' - a visionary tool to create artificial vocalizations in a laboratory setting. ${ }^{65}$ Kellogg also occasionally pressured the designers to rethink their blueprints and proto-types, which extended to an invitation to adapt the ACA's portable Magnemite model to fit the needs and financial means of field recordists like himself. ${ }^{66}$ Such customized designs allowed bird sound recording its own corporate niche. It also obscured the boundary between manufacturers and users by standardizing some of the modifications that pioneering recordists had made in their own recording apparatus. Likewise, the Cornell Laboratory of Ornithology maintained close connections to amateur recordists and professional biologists, and provided them with technical advice.

Technical skills and components were not the only site of convergence for this community of recordists. Increasingly, initiatives emerged across institutional boundaries to foster the scientific use of sound recordings. The International Committee of Bio-Acoustics conference mentioned above is an example of interdisciplinary collaboration in academia. But interestingly, such initiatives did not remain exclusive to professional scientists only. One of the first alliances between academic researchers and broadcasters had in fact been initiated by Ludwig Koch, whom we encountered in chapter 3 , and who donated his private collection of nature recordings to the $\mathrm{BBC}$ on the condition that it installed a scientific panel to oversee and develop its use as an instrument of research. The panel consisted of influential public scientists such as Max Nicholson and Julian Huxley, William Thorpe in Cambridge, representatives of the BBC as well as of several British naturalist organizations, including the Royal Society for the Protection of Birds (RSPB) and the Severn Wildfowl Trust. Although not formally recognized by the BBC, the panel provided an important platform. In the words of its chairman Max Nicholson, the panel was to "form a link and a sieve between those interested in the scien-

\footnotetext{
${ }^{65}$ CUL, Kellogg Papers, 4:12, Letter Peter Paul Kellogg, N.M. Haynes, Kosinski, F.K., 6 September 1954. The tool never reached the stage of prototype however. For other interesting examples of synthetic sound production, see Levin (2006).

${ }^{66}$ For instance CUL, Kellogg Papers, 4:12, Letter Peter Paul Kellogg to N.M. Haynes, 27 January 1955, Kellogg Papers (CUL): 4:12, and CUL, Kellogg Papers, 4:7.
} 
tific use of the collection and the BBC which took care of its preservation". ${ }^{67} \mathrm{It}$ established liaisons with both amateur and professional contacts and engaged them in bio-acoustics research on the collection. ${ }^{68}$ By 1953, the panel also agreed that the British scientific ornithological establishment could accommodate duplicates of the collection, and so copies were distributed to the British Trust for Ornithology, the Oxford Edward Grey Ornithological Institute and Cambridge's Department of Zoology. While the other institutes worked the collections much less intensively, William Thorpe and Peter Marler made great use of the BBC recordings to articulate some of their initial hypotheses. ${ }^{69}$

In addition, the BBC and the Cornell Library of Natural Sounds themselves exchanged recordings, on the condition that Cornell could distribute $\mathrm{BBC}$ recordings to authorized research workers such as the Cambridge sub-department of animal behavior, while the $\mathrm{BBC}$ would be allowed to use Cornell recordings for its own purposes of broadcast free of royalties. ${ }^{70}$ Moreover, in the following years, the $\mathrm{BBC}$ established contacts with nature recordists and radio services abroad and explored the possibilities to acquire or exchange recordings with them. ${ }^{71}$ Likewise, the Cornell Lab of Ornithology had built an extensive network of scientific and non-scientific allies. Throughout the years, Kellogg in particular had established friendly relations with amateur recordists and academic ornithologists who placed their recordings in the Library of Natural Sounds, as well as jointly organized expeditions (such as by the American Museum for Natural History and the American Columbia Broadcasting System)..$^{72}$ By the mid-1950s, the Cornell Library of Natural Sounds had also honored numerous requests for recordings from dozens of European and American research institutes; research laboratories such as MIT's Elec-

\footnotetext{
${ }^{67}$ WAC, BBC Records, R-46-364-3/2B, Note "Extract from Max Nicholson's opening address at the joint meeting of the Linnean Society, the British Trust for Ornithology, and the British Ornithologists' Union”. Emphasis mine.

${ }^{68}$ The extent to which such liaisons could be built appeared again to be limited. With Thorpe, the panel was also embedded in international bird song research. When the bio-acoustical community convened in Pennsylvania, for instance, Thorpe invited the BBC to associate itself with the planned International Institute of BioSound, but the BBC administrators eventually felt that this would lead too far from their initial 'scientific engagements". WAC, BBC Records, R46-719-1, Note "Minutes of the $6^{\text {th }}$ BBC Advisory panel on bird recording", 2 November 1955.

${ }^{69}$ One reason for the passivity of the other institutes appears to have been that the director of Oxford's Edward Grey Institute, David Lack, is reported to have settled with William Thorpe that bird song research would be exclusive terrain for the Cambridge zoologists.

${ }^{70}$ CUL, Kellogg Papers, 2:8, Letter Eric Simms to Peter Paul Kellogg, 13 December 1954. WAC, BBC Records, R46-365-2 1B, Letter Paul Kellogg to Eric Simms, 26 January 1955.

${ }_{71}$ Around 1963, correspondence and contracts demonstrate collaborations with a few dozen recordists and radio organizations, including the British amateur recordist John Kirby and Victor Lewis, and the recordist Canadian E.D.H. Johnson, ornithologists such as Terry Gompertz and radio organizations such as Nederland Radio and Norwegian Radio. WAC, BBC Records, R46-628, Memo from assistant head of Central Programme Operations to Programme Contacts, 31 July 1963. WAC, BBC Records, R46-366-1 1A, Memo "Some notes on Nat. Hist. Broadcasting and potential in the U.S.S.R., Finland, Sweden and Denmark", Jeffrey Boswall to Natural History Unit, not dated. WAC, BBC Records, R46-719-1, Memo "Natural History Contacts in the U.S.A.”, 20 March 1959.

${ }^{72}$ CUL, Kellogg Papers, 1:1, Letter Dean Amadon to Peter Paul Kellogg, 16 May 1956.
} 
tronics Research Lab, academic zoology departments such as Thorpe's in Cambridge, or specialized industry, focusing for instance on pest control.

Although such exchanges connected users and producers of recordings in a loosely-tied community, they did not lead to any systematic pooling of recordings and sound archives. Instead of the permanent supra-institutional infrastructure that the International Committee of Bio-Acoustics had envisioned, these recordings were made available only for individual and specified use. In fact, even when recordings were exchanged, both the $\mathrm{BBC}$ and Cornell carefully negotiated their terms of conditions. When the British Trust for Ornithology began to use their copies of $\mathrm{BBC}$ recordings in public lectures they were reprimanded, since the BBC found it not "in our own interest to tolerate such a free circulation of what is, after all, one of our broadcasting assets" ${ }^{73}$ Likewise, Cornell usually shielded their recordings from commercial or hobbyist use by asking a royal fee of a hundred dollars per species per occasion. Although educational, conservational or governmental uses were generally encouraged, and recordings would be provided at nominal cost, the Cornell Library of Natural Sounds was very concerned with what they considered 'piracy' and illegitimate usage of their recordings. ${ }^{74}$ In principle, recordings would be distributed for free to scientific workers. However, standard request forms usually had space only for five so-called 'cuts', or edited segments of a field recording. Moreover, valid requests for recordings by researchers required a scientific justification for their use as well as a signature of approval from the director of research at the requesting institute. Other sound archives, such as the British Institute of Recorded Sound and the Berlin Tierstimmenarchiv, followed a similar protocol, which allowed them to carefully negotiate the scientific and commercial use of their recordings.

Indeed, these sound archives did not only function as a liaison between users and producers of ornithological sound recordings but also as a sieve that not only promoted but also controlled the circulation of recordings. Of course, recordings would often still circulate informally. Liaisons within the field and particularly with Kellogg would allow researchers to surpass such administrative measures. Moreover, their easy duplication also enabled recordings to circulate informally, even if their exchange had been limited formally. British amateur ornithologist Myles North, for instance, received extensive logistical and financial support from Cornell for his recording expeditions. But the recordings produced under these conditions were at the same time relayed to William Thorpe in Cambridge, with whom North corresponded at the time. Comparably, the BBC would pay for recordings by naturalists who would at the same time contribute their material to the Cornell Lab of Ornithology for free.

\footnotetext{
73 WAC, BBC Records, R46-719-1, Letter Desmond Hawkins to Eric Simms, 14 March 1955.

${ }^{74}$ CUL, Kellogg Papers, 2:19, Note "Pirating of bird sound recordings belonging to Cornell" by Peter Paul Kellogg, February 1958. CUL, Kellogg Papers, 3:3, Letter L. Irby Davis to Peter Paul Kellogg. 22 January 1959. CUL, Stillwell Papers, 1:4, Letter Peter Paul Kellogg to Jerry Stillwell, 28 August 1952.
} 
Such formal and informal exchanges demonstrate how objects, tools and research materials may connect different social groups with different objectives across disciplines or institutions. Yet as recordings began to flow between institutes and individuals, they also shifted between different regimes of ownership. Each transfer between these regimes required careful translation and negotiation in order to be allowed to function as scientific data, by institutes such as the Cornell Library of Natural Sounds or the BBC's Bird Song Scientific Panel, making use of legal mechanisms such as copyright. The next section will examine in more detail how exactly each of these groups managed to use this effect in their advantage. It will do so particularly by zooming in on the exchanges between academic ornithologists and amateur recordists. Trading on alternative usages, both scientists and recordists managed to use recordings as bargaining chips to negotiate their position in this instrumental community and ensure the cooperation of others.

\section{A Moral Economy of Scientific Recording}

From a Mertonian point of view, science has long been claimed to work within a "gift economy". Contrary to the regular "market", research within this academic logic is supposedly communally shared rather than made privately profitable. The free flow of scientific ideas and findings has been said to be structured by moral principles of reciprocity, responsibility and reputation (Biagioli, 2003; Hagstrom, 1982; Merton, 1971). In science, therefore, the (legal) possibility of intellectual property or copyright on research materials seems to be at odds with a moral principle of open and unconditional access to scientific materials. At the same time, scholars in science and technology studies have in various ways begun to dispute empirically the validity of a normative structure supposedly universal to all branches of science. Research on the relations between academy and industry and on the commercialization of scientific knowledge through patenting, contract research or spin-off enterprises has highlighted the operation of "market principles" in science and has detected corresponding shifts in its normative regimes (Etzkowitz, 1989; Mirowski \& Sent, 2002; Nelkin, 1984; Rasmussen, 2004; Zuckerman, 1988). Others have pointed out that even though the distribution of credit and recognition to scientists for ideas and research materials requires disclosure, their public exchange is often strategic and selective, especially in those fields where economic gain can be expected, such as genetics or biomedicine (Evans, 2010; McCain, 1991).

Because restricted access to research materials provided potential collaborators with a strategy to negotiate and secure other resources, customs of quasi unconditional distribution of research materials have been found to be highly unusual (Hilgartner \& Brandt-Rauf, 1994). In fact, Robert Kohler's (1994) description of a group of experimental Drosophila researchers is especially distinctive, precisely because its 'moral economy' had been characterized by a free exchange of research materials. Interestingly, Kohler ascribes this peculiar culture to the abundance with- 
in the community of available colonies of fruit-fly mutants, which were the group's primary experimental instrument and resource. The workplace culture of this small 'fly group' emerged around a 'standard' organism, on the basis of communality of materials, ideas, expertise, craft knowledge or students. Because mutant colonies could easily be reproduced, researchers did not have to compete for scarce resources. As a result, they benefited most from a collaborative situation in which everyone freely shared advice and resources. Like fruit-fly colonies, recordings were of course relatively easy to duplicate. But unlike fruit-fly colonies, recordings were not exclusive to the scientific community. They also circulated in other contexts that maintained, however, different regimes of openness and availability. Legal and social mechanisms such as copyright regulated the circulation of recordings in these contexts. The last section has shown that copyright enabled its owner a position as gatekeeper. In this section, I will argue that copyright could be used not only to shield recordings from certain users and uses, but was also strategically deployed in such a way that it helped to establish a particular moral economy among recordists. In that sense, 'market principles' did not necessarily represent a new normative structure for science altogether, but rather helped to reinforce the norms of a local scientific community.

Firstly, for the Library too, recordings were not just scientific samples; they also functioned as assets or commodities that could be capitalized in order to generate new resources. Record sales and copyright licenses were the primary source of financial support for the Laboratory of Ornithology. Since its first experiments in the 1930s, the Lab had compiled a great number of albums, both atmospheric recordings and the instructive auditory field-guides for ornithologists from the collection. ${ }^{75}$ It had published these either alone or in collaboration with the Cornell University Press, which managed the royalties. By 1958, the annual income of these record sales and royalties amounted to more than $\$ 10.000$ annually - enough for the sound collecting project to be self-sustainable. ${ }^{76}$ For the University this kind of revenue was also reason to accept the Lab of Ornithology as a formal Cornell research institute, independent from the department of Conservation that had accommodated the ornithologists in preceding decades. The profit from these investments provided the means with which the Lab organized recording expeditions, acquired and modified professional recording equipment and most importantly, sustained a troupe of (mostly semi-amateur) recordists in their endeavors.

\footnotetext{
75 These gramophone records were practically impossible to take outdoors, as some skeptics remarked. The field-guides targeted a wide audience of ornithologists, who could use these gramophone records to train themselves at home in recognizing 'typical' vocalizations of species of a particular habitat. To issue these recordings, the Lab of Ornithology collaborated with Cornell University Press and in principle not with larger publishers, such as Columbia Records. Not only did this give the Laboratory tax exemption on their sales, it also permitted the ornithologists to keep in control of the production and publishing process. CUL, Kellogg Papers, 7:22, Letter Paul Schwartz to Peter Paul Kellogg, 14 October 1963.

${ }^{76}$ CUL, Kellogg Papers, 2:18, Memo "Laboratory of Ornithology, Cornell University, Cumulative Financial Report for the period ending January 31 1960)".
} 
It did so by offering, as Kellogg put it, "leadership, inspiration, encouragement, material help and recognition to anyone wishing to study living birds." 77 The Lab offered its leadership primarily by coaching those recordists who reported at the Library of Natural Sounds in the technical complexity of recording birdsongs outdoors. Recordists would send in recordings and receive feedback by mail. By the end of the 1950s, Cornell also adopted and sponsored the quarterly Bioacoustics Bulletin, which was to serve as an accessible platform for discussing technical issues concerning bird sound recording by both amateur and academic recordists. Occasionally, recordists also got the opportunity to spend some time with Kellogg and others, during which they would dis-assemble their gear and experiment with acoustic effects. ${ }^{78}$ This kind of pedagogy fostered informal relations between recordists and scientists, which facilitated exchange of both expertise and goods. But such technical training was also constitutive of a community of practice in which recordists came to share similar approaches and internalize an understanding of what makes 'good recording'. As Kellogg wrote to amateur recordist Irby Davis, "I would be awfully glad to listen to one of your reels just to get an idea of the way you are handling the situation in the field. I feel sure that almost any technique which fits your needs can be adapted to ours." ${ }^{\prime 79}$ As chapter 3 has shown, Cornell ornithologists favored a specific way of recording, and these exchanges helped to ensure that other recordists would themselves adopt such directional techniques: "I hope that you will be able to get some really close-up portraits of the interesting birds, many of which we heard only in the distant background on your reel." 80

Kellogg's feedback also made frequent appeals to the conscientious recordist: "I am becoming more and more fussy about the individual bird, which does the singing for my recording and I guess you feel much the same way about it $[\ldots]$ The amount of distortion on your recordings is small enough so that I think the average listener, who is not well acquainted with bird song, would not object to it at all, but I am sure you know what I mean and what I am driving at." "81 Such advice aimed to cultivate a professional - that is, a scientific - mode of listening among his collaborators. Scientific listening distinguished itself from the perceptive abilities of professional and commercial recordists who could hardly be trusted to "judge when a bird song has been recorded correctly. The ears of these people are just not trained for such sounds [ ...] they tend to tolerate distortions, which are absolutely unacceptable to a person familiar with the birds in the field." 82 Recordists should be listening with the ears of the future analyst of the recordings, demanding an even higher fidelity than the record industry. Clearly, collaborators had to be taught not only how to record but also how to listen correctly.

\footnotetext{
${ }_{77}$ CUL, Kellogg Papers, 6:19, Letter Peter Paul Kellogg to Myles E. North, 7 December 1962.

78 As reported for instance by (Stillwell, 1964).

${ }^{79}$ CUL, Kellogg Papers 3:4, Letter Peter Paul Kellogg to L. Irby Davis, 15 October 1954. Emphasis mine.

${ }^{80}$ CUL, Kellogg Papers, 3:4, Letter Peter Paul Kellogg to L. Irby Davis, 31 October 1954. Emphasis mine.

81 CUL, Stillwell Papers, 1:4, Letter Peter Paul Kellogg to Jerry Stillwell, 17 July 1952. Emphasis mine.

82 CUL, Kellogg Papers, 2:10, Letter Peter Paul Kellogg to Walter Buchen, 7 August 1951.
} 
That voluntary collaborators listened and recorded in the right way was conditional in part on their access to the right tools and equipment for the job. Interestingly, Cornell and associated scientists not only provided this equipment, but managed to make it part of a trade for recordings. Dr. William Fish, for instance, supplied amateur recordist Jerry Stillwell with a 30" parabolic reflector in exchange for some of Stillwell's recordings. ${ }^{83}$ This was not just a philanthropic project. The exchange was actually mutually beneficial, since this way Fish ensured recordings would be made with the right gear as well as his own access to them. Stillwell, on the other hand, acquired gear that was not always easy to get by as well as the scientific appreciation of his recordings. Recordists themselves also became aware of the alternative values of their recordings as currency for other services. One professional ornithologist on expedition wrote to Kellogg proposing: "I wonder if I could strike a bargain with you? Would your department be willing to send me a complete set of equipment from Amplifier Corp., if I were to pay for it and let you use anything I was able to record." 84 More commonly, however, the initiative would come from the Library of Natural Sounds itself:

We both regard the analytical studies which you are making of birdsongs as very important contributions and if a thousand dollars would help you with your work, and in clearing up some of your equipment problems, I believe the group here could be convinced rather easily to purchase the rights for publication of this material, even without assurance that they would get their money back. If it did come back, then there would be more available for further publications or grants. If such a proposition interests you, please let me know. .5

This 'mutually beneficial' proposition from Kellogg to his colleague bio-acoustician Bill Fish illustrates the different guises under which recordings came to work. In order to sustain the availability of recordings for scientific work, recordings (as well as their exclusivity in terms of copyright) were acquired and distributed as commodities to generate profit for the Laboratory. This profit could be invested again in better equipment or new publications, benefiting both the Lab and their recordists. In particular cases, these funds enabled the Library to make arrangements for recording equipment, transportation, and even living stipend to prospective recordists, often on condition that "all ornithological recordings and collections shall be the property of the Laboratory with the understanding that they will always be made available to you." 86 By establishing itself as the owner of the recordings and allowing for the right of the author to loan, the Library of Natural Sounds posi-

\footnotetext{
83 CUL, Stillwell Papers, 1:1, Letter William Fish to Jerry Stillwell, 10 April 1950.

${ }^{84}$ CUL, Kellogg Papers, 7:14, Letter William Sladen to Peter Paul Kellogg, 28 April 1960.

85 CUL, Kellogg Papers, 3:34, Letter Peter Paul Kellogg to William Fish, 20 November 1952.

${ }^{86}$ CUL, Kellogg Papers, 3:4, Letter Peter Paul Kellogg to L. Irby Davis, 18 November 1957.
} 
tioned itself such that it could shift recordings across the academy-industry boundary. Such transactions, and the bargaining on copyright that was part of it, ultimately served to secure a stable data-stream to the bio-acoustics community.

The Library did not in all cases get to buy the copyright to recording collections. In those cases, recordists were given the opportunity to retain the legal ownership of their recordings and to restrict their availability to commercial uses. Under such circumstances, the Library often proposed to act on behalf of the owner to negotiate the commercial use of the recordings it had been given in custody with private parties and corporations (such as Walt Disney). The yields from such successful negotiations would be divided between the Lab and the original copyrightholder of the recordings. Although the actual profit for the Library or for the recordists themselves was often marginal considering the expense of equipment and recording expeditions, these interactions did serve a more important purpose: the Lab's contacts and institutional visibility provided a structural incentive for amateur recordists not to stock their collections privately, but to make them public scientifically in order to capitalize them commercially. A successful commercial application of their recordings, after all, also represented social capital for recordists.

Other recordists would voluntarily share or surrender their copyright in favor of the Library of Natural Sounds. As Laboratory associate Myles North assured Kellogg, "[o]nce anything is lodged with the Laboratory's library, then the Laboratory can let anybody have the use of these results either free or for any sum it cares to charge, and such sums charged are, of course, credited to the Laboratory and not to me. If however anybody applies direct to me for the use of records, then I would supply them as available and make my own charge, but without ever surrendering any copyright." 87 Amateur recordist Donald McChesney further specified, "we delivered these tapes to you as a gift to the laboratory". "Consequently they, like the other tapes which we have consequently given to the Laboratory, are the property of the Laboratory and we have no jurisdiction over their disposition or use". ${ }^{8}$ Such donations of copyrights were sometimes actively solicited, especially when the Laboratory sought individual recordings to use on the commercial records they issued: "Since royalties from the album will be used entirely to support the work of the Laboratory, we are not offering to pay for the use of recordings but consider them as a contribution to the Laboratory. If this is not satisfactory to you, we would appreciate knowing under what conditions we might have permission to use [it]."89 This strategy actively encouraged recordists to surrender their rights as copyright-holder of the recording to the benefit of scientific research and the Laborato-

\footnotetext{
${ }^{87}$ CUL, Kellogg Papers, 6:19, Letter Myles E. North to Peter Paul Kellogg, 8 July 1963.

${ }^{88}$ CUL, Kellogg Papers, 5:46, Letter Donald S. McChesney to Peter Paul Kellogg, 23 October 1958.

${ }^{89}$ CUL, Kellogg Papers, 4:1, Letter Peter Paul Kellogg to Pershing B. Hofflund, 26 July 1961. Kellogg directed similar requests also at the $\mathrm{BBC}$ natural history unit: "I would like to take you up on your offer to try to locate some of these and determine under what conditions we would be permitted to use them. We would prefer to accept them as a contribution to the support of the Laboratory, and I hope that with BBC this will be possible.” CUL, Kellogg Papers, 2:1, Letter Peter Paul Kellogg to Jeffrey Boswall, 9 July 1961.
} 
ry in particular. But donations of recordings and their copyright had also often simply been inspired by the structural support to amateur recordists and the personal relations they had established with people in the Laboratory. Recordist Paul Schwartz, for instance, acknowledged that "I've never thought of the recordings deposited in the Laboratory as having any monetary value. To me it's part of a job I'm doing, quite frankly very heavily influenced by our personal friendship." 90 Sharing recordings served as a badge of professional identity but also an emblem of friendship. In that regard too, recordings represented symbolic capital.

Such symbolic and social capital was further perpetuated by the frames of recognition that the Library established for such contributing recordists, for instance by appointing long-term collaborators to so-called 'research associates'. According to Kellogg, an associate "received no pay but had full rights as a member of the staff of the Laboratory of Ornithology. He was also given laboratory space. This was of course of considerable advantage to him in that it gave him prestige and a good address. The University likewise shared credit for anything he accomplished." 91 Amateur recordists thus received feedback, encouragement and recognition for the papers they intended to publish and the recordings they collected. But above all, the appointment served as an honorary mechanism that not only represented the institute's gratitude but also intensified reciprocal commitment between the Laboratory and the recordist. ${ }^{92}$ As staff members, research associates were expected to naturally support the advancement of the Laboratory's scientific collection with their recordings and to contribute to its research. The appointment to associate thus came with both rights and responsibilities.

This variety of exchanges traces the contours of an economy in which ownership and authorship of recordings were translated into a range of monetary, symbolic and social capitals. Specifically, recordings came to serve as a currency for specialized equipment, status, commercial success, access to expertise and support, as well as a way for recordists to engage in the community socially. On the one hand, these transactions complemented the objectives of the technology-fascinated sound hunters themselves, who wanted to become and be recognized as competent high-fidelity recordists. On the other hand, they aided the scientific user too, in locating and centralizing recordings, while ensuring that they were made in the right way'. On the whole, these transactions enabled the Library to make a strong appeal to the recordist to follow their instructions in detail. For many recordists, for instance, editing work was often the more tedious part of their field expedition and reduced the more exciting time spent in the field. But their engagement in a trade with the Library established the contribution of their recordings and completed field notes as part of a commitment, rather than a voluntary contribution (which

\footnotetext{
${ }^{90}$ CUL, Kellogg Papers, 7:20, Letter Paul Schwartz to Peter Paul Kellogg, 27 December 1961.

${ }^{91}$ CUL, Stillwell Papers, 1:2, Letter Peter Paul Kellogg to Jerry Stillwell, 7 April 1951.

92 The arrangement itself was not without controversy among the Laboratory staff, some of who felt that recordists without formal qualifications in ornithology should not be given the title 'research associate'. CUL, Kellogg Papers, 5:43, Letter Peter Paul Kellogg to Donald S. McChesney, 17 November 1961.
} 
could be postponed endlessly). Such a commitment was not usually a legal obligation (as contracts only defined the ownership of recordings), but an understanding of reciprocity among recordists and scientists. Thus the circulation of recordings (in material or other symbolic forms) also structured social customs within the community.

Above all, providing equipment and offering expertise in exchange for recordings was a means to establish a common practice among collaborating parties. This included the way sounds were recorded in the field, and the protocols that were followed. Many of the portable battery-operated tape recorders suffered for instance from severe deviations from the desired standard recording speed when connected to foreign electricity grids. The resulting deviations in pitch were often hard to determine without recordings to compare them with. The Library requested that recordists played a standard tone with a cheap pitch pipe that the Lab provided for free, which would allow the future user to calibrate the playback equipment. Similarly, recordists were required to supply as much data as possible to the identification, either spoken on the tape, or written down in field documentation, to make the recordings valuable to workers in diverse areas of investigation. "For the privilege of making copies of any of your Mexican bird songs [ . . . ] we hereby offer you $\$ 500[\ldots]$ We very much hope that on your future recordings you will announce the bird's name, the data, locality, as well as keep adequate field notes concerning the contents of each reel. It would also be of considerable scientific value if you would make it a habit to sound a pitch-pipe, preferably the A note (440cps). ${ }^{\prime 93}$

The exchanges also helped the scientific staff to ensure that amateur recordists did not tinker with the final recordings too much in order to have them sound well. Filtering of frequencies and editing silent segments out were tempting mechanical interventions - especially to recordists with a fascination for hi-fi - because they reduced levels of extraneous noises, prevented wasting costly 'empty' tape, or made recordings fit for commercial purposes. Although clumsy editing was generally not hard to detect, checking the veracity of donated recordings required considerable listening skills and social rapport with their contributor. As Kellogg pointed out to a contributor, "[i]t is my feeling from listening to the record that someone has already seriously attenuated the high frequencies and I know that many of the low frequencies have been attenuated. What I would like to do, and I think you should do, is to try to get recordings which will need no filtering at all." 94 These bioacousticians requested from their collaborators a deliberate self-restraint from any 'aestheticizing' interventions: "I confirm that as requested, I shall not use the bandpass filter at all in the copying, so you will get the true record including all the hums and buzzes and external sounds which you can of course filter out yourself." 95 To

\footnotetext{
${ }^{3}$ CUL, Kellogg Papers, 3:4, Letter Peter Paul Kellogg to L. Irby Davis, 24 February 1954.

${ }^{4}$ CUL, Stillwell Papers, 1:5, Letter Peter Paul Kellogg to Jerry Stillwell, 3 October 1952.

${ }^{5}$ CUL, Kellogg Papers, 6:20, Letter Myles E. North to Peter Paul Kellogg, 12 February 1963.
} 
be sure, the point is not that the Laboratory staff did not intervene in the recordings at all; on the contrary, they put considerable effort in editing some recordings before filing them. But they wanted to have control over that process.

I am anxious to take you up on your offer to send representative samples of Bewick wren songs. I'm preparing to make more tracings and would like to include any that you can send - at your earliest convenience. Actually, I'd like best to have them in unent [sic] sequences so that I can get data on interval length, signing rate, sequences of patterns and changes in patterns. But I'll be grateful to have just representative samples as you select them. All the records you have of the species, from any and all parts of the country. And when they are analyzed I'll send you dope on them and the records you sent last October, which were recorded on June 4, 1952. Even if you think some of the records are not so good, they may 'analyze' alright. Please send them along. If you will send me all your originals. I'll copy them immediately and return the originals. The copies will be used only for analytical purposes. ${ }^{96}$

This request by Dr. William Fish to amateur recordist Stillwell is a telling example of the importance these researchers attached to working from un-altered, original recordings. Their preference for the original tied in with a concern for the technical inferiority of the copy; re-recording and duplication of the original at a different tape speed or with different equipment settings might, after all, drastically alter sound quality or introduce unwanted acoustic artifacts, some of which would possibly not be recognized as such (Tall, 1958). Yet such demands to share both best and worse recordings were not easy to comply with for the hi-fi fascinated recordist, as Fish himself testified further in his letter: " [] added a fair number of species to the collection this year. Not all first calls, of course. A very fine sequence of Fox Sparrow songs. I remember that you requested some of my earlier records of this bird. I never sent them because they had a faint buzz in the background. The new ones I'd be proud to have you hear, if you care to." 97 Clearly, technical pride was not exclusive only to the amateur recordist. But as technical preferences might also lead to a misguided selectivity in contributing potentially valuable data, this was something scientists wanted to guard against. Although the trade of 'recordings for benefits' did not by itself ensure that other concerns would prevent data to be fully disclosed, it did nourish a moral framework and a basis of trust among collaborators that when requested they would share all data they possessed.

Occasionally, such shifting of resources (in expertise, instruments and funds) did not suffice to fasten the Library's claim to the recordings. One prospective

\footnotetext{
${ }^{96}$ CUL, Stillwell Papers, 1:2, Letter William Fish to Jerry Stillwell, 19 August 1954.

${ }^{97}$ CUL, Stillwell Papers, 1:2, Letter William Fish to Jerry Stillwell, 19 August 1954.
} 
ist for instance had appealed to the Laboratory for support in assembling a recording outfit for his recording expedition, upon which Kellogg had offered to have "someone who knows about recording birds to go with you?" When the recordist finally declined this offer because he "preferred not to have anyone along who would not be classified specifically as his assistant," Kellogg observed that "he seemed rather reluctant to share any of the credit or specimens coming from such a trip." 98 Such ostensive proprietary claims were rather rare in the Laboratory's circles, where specimens were made publicly available.

At times these distinctions confused also the recordists themselves. When the Library staff provided a group of scientists at the American Museum for Natural History with a data-set that amateur recordist (and official research associate) Irby Davis had contributed, Davis got very disturbed. He had been planning to write a paper on that exact set of recordings, and had in the meantime deposited them at the Library without formally restricting their distribution to third parties. For Davis, sharing specimens did not by definition imply sharing research opportunities. The disagreement solicited from a fellow amateur recordist, Donald McChesney, the comment that

Irby looks upon the birds of Mexico as lying within his own private domain. This runs somewhat counter to my understanding of scientific work in general and the work of the Laboratory in particular. I had an idea that we were all working in a common effort for the advancement of human knowledge. And quite apart from the ethical aspects, hasn't Irby in large measure been supported by the Laboratory or by agencies made available to him through the Laboratory? It seems to me that this might in all fairness, have some bearing on the scientific use of the products of his efforts. ${ }^{99}$

This remark uniquely verbalizes a moral imperative with regard not only to the sharing of specimens but even to research problems. Its etiquette was not only premised on an abstract belief in the communality of scientific research. It was also inscribed locally through the Laboratory's investment and support in individual recordists. While the precise conditions for these exchanges were rarely made explicit, they seem to be guided by an understanding that in exchange for such support the owner and author of the recording was expected to at least distance himself from any appeals to exclusivity.

Taken together then, these transactions represent a rich tapestry of arrangements through which recordings have been dissociated from recordists' private collections and made accessible to scientific workers, by not treating potential data exclusively as data. Instead, the Library of Natural Sounds advantageously moved

${ }^{98}$ CUL, Kellogg Papers, 5:46, Letter Peter Paul Kellogg to Donald S. McChesney, 17 September 1957.
${ }_{99}$ CUL, Kellogg Papers, 5:46, Letter Donald S. McChesney to Peter Paul Kellogg, 22 October 1958. 
around recordings in different guises throughout different regimes that operated distinct notions of ownership, access, credit and status. In these regimes, recordings were conceived of as much as assets, commercial commodities or trophies, as they represented sets of scientific data. The Library of Natural Sounds articulated recordings as a resource in each of these regimes through arrangements of copyright and ownership, which, in turn, acted as a strategic site to demarcate an academic type of exchange rather than undercut it.

In a similar vein, sociologist Fiona Murray (2010) has shown how life scientists managed to appropriate the commercial logic of the industrial patent to the advantage of the scientific community and its exchanges. Murray describes the aftermath of the patenting and subsequent exclusive licensing of the oncomouse, which several limited the informal exchange of this widely-used experimental resource in the scientific community. However, Murray explains, the genetic community ultimately managed to transform the industry's aggressive patenting and commodification customs into a hybrid strategy. This strategy, when carefully applied, could be used to prevent unwanted commercial involvement. For instance, scientists started patenting defensively, at the same time imbuing these resources with a new symbolic status as protecting the scientific commons. Patents further allowed scientists to strategically co-opt industry in making further investments in scientific ideas, or to get other ideas disseminated as widely as possible. Importantly, the new meanings that were thus ascribed to intellectual property rights allowed academic scientists to further the traditional aims of academic science. The effect, as Murray points out, was that such interventions reinforced rather than dissolved the boundaries between the market and the academy (2010, pp. 378-9). Like the legal arrangements around experimental resources, copyrights on sound recordings clearly did not serve exclusively as a market trope. For although the Cornell ornithologists and bio-acousticians pursued copyright to the recordings they archived, they also managed to convert it into a mechanism that, paradoxically, helped to invigorate academic exchange.

Indeed, Ian Mitroff (1974) has argued that science's normative structure is more ambivalent than Robert Merton may have appreciated. Seemingly universally recognized scientific norms actually maintain a productive tension with some of their pendants. In particular situations, what Mitroff calls 'counter-norms' (such as 'secrecy' or 'private possession' rather than 'communality') may actually come to serve the purpose of science itself. Likewise, a strategic enforcement of proprietary control over scientific materials reinforced rather than undermined the academy's logic as well as its moral structure. What this section illustrates, then, is not so much a changing normative regime in science with regard to commercialization. This section has shown how copyright enabled the scientific community to enlist the cooperation from a host of collaborators and negotiate their subscription to a particular moral economy. Copyright provided bird song biologists the means with which to bargain their collaborators' adoption of scientific values, including selfrestraint (from aestheticizing interventions and tinkering with recordings for what- 
ever purpose), accurate bookkeeping (in annotating recordings), mutual disclosure and free sharing (of recordings in possession, intentions of use and the materials of analysis), and a renouncement of exclusivity. In addition, it enabled them to teach collaborators specific skills and stimulated them to adopt recording and listening techniques that were specific to the collecting and analysis of birdsong.

\section{Authorship and shared listening}

Besides ensuring scientists' access to data and fostering practitioners' skillful recording, editing and describing of auditory specimens, however, the Library also attempted to ensure the integrity as well as the precision of identifications and descriptions provided by a recordist. It did so by distinguishing the organization of ownership described above from a specific notion of authorship. Scientific authorship is comparable to commercial copyright, as both distribute credit and rights by a principle of priority. But whereas copyright denotes the terms of expression in fiction or artifacts, authorship generally applies to the actual content that is described. So commercial copyright arrangements are usually distinguished from scientific authorship by reference to science's insistence on disinterestedness and communality (Biagioli, 1998; Biagioli \& Galison, 2003). While terms of expression could be owned, claims to truth could not. Instead, they were protected and rewarded for on the terms of authorship. As recordings transformed from private property to a communal resource through the trading of the Library, recordists could choose to renounce their ownership and copyright but they did not cease to be 'authors'. In practice, unless it would be impractical to do, scientists who used recordings from any of the sound archives, would still acknowledge or credit the producer of the recordings. Occasionally, authorship of a recording would entitle the recordist even to authorship of a scientific publication that had used his recordings in its analysis.

Authorship did not only distribute credit or recognition though. It was also considered simply an administrative necessity for a recording to exist within the sound archive. The Library's 'Field and Editing Notes' forms required at least the name of a recordist before they could be processed in the catalogue (figure 4.3). Within this system, recordings could not be authorless, as Peter Kellogg indicated upon receipt of a set of recordings: "we would appreciate having the name and address of the doctor who recorded it, just in case someone in the future might like to ask him more about it."100 As Mario Biagioli notes, is "not only because the scientist deserves fair credit for it, but because it has to be marked in order to exist, to be recognized as a specific truth, not just a chunk of undifferentiated, undescribed nature" (Biagioli, 1998, p. 5). Like scientific claims, ornithological recordings required some form of authorship. If copyright organized only the distri-

${ }^{100}$ CUL, Kellogg Papers, 3:1, Letter Peter Paul Kellogg to Robert Dickerman, 7 April 1960. 
ings required some form of authorship. If copyright organized only the distribution of reward, authorship also distributed accountability for a claim. Through its author, recordings shifted from being a random sonic event to a claimed truth. Through authorship, its producer was supposed to assume responsibility not only for the way it was produced and edited technically, but also for the sincerity with which it was identified and the detail and reliability of its accompanying notes.

Nevertheless, only rarely the recordist would be the sole author of a recording. As recordings could be owned privately and collectively at the same time, they could be authored by its recordist and the ornithological community too. First of all, each field and editing form distinguished between several authorial roles; though the recording would be principally authored by the recordist who had made the recording in the field, the forms required separate entries for those who identified and those who edited the catalogued sounds. For sure, field recordists could fulfill several of these roles. In fact, contributors of large sets of recordings were occasionally invited to copy and edit their work on-site at the Laboratory, where they had professional infrastructure at their disposal. But it also allowed others at the Lab to participate in the sound editing, and to assist in annotating the tapes as completely as possible or to deliberate particular entries. While sound editors would not usually consider themselves knowledgeable enough to question the actual identification, they assessed the quality of the recording, transcribed the tape-recorded field notes and identified additional background sounds (Interview Little). Thus, besides the field recordist at least one other listener would be enlisted on the form. Far from "invisible technicians" then, sound editors and other ornithologists were given an explicit authorial role in this stage of the administration of scientific data even though they would rarely be represented in scientific print (Shapin, 1989).

Secondly, a diverse group of listeners could be involved in the identification of the recording. When the recordist himself was not sufficiently knowledgeable to make a convincing identification, the recording could be deliberated by the collective of fellow ornithologists on location or at the Lab. Especially in the first half of the 1950s, the atmosphere at the Lab was such that students, faculty and visitors would drop by and browse the archive, meanwhile lending their expertise to unidentified items (personal communication Little, email April 8 \& 12, 2011). Even though it would hardly be organized, such diagnostic listening could be more authoritative when it was shared collectively. As Kellogg informed one of his collaborators, "[a]ll of us can't agree on the identification of what is on the reel." The recordist tried to counter their suspicion of a technical defect, but he could not "help but feel [ . . . ] that your collective ears at Cornell are accurate to a point that may well indicate a flaw". ${ }^{101}$ Later, when the geographic scope of the collection outgrew the expertise of most researchers at the Laboratory, they would regularly solicit the opinions of experts in their network. Recordists regularly reported to have revisited the results of their field expeditions with local experts. For certain questionable but

${ }^{101}$ CUL, Kellogg Papers, 1:37, Letter Ed Boyes to Peter Paul Kellogg, 12 November 1951. Emphasis mine. 
potentially important recordings, the Laboratory also reached out to the entire birding community. As one of the Lab's collaborators later observed, "that outreach, I think, did a lot to build confidence in the trustworthiness of the LNS as well as to increase interest in improving and expanding the archive even further (Interview Little). Interestingly, such inter-subjective identifications were understood not so much as a marker of uncertainty but of reliability, and could be used again as a token of exchange between institutes.

Standardized forms for "Field and Editing Notes" also served in another way to ensure the validity of identifications, by explicitly requiring its producer to indicate how they had been validated; had they been heard or confirmed visually. The category of visual confirmation was introduced only in the editing forms by 1961, to accommodate the skepticism by for instance systematists quoted above. As William Fish explained the relevance of such a category, "[i]f the recordist cannot see the animal recorded or cannot identify the animal he sees vocalizing, he should not attempt to identify the material. [However] one must then add the following: unless the recordist can do so unequivocally on the basis of adequate experience with the species involved." 102 Thus, in order to ensure that recordists would not make incorrect identifications in the field, exclusively auditory recognitions should not be taken as fact without consideration of the recordists' (demonstrated) experience and expertise. In case of a visual confirmation, of course, the identification could be steered in the more familiar epistemic territory of sight records. While sight records remained by no means undisputed in ornithology (Barrow, 1998), they were often granted primacy over recorded sounds, even if those sounds had been identified differently by several independent listeners, and in some hotly debated cases, eventually only the tried-and-tested method of specimen collecting would be accepted. ${ }^{103}$

Such forms aimed to make transparent the ways in which identifications and descriptions had been collected, to the editor and curator of the collection as well as to the user of the recording. The labels and paper forms thus worked not only as tools with which private recordings could be transformed into public possessions; they also served as a site where individual experiences were translated into public claims. Paper forms helped to construct workable claims - claims around which a minimum of epistemic uncertainty existed. They did so, first of all, because as

\footnotetext{
102 CUL, Kellogg Papers, 3:32, Letter William Fish to Peter Paul Kellogg, 31 December 1961.

103 For instance, Kellogg was informed that one of his cuts of Indigo Bunting sounded with reasonable certainty like Lazuli Bunting, but replied that although the authors were confused and realized that the song should actually be of a Lazuli Bunting, a visual identification at close range of the bird had settled the matter. CUL, Kellogg Papers, 1:9, Letter Peter Paul Kellogg to David Johnston, 5 June 1963. A specimen could demonstrate the presence of a specific bird in the environment, although strictly the bird had to be shot while singing to which, evidently, again only the recordist himself could testify. With regard to an identification that several listeners disputed, Paul Schwartz advised Paul Kellogg for instance that "My stand is that in my files the bird remains N.griseus with a question mark. If someone proves this wrong by shooting the bird while it's singing I'll gladly change." CUL, Kellogg Papers, 7:20, Letter Paul Schwartz to Peter Paul Kellogg, 15 August 1961.
} 
standardized forms they could move through the various informal channels of peer review. But, secondly, they also integrated recordings in a moral culture with authorship as a badge of responsibility. As noted above, recordings served to establish a record of recognition for technical and naturalistic competence among particular groups, but they could as easily corrupt such a record. Authorship of recordings directly reflected on the author's reputation.

This becomes clear among others in an exchange of recordings between two researchers at the Commonwealth Scientific and Industrial Research Organization and William H. Thorpe at Cambridge University. Dr. Robinson had been studying and recording Australian bird calls, excerpts of which he had forwarded to both Dr. Meakins and Dr. Thorpe. Upon hearing the copy, however, Dr. Meakins rushed to warn Thorpe that the recording was most probably an imitation by the Australian lyre-bird, an exceptional mimicker but easily recognizable in its labored and inaccurate rendition of the female call. ${ }^{104}$ By doing this, Meakins not only labeled the recording as a possible imitation; he also questioned the reliability of Robinson's field craft. The polemic that ensued was eventually closed when Meakins reinstated Robinson's reputation and renounced his own expertise: "I realized that my letter might appear to throw doubt on Dr. Robinson's competence as an ornithologist. This was not intended. [ . . . ] Since I am merely an amateur 'bird-watcher' I would not wish to urge my opinion in preference to his. I now understand that Dr. Robinson is quite sure that the recording is of the Eastern whip-bird."105

Controversies such as these were not uncommon among ornithologists, and like the one above they were usually small and temporary fissures that were smoothened locally. As this example also demonstrates, however, empirical claims (towards specific classifications established in the field) were embedded in a clear scheme of accountability. Recordists did not only feel morally responsible for making the recording itself, but also for what they testified it represented. This was the case in the informal exchange sketched above, but recognition of this dual role of authorship was also more systematically inscribed in the administration of the scientific recording. Sound recordings were of course not the only type of specimen in which the collector was explicitly marked. Yet more specific to sound recordings as scientific specimens, however, was that within this morally laden economy, their authorship on the one hand served a practical purpose of distributing credit and recognition, and on the other channeled accountability for the reliability of the recording as a document of nature.

\footnotetext{
${ }^{104}$ CaUL, Thorpe Papers, Ms.Add 8784:10, Letter F.N. Robinson to William Homan Thorpe, 20 August 1963. CaUL, Thorpe Papers, Ms.Add 8784:10, Letter R.J. Meakins to William Homan Thorpe, 27 August 1963. The lyre-bird is known to be a great mimicker of bird songs, and has become popular with a wide audience with a David Attenborough documentary as a great mimicker also of a great variety of mechanical sounds.

105 CaUL, Thorpe Papers, Ms.Add 8784:10, Letter R.J. Meakins to William Homan Thorpe, 4 September 1963.
} 


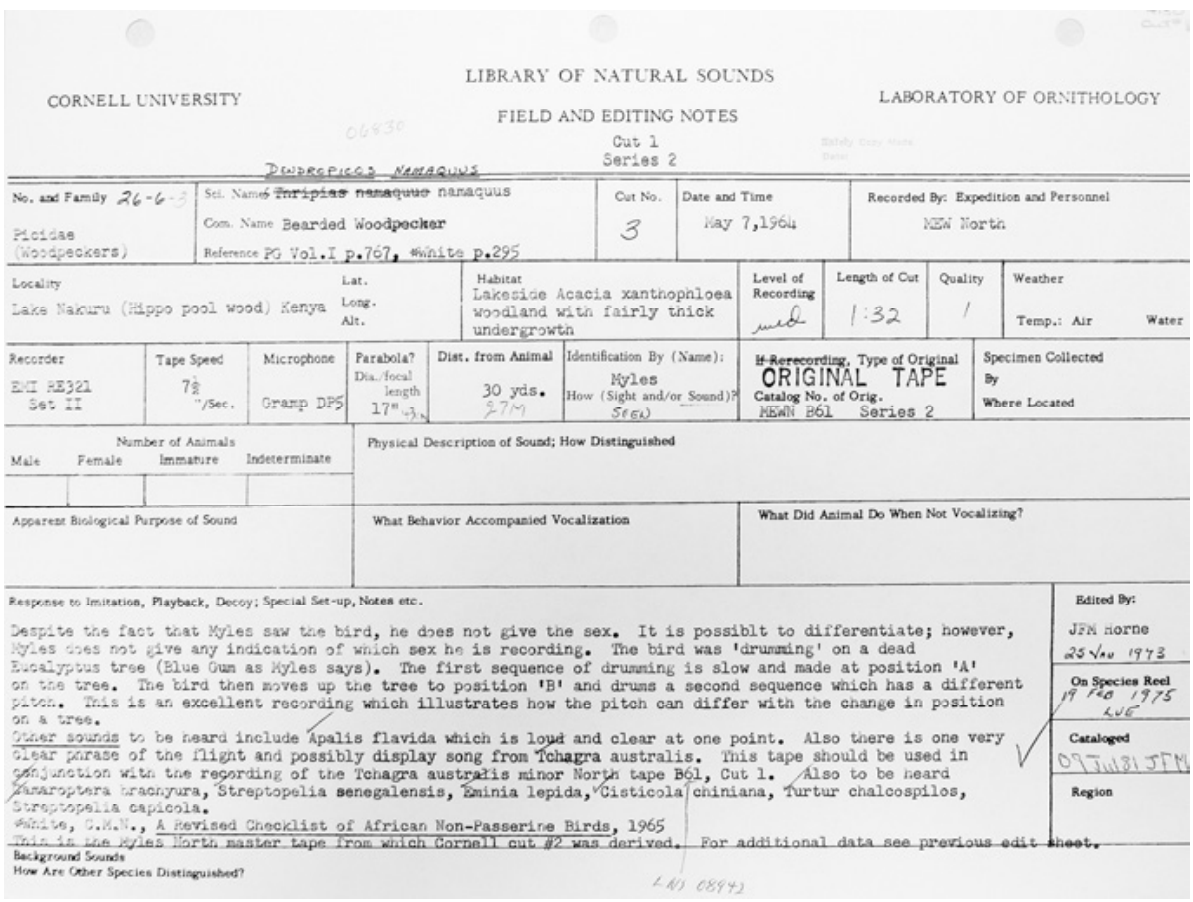

Figure 4.3

Cornell Library of Natural Sounds field and editing notes form.

\section{Conclusion}

One of the issues this book seeks to illuminate is how the scientific community has attempted to transform a popular and mundane technology like sound recording into a scientific tool. Turning popular recording practices into science required getting to grips with sound recording's existing material and social organization. Tape recordings were relatively easy to duplicate and thus fitted scientists' demands for wide-spread circulation among peers. Yet their range was also customarily restricted by a legal discourse of copyright and authorship that had accompanied the technology already since the beginning of the twentieth century (Diamond \& Adler, 1940). Moreover, as this chapter has shown, tape recordings were flexibly interpreted and invested with local meaning across social groups (Bijker, Hughes, \& Pinch, 1987). Nature recordings assumed at the same time the role of scientific data, commercial assets, as well as social and symbolic capital.

Scientists managed to establish sustained collaborations with broadcasters, record producers, industrialists and recordists, by appropriating the logics of the amateur scientist and the recording economy as their own, along with its tropes, such as copyright. In contrast to what the participants at the Bio-acoustics confer- 
ence in 1956 had envisioned to become the Animal Phonography collection, sound archives such as the Cornell Library of Natural Sounds did not uniquely warehouse records of scientific relevance. Instead, I have shown how by appropriating copyright they operated at the same time as a scientific institute, a clearing-house for amateur observations, a record publisher and a philanthropic organization. These multiple functions enabled the sound archive to position itself as a hybrid at the intersection of amateur, commercial and scientific recording, thus enhancing opportunities for organizing and investing in stable and reliable data-streams.

Data-streams, this chapter has shown, are complex and heterogeneous. Ensuring useful scientific recordings required after all that they were made by recordists with the right instruments, techniques and skills to make and the willingness to share them. In ensuring such data-streams, the Cornell Laboratory of Ornithology and its Library of Natural Sounds thus mobilized their recordings as flexible and mobile resources. Once collected, recordings could be published, which enhanced the institute's visibility, provided an income on royalties and even established a basic knowledge of specific bird sounds with its listeners. Such visibility attracted aspiring recordists, which could be stimulated to adopt specific recording techniques, while its income could be invested in equipment for recordists or the royalty-free acquisition of their recordings. Importantly, this also fostered social ties with the institute as well as a sense of reciprocity. Like Bruno Latour and Steve Woolgar's (1986) 'cycle of credibility', in which credit is continuously reinvested to expand and accelerate scientific work, the reproduction of this moral economy suggests a quasi-economic model. But unlike the 'cycle of credibility', the scientific community is no isolated or self-contained system, nor is credibility its sole currency. This chapter has shown recordings to acquire monetary, social and symbolic value and to be exchanged in each of these currencies. Importantly, rather than jeopardizing its scientific usefulness, this brokerage of recordings as variable resources enabled the sound archive to operate also as a pedagogical bridgehead that transferred knowledge, skills, routines, customs and values to the recording community. Previous chapters have shown recordings to serve diverse purposes at the same time. In this cycle likewise, sound recordings have proved to be a particularly versatile resource, as they simultaneously also served as potential scientific data (mimetic), to exemplify good recording practice or to standardize an aural discourse for identifying birds (didactic), to prepare recordists for the aural experience of the field (mnemonic), and to invite recordists to commit to sound recording or to make their work accessible to scientific use (alluring).

A natural starting point to frame this process has been Leigh Star and James Griesemer's work on 'boundary objects' (1989), because it reports on a remarkably similar historical circumstance. In the first decades of the twentieth century, the Museum for Vertebrate Zoology at Berkeley assembled a natural historical collection through a cooperative effort by a number of very different actors. The authors hold that despite their diverse skills, theoretical premises, practical interests or social background, collaborators managed to cooperate fruitfully. This, they argued, 
was due in part to the standardization of methods and the construction of so-called 'boundary objects' - objects that are robust enough to maintain coherence, but plastic enough to adapt to the local needs of a heterogeneous group of users. In the context of this chapter, their thesis does alert us to a number of boundary-crossing entities, and the ways in which they have facilitated the exchanges between amateur recordists, broadcasters, movie producers, ornithologists and other biologists. As Star and Griesemer themselves note, standardized recording forms as well as the repository of specimens itself helped to transport field observations and editing notes between different social worlds. Another significant type of boundary objects I have described concerns copyrighted recordings, which despite their legal robustness could be reconstructed locally, for instance into a token to strengthen social relations.

The significance of this framework of 'boundary translations' lies especially in clarifying why such cooperation worked as it did, epistemically. Boundary objects, after all, facilitate cooperation without coercion because they translate actor's interests across social boundaries. Star and Griesemer (1989) are less clear, however, on how such collaborations came to be established in the first place, and how they came to be successfully organized socially. They point out that "convincing" allies into conformity to a standard method was largely a matter of negotiation. This negotiation, they suggest, could take the form of a mixed economy of goods and information, involving bartering, trading and buying of scientific specimens. But due to their focus on the infrastructure of collaboration, they did not expand on how exactly this economy worked to ensure the reliability and credibility of the information and goods that collaborators exchanged. How, then, did this economy helped to discipline non-scientists into conformity to a specific set of methods as accurately and precisely as need be? It is exactly by looking more closely at what exactly is exchanged and to what effect that we may see how this is achieved.

The economy described in this chapter is one in which scientists were not usually in a unique position to manage by themselves such flows within a network of collectors. It is particularly because their specimens had a concrete value in other social contexts too that non-scientists had to be persuaded to appropriate a specific standardized method and consider their records as potential scientific specimens. The exchanges between amateur recordists and scientists above suggest that the circulation of a standardized field-notation form or the standardization of recording techniques (through the parabolic reflector) alone for instance were no conclusive means of 'disciplining' collaborators across social worlds. For a standardized form to become effective at all, their users also had to possess specific knowledge, skills and an understanding of what good recording entailed. They also had to participate in the Library of Natural Sound's customs and working habits, and come to share in scientific norms that were not necessarily their own. Sound recordings could only become useful and credible if their producers also adopted good bookkeeping, resisted aesthetizing interventions and enabled the free exchange of their recordings, instead of insisting on private ownership or tinkering with imper- 
fect' recordings. This chapter has outlined how the trade of specimens established productive relations across social boundaries, but that these were dependent not only on the bare economics of translation.

In the first place, recordings, as pointed out above, helped to export knowledge and conventions across boundaries, by standardizing an aural discourse and setting an example of good recording practices. But this chapter has shown that the exchange of such recordings was at the same time constitutive of what I have called a moral economy, in which copyright and commercial exchanges also instituted a scientific normative frame. Steven Shapin (1994) has demonstrated how the culture of experimental natural philosophy in early modern England was deeply indebted to the conventions of civil society. Science widely borrowed from the social and moral codes or norms of its gentlemanly culture, in which men of standing were considered reliable truth-tellers. Likewise, this moral economy of sound recording borrowed commercial tropes such as copyright and mobilized recordings according in different social, monetary and symbolic currencies to establish flows of specimens and to ensure their scientific credibility. Some of these trades effectively disciplined recordists with legal arrangements, but most exchanges actually nurtured a sense of community, reciprocity and responsibility. Collaborators, for instance, 'selflessly' abandoned their copyright by supplying recordings out of a feeling of moral obligation, gratitude or to renew social bonds within the community in the same way as sharing their records might give them a small financial gain. This exchange of recordings was also moral in that it balanced the various functions of recordings as social capital (regarding them as hunting trophies or enabling a research associate-ship) with the responsibility for sharing recordings and for vouching for their reliability and veracity. Through this tapestry of hybrid, commercial and academic, exchanges, recordings thus nurtured what Morgan Meyer (2010) has termed 'weak ties' between scientists and their collaborators. The economic exchange of information and goods constituted a (provisional and often fragile) social cohesion within this network. As such, this moral economy also only exists through a fragile system of sustained negotiation and trading with the groups on which the archive was dependent. Where some historians have described moral economies that articulate long-standing values such as objectivity or empiricism that remain relatively stable across scientific expert communities, the stability of this moral economy dependent to a large extent on how successful scientists were in continuing to mobilize their data in alternative currencies.

Chapters 3 and 4 have demonstrated how the production of scientific field records assumed the configuration of both recording instrument and the recordist, in function of its analysis. Their choices matter for the quality and credibility of the work scientists perform in their laboratories: the kinds of analytical inference they can make from a recording depended, for instance, on the ways it had been produced, the kind of data provided with it and the quality of the sound. Let us now turn to that analysis to examine how scientists proceeded to transform the sounds of wild birds in the field into scientific objects. 



\section{Patterned Sound: \\ Inscriptions and the trained ear in bird song analysis}

\section{Introduction}

"The invention of a novel analytical technique often helps to launch a new science. What microscopes were for the emergence of cell biology as a discipline, or the cathode-ray oscilloscope for neurophysiology, it was the sound spectrograph that, immediately after the Second World War, enabled the birth of the science of birdsong [ . . . ] Until about 1950, everyone interested in birdsong had no choice but to work by ear. Only when the sound spectrograph became available was it possible, for the first time, to grapple objectively with the daunting variability of birdsong" (Marler, 2004, p. 2). Thus biologist Peter Marler sketched in the latest textbook on bird song biology what he regarded as a formative shift in the discipline. ${ }^{106}$ Sound spectrographs produced graphic representations of the frequency, amplitude and loudness of a sound sample, and were thus commonly interpreted as a 'picture of sound'. It was this application that according to Marler, "elevated studies of song dialects [... ] from the birdwatcher level to the status of scientific research" (Marler, 2004, p. 11). From 1952 on, Marler pioneered the instrument with his boss William H. Thorpe in their first work on bird song at the Department of Zoology of Cambridge University. For Thorpe, the sound spectrograph supplied both a new form of notation and a method of precise measurement that allowed analysts to avoid the "dangers of subjective interpretation" embedded in earlier notation technologies (1954, p. 465).

The sound spectrograph had been developed as a commercial application by Bell Laboratories to aid deaf communication. But by 1950, it also appeared to solve one of the problems that had preoccupied students of bird song already since the

\footnotetext{
106 The microscope proved a popular trope. Reviewing a hundred years of bird song research, biologist Myron Baker for instance also likened the "new horizons in bird song studies" opened up by the sound spectrograph to the "new world of organisms revealed by the first microscope" (2001, p. 3). The suggestion of these analogies is that like the microscope, sound spectrography ultimately had enabled biologists access to a more sophisticated resolution of analysis of sound.
} 
turn of the twentieth century: how to represent bird song not only precisely and objectively, but also intelligibly. Since Albert Brand's (1937) critique of human hearing, students of bird song had experimented with various 'mechanically objective' techniques of sound visualization. Yet here was an instrument whose developers claimed would not only visualize sound, but would even provide an objective visual language for sound, pairing precise analysis of complex sounds with the ease of an intuitive readability.

Sound spectrographers' aspiration to by-pass the aural experience of sound completely through visualization follows in a much longer scientific tradition in which mechanical and visual signs came to stand in completely for the signified to guide scientists' understanding of the world (Brain, 2002; Daston, 2001; Lenoir, 1998; Wise, 2006). This is particularly evident in the study of sound. Historian of science David Pantalony (2004) describes for instance how nineteenth-century acoustician Rudolph Koenig deliberately designed instruments and visualization techniques for his vowel studies that would allow him to "rely less on the expert ear and more on the eye" (p. 440). This shift, Pantalony argues, represented a break with past studies that used to rely as much on the students' auditory and musical skill as they did on mechanical instruments. Since the nineteenth century, a longstanding desire to accomplish the autographic inscription of acoustic vibrations has taken shape in disciplines such as linguistics, acoustics and music. Such mechanic recording would allow sounds not only to become objectively registered but also to become universally readable (Brain, 1998; Hankins \& Silverman, 1995; Ingold, 2007; Kahn, 1999; Rieger, 2009). In the words of media arts theorist Douglas Kahn, such visible sound techniques and automatic recording instruments have since the eighteenth century been deemed to make "sound tangible and textual by making the invisible visible and holding the time of sound still” (2002, p. 180).

Mechanical images, it thus seems, have gradually come to replace the trained ear as an epistemic tool for many disciplines of sound analysis. In the light of the historical ascendancy of such mechanical visualizations in scientific practice, it is tempting to take the swift adoption of the sound spectrograph to signify a similar deliberate move towards visual inscription, to substitute for direct auditory experience. At first glance, these inscriptions do indeed seem to discard the human 'expert ear' in favor of the mechanical ear of the recording instrument. But such observations demand caution, so as not to get caught up into what Jonathan Sterne (2003) has described as a 'zero-sum game' of sensory modalities. One does not by necessity orientate one's sensory experience of the world exclusively, either visually or aurally. Understanding the ubiquity of sound spectrography in birdsong biology thus requires a careful consideration of how it has been embedded in an analytical and representational practice that, although surely ostensibly visual, was never entirely mute itself. Nor did scientists themselves always want or pretend it to be. In this chapter, I will thus attend to minutiae of the ways of analyzing and representing, listening and looking at sound that biologists of birdsong at the Cambridge Department of Zoology developed in their spectrographic work. 
In this chapter, I will argue that the sound spectrograph did not achieve the instantaneous intelligibility of a visual language that their users had anticipated, and that would allow them to avoid the problems of subjective intuition. In fact, as the notion of a universal spectrographic language proved difficult to maintain in practice, scientists could not always do away with listening experience completely. From the late 1950s onwards, the students of birdsong at the Cambridge Department of Zoology recognized that an efficient use of sound spectrograms occasionally required sensory and manual refinement as well as the intuitive judgment of an experienced ear. The extent to which the trained ear could be deployed in the analysis of mechanically recorded bird song was subject to controversy, however. Tracing the (sometimes unsuccessful or controversial) ways in which Cambridge students of bird song sought to negotiate the authority of spectrographic visualization vis-à-vis that of an embodied experience of sound, this chapter evokes Bruno Latour and Steve Woolgar's (1986) notion of 'inscription' to conceptualize how such visualization practices contributed to the science of bird song, and to understand how different inscriptive technologies ultimately were weighed.

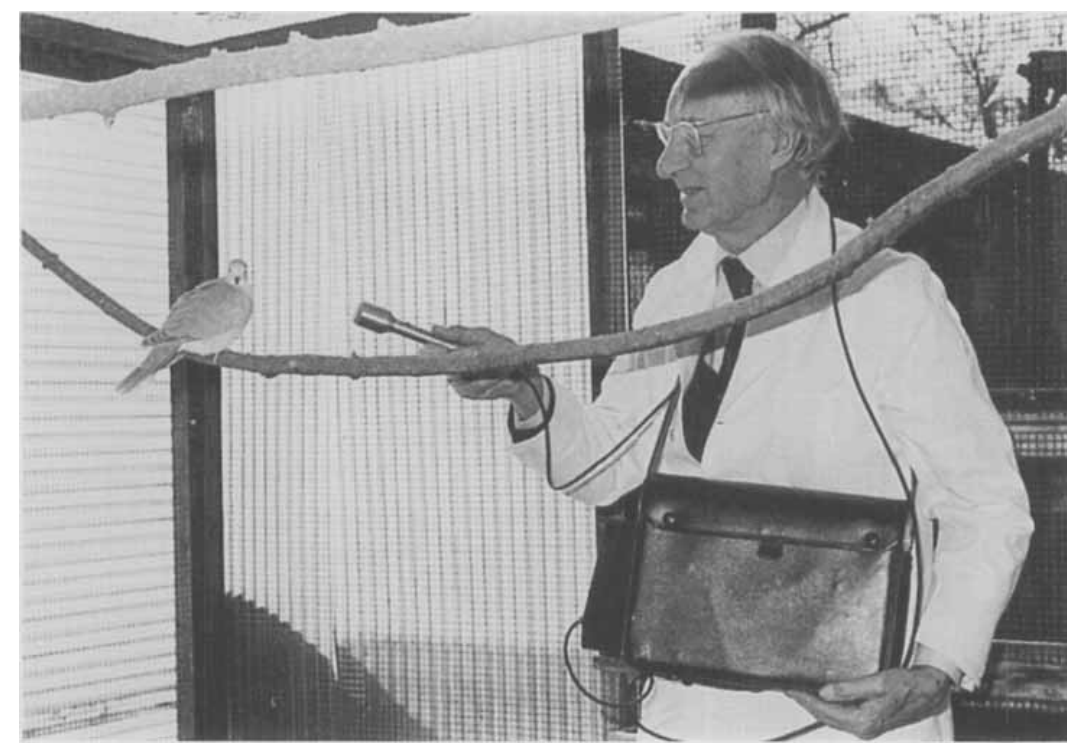

Figure 5.1

William H. Thorpe recording a dove at the Madingly Ornithological Field Station in Cambridge.

Photo courtesy of Les Barden. 


\section{Visible hearing}

The Bell Telephone Laboratories began developing the sound spectrograph in 1941. They initially had conceived of it as one of their telephone products, but it was soon rated as a classified project because of its potential military relevance. The instrument automatically broke down complex sounds into individual components and represented them in a visual order. This principle was expected to find useful applications in war-time cryptanalysis and naval intelligence, either to reconstruct and decode scrambled speech or to distinguish friendly and enemy naval crafts by their engines' signature sounds (Fehr, 2000; Marler, 2004; Radick, 2007). Immediately after the war, however, Bell Labs engineer Ralph K. Potter and his colleagues continued the project to develop the spectrograph into a commercial appliance for immediate translation of sound into script which, they hoped, would aid the deaf in using the Bell telephone (Potter, Kopp, \& Green, 1947).

The idea of converting sounds into script was not new. But when Potter and his colleagues first introduced the sound spectrograph to the public in a 1945 Science article and the 1947 monograph Visible Speech, they explicitly distinguished it from other such existing methods of sound inscription. Just like the Cornell ornithologists, phoneticians and psychologists had experimented with reading sound recordings from film, while acousticians had favored tested methods like strobophotography or audio-oscillators to study acoustic phenomena (Mills, 2010; Thompson, 2002). But such inscriptions, the authors now argued, were simply "unreadable to the eye" (Potter, et al., 1947, p. 4). The problem was not so much the resolution of detail but actual meaningful decoding. Oscilloscopes for instance displayed variations in acoustic energy over time, which was then displayed as a waveform (see figure 5.2). But although such waveforms provided crucial information on the physics of sound, they gave very few clues as to the actual auditory experience of the wave. Quite tellingly, Potter compared the oscillograms to lines of letters stacked on top of each other - much information indeed, but quite unreadable. In contrast, the sound spectrograph, which displayed a series of vertical shaded bands, plotted sound energy and frequency against a time dimension (see figure 5.3). As such, it did not represent an acoustic waveform but illustrated its actual perception (Mills, 2010). According to its developers, the sound spectrograph produced after all a "translation [of sound] similar to that made by the ear. It should spread out the dimensions of speech so that they were visible to the eye as they are audible to the ear" (Potter, et al., 1947, p. 4).

The spectrograph enables one to see what one hears, Potter explained, because it had been modeled on a schematic cochlea of the inner ear (Potter, et al., 1947, pp. 10-1). After all, the inner ear was believed to be made up of sensitive elements that each were tuned to a particular frequency and it was the sum of reactions by these elements that gave a physical sensation of tone. Analogously, the sound spectrograph automatically applied the Fourier principle by unraveling a 
complex sound into the simpler sound waves that constituted it. ${ }^{107}$ Put very schematically, the device would record a sound signal from a magnetic tape recorder, and then loop this signal through a filter that successively tuned to progressive frequency ranges. A stylus then traced the sound energy present in each of these successive frequency bands on a revolving roll of electrically sensitive paper. Inscribing these frequencies directly onto the paper - in a way similar to the mechanic inscriptions made on the wax cylinder - thus resulted in a frequency spectrum, measured in function of time, along with the sound's amplitude (Koenig, Dunn, \& Lacy, 1946).

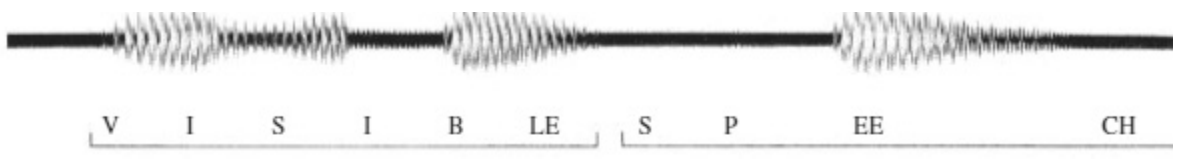

Figure 5.2

Original oscillogram of the phrase 'visible speech'.The horizontal axis expresses time, the vertical axis sound wave pressure.

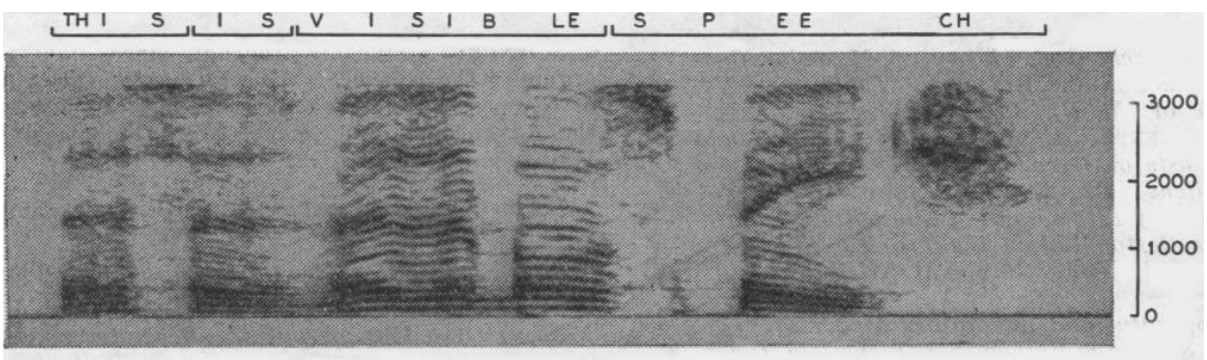

Figure 5.3

Original spectrogram of the phrase 'visible speech'. The horizontal axis expresses time, the vertical axis frequency. Amplitude is suggested by the darkness of the trace.

Bell's original idea to model the sound spectrograph on the human ear, however, had also served to substitute it for the deaf. As media historian Mara Mills (2010) explains, deafness systematically served as a pre-text for the development of sound inscription technologies. This pertained to the practical application of such technologies in deaf education, but the genealogy of 'visible speech' has also followed a more general conviction that it would be desirable and possible to substitute hearing completely by seeing. Mills quotes for instance Hans Günter Tillmann (1995), stating that nineteenth-century experimental phoneticians "assumed, first, that

\footnotetext{
107 The sound spectrograph does for sound what an optical spectrograph does for white light, by distinguishing it in its constituent color frequencies. Likewise, the sound spectrograph distinguishes a sound in its constituent sound frequencies, plotting them in relation to time and amplitude (loudness).
} 
speech could be exhaustively investigated as a purely mechanical process, and secondly that the listener could be replaced by a deaf observer." For scientists such as these, 'visible hearing' was not so much a physical necessity as it was an epistemic aspiration. The history of inscription technologies shows that such instruments were not only conceived of in terms of sensory prostheses for the deaf, but also as aids to able-hearing linguists and acousticians to transform sound into a scientific object (Brain, 1998; Sterne, 2003). These scientists aspired towards the conversion of sound into a set of readable signs, without losing crucial bits of information. Once sound could be 'read' from the image, subjective experiences of listening to the sound itself could then effectively be eliminated (Levin, 2006).

This was possible, the developers of the sound spectrograph explained, because both aural and visible languages were made up of patterns, and similar expressions were to have grossly similar patterns. Their preliminary evidence seemed to suggest that based on the so-called indexicality of sound and image, a new kind of visible $\mathrm{ABC}$ could be assembled that, with sufficient training, anyone could learn to read. Together with phoneticist George Kopp and his psychologist assistant Harriet Green, Potter set up a training program to test this assumption, by training five normally hearing women to master such visual language (1947). By the time the experimenters published their monograph, however, the project had not yet yielded conclusive proof that visual hearing was efficiently achievable. Meanwhile, researchers in the Haskins Laboratories had set out to tackle the problem reversely. Physicist Franklin Cooper and psychologist Alvin Liberman had designed a printto-sound machine to read out for the blind, but got stuck when their respondents failed to learn to 'read' the sounds (Fehr, 2000; Liberman \& Cooper, 1972). In order to learn more about the minimal parameters of intelligible speech perception, they experimented with playing back spectrograms on which they themselves had drawn simple patterns. While these experiments demonstrated that simple acoustic patterns could actually translate into simple visual patterns, as the developers of the spectrograph had anticipated, the displays of actual speech also proved too complex and ambiguous for a human listener to be able to read (Cooper, Liberman, \& Borst, 1951).

It soon became clear that the development of a truly visible language was far from completion, but the Bell engineers foresaw other applications. While human speech might be too complex for spectrographic reading, simpler patterns might display just fine. Potter himself had in his spare time been experimenting with the display of animal sounds that had been recorded by the Cornell Laboratory of Ornithology. ${ }^{108}$ His results suggested that their instrument would also enable biologists "to analyze, compare, and classify the songs of birds, and, of even more importance, it will be possible to write about such studies with meaningful sound pictures" (Potter, 1945, p. 470). A few years after linguists discovered the potential of the spectrograph, ornithologists followed suit.

${ }^{108}$ Ralph K. Potter to Arthur A. Allen, 29 June 1948, Kellogg Papers (CUL), 1:25. 
By 1952, the ornithologists at Cornell had arranged for access to a spectrograph through their colleague at the modern language department, Charles Hockett. ${ }^{109}$ Entomologist and amateur ornithologist Donald J. Borror had acquired first-hand experience of the spectrograph during military service and with Carl Reese secured access to one at the astronomy department of his home university (Marler, 2004). ${ }^{110}$ In Britain, meanwhile, a British engineer and amateur ornithologist alerted his fellow-ornithologists of the British Ornithologist Union to this existence of the device: "The wealth of information contained in such records is instantly apparent. What is perhaps even more important is their objectivity. To compare the song of one bird with another, or that of the same species of birds at different seasons, need no longer be a matter of mental impressions, difficult to convey, but can now be a question of instant reference and verification" (Bailey, 1950, p. 121). The author had also located one at the General Post Office Research Station in London and announced their willingness to accommodate serious researchers. ${ }^{111}$ William Thorpe meanwhile had located one at the Admiralty naval Research Laboratory, and called upon the help of its researchers for the analysis of the BBC recordings he had just acquired (Burkhardt Jr., 2005, p. 343). Within a year, he acquired a grant that allowed him to purchase a sound spectrograph to install at the Cambridge University ornithological field station at Madingley that he directed.

Spectrographs began to make their appearance in ornithological literature from 1953 onwards. Existing methods of analysis, they noted, had at best been subjective attempts. As William Thorpe noted, they had all suffered from "the primary difficulty of perceiving accurately by the naked ear elaborate sound patterns of high frequency, high speed and rapid modulation" (Thorpe, 1954, p. 465). Ohio biologist Donald Borror acknowledged that a naturalist such as Aretas Saunders possessed "an exceptional ability to analyze bird songs by ear" (1956, p. 211). But even in Saunders' graphic notation, Borror and his colleague Carl Reese observed, relevant "characteristics cannot be accurately determined by ear alone". Hence, they and several other papers published at the same time observed, "most accounts were merely subjective descriptions and not accurate analysis" (Borror \& Reese, 1953, p. 271; Collias \& Joos, 1953; Kellogg \& Stein, 1953). Even Saunders himself, looking back on a shift from "octaves" to "kilocycles" in bird song study, acknowledged the potential of the spectrogram for the study of bird song. "Writing from the standpoint of what the ear hears," he notes, his observations "may be more or less different from what the vibralyzer [a type of sound spectrograph] records" (Saunders, 1961, p. 598). Indeed, like Brand's sound-film had done before,

\footnotetext{
109 Peter Paul Kellogg to William Fish, 31 October 1951, Kellogg Papers (CUL), 3:34.

110 ("Science: Visible Bird Song," 1953) Cornell's commercial spectrograph would be modified to their needs by the linguist Martin Joos who, as a cryptanalyst for the US Signal Security Agency, had worked intensively on the instrument. After the war, he applied that expertise in his own phonetics research, while pioneering a project with zoologist Nicolas Collias in the study of domestic fowl.

111 The COLOSSUS war computer was developed at the G.P.O. Research Station for telegraphy and telecommunication.
} 
these spectrograms seemed to expose the perceptive limits of human hearing, particularly when it came to the time resolution of rapid bird songs. As Donald Borror and Carl Reese demonstrated in one of their first spectrographic studies, what had sounded as faint lisps or a single buzzy note to the ear, appeared clearly as a series of separate notes in the spectrographic image. In a familiar turn of phrase, they concluded that the spectrograph "will provide objective data that are more detailed and accurate than those obtained by most of the methods heretofore used" (Borror \& Reese 1953, p. 276). Likewise Thorpe concluded that while "vocalizations were formerly the most difficult of all [behavioral] releasers to investigate precisely, they have now become far more readily amenable to analysis than many patterns of visual and olfactory stimulation" (Thorpe, 1954, p. 465).

\section{Visual patterns}

Clearly, the sound spectrograph was expected to make the study of birdsong more precise. What then did it allow its ornithologist users to do more than they could by ear? An example from the way in which the sound spectrograph found its first applications by William Thorpe and Peter Marler at the Cambridge department of Zoology may make this insightful. When botany graduate Peter Marler first prepared to become a research fellow at Cambridge, he had already conducted on his own a large-scale study of chaffinch song based on a classification of chaffinch songs based on transcriptions made in France, the Azores, the Scottish Highlands and the British countryside (Marler, 1952). This study, which he had completed only by ear, had set out to debunk what seemed like a common misconception among field ornithologists, namely that birds display a regional variety and thus maintain a song that is regionally characteristic (Radick, 2007). Instead, he observed, chaffinches seemed to maintain an immense variety of different song types, so-called song dialects, which were differently distributed across different regions. Such variations, he speculated, could be explained by the way individual chaffinches learned their song. In a study on chaffinch song, the Danish ethologist Holger Poulsen (1951) had just suggested that at least part of the Chaffinch song is learned from adult birds in early adolescence. Hence, convergence could take place between the songs of birds in the same localities.

This force of adaptation, and its role in variation, became the subject of Thorpe's spectrographic experiments on the learning abilities of birds (Thorpe, 1951), extending Poulsen's experiments. Poulsen had reared two chaffinches in the seclusion of his laboratory that produced abnormal songs, which allowed him to specify some of the song elements that birds developed innately, and at what stage in their development these became modified. In similar fashion, Thorpe (1954) had isolated several groups of juvenile birds in aviaries and exposed them to different degrees to the songs of mature singing birds. This allowed him to control different stages of development and to establish which parts of their song birds acquired 
without learning. But whereas Poulsen had listed changes in song by ear, Thorpe reproduced these songs in spectrograms to inspect them visually. This enabled him to confirm or specify Poulsen's observations. The sound spectrograph enabled him to follow in more detail how songs developed over time (Radick, 2007). He found, for instance, that young chaffinches indeed seemed to possess a minimal 'blueprint' for their song, which determined among others its length and form. All other details had to be learned. Some elements, Thorpe observed, the chaffinch must have learned already in its first weeks, even before it sang itself, suggesting an instance of Lorenz' concept of 'imprint' to which Thorpe was sympathetic. The experiments also confirmed Marler's suggestion. Since chaffinches were shown to refine their song through imitation in their first spring, as they competed for territory where they stayed the rest of their life, their songs naturally converged in local, but nonetheless individually distinctive, patterns. But the spectrograms also demonstrated that even as chaffinch songs matured, they were not completely fixed. Some elements of its song displayed subtle differences between the first and second year, that Thorpe noted, "are so minute as to be practically imperceptible to the naked ear, although they will show up on the spectrograph" (Thorpe, 1954, p. 468). Spectrographic renderings supposedly portrayed the acoustic structure of a song, and it were exactly the minute variations in these structures that remained imperceptible to the human ear that caught the attention of pioneering spectrographers.

Comparisons of spectrographic representations made clear that individual bird song was much less stable than had been assumed before. It did so to such an extent that in a paper for a symposium on 'animal sounds and communication' for an American Institute of Biological Sciences symposium in 1958, Marler (1960) took the opportunity to take stock of some of the questions that these early spectrographic studies had raised. It had long been thought that the distinctiveness of a species' song served as a reproductive isolating mechanism. However, Marler pointed out, spectrographic studies of bird song made increasingly clear that variation was a much more prominent organizing principle than so far had been acknowledged. Such variation took place on several biological levels simultaneously. There was, of course, geographic variation, illustrated by the fact that chaffinches of the same species in the Azores sang less elaborately than in Britain. But within a single given geography, adjacent populations of birds also seemed to employ various song dialects. Moreover, even within a single population of birds, individual birds consistently varied their song to such a degree that experienced field observers could use it to distinguish between individuals. Finally, within a single birds' repertoire too, there could be up to hundreds of song themes. While such variations had to different extents been suggested by field observations before, spectrographic methods became adopted as a means for studying such variations much more systematically. The balance between the individuality of a bird's song and its conformity to local, geographic and specific patterns seemed to have been fine-tuned through adaptation and selection. Marler and Thorpe's early work seemed to have 
highlighted some of the mechanisms of variation in place for chaffinches, but as yet, they could only speculate as to its precise behavioral purposes.

A first step in beginning to answer these unfolding questions was to compile an adequate description of occurrences of variations on all of these levels for species other than chaffinch. By the end of the 1950s, this challenge had been confronted by several papers, such as those by Marler (1959; 1960; Marler \& Isaac, 1960a, 1960b), Donald Borror (1959, 1961), Wesley Lanyon and William Fish (1958), Robert Stein (1956), R. Andrew (1957) and Gerhard Thielcke (1961) reporting on audio-spectrographic analyses, while others refined experimental techniques to study the social functions of vocalization in the field (Weeden \& Falls, 1959). Traditional ornithological studies had restricted their focus to the song of a small number of individuals or a small population at most. These papers, however, collectively shifted their attention the inventory and comparison of song repertoires of several populations at once. The spectrograph moreover obliged them to organize their investigations differently. If the naturalists in chapter 2 had traditionally preferred elaborate and varied songs, these recordists necessarily turned towards birds whose repetitive and short songs could effectively be represented in a spectrogram. Around 1958, the spectrograph was limited to analyze and represent fragments of 2 to 4 seconds, and shorter, repetitive songs were more easily suited to the kind of analysis the spectrograph produced. Thorpe's favored experimental subject, the chaffinch, for instance had not only been selected because it bred well in captivity, but also because it allowed one to take representative samples of variation in their song. After all, he noted, it had "a complex but not too elaborate phrasical song of medium frequency range and convenient length" that was well-known to display local peculiarities (Thorpe, 1954, p. 466).

While the sound spectrograph had not been responsible for the observation of variation and inquiry into its mechanisms, its comprehensive analysis greatly facilitated, accelerated and amplified the kind of representation that actually benefited studies of variation on such a large scale. It allowed the analyst to focus not on specific features or parameters only, such as pitch or duration, as musical recordists had done before. Instead, the analyst adopted the spectrograph developers' view that "what the sonagrams show best is pattern".112 A spectrogram could be analyzed quantitatively or qualitatively, the latter by close inspection of the measurable characteristics of the sound spectrum displayed. Spectrographers thus examined and compared the visual print or 'structure' as they called it of a song fragment, often with regard to its shape and spacing. A typical paper of song dialects of the white-crowned sparrows by Peter Marler and by then his Berkeley colleague Miwako Tamura (1962) for instance, introduced a glossary to song components, such as 'notes', 'phrases' and 'syllables', that were distinguished not so much on the basis of their aural impression but on the basis of their visual shape. This distinction in

${ }^{112}$ CUL, Kellogg Papers, 1:22, Letter Donald J. Borror to Peter Paul Kellogg, 12 October 1961. 
visual components instilled a different conception of the structure of a bird song that allowed they would draw up detailed comparisons (figure 5.4).113

But even though the sound spectrograph had simplified the ways to read variations in song structures, doing so was not as straightforwardly simple as had been implied by the claims with which the spectrograph initially had been heralded. Despite the device's automaticity, producing useful spectrograms required selections to be made, settings to be decided upon, and images to be reproduced and eventually printed. For instance, the selection of the frequency interval or band (the unit of analysis) with which the sound spectrograph made its calculations affected the resulting image in important ways. At Cornell, this elicited from Peter Kellogg the observation that "the important thing about the [sound spectrograph] is that no one trace shows everything. The technique used in an analysis is very dependent upon the characters you wish to show or emphasize." 114 For that reason, practices for reproducing spectrograms could differ significantly and controversially.

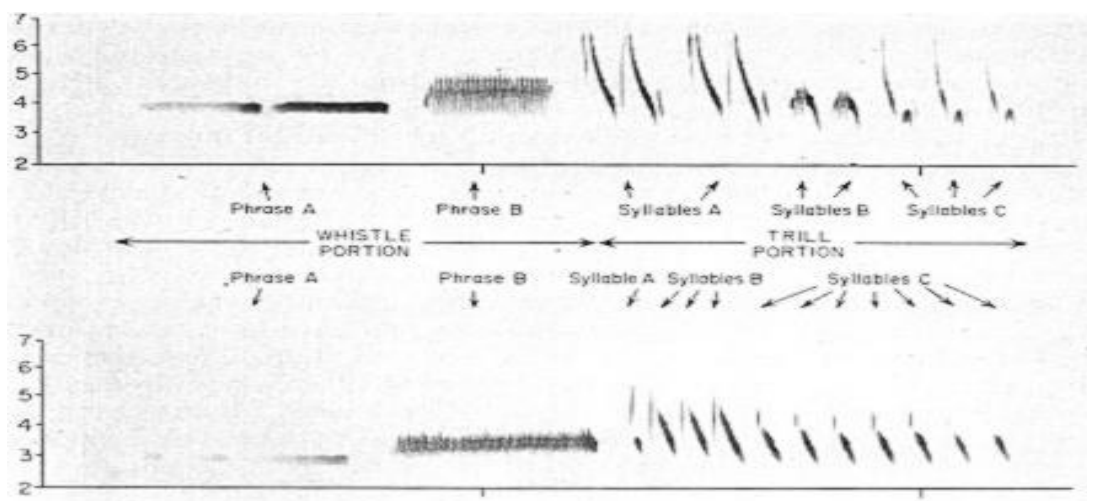

Figure 5.4

Visual model for dividing song 'structures' into analyzable components.

\footnotetext{
113 One of the results of this spectrographic atomism was that terminology once again ranked prominently among the controversial issues, as it derived directly from an uncertainty as to what and how to compare among species. A session on terminology during a unique bio-acoustics session at the International Ornithological Congress in 1962 discharged "almost a riot[:] divergent and strong opinions came from every quarter and it was obvious that we are still in a very elementary stage on that score." As individual researchers and research groups gradually developed more detailed analysis of song segments, terms that were adopted from music or linguistics took on deviating meanings. Such problems in defining a standard terminology for the acoustic components and patterns under study was persistent at least for the following two decades and even by the end of the twentieth century was not completely resolved. See (Baker, 2001; Shiovitz, 1975).

114 CUL, Kellogg Papers, 3:39, Letter Peter Paul Kellogg to Crawford H. Greenewalt, 11 October 1962.
} 


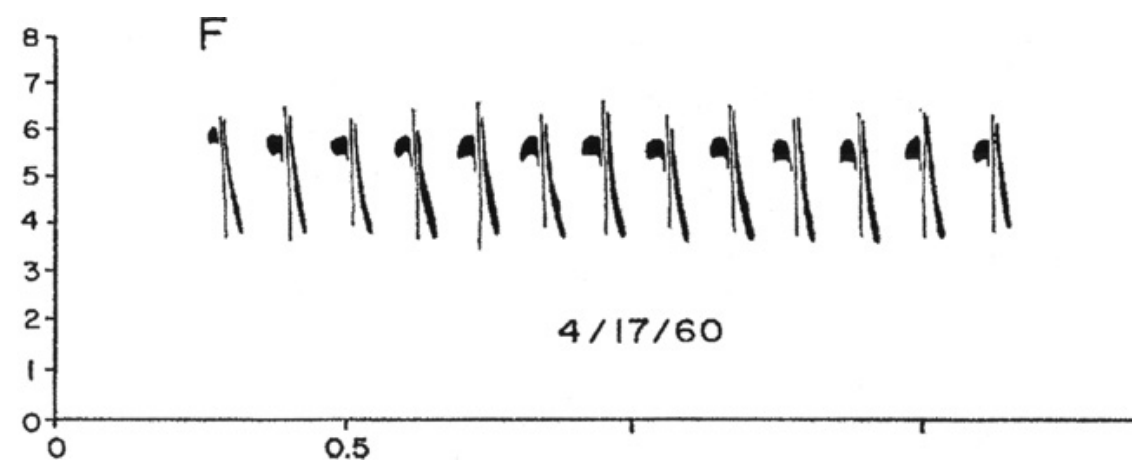

Figure 5.5

Ink tracing by hand of a spectrogram.

Some users found that the analytical wealth of data in the spectrogram actually prohibited a good understanding of its spectral properties. In a note on the illustrations to his 1961 monograph on bird song, for instance, William Thorpe explained that "for many purposes of the student of bird behaviour, and for the general ornithologist, sound spectrograms contain a great deal more information than is relevant to the particular point at issue." For that reason, he had found it often "advantageous to reproduce [the spectrograms] in a somewhat diagrammatic and stereotyped form which draws attention to the main items of information without confusing the picture with a great deal of irrelevant detail" (Thorpe 1961, p. xii). Indeed, in order to highlight relevant 'structures' and mark significant 'patterns' in a song phrase, the biologists associated with the Cambridge Department for Zoology traced the original spectrograms with pen and ink. Alternatively, they sometimes reproduced them as high-contrast photographic plates. This not only facilitated their reproduction in print but, as Marler and Tamura (1962, p. 369) noted, also allowed them to retouch the copies with white paint in order to mask traces of 'background noises' that had been picked up by the microphone (figure 5.5).

Indeed, the majority of spectrograms from this period that are kept in the archives of the Cambridge Department of Zoology and the Berlin Tierstimmenarchiv has been adjusted to some degree, which illustrates that such interventions were carried out regularly and routinely. ${ }^{115}$ In a note on spectrogram publications for contributors to the ornithological journal The Condor, biologist William Thompson suggested for instance that authors should prepare spectrograms for publication by photographing them with high contrast film to produce a strictly black-andwhite print. Not only was this found to be less expensive to print than original halftone images, Thompson also added that "with this method the markings of extraneous sounds may be opaque out with paint or white correction fluid" (Thompson, 1979, p. 220). Quite aptly, Mundy (2009) has described this process as calligra-

115 In fact, all the spectrograms that have been archived at the W.H. Thorpe papers in Cambridge show some form of corrective intervention (Field Notes CaUL Thorpe Papers). 
phy, because it required skillful penmanship as well as a sharp sense for which traces could and should not be eliminated in order to preserve a spectrographic pattern's 'essence'. This was a delicate process, by which contrast and sharp or faint features were adjusted, in part by relying on the author's auditory impressions of a sound.

But the suggestion of calligraphy is apt also in another, unsuspected way. Clearly influenced by the sound spectrograph's developers' expectations of an objective sound language, Thorpe and his assistant Barbara Lade suggested that the sound spectrograph might not only provide a means for objective analysis, but even for objective notation (1961). Such a notation, they argued, would be objective and precise, but at the same time allow them to be read and used by the field student, thus bridging laboratory analysis with field experience. To this end, Thorpe and Lade had begun to develop a series of conventional symbols for bird song types, based on their spectrographic shape. They halved the time-scale and doubled the frequency axis which resulted in long curved brushstrokes of different thickness (Figure 5.6). With distracting information eliminated to show just "the essence of the pattern", the symbols would allow readers to recognize a sound by their spectrographic shape just as birdwatchers recognized a distant bird by its 'jizz', an essential character that could unambiguously be perceived (Law \& Lynch, 1988; MacDonald, 2002). However, the notations also placed a considerable strain on the reader. Most producers of spectrograms used a setting that represented sound on the linear scale of frequency, while human listeners generally perceive pitch logarithmically in relation to frequency. ${ }^{116}$ This made it difficult to translate a physical measure back into the subjective pitch by which field ornithologists perceived a sound in the field (Hold, 1970).

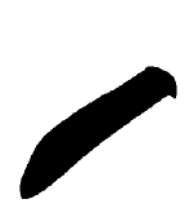

iii a
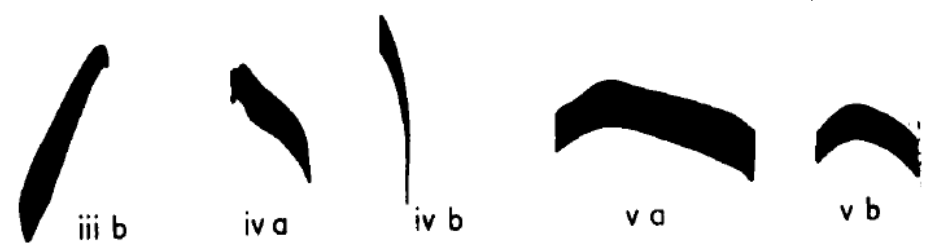

F1GURR 5. Simple notes of longer duration: a. sonogram, b. notation. i, Red-eyed Towheo Pipilo e. erythrophthalmus. ii, Whitethroated Sparrow Zonotrichia albicollis. iii, White-eyed Towhee P. e. alleni. iv. Willow Warbler Phylloscopus trochilus. v, Icterine Warbler Hippolais icterina.

Figure 5.6

Thorpe \& Lade's diagrammatic notation based on sonagrams.

As a result, this 'objective' notation would hardly be of actual use as a notation in the field. The reduction of the spectrogram's visual complexity to a diagrammatic

${ }^{116}$ Every single octave in pitch thus equals a frequency that doubles in hertz. 
pattern would, however, prove a useful approach to categorize song fragments (Grimes, 1966; Kroodsma \& Miller, 1980; Thompson, 1970; Thorpe, 1961b). Indeed, the improvement of spectrograms was not just a matter of aesthetic taste - it served an analytical purpose too. By adjusting these visual traces, the analyst achieved, after all, a much greater control over the audible phenomena themselves, allowing him to make a more precise distinction between 'noise' and the scientifically interesting 'sounds'. In this sense, this graphic intervention is oddly comparable to the parabolic microphone that I discussed in chapter 3, and the sound-proof rooms that Thorpe introduced in his laboratory (Thorpe \& Hinde, 1957). Both the microphone and the stylus are mechanic instruments geared not only towards the fullest and most objective representation, but also to the strategic selection and categorization of an acoustic phenomenon. For both techniques, the mechanical processing of sound also enabled the recordist to distinguish and eliminate unwanted noise from desired information. In this regard, noise referred interchangeably to acoustic interference as well as scrambled information, which were both unintelligible and unpleasant at the same time. Just as the close-up recording sampled the sound against a seemingly generic, mute backdrop, such calligraphic techniques too placed the visualized sound against a white, and therefore equally 'mute', background (Bruyninckx, 2012). Visualization thus functioned as a powerful filter to distinguish pattern from noise.

But while for Thorpe and his former students such enhancements of the original spectrogram served an analytic purpose by enabling further categorization (of song types, of noise and information, of patterns), such attempts to make spectrograms more readable to the eye were not embraced by all. In the United States, Thorpe's new book and especially his casual note on reproducing spectrograms had been received with astonishment. Cornell ornithologist Robert Stein and Ohio bioacoustician Donald Borror prepared critical reviews. Likewise, Cornell ornithologist Peter Kellogg found that

[Thorpe's] idea that, for economy and perhaps for neatness, it is a good idea to trace spectrograms rather than to reproduce them directly, is a technique which I most seriously question. In tracing a spectrogram, so as to clean it up, and also so that it may be reproduced as a line drawing, it is almost impossible to keep from changing the picture a little so as to make it more precisely fit your ideas. This results in emphases which were not present in the original and in the omission of everything which you consider to be, but which may not be, an artifact. In one instance, this technique had led to the inclusion of material not in the original. ${ }^{117}$

117 CUL, Kellogg Papers, 8:1, Letter Peter Paul Kellogg to Gustav A. Swanson, 30 January 1962. CUL, Kellogg, 6:19, Letter Peter Paul Kellogg to Myles E. North, 30 January 1962. 
In contrast, Kellogg favored as little intervention as possible: "I am in favor of publishing spectrograms as they come from the machine rather than to trace them so as to emphasize the pattern and eliminate any details which the author considers at the moment to be of no importance."118 Kellogg admonished his colleagues and research associates to take reproduction seriously: "I would like to see the spectrograms [...] authentically reproduced so that they could be used for study with the same confidence as one could use the originals. It might be necessary to reduce some of them slightly, but this should not hurt them much."119 He also carefully deliberated with colleagues and printers to achieve such authentic reproduction as best as possible. As he questioned a colleague at the American Institute of Biological Sciences about their reproduction processes for a publication he contributed to, they found that results differed significantly with printing techniques and that printers were often "amazed to find that I preferred it to be grey". ${ }^{120}$

Well-reproduced spectrograms even became a marker of professionalism. Cornell research associate Irby Davis suggested that badly reproduced spectrograms by a Cornell researcher reflected poorly on the institute's reputation: "Everything else, the drawings, paintings, and the photography are of excellent professional quality. But the spectrograms are terrible [... ] Since the Lab is known all over the world as the leading place for sound work on birds it will be a bit hard to explain how such bad work was permitted to come out from the institution."121 The differences in standards applied to spectrographic imagery also fuelled suspicion regarding Marler and Thorpe's results among ornithologists at Cornell. Particularly Davis, a retired civil engineer who had developed an expertise with the sound spectrograph, dreaded what he considered Cambridge researchers' lack of expertise in acoustics and electrical engineering. Whereas technically-minded ornithologists at Cornell and elsewhere had taken to rewiring and modifying the commercial Sonagraph to their advantage, he believed, Marler instead had simply black-boxed the instrument. This 'ignorance' would cause him to read mechanic artifacts or, even worse, theory into the spectrographic data. ${ }^{122}$ Because such criticism threatened to strain relations between the groups of bio-acousticians, Kellogg instead sought to ingrain other bio-acoustical researchers with the possible pitfalls of spectrographic analysis in a series of articles featured in the Bioacoustics Bulletin that he had just instituted at Cornell.

But however subdued they may be, such skirmishes are illustrative of the variety of practices that had emerged around the sound spectrograph by 1960, and the different gestures of objectivity that their users developed in these sound-images.

\footnotetext{
118 CUL, Kellogg Papers, 1:22, Letter Peter Paul Kellogg to Donald J. Borror, 26 October 1961.

${ }^{119}$ CUL, Kellogg Papers, 3:3, Letter Peter Paul Kellogg to L. Irby Davis, 20 April 1962.

${ }^{120}$ CUL, Kellogg Papers, 1:22, Letter Richard E. Barthelemy to Peter Paul Kellogg, 14 August 1961.

${ }^{121}$ CUL, Kellogg Papers, 3:3, Letter L. Irby Davis to Peter Paul Kellogg, 5 February 1962.

122 CUL, Kellogg Papers, 3:3, Letter L. Irby Davis to Peter Paul Kellogg, 15 February 1961. CUL, Kellogg Papers, 3:39, Letter Peter Paul Kellogg to Crawford H. Greenewalt, 13 February 1961. CUL, Kellogg Papers, 3:3, Letter Peter Paul Kellogg to L. Irby Davis, 2 December 1960 and on.
} 
For their critics, it had seemed after all that Thorpe or Marler's spectrograms permitted a dangerously subjective influence on their analyses. The commitment to an exclusively mechanically restricted interpretation of visual data that this critique displayed, echoes again the discourse that Lorraine Daston and Peter Galison (2007) labeled as 'mechanical objectivity' and that we have also seen inscribed in the electrical microphone. Marler and Thorpe, for their part, did trust the perceptive qualities of the machine more than their own. But the cluttered image and incidental detail, they found, also compromised effective analysis. They thus relied as much on the informed and experienced user as they did on technological means to distill from the noise a more sophisticated, distinctive image. This discourse in turn corresponds in important ways with what Daston and Galison have termed 'trained judgment', a twentieth-century supplement to the doctrine of selfelimination in mechanical objectivity that did leave room for skilled interpretation and expert judgment. The ideal of 'trained judgment' did not reject objective instruments right out, but unlike 'mechanical objectivity' it did permit a role for intuition and cultivated perception alongside the protocol-based image to distinguish salient and significant structures, categories or patterns. Likewise, these Cambridge zoologists had developed a spectrographic practice that permitted, even required, a trained observer to order complex acoustic information for the reader. By relying only on the indiscriminate procedures of the sound spectrograph, the biologist would risk, after all, obscuring exactly those detailed structures and patterns of variation that scientists had developed a theoretical interest in. As I will show in the next section, this regime of trained judgment extended not only to 'spectrographic' patterns, but also to listening for aural patterns.

\section{Aural patterns}

Clearly, despite the claims for objectivity and universal intelligibility with which the spectrograph had been heralded, these traits themselves remained matters of local negotiation. Although sound spectrographers pursued mechanical sound analysis to circumvent subjective impressions, the realities of spectrographic visualization nonetheless seemed to require of some analysts a skilled hand and perceptive eye and ear. But embodied aural experience informed analysis of bird song also in other ways.

Chapter 4 has shown already that listening continued to play a significant role in the field collecting and identification of bird song records. These experiences also resonated in research papers based on such field work. Since it was impossible to record all aural experiences on tape, such observations were often accounted for verbally. Verbal descriptions of the vocal behavior of a bird appeared instead of or alongside spectrographic analyses, as part of the ethological descriptions of behavior in both behavioristic journals such as Animal Behaviour and traditionally ornithological journals such as The Auk. These papers relied on rudimentary descriptions 
and syllabic notations, to give an impression of how the sound might appear "to the human ear". This phrase in particular flagged a purposefully subjective and descriptive account that evoked information that could not be conveyed otherwise or marked a perceptive minimum to orient the observations of other ornithologists. The persistent presence of the observer's ear is illustrated by British ornithologist Derek Goodman's comparative analyses of bird vocalization behavior. In a series of descriptions of blue waxbill calls, Goodwin (1965) noted for instance that its contact call, “a loud, clear, high-pitched 'tseep-tseep' or 'sweet-sweet' with a somewhat interrogative tone [, . . . ] does not, to my ears, usually sound squeaky." And although this call might easily be confused with that of a related species, "the experienced ear can usually identify the caller." For other calls, "I cannot distinguish by ear which of the three forms is calling” (Goodwin, 1965, pp. 287-90).

Aural observations also provided an evidential basis for further statistical analysis. This was often the case when monitoring the results of playback experiments and observations of behavior in the field. Observers listened not only for whether a bird responded or not, but also what exactly had been responded. In a study to investigate how cardinals may adjust and coordinate their song patterns to the song of neighboring birds by playing back pre-recorded songs, McGill biologist Robert Lemon noted that "the data was recorded by hand after identification of the songs by ear. This method is feasible with cardinals because of the relative simplicity and stereotypy of their patterns of song" (1968, p. 158). In a later study in which he had sought to explore the statistics of variations in sound patterns, he and his co-author noted that although all songs had dutifully been analyzed with a sound spectrograph, "much information, however, especially relating to the sequences of different song types, was gathered by listening to the birds sing and then recording the data in a notebook" (Lemon \& Chatfield, 1971, p. 1).

However, aural experiences did not remain exclusive to field observations only. Sometimes they also played a role in the organization and interpretation of sound spectrographic data itself. Analysts for instance occasionally reported their reliance on a kind of discriminative listening when considering song types in the laboratory. While most papers did not include details on the ways in which such data had been classified, these explicitly invoked aural experience alongside spectrographic renderings as an aid to interpret and compare sound fragments or distill analytic classifications. This was the case for instance in some of the first spectrographic studies. When classifying Carolina wren song phrases for the variations they displayed with regard to number, length and notes, Donald Borror (1956) had evidently relied on the sound spectrograph. But in drawing up his classification of song phrases, he had found that the chief difficulty had been in defining the beginning and end of a song phrase on an image. This was important, because "a different delimitation of the phrases would for most songs result in a different classification" (p. 223). Here he had found that spectrographic imagery could best be combined with listening to the recordings played at reduced tape speed. In a comparable vein, at Cambridge, William Thorpe observed that recorded sounds could be 
studied by a variety of means. Of course, the sound spectrograph seemed "by far the most valuable method". Yet "play-back at the lower speeds is an enormous aid to the ear, particularly with sound patterns [... ] having extremely rapid repetitions and relatively high frequencies. [ . . . It sometimes happens that comparison of songs of related species at decreased speeds brings to light resemblances which would otherwise have escaped notice" (Thorpe, 1958, p. 542). In such cases, the sound spectrograph could again help to verify and corroborate those observations that had been made by ear.

Such discriminative listening continued to play a role even when sound spectrography had steadily been consolidated as the standard tool in bird song biology. Around 1975, British biologists Marler and Mundinger for instance reported that the seven types of vocalizations that they had distinguished in their field study had been "classified by ear and by sound spectrographic analysis" (Marler \& Mundinger, 1975). Here, aural observations made in the field and spectrographic analyses had both fed into the categorization. On a similar note, British biologists Slater and Ince (1979) reported their reliance on experienced listening in drawing up a classification of the songs they collected in the field. When preparing spectrograms of each song type, they had found that "with practice many of the more distinctive song types could be identified by ear" (p. 148). These identifications were made even easier by listening to slowed down recordings, while having the typical sonagrams in hand. Checking their identifications by spectrographic analysis, the authors reported finding a host of reliable features that could help distinguish between some similar-sounding song types, and had failed to find them for a few others. Hence the balance between listening and looking depended on the task at hand, as well as the types of sound being listened to.

In some cases, they had found, the differences between song types had looked slight on the sonagram, but the authors had nevertheless chosen to classify them separately, on the basis that certain differences in quality had been "immediately recognizable in the field on the first occasion that song type Y was heard" (Slater \& Ince, 1979, p. 157). Another category had been formed by song types for which "there is no doubt that they should be regarded as distinct because the differences in form between them are consistent", even though the authors had been "unable to separate them reliably by ear" (Slater \& Ince, 1979, p. 157). Trained judgment thus operated at two levels. First, it helped the recordist to recognize similarity relations, family resemblances and distinctive types in the diversity of records. But in a second and related way, trained judgment also involved a keen awareness for when particular judgments could dependably be relied on or not. A trained observer was able to tell, for instance, when aural impressions could authoritatively trump the evidence suggested by a spectrogram.

In any case, listening was not to be applied unrestrictedly, and should only supplement mechanical records. Slater and Ince (1979) after all also found that some of their observations on chaffinch song variation did not match Peter Marler's earliest study on chaffinch variation, which, as a student, he had completed 
entirely by naturalist standards, meaning by ear and pencil (1952). The discrepancy in some observations, they noted, was probably due to the fact that Marler's original collecting and analysis had been carried out by ear alone. And while most end phrases of a chaffinch song might reliably be recorded by ear, its extremely rapid trill usually displayed differences that were particularly hard to notice by the human ear without a sound spectrogram. Thorpe and his colleagues acknowledged that "any study of sound presupposes the use of the ear, [ . . ] if the task is not to become cumbersome and time-consuming out of all proportion to the results achieved" (Thorpe, Hall-Craggs, Hooker, Hooker, \& Hutchison, 1972, p. 134). Spectrographing and comparing hundreds of records was a cumbersome and timeconsuming task, which could sometimes be performed more efficiently by the analyst when relying simply on his ear. But this reliance on aural experience should by all means be qualified by a record, since "human aural perception [... ] tends to reduce disorder to a preconceived order and may categorise within the familiar apperception masses those aspects of a study which, when considered with complete objectivity, may be most likely to lead to new notions and syntheses" (Thorpe, et al., 1972, pp. 134-5). For that reason, they suggested, a study of sound patterns was generally to "begin with aural classification and continue with suitable methods of mechanical analysis" (ibid., p. 135).

The trained listener that these spectrographic studies presupposed was thus different from Witmer Stone's trained musical listener described in chapter 2 or Albert Brand's all-too-human subjective listener described in chapter 3. Listening did not feature here as a distinctive skill, nor did it stand in direct opposition to the mechanical image. The interpretation of mechanical images required some sort of sensory and manual refinement; importantly, this was not an explicit or methodical approach, but a perception cultivated through immersion and experience with the sounds under study. Indeed, the experienced listeners implied in these papers did embrace the mechanical objectivity of a spectrographic image, but they had also developed an intuitive understanding of how to make such objective records work most efficiently. Interestingly, then, the identification of the patterns, categories and structures that biologists were interested in could not only based on a spectrographic morphology, but also on aural experience. Despite the assumption of congruity between aural and visual patterns underlying the sound spectrograph's original design, some aspects of bird song could not be captured by the spectrographic image alone. Hence the analyst occasionally also relied on the ear to adjust, categorize, classify sound; always, however, in conjunction to the mechanical record.

\section{Musical patterns?}

In fact, however persistent listening could be to the routine of spectrographic analysis, the authority of the trained ear itself was carefully delineated. Such restrictions to the domain which trained listening could be deployed became most clearly artic- 
ulated in the 1960s and 1970s when a handful of researchers expressed discontent with the standard spectrogram and began to codify bird sound in new, unconventional ways.

Among them were a few biologists and musicians that gravitated around William Thorpe at the Cambridge department of Zoology, who himself had begun to develop an interest in musical notation as an analytic tool. By 1962, Thorpe had shifted his attention from chaffinch song variations to the ritual "duet" vocalizations of male and female shrikes, and he had found that in order to appreciate exactly how these birds developed their song patterns through interaction, their variations could best be noted down musically. When sounds were used for communication, and particularly when they were of a musical nature, he noted, it was necessary to consider the ear rather than a mechanical instrument as the analyzer. One could assume, after all, that "since its essential structure is similar, the avian ear is subject to the same distortion" (Thorpe, et al., 1972, p. 135). To that end, he had started to develop a technique for musical transcription together with Myles North, a research associate of the Cornell Lab of Ornithology stationed in Kenya and an expert on musical transcription of bird song (figure 5.7). ${ }^{123}$ At Cambridge, he also collaborated with Joan Hall-Craggs, a professional musician with an interest in blackbird song, and composer Trevor Hold, whom Thorpe encouraged to develop a musical notation better suited to represent bird song. Importantly, these notations never found wide acclaim within the field of bird song biology. Yet these notations and their reception do give us some insight into the ways in which the domain of trained listening was demarcated.

These Cambridge researchers adopted musical transcription techniques because they were interested in a specific research problem. What they were interested in was to show not that birds developed their song, but how exactly they did so and according to which principles. And to demonstrate such developments qualitatively, they found, musical notation was as well suited as the shapes of acoustical structures produced by the sound spectrograph. In order to study how birds elaborated their song patterns through ritualized interactions, Thorpe noted, it was "essential to put [these songs] first into staff notation so that I can get certain things clear for myself and have the songs in a form which I can show to musical people and get their help and advice." 124 Even though such notations were not to suggest that bird song itself was inherently musical, they did bring to light several (aesthetically pleasing) patterns that suggested 'musical inventions' that had seemed to transcend biological requirements. Thorpe noted that "whether the musical tonal system employed and the manner of using it provides any justification for assuming the beginnings of a true artistic ability is still an open question" but it would "be dishonest to suggest that the biological theories at present available offer a com-

\footnotetext{
${ }^{123}$ CaUL, Thorpe Papers, Ms.Add. 8784 W.H.T. Set 8ii Folder II. For North's involvement in bird song transcription, see North (1950).

${ }^{124}$ CaUL, Thorpe Papers, Ms.Add. 8784 W.H.T. Set 8 ii Folder II.
} 
plete explanation for all bird vocalizations" (Thorpe, 1966, p. 357). Similarly, professional musician Joan Hall-Craggs had recorded and transcribed blackbird song in musical score, to conceptualize how the bird reorganized its song patterns in a way that had seemed to transcend their purely biological function. Hall-Craggs noted that since she was "a musician with the sole qualification in the study of bird song of being trained to listen to detail, it would be presumptuous to try to draw conclusions from this analysis". Yet it would be conceivable that the biological functions of blackbird song mixed with an aesthetic sense, even though, she realized, this was no easy hypothesis to accept as yet (Hall-Craggs, 1962, p. 294).

Although such observations might suggest a tendency to anthropomorphize bird song, these researchers noted that their methods had not surrendered accuracy or objectivity. Even for musical transcription, their trained ears had depended on mechanically objective records. Thorpe and Hall-Craggs had combined their interpretation of musical transcriptions with spectrograms of those records. Moreover aural transcriptions had only been made on the basis of tape recordings, which had allowed them to slow down the original sounds to half or even one sixteenth of the original speed. As such, the listener had been able to transcribe the rapidly uttered bird songs by ear in minute detail, with a corrective factor for transposing them back to their 'original' speed.
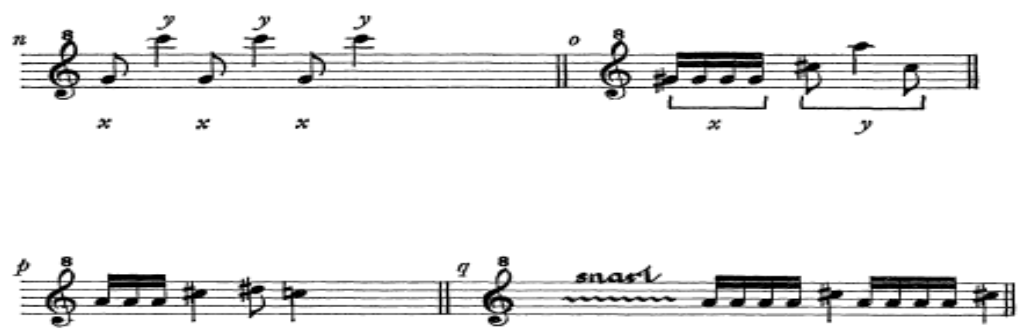

Figure 5.7

Musical notation of duetting Shrikes by Thorpe.

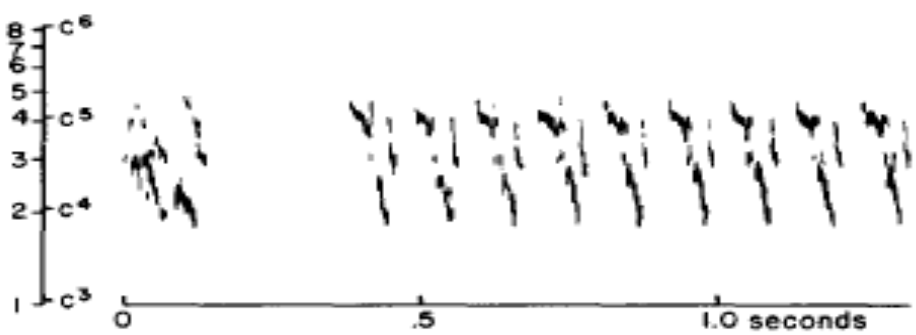

Figure 5.8

Adapted spectrogram fitted with logarithmic scale and musical octaves. 
Similar attempts to pair objective analysis with musical notation have been made outside the Cambridge department of Zoology too. In studying what Brown Towhee songs communicated to their conspecifics, ornithologist Joe Marshall Jr. had converted the linear frequency scale that recordists conventionally applied in the spectrogram to a logarithmic frequency scale. Spectrographers usually preferred the linear scale, because it compressed the frequency ranges and showed more detail. The logarithmic scale, however, presented frequencies as they would be experienced audibly, and thus could be fitted with musical octaves (figure 5.8). This was important, Marshall added, because "it is pitch and not frequency to which our hearing and that of the birds respond in nature, and for this reason the gross stretching apart of musical intervals in the upper part of the ordinary sonagram is absurd!" (Marshall Jr., 1964, p. 347).125 This led to a different perspective as well. Spectrographic studies of the same species had characterized objectively the variations in their song. But when it came to individual recognition among these birds, Marshall Jr. suggested, "many of the variations shown by the sonagram may be reducible audibly to a few, even granting that birds' ears are much more sensitive than man's" (1964, p. 354). Objective measurements of sound were thus to be complemented by audible impressions.

These initiatives and arguments found little resonance in the field of bird song biology initially, but by the late 1970s, they unfolded into controversy on the (dis)advantages of sound spectrography. Although indicatively minor, this controversy does give a good insight into the dynamic between looking and listening implied by practices of sound spectrography. In 1977, Marshall Jr. published a note repeating his call to abandon the linear scale in sound spectrography "because it resembles nothing in the real world". The logarithmic scale, on the other hand, "is reproducible and, like a musical score, constitutes a universal "language" or symbolism by which sounds can be recognized visually by their shapes on a graph" (Marshall Jr., 1977, p. 150). At Cambridge, Joan Hall-Craggs (1979) also lamented bird song biologists' attachment to a spectrographic standard that revealed nothing about sound patterns in the natural world: "I find it disquieting that auditory stimuli are often discussed in visual terms, for example, vertical and horizontal lines and streaks, chevrons, zigzags and various shapes. This may be due to the difficulty of imaging sound patterns as such when looking at unfamiliar sonagrams" (ibid., p. 185). Therefore she suggested that sound spectrograms could be made that, "while maintaining the objectivity of the analytical process, are (1) presented in a form more accessible to the auditory imagery of readers and (2) comprehensible in musical terms" (ibid., p. 186). This could easily be done, for instance by superimposing a musical score onto the sonagram (figure 5.9 and 5.10). After all, "the capacity for mental rehearsal and the memorizing of sound patterns [ . . should] be developed

125 Instrument manufacturers of commonly used spectrographs, such as Kay Electronics, later added a logarithmic display module to their commercial sound spectrographs but even then, the setting was barely used in practice. 
and fostered rather than allowed to atrophy through constant translation from sound form to visual form, even though the latter is indispensable for publication purposes" (ibid., p. 185).

This proposal was received critically, however, in a commentary in The Condor. Its author Edward Miller, objected that even though many of HallCraggs'suggestions might have "heuristic value [, . . . ] they are clearly biased: musical qualities of sound are defined by our perception" and that in order to find them, Hall-Craggs had focused on an insignificantly small fraction of all possible animal sounds. Moreover, "a musical (or other) notation of bird song implies a particular kind of structure or order. We must be careful not to assume that such order exists, just because of the system of notation used". Of course, he granted, "new methods of describing behavioral structures are important to the development of ethology. The value of some lies in their particular applications or in the insights they yield [ . . . ] The value of others will come from their objectivity, repeatability, ability to deal with detail, and wide-spread applicability. Conventional oscillograms, power spectra, amplitude sections and sound spectrograms offer these advantages" (Miller, 1980 , p. 234). A few years earlier, two other biologists, Charles Dobson and Robert Lemon (1977) had published a critical report on the perception of musical intervals in bird song which had a similar import. They had checked their own data on frequency intervals in white-crowned sparrow songs as well as Thorpe's own published data, but had found no significant indicator that those intervals correlated with fixed musical intervals. Thorpe's data could only be correct, they argued, because he had used two different scales simultaneously: "by doing so, closer conformity to musical scales could not help but occur" (ibid, p. 889). "Using such methods [as adapted musical notation]," the authors noted, "musicians such as Messiaen have been able to simulate natural bird song with some success. But the use of the standard musical notation commonly employed may lead one to overestimate the musical nature of bird song" (ibid. p. 890). The problem with musical notation, in other words, was that it implied a preconceived structure that led to subjective projections.

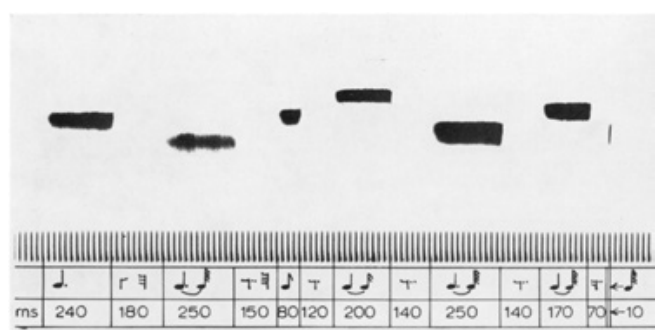

Figure 5.9

Sound spectrographic analysis of a wren song, with logarithmic scale and musical score imposed.

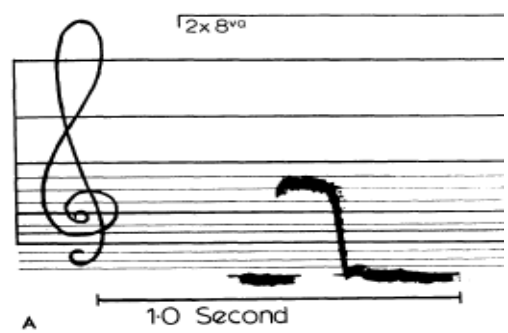

Figure 5.10

Musical stave made by a sound spectrogram, imposed with microtone intervals. 
This exchange of commentaries did not make significant waves in the field. At this point we may take it, however, to put into relief bird song biologists' epistemic investments in both the trained ear and the sound spectrograph. By combining spectrographic visualization with musical listening, this select group had not only welded together two distinct technologies that mediated and structured the acoustical world in very different ways (linearly and logarithmically) and that had constituted such strongly oppositional traditions since the 1920s and 1930s (see chapter 2 and 3). They had also sought to establish what had initially been the defining feature of the sound spectrograph: a natural language of sound that enabled not only an objective, but also transparent, immediate and intuitively intelligible representation of sound. A visual language, in other words, that bridged the objective physical properties of sound in the laboratory with their subjective, psychological experience in the field. Of course, the concept of visible speech underlying the sound spectrograph had proven unfeasible in its practical applications. Visual spectrographic patterns were not by definition congruous with aural patterns nor were they always immediately intelligible to the reading eye. At the same time, the concept (or rather, desire) did surface, albeit implicitly, repeatedly in the notational innovations developed at the Cambridge Department of Zoology - Thorpe's proposal for a diagrammatic notation or Hall-Cragg's notation of a musical spectrogram. Although these notations were never widely spread, they are significant in a media archaeological way. They signal a persistent concern with the conversion between 'objectively' textualized sound and its embodied experience that connects the Cambridge biologist in the 1970s with the naturalist in the 1910s. In both periods, students of birdsong sought to combine accurate, detailed analysis, visually, with an intelligibility that allowed sounds to be senses, aurally. In both periods, also, proponents recognized in musical notation a way to communicate sound effectively, while its critics objected to musical notation because of what they recognized to be a preconceived and therefore subjective format.

Apart from Miller's argument that musical notation was too specific in its application to be of much use, it is here also that at least part of the explanation for the disrepute of musical-spectrographic patterning in 1980 may be sought: at least since the 1920s, musical listening carried a tacit baggage that ranked it with the artistic and subjective, rather than the systematic or methodical, thus scientific. Chapter 2 has described how although musical listening had once seemed to afford the naturalist an authority as expert scientific listener, it has since been tainted by associations with anthropomorphism and amateur naturalism. Certainly by the 1960s had suggestions on the "validity of drawing upon human experience in the interpretation of bird song" and observations that "bird song has a much deeper significance than advertising alone" been relegated to the naturalist domain (Murie, 1962, pp. 181-2). After all, as Eileen Crist (1999) pointedly demonstrates, professional biologists had cultivated an increasingly mechanical idiom that allowed them to discuss phenomena that they had decreed to be unverifiable by the human ob- 
server, such as animal mind, emotion or aesthetic sensibility, in a technical and detached way. To establish the study of animal behavior as a rigorous science and to ward off any suspicions of anthropomorphism, they had thus sought to purge their observations from any possible 'subjective' inclinations.

Likewise, then, sound spectrograms were shielded off as carefully as possible from the suggestion of subjectivity. For sure, the previous sections have shown that intuition and trained judgment - visual as well as aural - was deployed when it was thought to enhance an effective appreciation of 'objective' sound patterns. But even here, the authority of trained judgment (itself certainly not generally adopted by all biologists of bird song) was not unlimited. It did not extend, for instance, to the production of musical notation and musical spectrograms, even though these forms of representation too aspired to identify particular sound patterns from an objective (tape or spectrographic) record. Musical notation, after all, had not only been dismissed as an inherently artistic and subjective form of transcription, it also aimed to foster the reader's aural experience of a sound. These, however, were exactly the individual, tacit and subjective interpretations that most bird song biologists had initially sought to by-pass. The spectrogram, in contrast, had seemed to dissociate sound from its individual experience.

\section{Visual inscriptions}

Over time the sound spectrograph's promise to connect the 'objective' and physical properties of sound with their 'subjective' or intuitive perception faded from view. Bird song biologists' reliance on the sound spectrogram has thus come to be based principally on its ability to package sound into travelling 'inscriptions', which Bruno Latour (1986) has famously termed 'immutable mobiles'. Indeed, in the antagonistic network perspective that Latour and Woolgar (1986) advocate, such paperwork is crucial to muster together and send off convincing proof to convince as many allies and criticasters as possible, in the absence of the original phenomenon or thing. In its most basic form, such inscriptions enabled unique sound events in the field to be casted in many identical copies and to be circulated widely. But as Latour points out, inscriptions are not only a matter of duplication. In fact, inscriptions have a host of additional advantages which help us to understand the importance that has come to be ascribed to the sound spectrograph.

In the first place, inscriptions are highly mobile; because they can be duplicated and printed, they can be circulated more easily through a network of peers. This enabled interpretations of bird song (accurate, inaccurate, conflicting or not) from very different places to be collected in a single place - the laboratory or a printed article - without having to resort to that specific sound event or even the recording thereof. Inscriptions are immutable; unlike printed inscriptions, recorded sounds were vulnerable to destruction (erasure) or alteration. Even with mechanical recording, replication on different locations remained precarious, depending on type, 
settings and calibration of the equipment. Inscriptions, on the other hand, crystallized such variables into a permanent representation. Inscriptions are flat and hence can more easily be dominated. Sonic inscriptions, like the musical staff, the graphic drawing or the sonagram, have always been rendered as two-dimensional forms. These forms had the same effect as the use of perspective to transpose an immense three-dimensional building to paper. They represented the dimensions of sound (time/rhythm, frequency/pitch, amplitude/loudness) on the flat surface of paper where they were more easily overseen, cut up, scaled, recombined or superimposed - in short, controlled. This is particularly evident in the routine practice of tracing images with pen and ink. In the flat dimensions of the image, sounds could be added or removed with an efficiency and economy that, despite innovations such as the parabolic microphone, did not exist in the field. Manipulations on paper enabled the researcher to intervene virtually (but none the less real!) in its soundscape. Intriguingly, the costs and effort that went into transforming the laboratory into a sound-proof room that could be used to protect bird song experiments against acoustic interference, were trumped by the ease with which researchers organized the soundscapes of the field spectrographically (Thorpe \& Hinde, 1957).

A particularly important effect of such transposition would be that very different inscriptions could be made optically consistent and hence fit a standard lay-out, which enabled its users to represent them synoptically - in the same plane. In this regard, flat and printed inscriptions work differently from sonic experience, as is illustrated by a sound spectrographic comparative analysis of Western meadowlark songs by Lanyon and Fish (1958). The article presents a plate of four spectrograms of a call note (Figure 5.11). Although the calls had been recorded in different field locations from California to Wisconsin, they could be presented, not only together in one plane, but also in the same scale. This commensurability of sounds that were sampled in very different environments enabled to authors to convincingly argue that all notes were identical, regardless of their geographical location. This quadruple comparison of evidence was Lanyon and Fish's central argument, made possible only by combining flat inscriptions and adjusting their scale of measurement. The optical consistency of sound spectrograms allowed researchers to accumulate elements from the soundscapes of dispersed geographies. To understand the additional value of such a representation in the context of bio-acoustic research into variation, one only has to imagine the same fourfold presentation of the original recordings, but played out loud uninterruptedly, simultaneously or even in rapid succession. Although trained listeners could try to compare a single pair of samples (as they indeed often would), none of the published research papers reported analytical benefits from simultaneous listening to four, let alone a hundred, samples. Compared to auditory inventories, within its flat dimensions the printed inscriptions could be made to 'speak' more easily only when they were being looked at - one at a time or all at once. 


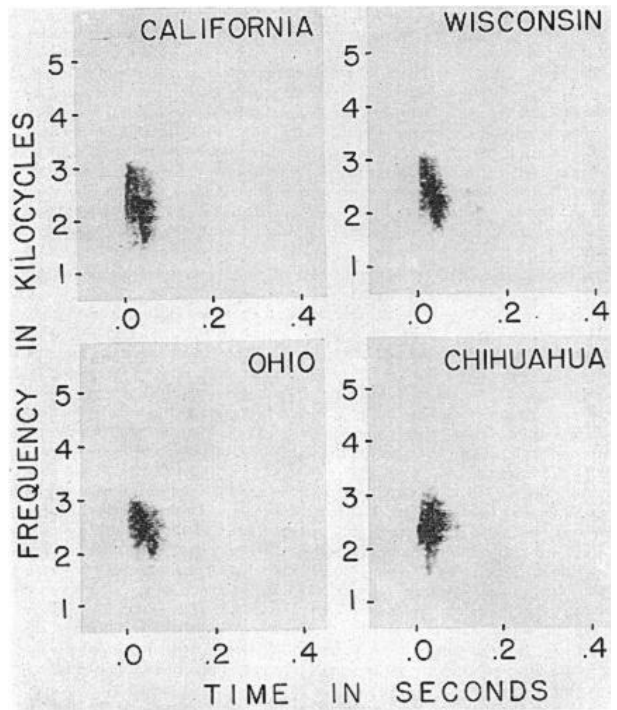

Figure 5.11

A synoptic display of Western meadowlark by Wesley Lanyon and William Fish.

Importantly, the Meadowlark inscriptions do something besides representing sound, in Latour's words, "synoptically." They enabled the authors to deal with the sequentiality of sound. After all, these unique sound events were not only tied to a specific time and place (being ephemeral) but also happened "in time" (being sequential). A record did preserve the sound itself, but when it was played back, every note was still evidently replaced by the next and next. Whereas listening necessarily takes place in time and thus takes time, inscriptions stabilized time and achieved its reversibility - allowing the reader to go back and forth or cut across sections pretty much at will. This stabilization and reversibility of time matters, as becomes clear most concretely when still images themselves are provided with a dimension of time and the analyst is asked to compare four moving images at the same time, whilst observing them through a narrow slit. Therefore, it is not the visual organization of information per se that is preferred over its auditory counterpart, but rather what it allows the researcher to do with it; to take control over both the time and space in which a sound event took place - by means of perspective, measuring scale and geometrical grids. Slowed down gramophone records and combined sound spectrograms both enabled this kind of control, but evidently to different extents.

Moreover, as Latour (1986) also reminds us, the inscriptive visualization of phenomena is not an end in itself; it is not imaging itself that guaranteed the authority of inscriptions among peers. As we have seen, a multitude of inscriptions would swamp an observer almost as much as the original sounds would. Indeed, for that reason, some researchers classified the sounds according to their aural 
impressions first, after which they spectrographed typical instances. But there is an advantage to imaging, Latour notes, as visual representations can be made to cascade with increasing efficiency into ever simpler, abstracted and crystallized inscriptions. As such, sound spectrograms merely provide a further step in the processes of sterilization, compartmentalization and abstraction of sound that begin with the focused, directional recordings produced in the field. Spectrograms can now be combined with benchmarks, geometry and scales, which makes that they can more easily be conceived of in function of a set of mathematical relations. Indeed, confronted with a multitude of recorded sound data, researchers do suffice with merely comparing spectrographic contours. Lemon and Herzog's (1969) inquiry into the organization of song in cardinals for instance yielded not just a collection of sonagrams (figure 5.11), but also, and especially so, a long list of statistical interventions which compressed dozens of individual sound records into a single table (figure 5.12). The sound spectrograph served this cascade particularly well because by its design it required the analysis of relatively short sound clips of a few seconds only. This contrasts, for instance to musical notation, which is virtually unlimited in its ability to render long aural sequences. Students relying on musical notation preferred birds with varied and often extensive repertoires, such as that of the song sparrow (Mundy, 2010). Spectrograms, instead, accommodated only vocalizations that were short and preferably repetitive, such as calls or songs of species such as Thorpe's chaffinch, whose variations were concise, stereotypical and thus easy to 'oversee'. As a result, differences between these short song samples were quantified by attending especially to the distribution of sound over the (vertical) frequency range, rather than its (horizontal) unfolding in time.

Once printed and categorized, hundreds of spectrograms were measured, after which the extracted information would in turn be punctualized into a matrix, table or graph. Numbers, more than images, can more powerfully be mobilized as proof in Latour's model, because they make it increasingly costly to dissent. As the rift between researchers at Cornell and Cambridge demonstrates, single images themselves could be disqualified or disbelieved based on the way they had been produced or the interpretation given to them. They could even be countered with just another image. But to argue against the graph as an abstraction of many individual sound events, requires one to muster at least an equal amount of sound events, abstracted from the field-site and cascading with equal speed and efficiency from recording to spectrogram to numbers to graph. 


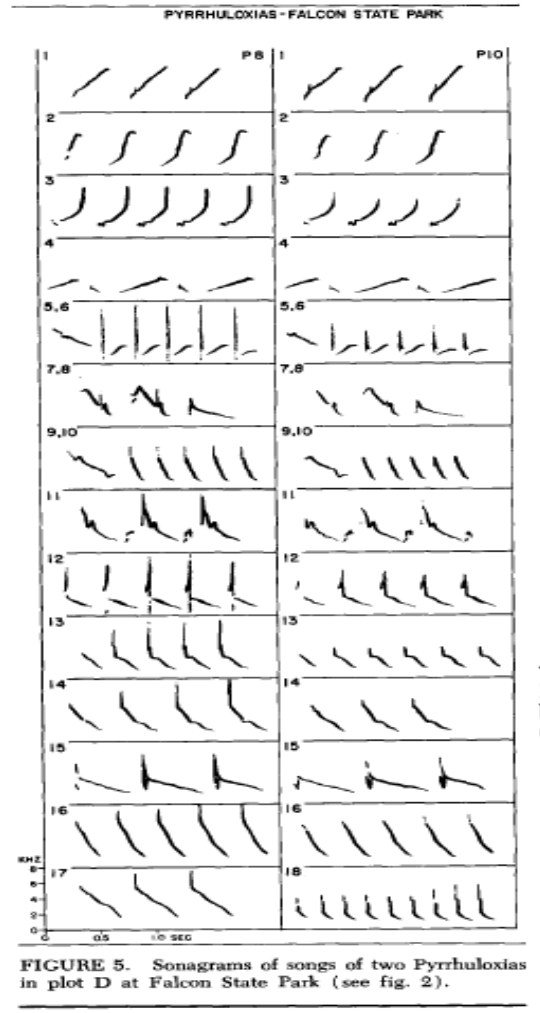

Figure 5.11

Sonagrams, enabling the synoptic comparison of songs of two individual birds in one location.

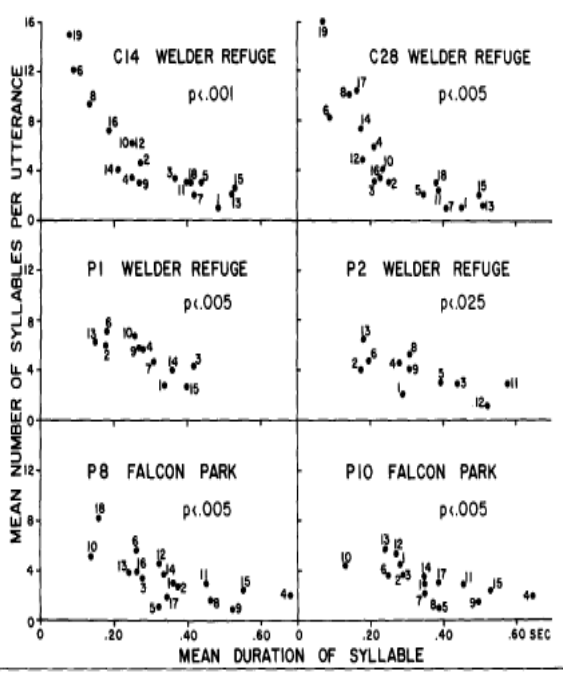

FICURE 6. The relation between the duration of syllables and the mean number of repetitions of the sylla. bles per utterance of song. The numbers on graph refer to the kinds of syllable; as such they are equivalent only between individuals of the same species in the same locality.

\section{Conclusion}

In this chapter, I have traced a history of the sound spectrograph in birdsong biology since 1950 through the minute ways in which biologists negotiated the role of sound visualization vis-à-vis aural experiences in the analytical and representational strategies of the sound spectrograph. Taking the Cambridge department of Zoology and its intersections with the field of bird song biology as a point of departure, I have shown that the ways in which avian acoustic phenomena have been rendered, interpreted and presented as reliable scientific data came about through the local negotiation of epistemic virtues of mechanical objectivity and skilled interpretation. The mechanical replication of the process of human hearing in the sound spectrograph dissociated hearing from the observer's ear. It also, again, exposed the perceptive limits of human hearing. Bird songs looked more complex on paper than 
when they had ordinarily been perceived by ear. This higher resolution of perception was thankfully employed in a new analytical tradition that aimed to map as much variety of detail as possible. Interestingly, however, this did not by itself deny the continued relevance of expert listening and related sonic skills in bioacoustics work. For sure, for the registration and codification of sound a majority of practitioners ranked mechanic imagery over human judgment. But to produce or interpret mechanically objective spectrograms itself, the analyst would rely on intuitive judgment and a skilled ear. By highlighting such instances of listening I do not intend to extend a putative hierarchy of the senses into the laboratory. Rather, they may serve as an entry to further our understanding of the complex dynamic between the instrument and the body of the researcher in scientific practice. How, then, have bird song biologists negotiated a role for embodied sound experience alongside spectrographic visualizations? This merits two observations.

The first concerns the inter-conversion of auditory impression into visual information with which hearing had been delegated to a machine. As Jonathan Sterne and several media historians quoted above point out, such a self-imposed muteness in dealing with acoustic phenomena was not exclusive to birdsong biology only. Since the first half of the nineteenth century, perfecting techniques for automatically transducing audible vibrations into visible phenomena was a constant concern for instrument developers and acousticians. With these devices emerged an interest in 'indexical' images of sound - visual tracings that had been directly structured by the acoustic phenomena themselves. In contrast to musical scores or other graphic schemes, which seemed to represent acoustics in a rather arbitrary fashion, automatic sound-images were regarded as a natural analogue to sound itself (Sterne 2003). Underlying these images was a rather holistic assumption that sound would be able to write itself, and that eventually such traces could stand in for those sounds without any loss of information. This motif of 'textual' sound inscriptions and the synesthesia of audible and visual patterns was embodied not only by the phon-autograph or even the phonograph. It also surfaced, among others, in the projection of the Bell Labs experimenters of a visible language for the deaf, as well as in the graphic modifications by ornithologists in Cambridge and elsewhere. Like Thorpe's diagrammatic notations or Marshall's logarithmically scaled spectrograms, all aspired towards the mechanic codification of a universally legible codification of natural sounds.

As this chapter demonstrates, however, such correspondence was never easy to achieve in practice and it is here that sonic skills can be observed to play a significant role. The failure of a spectrographic alphabet for bird vocalizations was ultimately intercepted by a musical notation which, although legible, was by no means 'autographic' or indexical. Similarly, listening was mobilized at times when the limits of the spectrographic image itself were exposed and visual information failed to stand in fully for auditory perception. This was most clearly the case when the interpretation of visual information was adjusted, classified or corrected based on auditory impression. Here, the perspective necessarily shifted back and forth be- 
tween the physical measurement of a sound and its perception. The failure of the spectrograph to establish a consistent and direct correspondence between sound and image, and to distinguish between pattern and noise, required the analyst to rely on his own embodied perception. In such cases, hearing was mobilized as a complementary 'sensuous technology' that helped to make sense of acoustic phenomena (Roberts, 1995). Indeed, although spectrograph users had publicly pitched the objectivity of the spectrograph against the subjectivity of former methods, this did not imply that they were irreconcilable epistemic positions per se. ${ }^{126}$ Unlike the group of audiophiles described by Perlman (2004), which strongly divided between 'meter readers', who relied on the authority of scientific and technical measurement, and 'golden ears', who privileged and prided themselves on personal experience, researchers such as Thorpe routinely integrated both in their practices. At the same time, the precise conditions under which trained judgment could be allowed to supplement the 'mechanically objective' instrument were carefully delineated. Not only by the distrust of certain bio-acousticians to intuitive interventions in spectrographic measurement, but also by the role and function of the spectrogram itself. As inscriptions, spectrograms were to congeal the interpretation of auditory information, not to open it again to the embodied (and therefore individual) experiences of the reader. Trained judgment could thus be assumed only with the analyst to aid an efficient production of authoritative spectrograms.

This leads us to a final observation. Indeed, the involvement of trained judgment was guided primarily by an implicit calculation of efficiency rather than a fundamental epistemic commitment to the ear. Among others, visual patterning was particularly useful in drawing up morphological classifications - sounds were categorized according to their graphic shape - but it was not always the most efficient approach, since spectrographing hundreds of records of at most ten seconds per turn was a very time-consuming job. Here, auditory impressions would be mobilized; classifications could be initiated based on aural impressions before spectrographing. Such exploratory or supportive work could not easily be codified or carried out mechanically, but was often assigned to aural discrimination. Such discriminations were efficient because they had often been grounded already in the somatic experience of field recording, thus connecting field experience with laboratory analysis. The practical ways with which expert listening and sonic skills have been integrated in bioacoustics work demonstrate that they afford interactions between researchers and instruments that are often different, sometimes richer, and sometimes simply more efficient than could be obtained by the mechanical image alone.

\footnotetext{
${ }^{126}$ A similar debate took place in the 1970 s as ethnomusicologists tried to determine how automatic and aural transcription, the 'objective' and 'subjective' should relate. 'There is little doubt that automatic transcriptions, with their detailed, external view of music, will eventually help us to understand some of the physiological and cultural processes of man. However, when the subject of study is concerned with the psychological or communicational aspects of music within a culture, aural transcription by a trained ethnomusicologist who has steeped himself in that culture may well be far more meaningful" (Jairazbhoy, 1977, p. 270).
} 



\section{Sound Science: Conclusion}

\section{Introduction}

This dissertation has traced a history of scientific sound recording. At its center have been the pioneering practices of academic researchers, sound archivists, public broadcasters, and a diverse bunch of naturalists, birdwatchers and recordists engaged in the recording and biological study of bird song. I have analyzed how these groups have crafted technologies of sound recording and listening into scientifically legitimate techniques that were being deployed to make sense of the acoustic behavior of birds. I have examined these techniques especially in their novelty years, as new possibilities began to congeal into routines and thus crystallized their users' interests. This focus on relatively short phases of appropriation should not obscure, however, how these technologies and techniques together structured bird song biology on a much longer term.

Scientists' concern with ambient noise is an interesting case in point here. In 2003, the Dutch ecologist Hans Slabbekoorn and his colleagues at Leiden University published a paper in Nature that signaled a remarkable behavioral adaptation of birds to their environments. They had found that great tits that live on noisy urban locations generally sing with a higher minimum frequency than the same species living in a forest environment where there is much less anthropogenic noise. This, the authors proposed, suggested that the species adapted its vocal repertoires to a higher-frequency range in order to prevent its song from being masked by lowfrequency noises. For if its song would structurally be disguised by other sounds, this would give the birds a serious evolutionary disadvantage: after all, the bird would be less successful in using its song to defend its territory or attract a mate (Slabbekoorn \& Peet, 2003). This and several studies appearing around the turn of the millennium have provided direct empirical evidence for the selective pressure that ambient noises exert on birds' vocal variations (Brumm \& Todt, 2002; Cynx, Lewis, Tavel, \& Tse, 1998; Warren, Katti, Ermann, \& Brazel, 2006).127

\footnotetext{
127 This work extends a theme in the biology of bird song that has emerged only relatively recently. Since the late 1970s, biologists have begun to consider the influence of the acoustic ecology on the signals that birds produced (Morton, 1975). They have theorized how forested environments, for instance, reflect, deflect or absorb sounds differently than open plains do, which makes that ambient noises, such as murmuring water or insect choirs, carry in different ways through these environments (Ryan \& Brenowitz, 1985). Such interfering
} 
This relatively recent reception of acoustic ecology and ambient noise as a theme in the study of bird song is not only biologically interesting. It is also suggestive of the cultural and material trajectories that I have described in the preceding chapters. Since 1930, after all, mechanical recording has rendered the acoustic environment of bird song a quasi-inevitable factor in any practice of field recording and research. And yet, acoustic interferences have long been regarded as an aesthetic and analytic disturbance of the recording and effective communication of song data. This concern has variously materialized in many of the tools, techniques and routines that scientists have developed to record and analyze bird song. Over time, directional recorders and parabolic microphones, spectrographic adjustments and sound-proof laboratory rooms together constituted a recording culture in which sonic sterility and the elimination of noise have been considered synonymous with the suggestion of sound control. It is of course difficult to gauge the precise impact of these techniques for parsing noisy acoustic contexts into individual auditory components on developments and advances of the field. ${ }^{128}$ Yet the pervasiveness of sterilizing listening and analyzing techniques suggests a particularly compelling reason for the fact that the acoustic context of bird song has remained of little analytic concern to biologists for so long. In that regard, these trajectories structured the specific kinds of knowledge that have and have not been produced.

The thematic persistence of noise control since 1930 illustrates what may be gained by reviewing the history of bird song recording once more, but now from a wider historical angle. It suggests, after all, that the technologies and practices that have featured individually in each chapter of this book actually welded together to form influential patterns of perception. These shaped and constrained how biologists have made bird song perceptible and how they have crafted it into an object of scientific investigation. In previous chapters, I have traced a select set of thematic histories that focused on local practices. This concluding chapter, finally, develops a retrospective transect to highlight some of the historical trajectories that have bound these local practices together. As I will show, they have done so not in successive sequence but by accumulating and sedimenting into a complexly layered scientific practice. These trajectories form the basis for the three subsequent sections to sort out answers to the three main questions that I have pursued in this book: First, how have ornithologists employed their ears in making sense of what they studied, that is, how and with help of what tools did they listen to their objects

noises, bio-acousticians have suggested, make signals more difficult to detect or recognize by birds (Langemann, Gauger, \& Klump, 1998; Wiley \& Richards, 1982). This has been recognized to constitute a competition for 'signal space' between species (Nelson \& Marler, 1990), and to require birds to apply a selective principle of 'acoustic scene analysis', whereby noisy sound environments are parsed into their individual acoustic components (Hulse, 2002).

${ }^{128}$ Indeed, even when Slabbekoorn and Peet tracked the influence of anthropogenic noises, they used a conventional "highly directional" microphone to sample song recordings alongside an omnidirectional microphone to make independent noise measurements. This allowed them to separate their bird song spectrograms from acoustic interference, much in the same way as bio-acousticians do in studies where noise is not a topic of research (Slabbekoorn \& Peet, 2003). 
of study? Second, how have such practices of mediated and unmediated listening generated new kinds of questions or findings? And finally, how have these kinds of listening come to be legitimized as authoritative and reliable scientific practices?

\section{Changing patterns of listening}

Let me first start by reviewing how and with help of what tools students of bird song listened to their objects of study. I will argue in this section that over the twentieth century, the listening practices of students of bird song have gradually shifted, in accordance with emerging technical possibilities, changing regimes in epistemic virtues and crystallizing scientific interests. These shifts in the role and relative importance of listening - which are schematically outlined in Table 6.1 implicated changes in who could listen authoritatively, what was being listened to and for what purpose.

In this book, I have situated the beginning of this history of scientific listening at the turn of the twentieth century, when naturalists first adopted a selfconsciously scientific mode of listening. Of course, listening had necessarily been part and parcel of field work before - indeed, when collecting specimens for museum taxonomies, hunters and field collectors evidently relied on exploratory and diagnostic listening abilities too in order to find and identify species. But by 1900 , listening also became explicitly part of the habitus of a new breed of scientist, the field observer. In the preceding decades, field observation had moved to the epicenter of popular and amateur interests, but now it gradually began to attract the attention of academic ornithologists as well. The self-consciously scientific aspirations of this emerging community of field ornithologists also affected their listening practices. Between 1900 and 1930, a number of problems materialized that, as this book shows, would keep students of bird song occupied for the ensuing decades: how to ensure that bird song was recorded scientifically, accurately and intelligibly, and that those recording them did so in the appropriate way.

These questions were reflected first in a controversy over what for long had seemed the only viable way of capturing, storing and reproducing sound: musical notation. By the $1910 \mathrm{~s}$, several recordists re-appropriated musical notation as a purposefully precise, systematic and thus scientific tool. At the same time, a growing group of critics dismissed musical notation for what they considered the aesthetizing and idealizing of bird song that it implied in their view. Both appreciations of musical notation represented diverging conceptions of who could listen and record authoritatively. For the first group, scientific notation presupposed a trained craftsman: although the ideal scientist-musician also possessed sensory acuity, a refined grasp of the conventions of musical notation as well as a virtuous scientific attitude were important. Accurate recordings were, after all, not so much distorted by the physical deficiencies of the listener as they might by willful subjective projections and a lack of scientific method of the observer. Scientist-musicians were thus 
to guard carefully against the idealizations that characterized the work of their pendant, the artist-musician. Still, their well-composed musical renderings of bird song in a Western key were soon criticized exactly for what they had sought to evade. Musical notation, its critics advanced, seemed worked, over-interpreted, and veering suspiciously close to artistic interpretation. These critics pleaded instead for the apparent instant transparency and simplicity of a graphic diagram. In contrast to musical notation, they argued, graphic schemes were easy to learn, to read and to write, practical for use in the field and for those reasons also in reach of a wider group of musically unskilled observers.

As I explained in chapter 1, this opposition also reflected diverging conceptions concerning the functions of these paper tools. After 1900, ornithologists aspired to compile extensive life histories of birds. Scientist-musicians thus aimed to record vocal repertoires as completely and accurately as possible to allow for a comparison of individual variations in other records. Although we have seen that not all scientist-musicians regarded bird song literally as music, they did ascribe their records a distinctly mimetic quality as representations of the natural world. Graphic recordists, on the other hand, were concerned as much with the communicability of a recording, which translated into the conviction that a recording should also be didactically or mnemonically effective. They found that recordings should not only be accurate, but also, and often especially so, help to teach or remember bird songs. As such, they aimed to foster the exploratory and diagnostic listening abilities of a larger community of non-expert recordists in the field. Sound recordings were thus to have multiple, sometimes even contradicting functions.

However, by the late 1920s, ornithologists anticipated they had found an answer to the question of how to record sound accurately. Around 1910, ornithologists had a scientific listener in mind whose physiological abilities had been relatively uniform. Therefore, listening scientifically implied training the ear to listen carefully and abstain from idealization and theoretical projections. Mechanical recordings, they expected, could help to resist such subjective projections. But mechanical recording did more than that; it also exposed the aural perception of an average observer to be hopelessly defective, selective and distracted, and the mind of even the most disciplined and trained listener easy to be tricked into hearing what it expected to hear. As a result, these recordists delegated listening to the microphone ear, which instead promised an impersonal and unselective 'mechanical objectivity' (Daston \& Galison, 2007). In order to effectively replace human listening, however, the mechanic ear had to emulate the selective attention and 'aural gaze' that the human ear enforced naturally and unnoticeably.

Such mechanic recordings enabled professional ornithologists to investigate familiar common bird songs in new ways. Slowing down gramophone records or examining sound-film prints visually under a microscope yielded a more detailed understanding of the structure or the specific phrasing of a bird's song, and it did so in different terms: analysts spoke of song properties such as tone height no longer in the musical terms of pitch but in the acoustical terms of frequency. But 
even though the ornithologist's authority had shifted away from musical listening to visual inspection, mechanical recording still required a specific set of new sonic skills to be acquired, if only to record sounds optimally, to monitor the equipment and diagnose its technical effects. Recording sounds with a machine clearly implied learning to listen like one.

Because of the technical complexity and cost of the recording equipment, mechanical recording remained the exclusive domain of only a small group of ornithologists and the technical professionals with whom they collaborated. So whereas these recordists had begun to distrust their hearing, until the late 1940s most field ornithologists instead remained reliant on their ears. Field studies now generally avoided recording sounds in notation, but still aimed to describe variations in birds' vocal repertoires by capturing vocalizations in words or by describing singing behavior statistically. Therefore, mechanical recording dissociated detailed (visual) acoustical analyses of bird song in the laboratory from most field observers' inevitable reliance on their own aural experience and perception. At the same time, mechanical recording also helped to bridge that opposition between lab and field and between an objective and subjective experience of sound, by stimulating the distribution of gramophone records. Mechanical recordings too could be ascribed different functions. Ornithologists relied on 'mechanically objective' recordings as mimetic representations, as a privileged means to study the natural acoustic world. Yet for science popularizers, the same records also possessed the potential to entice listeners through radio broadcasts or records and to foster their interest in the study of bird song, an alluring function of mechanical recordings. Moreover, gramophone records' wide circulation and uniform reception made them didactically effective too. Because these recordings rendered common bird songs aurally rather than diagrammatically, they did not require a competent reader.

These recordings did not only teach aspiring ornithologists to listen to bird song, but also set an example for how to record them. This became especially relevant when by the late 1940s commercial magnetic tape recorders became available. Because of its lower cost, portability and relative technical simplicity, this device made field recording accessible to a much larger group of amateur recordists and biologists. But like the phonograph, tape recording did not abolish the need for an ear in the field. First, the equipment itself often required a degree of monitory and diagnostic listening ability to ensure that technical defects (such as alternating tape speed) would not in any way alter the original sound. A nature recordist was therefore said to require more specialized listening skills than a professional recording engineer, to pick up subtle distortions in high-pitched bird sound. After all, unlike for the engineer, for the biologist not the realism of a sound mattered but its exactitude. Secondly, although mechanically exact registrations could now be collected on large scale by a variety of recordists, birds were still to be located and identified, whilst their vocal behavior was to be described and annotated in order to be of use to the biologist. Moreover, the observation of playback experiments, whereby recordists provoked behavior by playing recordings to wild birds, could not be dele- 
gated only to mechanical instruments. For these tasks, the recordist evidently relied on exploratory and diagnostic listening abilities. But although using one's ears was still an inevitable part of the field, field observers' listening authority was also carefully delineated. Identifications of a species required not only aural but also additional visual confirmation. And because tape recordings registered sounds as 'objectively' as possible, they also enabled other listeners to take part in the listening and to evaluate pending identifications. Consequently, mechanical recording had not only relieved the ear in the analysis of bird sound; it also distributed the 'ear-work' that took place in the field.

As chapter 5 has demonstrated, a comparable development took place in the bird song biologist's laboratory. Due to its low cost and portability, tape recording had pushed the economy of field recording to an unprecedented scale. This resulted in a rapidly expanding collection of potential data on birds' vocal behavior and particularly its variations across geography and life span. From the early 1950s onwards, biologists found assistance in the sound spectrograph, a device that provided detailed spectral analyses of complex sounds, to analyze the growing volume of potential data. By rendering their collections of field recordings as spectrograms, these biologists found that they could listen with a 'visual ear' to the variations in bird song structure that had previously only been suggested to the ear or by crude sound-film recordings. The spectral imprint of taped sound on calibrated paper allowed recordings to be scaled, juxtaposed, compared and mathematized on a much larger scale without having to rely on putative 'subjective' aural impressions. In fact, mechanical spectrograms even seemed to announce the complete substitution of hearing by reading. Breaking down songs to their smallest (morphological) components allowed researchers now to look for the principles by which songs get constructed, their countless variations as well as apparently universal elements.

However, although analytic listening seemed to be delegated to the proceduregoverned mechanical objectivity of the spectrographic image, here too, sonic skills continued to play a role. Scientists remained deeply aware of what they considered the limitations and flaws of the human ear. Yet around 1960 they also strategically invoked tacit aural skills again to prepare, correct or fine-tune their visual analyses, drifting occasionally into the domain of 'trained judgment' (Daston \& Galison, 2007). In fact, exactly those properties of the ear that had been discredited by the mechanical record around 1935 had made it seem a useful tool around 1960. The ear's tendency towards selection, filtering and its perception of only the crude essentials of a sound, after all, helped the listener to distinguish between signal and noise and to identify the clusters and family resemblances that were of analytical interest. But the ear was also deployed with caution and had a different purpose altogether; if listening had initially served to record and analyze acoustic structures, it now served a discriminatory or corrective purpose. The intuitions of an experienced ear enabled the analyst to classify or adjust subtle variations in already mechanically recorded song patterns. With that shifting purpose, the authority of listening had shifted too. The sophisticated intuition of the trained ear distinguished 
itself from the methodical listening that the scientist-musician had advocated around 1910. More than a methodological listening protocol, the trained ear depended on a sensitivity that had been cultivated by practice and continuous exposure. Although not less self-assured, this trained judgment was much more personal, tacit and implicit.

At the same time, however, the legitimacy of aural interpretation also remained controversial. Concerns about the noisy 'mechanically objective' image were not shared by all, and were even countered by concerns that the trained ear instead 'over-interpreted' the untarnished image. When ornithologists sought to reinterpret spectrographic images in musical notation, for instance, the ensuing criticism suggested that listening could not play a significant role in the actual analysis of song structures. However, the initiative to pair spectrographic renderings with musical notation had not merely aimed to re-appropriate listening as an analytical tool in the laboratory. It had at the same time intended to make spectrographic analyses meaningful again to the field ornithologist. Or, in the terminology developed above, it aimed to complement the mimetic assurances of the spectrogram with the didactic or mnemonic qualities of a musical diagram. In that sense, such spectrogram-modifications again exposed a familiar gap between the diverging roles that sound recordings played in ornithology: that of an object of analysis, as much as a tool for learning, recognition and navigation in the field.

In conclusion, over the course of the twentieth century, the human ear has become disqualified as a tool for analyzing the increasingly complex acoustical structures that biologists had become interested in. Instead, mechanical (and particularly visual) inscription processes promised more sophisticated access to acoustic structures, as well as a way to transport sensible evidence across geographical and professional boundaries. But despite this ostensive increase in mechanical recording and visualization instruments, the listening body did continue to be incorporated in investigations of bird song. Students of bird song continued to listen first of all in the field, which they inevitably navigated and structured by their own ears. In locating, identifying and describing bird sound in the field, recordists oriented themselves by relying on exploratory and diagnostic listening abilities. Moreover, in both the field and the laboratory, the sensuous qualities of the human ear would be deployed in embodied interactions with the recording instruments, to complement, monitor or fine-tune its mechanic processes of sound inscription.

Although the practiced ear did no longer suffice to chart complete acoustic structures from scratch, its qualities did allow workers to carry out tasks of recognition, diagnosis or categorization. Lorraine Daston (2001) has observed that despite the ambitions of eighteenth-century botanists and nineteenth-century sensory physiologists to eliminate the personal skill of the artist and the artisan, sensory refinement and bodily techniques did not, and often could not, disappear. Indeed, she explains, the standardization of description and nomenclature and the introduction of self-registering instruments repressed but never entirely suppressed the investigators' reliance on ineffable and inevitably personal sensory impressions. In a comparable 
vein, one may observe in the history of bird song biology a similar tension between scientists' growing distrust in human listening on the one hand, and its inevitable application in practical tasks on the other. As a result, listening displayed a continued utility as a tacit, technical or intuitive routine in well-delineated yet nonetheless epistemologically significant tasks.

\begin{tabular}{|c|c|c|c|c|}
\hline & $\begin{array}{l}\text { Who listens } \\
\text { authoritatively }\end{array}$ & Type of inscriptions & $\begin{array}{l}\text { Purpose of } \\
\text { listening }\end{array}$ & $\begin{array}{l}\text { Function of sound } \\
\text { record }\end{array}$ \\
\hline $\begin{array}{l}1880- \\
1930\end{array}$ & $\begin{array}{l}\text { Scientist- } \\
\text { musicians } \\
\text { Graphic } \\
\text { recordists }\end{array}$ & $\begin{array}{l}\text { Musical notation } \\
\text { Graphic/ } \\
\text { Syllabic }\end{array}$ & $\begin{array}{l}\text { Exploratory, } \\
\text { Diagnostic, } \\
\text { Analytic }\end{array}$ & $\begin{array}{l}\text { Mimetic, } \\
\text { Didactic } \\
\text { Mnemonic, } \\
\text { Didactic }\end{array}$ \\
\hline $\begin{array}{l}1930- \\
1950\end{array}$ & $\begin{array}{l}\text { Commercial } \\
\text { recordists }+ \\
\text { Ornithologist } \\
\text { recordists } \\
\text { Field observers }\end{array}$ & $\begin{array}{l}\text { Gramophone / } \\
\text { Sound-film } \\
\text { Graphic/syllabic } \\
\text { notation }\end{array}$ & $\begin{array}{l}\text { Exploratory, } \\
\text { Diagnostic, } \\
\text { Monitory } \\
\text { Exploratory, } \\
\text { Diagnostic, } \\
\text { Analytic }\end{array}$ & $\begin{array}{l}\text { Didactic, } \\
\text { Alluring }+ \\
\text { Mimetic } \\
\text { Mimetic, } \\
\text { Mnemonic, } \\
\text { Didactic }\end{array}$ \\
\hline $\begin{array}{l}1950- \\
1970\end{array}$ & $\begin{array}{l}\text { Commercial } \\
\text { recordists } \\
\text { Hobby } \\
\text { recordists }\end{array}$ & $\begin{array}{l}\text { Tape recordings } \\
\text { Tape recordings }\end{array}$ & $\begin{array}{l}\text { Exploratory, } \\
\text { Monitory } \\
\text { Exploratory, } \\
\text { Diagnostic } \\
\text { Monitory }\end{array}$ & $\begin{array}{l}\text { Alluring } \\
\text { Mimetic, } \\
\text { Mnemonic, } \\
\text { Didactic }\end{array}$ \\
\hline $\begin{array}{l}1950- \\
1980\end{array}$ & $\begin{array}{l}\text { Academic } \\
\text { recordists }\end{array}$ & $\begin{array}{l}\text { Spectrograms } \\
+ \text { Musical } \\
\text { notation }\end{array}$ & $\begin{array}{l}\text { Diagnostic, } \\
\text { Discriminative } \\
\text { Diagnostic, } \\
\text { Analytic }\end{array}$ & $\begin{array}{l}\text { Mimetic } \\
\text { Mimetic, } \\
\text { Mnemonic, } \\
\text { Didactic }\end{array}$ \\
\hline
\end{tabular}

Table 6.1

Overview of listening patterns. 


\section{New questions and knowledge}

The previous section has shown that birdsong biology has witnessed an array of listening techniques and recording practices, some of which biologists have claimed to have dramatically changed the field (Baker, 2001; Marler, 2004). With regard to the development of listening in bird song recording presented above, we may subsequently ask: how have such practices of (un-)mediated listening influenced the kinds of questions that bird song biologists became interested in and the knowledge that has been generated?

Already in section 2, we have seen some of the effects that new recording technologies have had on the organization of listening. Indeed, as the ornithologist exchanged the notebook and pencil for a microphone, birds' singing behavior could be recorded on a medium that allowed it to be transported to the laboratory, to be slowed down, played back, filtered, taken apart, compared and to be analyzed. This has enabled sound recording to become associated over time with a diverse set of knowledge practices. These ranged from description, observation and classification of bird song, each in their own way affiliated with a long tradition of natural history research, to the analysis of the acoustical composition and structure of a song as well as the testing of hypotheses associated with a more experimental approach in modern biology.

The development of new sound recording practices over time reflects some of the methodological shifts that occurred in ornithology itself, as it developed into a modern 'professionalized' biological discipline in the first half of the twentieth century. As chapter 2 and 3 have shown, the emergence of listening and sound recording in ornithological work has been associated with a more fundamental shift in orientation in ornithology from collection- to observation-based studies. From about 1930 onwards, experimental work and field-based ecological and behavioral studies had begun to take prominence over matters of collection-based morphology and systematics (Barrow, 1998; Battalio, 1998). So too, the experimental laboratory-based studies of song learning that ornithologists began to conduct from 1950 onwards drew on a long tradition of bird keeping, in which birds were trained to sing artificial songs, but at the same time also signaled ornithology's growing entanglement with specialized fields of biological inquiry such as ethology or bioacoustics (Birkhead, 2011; Haffer, 2001). But within these larger shifts, sound recording also manifested itself as a particularly versatile methodology. New applications always extended, rather than replaced, existing ones. Despite its emergence in a tradition of field-based observation of behavior, sound records were not only used to record observations. They were also used to 'collect' voices and thus became associated with a declining tradition of specimen collecting. By 1900, traditional taxonomic collections of physical bird specimens such as eggs or skins had been near complete (Kohler, 2006). But by 1930, new means of sound recording 
introduced bird vocalizations as a new type of specimen to be collected, which engages field collectors to the present day. ${ }^{129}$

Recordings thus became applied as a methodology in a variety of domains, ranging from taxonomy to studies of behavior and ecology. But whether ornithologists attempted to investigate the role of sexual selection in the evolution of bird song, the function of song in territorial defense or learning processes and behavioral patterns, one thematic development has been particularly noteworthy in the development of recording and study of bird song between 1880 and 1980: the recognition of variation in singing behavior. Initial records of bird song had been compiled for popular field-guides and had tended to emphasize the typical over the particular. However, as a growing group of field observers dedicated themselves to extensive descriptions of life history and the documentation of a species' complete vocal repertoire, song variations in the repertoires of species or populations became increasingly conspicuous. Around 1922, the amateur naturalist Aretas Saunders observed for instance that "the more one studies bird song, the more one attempts to make accurate records of songs, the more he becomes impressed with the fact that in almost all species there is great individual variation. Such variation is the rule, not the exception [and may be] individual, local, or geographical" (Saunders, 1922, pp. 386-8). Three decades later, thousands of records that he had collected by ear allowed him to demonstrate subtle differences in geographically distinct bird songs (Saunders, 1955).

The ability to record, compare and manipulate recordings in new ways further accelerated this process. Naturalistic sound registrations on gramophone record allowed observers to compare song types recorded in different localities with their own observations. On the basis of Ludwig Koch's published records of a selection of typical vocalizations, for instance, ornithologists assumed that birds maintained regional dialects that tied them to a distinct geographical context. Meanwhile, portable magnetic tape recorders made it increasingly cheap and easy to make greater numbers of recordings in a greater number of localities. In addition, visual means of recording like the spectrograph allegedly rendered the variable acoustic structures of a song even more clearly. This provided insights that were difficult to suspect by listening only, such as that birds may actually sing with two independent voices. Their representation of acoustic structures enabled biologists, moreover, to discern minute variations that could not always be picked up as easily by the human ear. At the same time, the technical limitations of these technologies of mediated listening also influenced the ways in which sounds were being interpreted and the kinds of sounds that were thus being selected. In order to make sound spectrography efficient at all, biologists focused for instance on repertoires that were not too extensive to sample representatively, song or calls that were concise enough to fit

\footnotetext{
129 It is estimated that by 1965, 25 percent of the world's 10.000 bird species had been tape-recorded. By 1982, the proportion has risen to about 50 percent. Estimates are that by 2003, more than 90 percent may have been recorded (Ranft, 2004).
} 
the spectrograph's ability to deal with short samples only, and its sounds recorded as much as possible in isolation of other birds in order not to pollute the spectrogram with noise. These technical conditions provided the conditions to focus research on the distribution of song elements within entire repertoires, and to shift attention away from sustained vocal interactions between birds or even from considering song as a musical exercise in the elaboration and variation of a theme. Such conditions further perpetuated the analytical interest in the selective pressures that brought about such instances of micro- and macro-geographical variation in song structures and singing patterns that Saunders had suspected.

Variation, after all, raised intriguing questions. These questions could be taxonomic, on the relation between different species or the mechanisms of evolution of a species. Since the late 1950s, archives of collected sound have proven to be a useful resource to establish, for instance, the relatedness or distinctiveness of certain (sub-)species (Alström \& Ranft, 2003; Davis, 1958; Ficken \& Ficken, 1967; Goodwin, 1964; Hardy, 1969; Kellogg, 1962c; Marshall Jr., 1964). The questions raised by variations could also be ethological, on the development of individual behavior: how do birds learn their song, what part of it is innate, and how does this relate to its apparent variability (Thorpe, 1961a)? To what extent is the acoustic structure of bird vocalizations determined by their function and to what extent do they adapt to changes in their environment (Marler, 1956)? The recognition that species' songs have specific universal acoustic elements across individuals further led to questions about the function of the composition of song repertoires, and what they communicate with regard to the location, identity and ability of individual birds (Catchpole, 1973; Konishi, 1964; White \& White, 1970). Such work has benefited greatly from the ability of playback. By playing back (sometimes artificially modified) sound recordings to wild or caged birds and recording their reactions, biologists were able not only to study bird structure but also to develop hypotheses and to test these experimentally (Miligan, 1966; Weeden \& Falls, 1959).

Clearly, technologies for recording and analyzing sound played an important role in answering these questions and raising new ones, particularly when they made perceptible by slowing down or congealing sound into an image what had remained imperceptible by the human ear. But the observations by Saunders also illustrate the role that the naked ear has often played in signaling issues of analytical importance. The scientific relevance of song variation had for instance been realized early on by evolutionary biologists such as Ernst Mayr or Julian Huxley, who quoted occasional observations by field ornithologists to raise the possibility that such geographical variations in song might actually be indicative of genetic diversification (Mayr, 1942; Radick, 2007). Thorpe's influential insights into the learning processes of chaffinch song too had initially been suspected by ear by the Dane Holger Poulsen. The sound spectrograph had enabled Thorpe, however, to determine the development of song patterns with much more detail. The sound spectrograph also enabled Thorpe to confirm the conclusions of his student Peter Marler on the mechanisms of such variations, based on aural records. These aural records, 
Marler had suggested, demonstrated that birds did not display regional variations as Koch's gramophone records had given reason to assume, but that they maintained often very local dialects that were perpetuated by new birds learning the songs of their older neighbors in a crucial phase of development.

New means of recording and listening to bird song did not, in other words, necessarily disqualify what had been discerned by ear. But importantly, it enhanced the efficiency and economy with which observations of bird song could be collected, analyzed and distributed. Marler later recalled that his "observations had not been too far off target". But it was by listening alone, he found, that "no one else could tell whether my results were believable or not" (Marler, 2004, p. 4). Mechanical recording not only assisted the study of bird song, by allowing sounds to be collected, compared, slowed down and analyzed with much more efficiency. It also enabled sound to be objectified into the forms of knowledge that Bruno Latour and Steve Woolgar (Latour, 1986; Latour \& Woolgar, 1986) have described as "inscriptions" whose mobility and immutability allowed knowledge claims to be authoritatively represented.

\section{Legitimizing sound recordings}

How, then, have such forms of (mediated) listening been legitimized as authoritative scientific practice? As the discussion in section 2 has shown, it was the 'mechanical objectivity' of the recording that formulated a provisional answer to this problem. Mechanical recording, after all, had seemed to enable the recordist and analyst to circumvent subjective and selective projections of the listener. Moreover, the process of mechanical recording enabled sounds to be cascaded into increasingly condensed forms that, according to Latour and Woolgar, greatly increased the cost to dissent with the claims that they supported and thereby with its authority. Importantly, however, this dissertation also shows such serial inscriptions themselves to be embedded in a social, technological and even embodied practice by which records came to be legitimized.

Indeed, one way to capture this history of scientific sound recording is to characterize it as the gradual assembling of an 'observational machinery' by which birds, their acoustic behaviors and their environments could be rendered as scientific inscriptions (Roth \& Bowen, 1999). Taken together, the recording processes described in chapter 3 to 5 dissociated sounds further from their original context to enable them to be reproduced as a coordinated set of data that could be replicated virtually endlessly and to be circulated, shared with and consulted by others. Such mobile inscriptive objects - aural as well as visual - afforded their owners an unprecedented control over fleeting aural phenomena. The micro-phonic transduction of an auditory phenomenon into electrical signals in effect constructed a new perceptual field in which sounds could be manipulated, modified and processed. Records thus enabled complex soundscapes to be partitioned, focused, amplified, 
filtered, sampled and, what I have termed sterilized (Bruyninckx, 2012). They extracted an acoustic phenomenon from the space and time in which it originally took place, and even from the time it took to listen to it. Mediated forms of listening allowed acoustic structures to be repeated endlessly, to be slowed down infinitely, or in case of a spectrographic image, to be congealed into form. Crucially, all of these interventions were part of a long trajectory by which the natural world could progressively be ordered. As I have shown in chapter 3 and 5 , these processes were not only similar to those applied to visual data, but also geared towards their eventual reproduction as visual data. As visual traces, inscriptions enabled records to be made perceptually consistent, combined, juxtaposed, compared and layered with other inscriptions. It is this 'cascade' of inscriptive processes, the parabolic record into the spectrogram into a table, that made recording not only a powerful analytic means, but also a potentially authoritative conveyor of scientific claims.

But the mere production, processing and distribution of recordings itself did not always suffice to restrict interpretation or settle disputes. The material conditions of each type of inscription were, after all, inextricably connected to different technological, cultural, economic and social conditions. Because these attenuated in different ways the persuasive power of the mechanical record, their credibility was often in turn subject to social matters of control and authority. Magnetic tape, for instance, was a cheap and versatile as well as vulnerable medium. It might easily crumple, be erased or over-copied. The material also enabled relatively easy montage, which made it a preferred medium among sound archivists and spectrograph users, because it facilitated the selection and combination of samples on storage reels or tapes prepared for spectrographic rendering. But in the hands of amateur or commercial recordists, the possibility to tinker or montage could also potentially diminish a tape's reliability as an authentic registration of sound. Similarly, the sound spectrogram represented a convenient obligatory passage point for processing recordings into accepted claims. In principle, it was very easy to duplicate in print, relatively easy to process into new inscriptions, and the expense and technical complexity of the equipment also privileged their production to professional bird song biologists. But even as a prime example of the cascading inscription, spectrograms too were subject to epistemological dispute amongst professional biologists. Where Cambridge ethologists had routinely relied on intuition and experience to adjust the spectrogram so that it would convey relevant patterns most effectively, Cornell ornithologists had remained dismissive and suspicious of such interpreted inscriptions and preferred to retain the integrity of the 'mechanically objective' image instead. To understand how sound records have become legitimate scientific objects, we cannot separate the character of mechanic inscription devices from the social conventions in which they have been embedded, and the labor involved in enforcing those.

As this dissertation has shown, sound recordings thus functioned within the seminal web of material, social and representational technologies (Shapin, 1984), as well as what historian of science and technology Lissa Roberts (1995) has identified 
as the 'sensuous technologies' of a human observer - the ways in which the observer deployed his or her body within this network. One context in which I have described the complex entanglement of these technologies has been in the Cornell Library of Natural Sounds' own 'moral economy'. Claims for the legitimacy of sound recordings became folded not only in the material technology of the tape record or representational technologies, such as the standardized form for field and recording notes. They also became institutionalized in social and moral technologies of exchange, reward and accountability, such as copyright and authorship. Crucially, this local moral economy did not only enable recordists to manage the 'economy' of recording, their production as well as circulation, but also consolidated the habitus of 'scientific recordist' amongst its socially diverse collaborators. These technologies thus also helped to establish epistemological guidelines and inculcate social norms and conventions. They ensured that recordists produced their recordings with the right equipment, without needlessly tinkering with tape records, by describing them correctly and as completely as possible. Finally, they were also deployed to ensure that recordists possessed the right sonic skills and field craft to make such field observations sufficiently reliable. Clearly, for inscriptions to work as such, their production had to be managed as precisely as possible - materially, socially and, indeed, also physically.

Indeed, a number of corporeal techniques and basic contextual skills have been required in the manufacture of successful inscriptions, such as handling magnetic tape, penmanship and a grasp of aural patterning for tracing spectrograms, perceiving the field through the mechanical ears of the microphone and those of others listening in, or simply picking up subtle distortions. But the production of dependable inscriptions rested not only on technical skills, but also on basic aural naturalistic knowledge. Although recording and analysis themselves could be mechanized, collecting and interpreting them still could not. Bird song could not be described authoritatively without a stable perceptual framework that enabled field observers to judge whether what they heard in the field was the sound of a bird, whether it was new or familiar, of which species and what behavior it displayed, and whether it was potentially relevant or not. Exactly because all recordists - academic, commercial and amateur - remained dependent on monitory, exploratory and diagnostic listening abilities in their field work, they required what John Law and Michael Lynch (1988) have termed a table of possibilities. A mental or concrete taxonomic array by which ornithological listeners may organize their perception in the field and bring their own tacit, idiosyncratic apprehensions of a sound in accordance with a standardized aural discourse. For this aural enskillment, listeners thus relied not only on the experience and field-craft that they acquired over time by themselves, but also on circulated records.

Because bird song biology has remained reliant on practiced listeners in the field, the organization of scientific sound recording has necessarily been interwoven with questions of pedagogy and instruction as well. This is an important point, because this need for aural enskillment of field listeners required a re-conversion: 
from the visual realm of 'mechanically objective' traces to that of the observers' own inevitably multi-sensorial (and especially aural) experience in the field. As section 2 has outlined, this tension between analysis and pedagogy has been of continuous concern to bird song biologists since 1900. It is for this reason that around 1915, musical diagrams were complemented with graphic notations that were claimed to be more easily readable and memorizable in field work. And it is for the same reason that biologists in 1965 sought to mend the sound spectrograph, in turn, with musical notation. As these examples suggest, the relation between analysis and pedagogy has been one of persistent tension. After all, sound recordings were both to reduce subjective, highly individual interpretation of sound and to foster a tacit, experiential knowledge of those sounds in the field to others.

This tension between encapsulating and mediating sound knowledge also explains why recording formats continued to co-exist as they did. New types of inscriptions did not simply obliterate one another; instead, they accumulated, proliferated and extended into local complexes of technical and social practice. Hence, around 1965, scientists, amateur and professional recordists would routinely capture, edit, archive, or exchange a bird's song on a magnetic tape record. But the same song could also be converted to the more robust and immutable medium of a gramophone record, which would be distributed for pedagogical purposes and popular display. That same record could also be found scribbled down as a personal graphic diagram in field or laboratory notes for the recordist's own reference, or even be rendered as a musical score to stimulate alternative conceptions of aural patterns; and ultimately, that recording would be converted into a spectrogram that served further analysis and could be integrated as proof in scholarly publication. Each of these media captured and codified sound in a different way, appealed to different audiences and functions, and came with different conventions of scientific authority.

Therefore, for a full understanding of how sound recording and listening have been organized as scientific practice in a socially diverse field science such as ornithology, we need to take into account a more complex economy of sound recording. Recordings, after all, necessarily acquired multiple functions; based on examples in the rich history of scientific representation, I have specified their roles as not only 'mimetic', but also 'didactic', 'mnemonic' and 'alluring'. Recognizing this range of possible functions, this dissertation has shown that the production and legitimization of scientific records has almost invariably also involved the distribution of alternatively accessible, popular, memorizable, instructive, amazing or enjoyable recordings. Bird song recordings have been published in the form of phonograph records, tapes, musical notations, graphic forms, as aural taxonomic fieldguides or as compiled soundscapes, as illustrations on radio broadcasts or as artistic interpretations. It has not been within the scope of this book to consider in detail each of the audiences that have been implicated in the consumption of ornithological records. It has shown, however, that many of these diverse functions and audiences have often been implied and negotiated in the production of scientific rec- 
ords. Its producers sought to align their own analytic applications with the instructive and popular uses on which they variously depended, for financial support or labor.

The parabolic recording technique has been a case in point here. Its close-up and sterilized records enabled sounds to be reproduced better as spectrographic images, but its focused and perspective-less sound has also provided a basis of sound samples that were used on auditory field-guides to instruct aspiring ornithologists on the defining features of a species' song, or provided the raw material with which new artificial, but nonetheless evocative and potentially alluring, soundscapes and radio broadcasts were created for the more general listener. Indeed, such recordings have in important (and sometimes unforeseen) ways contributed to the development of scientific recording. Many of the amateur tape recordists who started recording in the 1950s, after all, reported to have found themselves inspired by the records distributed by the Cornell Laboratory of Ornithology or BBC broadcasts. Understanding how sound recording stabilized as a scientific practice in fact requires grasping exactly this: that the ways in which recordings were produced and made to circulate beyond the scientific domain ultimately mattered to their appreciation, legitimization and success. Taken together then, this dissertation has shown that understanding how sound recordings gained currency as scientific material in a field science such as that of bird song biology, requires paying attention to the fluidity of inscriptions and the conversions that they underwent - between different media, between different social and professional contexts, as well as between different sensory modalities.

\section{Conclusion}

In this concluding chapter, I have outlined some of the ways in which scientific sound recording stabilized within a historically specific technological culture. I have shown how many of the issues that concerned bird song biologists at the turn of the century continued to do so in subsequent decades. At the same time, how people listened and how they used recordings to do so has also gradually changed. They are, moreover, likely to be changing still. As chapter 5 has shown, William Thorpe had been unsuccessful in teaching ornithologists to listen synesthetically, that is, listening by looking at a spectrogram or diagram. This, however, is exactly what a number of recent popular books dedicated to the study and identification of birds have set out to do. In his book The Sound Approach to Birding, birdwatcher Mark Constantine (2006) teaches readers how to understand bird sound by reference not only to a CD but also to a series of spectrograms. Birdsong authority Donald Kroodsma (2007) has taken a similar approach in the widely acclaimed popular scientific book titled The Singing Life of Birds.

In his book, suggestively subtitled The Art and Science of Listening to Birdsong, Kroodsma explained his craft: "You must have exceptional ears,' people often say 
to me as they lament how tone-deaf they must be in comparison. 'No,' I reply, 'they're actually pretty pathetic, and I have no musical ability whatsoever. But like most of us, I have well-trained eyes, and it is with my eyes that I hear." Kroodsma does not advertise a reduction of the aural to the visual here, but rather a synesthetic ability to hear what he sees, and to see what he hears. This, he explained, is a skill that he acquired with practice and habit. "As a bird sings," he explains, "I see the rudiments of a sonagram form in my mind [ . . . It's an unavoidable habit developed from years of watching song displays this way on my computer screen. It is the patterns I see that enhance the beauty I hear" (2007, pp. 1-2). Likewise, Constantine assures his reader, "when you put timbre, pitch and timing together and give them a stir you get structure and syntax. [ . . ] Bird sound has structure but you can only see it in a sonagram. Learn to read a sonagram and you are on the road to success" (2006, p. 25). Sonagrams, the authors announced, could replace the variety of methods with which recordists and bird-watchers, to this day, still attempt to capture the essence of a vocalization. The Hamlyn guide to birds of Britain and Europe, by Bruun, Delin \& Svensson (1992), developed around 120 different adjectives to convey the quality of bird sound: the sound of the Sandwich Tern, for instance, is imaginatively described as "amalgam being pressed into a tooth". "Such colourful descriptions are worth attempting," Constantine noted, "but in practise [sic] few of us have the poetic talent to match them" (Constantine \& SoundApproach, 2006, p. 17).

But the modern-day birdwatcher did not achieve such synesthetic listening by training only; in comparison to Thorpe's time, the modern-day birdwatcher now also benefits from changes in technological culture. Kroodsma and Constantine indeed assume their readers to have easy access to the possibilities that digital audio affords, due to the proliferation of personal computers, laptops and free audio processing software. When Constantine started listening, "I bought a Mac lap-top, and was producing my own sonagrams a short time later. I won't pretend I found it easy, but it was very satisfying. It meant I could make sound recordings in the field, analyse them at home, and compare them with published recordings and sonagrams" (Constantine \& SoundApproach, 2006, p. 28). Likewise, Kroodsma recalls that "graphing a bird's sound not too long ago required equipment costing thousands of dollars," yet now everyone can "get the appropriate software program, a laptop computer, and a microphone, and you can watch the songs dance across your computer monitor in the great out-of-doors as you listen to birds there. Listen as you see, and you will hear a different world singing to you" (2007, p. 409). The Cornell Laboratory of Ornithology for instance developed specialized bioacoustical software for the spectrographic analysis of animal sound, called Raven Pro, but has also made a less advanced version available for free, which Kroodsma advises his readers to use. Now techniques of visualization are no longer the privilege of advanced biological laboratories, and the production, editing, duplication, distribution and exchange of sound recordings made in the field is easier than ever before, conditions for recording and listening to bird sound in the field appear to 
be changing again. It may indeed remain to be seen what different worlds new listeners will still hear singing to them. 


\section{Appendix A: \\ Source collection and their abbreviations}

Allen Papers (CUL): Arthur A. Allen Papers, \# 21-18-1255, Division of Rare and Manuscript Collections, Carl A. Kroch Library, Cornell University Library.

BBC NHRU (WAC): British Broadcasting Corporation, Recording General and Natural History Recording Unit files, Record Units R46, R57, S26, British Broadcasting Corporation, Written Archives Center.

BLOWS Records (BL): British Library of Wildlife Sounds, Records, 1969(ongoing).

Brand Papers (CUL): Albert R. Brand Papers, \# 21-18-899, Division of Rare and Manuscript Collections, Carl A. Kroch Library, Cornell University Library.

Kellogg Papers (CUL): Peter P. Kellogg Papers, \# 21-18-893, Division of Rare and Manuscript Collections, Carl A. Kroch Library, Cornell University Library.

MLNS Papers (CLO): Cornell Laboratory of Ornithology, Macaulay Library of Natural Sounds, Records 1931-(ongoing).

Stillwell Papers (CUL): Jerry and Norma Stillwell Papers, \#2621, Division of Rare and Manuscript Collections, Carl A. Kroch Library, Cornell University Library.

Tanner Papers (CUL): James Taylor Tanner Papers, \#2665, Division of Rare and Manuscript Collections, Carl A. Kroch Library, Cornell University Library.

Thorpe Papers (CaUL): William Homan Thorpe Papers, GB 012 Ms.Add 8784, Manuscript Collections, Cambridge University Library.

Tierstimmenarchiv Records (HU): Humboldt Universität Tierstimmenarchiv, Records, 1951-(ongoing). 



\section{Appendix B: Interviews}

This dissertation draws on a selection of oral interviews with naturalists, recordists, sound archivists and ornithologists. These were collected in part by the author himself (I), and in part by the British Library and other institutes as part of oral history programs on the history of sound recording (II).

Jeffrey Boswall (BBC Natural History Unit producer \& ornithologist)

24 July 2009, Bristol (UK)

Roger Boughton (Chairman of the Wildlife Sound Recording Society)

14 May 2010, Ennerdale (UK)

Greg Budney (Curator Macaulay Library of Natural Sounds)

10 September 2010, Cornell Lab of Ornithology (USA)

Alan Burbidge (Wildlife recordist)

15 May 2010, Ennerdale (UK)

Martha Fischer (Archivist at Macaulay Library of Natural Sounds)

10 September 2010, Cornell Lab of Ornithology (USA)

Karl-Heinz Frommolt (Curator Tierstimmenarchiv)

10 February 2009, Humboldt Universität Berlin (DE)

Randolph Little (Recordist at Cornell Lab of Ornithology)

10 October 2010, Cornell Lab of Ornithology (USA) + personal communica-

tion by email April 2011

Matt Medler (Archivist at Macaulay Library of Natural Sounds)

10 September 2010, Cornell Lab of Ornithology (USA)

Richard Ranft (Head Sound \& Vision, British Library Sound Archive)

22 April 2009, British Library (UK)

Magnus Robb (Wildlife recordist)

8 March 2008, Putten (NL)

Hans Slabbekoorn (behavioral biologist)

17 March 2008, Institute of Biology Leiden (UK)

Guenter Tembrock (behavioral biologist, founder of Tierstimmen-archiv)

10 February 2009, Berlin (DE) 
Cheryl Tipp (Curator of the British Library Sound Archive Wildlife section) 23 April 2009, British Library (UK)

(II)

John F. Burton (Former curator of BBC wildlife sound archive)

3 May 2001, by Christopher Parsons

Desmond Hawkins (BBC natural history unit producer)

9 October 1998, by Chris Parsons (Wildscreen Archive)

M. Peter Keane (Recordist at Cornell Lab of Ornithology)

26 September 1983, by Jeffrey Boswall

John Kendrick (Wildlife recordist)

January 1984, by Ron Kettle (C90/18/01 British Library)

John Kirby (Wildlife recordist)

21 June 1983, by Patrick J. Sellar (C90/05/01 British Library)

Victor C. Lewis (Wildlife recordist)

14 March 1983, by Patrick J. Sellar (C90/01/01 British Library)

Richard Margoschis (Wildlife recordist)

January 1984, by Elizabeth Brett (C90/19/01 British Library)

Philip Monson (Former BBC recording engineer)

June 1984, by Ron Kettle (C90/57 British Library)

Sture Palmér (Wildlife recordist)

30 March 1983, by Patrick J. Sellar (C90/03/01 British Library)

Eric Simms (Former curator of BBC wildlife sound archive)

March 1983, by Elizabeth Brett (C90/42 British Library)

Carl Weismann (Wildlife recordist)

28 March 1983, by Patrick J. Sellar (C90/02/01 British Library) 


\section{List of illustrations}

Figure 1.1 Cornell ornithologist Peter P. Kellogg on field expedition. Reproduced from: Brand Papers (CUL), 2:1. Reproduced with kind permission of Division of Rare and Manuscript Collections, Carl A. Kroch Library, Cornell University Library.

Figure 2.1 Transcript of Bobolink song by Ferdinand S. Mathews. Reproduced from: Mathews, F. S. (1904). Field Book of Wild Birds and Their Music: A Description of the Character and Music of Birds. New York: Putnam, p. 51.

Figure 2.2 Adapted 'scientific' musical notation by Hans Stadler and Cornel Schmitt. Reproduced from: Stadler, H. \& Schmitt, C. (1915). The Study of Bird-Notes. British Birds 8(1), p. 7. Reproduced with kind permission of British Birds.

Figure 2.3 Musical notation of Fox Sparrow song by Robert T. Moore. Reproduced from: Moore, R. T. (1913). The Fox Sparrow as a Songster. The Auk 30, p. 178.

Figure 2.4 Musical notation of Black Redstart by Alwin Voigt. Reproduced from: Voigt, A. (1913). Excursionsbuch zum Studium der Vogelstimmen. Praktische Anleitung zum Bestimmen der Vögel nach ihrem Gesange von prof. dr. A Voigt (6th ed.). Leipzig: Quelle u. Meyer, p. 37. Reproduced with kind permission of Quelle-Meyer.

Figure 2.5 Musical notation by Bernard Hoffmann. Reproduced from: Hoffmann, B. (1908). Kunst und Vogelgesang in ihren Wechselseitigen beziehungen vom naturwissenschaftlichmusikalischen Standpunkte: Quelle \& Meyer, p. 55. Reproduced with kind permission of Quelle-Meyer.

Figure 2.6 Graphical recording of Field Sparrow song by Aretas A. Saunders. Reproduced from: Saunders, A. A. (1915). Some Suggestions for Better Methods of Recording and Studying Bird Songs. The Auk, 32(2), p. 175.

Figure 2.7 Graphical - syllabic recording of a Curlew by William M. Rowan. Reproduced from: Rowan, W. M. (1925). A practical method of recording bird-calls. British Birds, 18(1), p. 18. Reproduced with kind permission of British Birds.

Figure 3.1 Preparing the recording-van in the field. Reproduced from: Nicholson, M., \& Koch, L. (1937). More Songs of Wild Birds. London: H. F. \& G. Witherby, Ltd, p. viii.

Figure 3.2 Listening at the loud-speakers in the mobile studio. Reproduced from: Nicholson, M., \& Koch, L. (1937). More Songs of Wild Birds. London: H. F. \& G. Witherby, Ltd, p. 5. 
Figure 3.3 Cornell ornithologist James Tanner 'aiming' the parabolic reflector. Reproduced from: Brand Papers (CUL), 2:1. Reproduced with kind permission of Division of Rare and Manuscript Collections, Carl A. Kroch Library, Cornell University Library.

Figure 3.4 British recordists fixing up a microphone near a song-perch. Reproduced from: Nicholson, M., \& Koch, L. (1937). More Songs of Wild Birds. London: H. F. \& G. Witherby, Ltd, p. 4.

Figure 3.5 Schemes illustrating the recording range of an ordinary crystal microphone and parabolic reflector. Reproduced from: Purves, F. (1962). Bird Song Recording. London: The Focal Press: p. 38-41.

Figure 4.1 Amateur recording couple Jerry and Norma Stillwell with their equipment in the field. Reproduced from: Stillwell, N. (1964). Bird Song. Adventures and Techniques in Recording The Songs of American Birds. New York: Doubleday \& Company, Inc., p. 51.

Figure 4.2 Kellogg testing a mobile recording unit with parabolic reflector. Reproduced from: Kellogg Papers (CUL), 7:7. Reproduced with kind permission of Division of Rare and Manuscript Collections, Carl A. Kroch Library, Cornell University Library.

Figure 4.3 Cornell Library of Natural Sounds field and editing notes form. Reproduced from: MLNS Records. Record number 06830. Courtesy of Cornell Library of Natural Sounds.

Figure 5.1 William H. Thorpe recording a dove at the Madingley Ornithological Field Station in Cambridge. Reproduced from: Hall-Craggs, J. (1987). Obituary. William Homan Thorpe. Ibis, 129(s2), p. 568. Courtesy of Les Barden, reproduced with kind permission of Wiley Publishers.

Figure 5.2 Original oscillogram of the phrase 'visible speech'. Original source: Potter, R. K., Kopp, G. A., \& Green, H. C. (1947). Visible Speech. London: Macmillan and Co. Reproduced from: Marler, P., \& Slabbekoorn, H. (Eds.). (2004). Nature's Music. The Science of Birdsong. Amsterdam et al: Elsevier Academic Press.

Figure 5.3 Original spectrogram of the phrase 'visible speech'. Reproduced from: Potter, R. K. (1945). Visible Patterns of Sound. Science, 102(2654), p. 464. Reproduced with permission of Science Magazine.

Figure 5.4 Visual model dividing song 'structures' into analyzable components. Reproduced from: Marler, P., \& Tamura, M. (1962). Song "Dialects" in three populations of white-crowned sparrows. The Condor, 64(5), p. 369. Reproduced with kind permission of the Cooper Ornithological Society

Figure 5.5 Ink tracing by hand of a spectrogram. Reproduced from: Marler, P., Kreith, M., \& Tamura, M. (1962). Song Development in Hand-Raised Oregon Juncos. The Auk, 79(1), p. 15.

Figure 5.6 Thorpe \& Lade's diagrammatic notation based on sonagrams. Reproduced from: Thorpe, W. H., \& Lade, B. I. (1961). The songs of some families of the Passeriformes. I. Introduction: the analysis of bird songs and their expression in graphic notation. Ibis, $103 a(2)$, p. 238. 
Figure 5.7 Musical notation of duetting Shrikes by Thorpe. Reproduced from: Thorpe, W. H. (1966). Ritualization in Ontogeny. II. Ritualization in the Individual Development of Bird Song. Philosophical Transactions of the Royal Society of London. Series B. Biological Sciences, 251(772), p. 355. Reproduced with kind permission of the Royal Society of London.

Figure 5.8 Adapted spectrogram fitted with logarithmic scale and musical octaves. Reproduced from: Marshall Jr., J. T. (1964). Voice in Communication and Relationships among Brown Towhees. The Condor, 66(5), p. 346. Reproduced with kind permission of Cooper Ornithological Society.

Figure 5.9 Sound spectrographic analysis of a wren song, with logarithmic scale and musical score imposed. Reproduced from: Hall-Craggs, J. (1979). Sound Spectrographic Analysis: Suggestions for Facilitating Auditory Imagery. The Condor, 81(2), p. 190. Reproduced with kind permission of Cooper Ornithological Society.

Figure 5.10 Musical stave made by a sound spectrogram, imposed with microtone intervals. Reproduced from: Hall-Craggs, J. (1979). Sound Spectrographic Analysis: Suggestions for Facilitating Auditory Imagery. The Condor, 81(2), p. 189. Reproduced with kind permission of Cooper Ornithological Society.

Figure 5.11 A synoptic display of Western meadowlark songs from different regions by Wesley Lanyon and William Fish. Reproduced from: Lanyon, W., \& Fish, W. (1958). Geographical Variation in the Vocalization of the Western Meadowlark. The Condor, 60(5), p. 340. Reproduced with kind permission of Cooper Ornithological Society.

Figure 5.12 Sonagrams enabling the synoptic comparison of songs of two individual birds in one location. Reproduced from: Lemon, R. E., \& Herzog, A. (1969). The vocal behavior of Cardinals and Phyrrhuloxias in Texas. The Condor, 71(1), p. 6. Reproduced with kind permission of Cooper Ornithological Society.

Figure 5.13 Further 'cascade': graph representing the statistical relations for the syllables of songs for six separate individuals in two different localities. Reproduced from: Lemon, R. E., \& Herzog, A. (1969). The vocal behavior of Cardinals and Phyrrhuloxias in Texas. The Condor, 71(1), p. 8. Reproduced with kind permission of Cooper Ornithological Society. 



\section{Bibliography}

Abbott, A. (1988). The System of Professions. An Essay on the Division of Expert Labor. Chicago: University of Chicago Press.

Abbott, C. C. (1896). Bird-Land Echoes. Philadelphia: J.B. Lippincott Company.

Ainley, M. G. (1979). The Contribution of the Amateur to North American Ornithology: A Historical Perspective. The Living Bird, 18(1): 161-77.

Alberti, S. J. M. M. (2001). Field, Lab and Museum: The Practice and Place of Life Science in Yorkshire 1870-1904 (PhD thesis). University of Sheffield, Sheffield.

Alexander, H. G. (1943). Report on the Bird-Song Inquiry. British Birds, 36(4): 6572.

Allen, F. H. (1919). The Evolution of Bird-Song. The Auk, 36(4): 528-36.

Allen, D. E. (1976). The Naturalist in Britain. Princeton, NJ: Princeton University Press.

Alpers, S. (1998). The Studio, the Laboratory, and the Vexations of Art. In C. A. Jones \& P. Galison (Eds.), Picturing Science, Producing Art (pp. 401-419). New York: Routledge.

Alström, P., \& Ranft, R. (2003). The use of sounds in avian systematics and the importance of bird sound archives. Bulletin of British Ornithologists' Club, 123A: 114-35.

Altman, R. (Ed.). (1992). Sound Theory/Sound Practice. New York \& London: Routledge.

Amann, K., \& Knorr Cetina, K. (1988). The fixation of (visual) evidence. Human Studies, 11(2/3): 133-69.

Ames, E. (2003). The Sound of Evolution. Modernism/Modernity, 10(2): 297-325.

Andrew, R. J. (1957). A comparative study of the calls of Emberiza SPP (Buntings). Ibis, 99(1): 27-42.

Atikson-Grosjean, J., \& Fairley, C. (2009). Moral Economies in Science: From Ideal to Pragmatic. Minerva, 47(2): 147-70.

Axtell, H. H. (1938). The song of Kirtland's warbler. The Auk, 55(3): 481-91.

Bailey, C. E. G. (1950). Towards an Orthography of Bird Song. Ibis, 92(1): 115-22.

Baker, M. C. (2001). Bird Song Research: The Past 100 Years. Bird Behavior, 14(1): 3-50.

Bales, S. L. (2010). Ghost Birds. Jim Tanner and the Quest for the Ivory-billed Woodpecker, 1935-1941. Knoxville: University of Tennessee Press. 
Baptista, L. F., \& Gaunt, S. L. L. (1997). Bioacoustics as a tool in conservation studies. In J. R. Clemmons, \& Buchholz, R. (Eds.), Behavioral Approaches to Conservation in the Wild (pp. 212-242). Cambridge: Cambridge University Press.

Barrow, M. V. (1998). A Passion for Birds. American Ornithology after Audubon. Princeton NJ: Princeton University Press.

Barrow, M. V. (2000). The Specimen Dealer: Entrepreneurial Natural History in America's Gilded Age. Journal of the History of Biology, 33(3): 493-534.

Barrow, M. V. J. (2011). On the Trail of the Ivory-Bill: Field Science, Local Knowledge, and the Struggle to Save Endangered Species. In J. Vetter (Ed.), Knowing Global Environments: New Historical Perspectives on the Field Sciences (pp. 135-161). New Brunswick: Rutgers University Press.

Battalio, J. T. (1998). The Rhetoric of Science in the Evolution of American Ornithological Discourse (Vol. 8). London/Stanford, CO: Ablex Publishing Corporation.

Bevis, J. (2010). aaaaw to zzzzzd: The Words of Birds. Cambridge, MA: MIT Press.

Beyer, G. G. (1900). The Ivory-Billed Woodpecker in Louisiana. The Auk, 17(2): 97-9.

Biagioli, M. (1998). The Instability of Authorship: Credit and Responsibility in Contemporary Biomedicine. The Journal of the Federation of American Societies for Experimental Biology, 12(1): 3-16.

Biagioli, M. (2003). Rights or Rewards? Changing Frameworks of Scientific Authorship. In M. Biagioli \& P. Galison (Eds.), Scientific Authorship. Credit and Intellectual Property in Science (pp. 253-80). New York and London: Routledge.

Biagioli, M., \& Galison, P. (Eds.). (2003). Scientific Authorship. Credit and Intellectual Property in Science. New York \& London: Routledge.

Bijker, W. E., Hughes, T. P., \& Pinch, T. J. (Eds.). (1987). The Social Construction of Technological Systems: New Directions in the Sociology and History of Technology. Cambridge, MA: MIT Press.

Bijsterveld, K. (2001). The Diabolical Symphony of the Mechanical Age: Technology and Symbolism of Sound in European and North American Noise Abatement Campaigns, 1900-40. Social Studies of Sciences, 31(1): 37-70.

Bijsterveld, K. (2003). 'The City of Din': Decibels, Noise, and Neighbors in the Netherlands, 1910-1980. Osiris, 18: 173-93.

Bijsterveld, K. (2004). 'What do I do with my tape recorder . . . ?': Sound hunting and the sounds of everyday Dutch life in the 1950s and 1960s. Historical Journal of Film, Radio and Television, 24(4): 613-34.

Bijsterveld, K. (2008). Mechanical Sound. Technology, Culture, and Public Problems of Noise in the Twentieth Century. Cambridge: MIT Press.

Bijsterveld, K., \& Jacobs, A. (2009). Storing Sound Souvenirs: The Multi-Sited Domestication of the Tape Recorder. In K. Bijsterveld \& J. v. Dijck (Eds.), Sound Souvenirs: audio technologies, memory and cultural practices (pp. 25-42). Amsterdam: Amsterdam University Press.

Bircham, P. (2007). A History of Ornithology. London: Collins. 
Birkhead, T. R. (2003). A Brand-New Bird. How two amateur scientists created the first genetically engineered animal. New York: Basic Books.

Birkhead, T. R. (2011). The Wisdom of Birds: An Illustrated History of Ornithology. London: Bloomsbury Publishing.

Birkhead, T. R., \& Balen, S. v. (2008). Bird-keeping and the development of ornithological science. Archives of Natural History, 35(2): 281-305.

Boon, T. (2009). The Professionalisation of Natural History Filmmaking and the Discipline of Biology: The Role of Julian Huxley. Paper presented at the BSHS Conference

Borror, D. J. (1956). Variation in Carolina Wren songs. The Auk, 73(2): 211-29.

Borror, D. J. (1959). Variation in the Songs of the Rufous-sided Towhee. The Wilson Bulletin, 71(1): 54-72.

Borror, D. J. (1961). Intraspecific Variation in Passerine Bird Songs. The Wilson Bulletin, 73(1): 57-78.

Borror, D. J., \& Reese, C. R. (1953). The Analysis of Bird Songs by Means of a Vibralyzer. The Wilson Bulletin, 65(4): 271-303.

Bowker, G. C. (2000). Biodiversity datadiversity. Social Studies of Science, 30(5): 64383.

Brady, E. (1999). A spiral way: how the phonograph changed ethnography. Jackson: University Press of Mississippi.

Brain, R. M. (1998). Standards and Semiotics. In T. Lenoir (Ed.), Inscribing Science. Scientific Texts and the Materiality of Communication (pp. 249-285). Stanford, CA: Stanford University Press.

Brain, R. M. (2002). Representation on the Line: Graphic Recording Instruments and Scientific Modernism. In B. Clarke \& L. D. Henderson (Eds.), From Energy to Information. Representation in Science and Technology, Art, and Literature (pp. 155178). Stanford, CA: Stanford University Press.

Brand, A. R. (1932). Recording Sounds of Wild Birds. The Auk, 49(4): 436-9.

Brand, A. R. (1934). Songs of Wild Birds. New York: Thomas Nelson and Sons.

Brand, A. R. (1935). A method for the intensive study of bird song. The Auk, 52(1): 40-52.

Brand, A. R. (1936). More Songs of Wild Birds. New York: Thomas Nelson and Sons.

Brand, A. R. (1937). Why bird song can not be described adequately. The Wilson Bulletin, 49(1): 11-4.

Brand, A. R., \& Axtell, H. (1938). Song of the Chipping Sparrow. The Auk, 55(1): 125-6.

Brumm, H., \& Todt, D. (2002). Noise-dependent song amplitude regulation in a territorial songbird. Animal Behaviour, 63(5): 891-7.

Bruun, B., Delin, H., \& Svensson, L. (1992). Birds of Britain and Europe. London: Hamlyn.

Bruyninckx, J. (2012). Sound Sterile: Making Scientific Field Recordings in Ornithology. In T. Pinch \& K. Bijsterveld (Eds.), The Oxford Handbook of Sound Studies (pp. 127-50). Oxford/New York: Oxford University Press. 
Budney, G. F., \& Grotke, R. W. (1997). Techniques for Audio Recording Vocalizations of Tropical Birds. Ornithological Monographs (48): 147-63.

Burkhardt Jr., R. (1992). Huxley and the Rise of Ethology. In K. C. Waters \& A. V. Helden (Eds.), Julian Huxley. Biologist and Statesman of Science (pp. 127-149). Houston, TX: Rice University Press.

Burkhardt Jr., R. W. (1999). Ethology, natural History, the Life Sciences, and the Problem of Place. Journal of the History of Biology, 32(3): 489-508.

Burkhardt Jr., R. W. (2005). Patterns of Behavior. Konrad Lorenz, Niko Tinbergen, and the Founding of Ethology. Chicago: University of Chicago Press.

Burkitt, J. P. (1922). Observations on Song-periods. British Birds, 15(12): 299.

Burton, J. F. (1967). The scientific use of BBC wildlife sound recordings. Ibis, 109(1): 126.

Burton, J. F. (1969). Wildlife Recordings in the BBC Sound Archives. Recorded Sound, 34 .

Busnel, R.-G. (Ed.). (1963). Acoustic behavior of animals. Amsterdam: Elsevier

Cambrosio, A., Jacobi, D., \& Keating, P. (1993). Ehrlich's "Beautiful Pictures" and the Controversial Beginnings of Immunological Imagery. Isis, 84(4): 662-99.

Catchpole, C. K. (1973). The Functions of Advertising Song in the Sedge Warbler (Acrocephalus schoenobaenus) and the Reed Warbler (A. scirpaceus). Behaviour, 46(3/4): 300-20.

Catchpole, C. K., \& Slater, Peter J. B. (1995). Bird Song: Biological Themes and Variations. Cambridge: Cambridge University Press.

Chanan, M. (1995). Repeated Takes: A Short History of Recording and Its Effects on Music. London/New York: Verso.

Chapman, F. (1915). Bird Clubs in America. Bird-Lore, 17: 348.

Cheney, S. P. (1892). Wood Notes Wild. Notations of Bird Music. Boston: Lee \& Shepard Publishers.

Clark, X. (1879). Animal Music, its Nature and Origin. The American Naturalist, 13(4): 209-23.

Clarke, A., \& Fujimara, J. (Eds.). (1992). The Right Tools for the Job: At Work in Twentieth-Century Life Sciences. Princeton: Princeton University Press.

Classen, C. (1993). Worlds of Sense: Exploring the Senses in History and Across Cultures. London/New York: Routledge.

Coates, P. A. (2005). The Strange Stillness of the Past: Toward an Environmental History of Sound and Noise. Environmental History, 10(4): 636-65.

Coffin, L. V. B. (1928). Individuality in Bird Song. The Wilson Bulletin, 40(2): 95-9.

Collias, N. E., \& Joos, M. (1953). The Spectrographic Analysis of Sound Signals of the Domestic Fowl. Behaviour, 5(3): 175-88.

Collins, H. M. (2001). Tacit Knowledge, trust, and the Q of sapphire. Social Studies of Science, 31(1): 71-86.

Collins, H. M., \& Pinch, T. (1993). The Golem: What You Should Know about Science. New York: Cambridge University Press. 
Constantine, M., \& SoundApproach. (2006). The Sound Approach to Birding: A Guide to Understanding Bird Sound. Dorset: The Sound Approach.

Cooper, F. S., Liberman, A. M., \& Borst, J. M. (1951). The Interconversion of Audible and Visible Patterns as a Basis for Research in the Perception of Speech. Proceedings of the National Academy of Science, 37(5): 318-25.

Copeland, P., Boswall, J., \& Petts, L. (1988). Birdsongs on Old Records. A Coarsegroove Discography of Palearctic Region Bird Sound 1910-1958. London: The British Library National Sound Archive Wildlife Section.

Corbin, A. (1998). Village Bells: Sound and Meaning in the Nineteenth-Century French Countryside (M. Thom, Trans.). New York: Columbia University Press.

Craig, W. (1926). The Twilight Song of the Wood Pewee: A Preliminary Statement. The Auk, 43(2): 150-2.

Crist, E. (1999). Images of Animals. Anthropomorphism and Animal Mind. Philadelphia: Temple University Press.

Cynx, J., Lewis, R., Tavel, B., \& Tse, H. (1998). Amplitude regulation of vocalizations in noise by a songbird,Taeniopygia guttata. Animal Behaviour, 56(1): 10713.

Dalton, R. (2005, 8 September). A Wing and a Prayer. Nature: 188-90.

Daston, \& Galison. (2007). Objectivity. New York: Zone Books.

Daston, L. (1995). The moral economy of science. Osiris: 10: 3-24.

Daston, L. (2001). Scientific Objectivity with and without Words. In P. Becker \& W. Clark (Eds.), Little Tools of Knowledge: Historical Essays on Academic and Bureaucratic Practices (pp. 259-84). Ann Arbor: University of Michigan Press.

Daston, L., \& Sibum, H. O. (2003). Introduction: Scientific Personae and Their Histories. Science in Context, 16(1/2): 1-8.

Davis Jr., W. E., \& Jackson, J. A. (Eds.). (1995). Contributions to the History of North American Ormithology. Cambridge, MA: Nuttal Ornithological Club.

Davis, L. I. (1958). Acoustic Evidence of Relationship in North American Crows. The Wilson Bulletin, 70(2): 151-67.

De Bont, R. (2009a). Between the Laboratory and the Deep Blue Sea: Space Issues in the Marine Stations of Naples and Wimereux. Social Studies of Science, 39(2): 199-227.

De Bont, R. (2009b). Poetry and Precision: Johannes Thienemann, the Bird Observatory in Rossitten and Civic Ornithology, 1900-1930. Journal of the History of Biology, 44(2): 171-203.

Diamond, M., \& Adler, J. H. (1940). Proposed Copyright Revision and Phonograph Records. Air Law Review, 11: 29-57.

Dixon, C. (1897). Our favourite song birds. Their habits, music, and characteristics. London: Lawrence and Bullen, Ltd.

Dixon, R. (1917). The Human Side of Birds. New York: Frederick A. Stokes Company.

Dobson, C. W., \& Lemon, R. E. (1977). Bird song as music. Journal of the Acoustical Society of America, 61(3): 888-90. 
Doughty, R. W. (1975). Feather Fashions and Bird Preservation: A Study in Nature Protection. Berkeley and London: University of California Press.

Douglas, S. J. (2004). Listening In: Radio and The American Imagination. Minneapolis: University of Minnesota Press.

Dreher, C. (1931). Microhone Concentrators in Picture Production. Journal for Society of Motion Picture Engineers, 14(1): 23-30.

Dunlap, T. R. (2011). In the Field, Among the Feathered: A History of Birders and Their Guides. Oxford: Oxford University Press.

Elway, T. (1932). The Microphone, Radio's Electric Ear. Radio News, 13(7): 555-73.

Etzkowitz, H. (1989). Entrepreneurial Science in the Academy: A Case of the Transformation of Norms. Social Problems, 36(1): 14-29.

Evans, J. A. (2010). Industry Collaboration, Scientific Sharing, and the Dissemination of Knowledge. Social Studies of Science, 40(5): 757-91.

Falls, J. B. (1992). Playback: a historical perspective. In P. K. Mc Gregor (Ed.), Playback and studies of animal communication (pp. 11-33). New York: Plenum Press.

Fehr, J. (2000). 'Visible Speech’ and Linguistic Insight. In H. Nowotny \& M. Weiss (Eds.), Shifting Boundaries of the Real: Making the Invisible Visible (pp. 31-49). Zürich: vdf Hochschulverlag AG an der ETH.

Ficken, M. S., \& Ficken, R. W. (1967). Singing Behaviour of Blue-Winged and Golden-Winged Warblers and Their Hybrids. Behaviour, 28(1/2): 149-91.

Fine, T. (2008). The Dawn of Commercial Digital Recording. ARSC Journal, 39(1): $1-17$.

Fitzpatrick, J. W. e. a. (2006). Clarifications about current research on the status of Ivory-billed Woodpecker (Campephilus principalis) in Arkansas. The Auk, 123(2): 587-93.

Frings, H., Frings, M., Cox, B., \& Peissner, L. (1955). Auditory and Visual Mechanisms in Food-finding Behavior of the Herring Gull. The Wilson Bulletin, 67(3): 155-70.

Futuyama, D. J. (1986). Reflections on Reflections: Ecology and Evolutionary Biology. Journal of the History of Biology, 19(2): 303-12.

Galison, P., \& Thompson, E. (Eds.). (1999). The Architecture of Science. Cambridge, MA: MIT Press.

Garstang, W. (1922). Songs of the birds. London: John Lane.

Gaunt, S. L. L., Nelson, D. A., Dantzker, M. S., Budney, G. F., \& Bradbury, J. W. (2005). New Directions for Bioacoustics Collections. The Auk, 122(3): 984-7.

Gibling, S. P. (1917). Types of Musical Listening. The Musical Quarterly, 3(3): 385-9.

Gieryn, T. F. (2002). Three Truth-Spots. Journal of the History of the Behavioural Sciences, 38(2): 113-32.

Gieryn, T. F. (2006). City as Truth-spot: Laboratories and Field-sites in Urban Studies. Social Studies of Sciences, 36(1): 5-38

Gitelman, L. (2008). Always Already New. Media, History and the Data of Culture. Cambridge, MA: MIT. 
Gooday, G. (1991). 'Nature' in the laboratory: Domestication and Discipline with the Microscope in Victorian Life Science. British Journal for the History of Science, 24(3): 307-41.

Goodman, D. (2010). Distracted Listening: On Not Making Sound Choices in the 1930s. In D. Suisman \& S. Strasser (Eds.), Sound in the Age of Mechanical Reproduction (pp. 15-46). Philadelphia: University of Pennsylvania Press.

Goodwin, C. (1994). Professional vision. American Anthropologist, 96(1): 606-33.

Goodwin, D. (1964). Some calls and displays of the picazuro pigeon. The Condor, 66(5): 418-22.

Goodwin, D. (1965). A comparative study of captive Blue Waxbills. The Ibis, 107(3): 285-315.

Graber, R. R., \& Cochran, W. W. (1959). An Audio Technique for the Study of Nocturnal Migration of Birds. The Wilson Bulletin, 71(3): 220-36.

Grasseni, C. (Ed.). (2007). Skilled Visions. Between Apprenticeship and Standards. New York/Oxford: Bergham Books.

Greene, P. D., \& Porcello, T. (Eds.). (2005). Wired for sound: engineering and technologies in sonic cultures. Middletown, CO: Wesleyan University Press

Grimes, L. (1966). Antiphonal singing and call notes of Laniarius Barbarus Barbarus. The Ibis, 108(1): 122-6.

Griscom, L. (1922). Problems of Field Identification. The Auk, 39(1): 31-41.

Griscom, L. (1923). Birds of the New York City Region. New York: American Museum of Natural History.

Haffer, J. (2001). Ornithological research traditions in central Europe during the 19th and 20th centuries. Journal of Ornithology, 142(Suppl 1): 27-93.

Haffer, J. (2007). The development of ornithology in Central Europe. Journal of Ornithology, 148(Suppl.1): 125-53.

Haffer, J. (2008a). The origin of modern ornithology in Europe. Archives of Natural History, 35(1): 76-87.

Haffer, J. (2008b). Ornithology, Evolution, and Philosophy: The Life and Science of Ernst Mayr 1904-2005. Berlin: Springer.

Hagstrom, W. O. (1982). Gift Giving as an Organizing Principle in Science. In B. Barnes \& D. Edge (Eds.), Science in Context (pp. 21-34). Cambridge, MA: MIT Press.

Hall-Craggs, J. (1962). The Development of Song in the Blackbird. The Ibis, 104(3): 277-300.

Hall-Craggs, J. (1979). Sound Spectrographic Analysis: Suggestions for Facilitating Auditory Imagery. The Condor, 81(2): 185-92.

Hankins, T. L., \& Silverman, R. J. (1995). Instruments and the Imagination. Princeton: Princeton University Press.

Hannaway, O. (1975). The Chemists and the World: The Didactic Origins of Chemistry. John Hopkins University Press.

Hardy, J. W. (1969). A taxonomic revision of the new world Jays. The Condor, 71(4): 360-75. 
Hardy, J. W. (1975). A Tape Recording of a Possible Ivory-billed Woodpecker Call. American Birds, 29(3): 647-51.

Heinroth, O., \& Koch, L. (1935). Gefiederte Meistersänger. Berlin-Lichterfelde: Hugo Vermühler Verlag.

Helmreich. (2011). Underwater Music: Tuning Composition to the Sounds of Science. In T. Pinch \& K. Bijsterveld (Eds.), The Oxford Handbook of Sound Studies (pp. 151-75). Oxford: Oxford University Press.

Helmreich, S. (2007). An antropologist underwater: Immersive soundscapes, submarine cyborgs, and transductive ethnography. American Ethnologist, 34(4): 62141.

Henderson, K. (1991). Flexible Sketches and Inflexible Data Bases: Visual Communication, Conscription Devices, and Boundary Objects in Design Engineering. Science, Technology \& Human V alues, 16(4): 448-73.

Henke, C. R., \& Gieryn, T. F. (2008). Sites of Scientific Practice: The Enduring Importance of Place. In E. J. Hackett, O. Amsterdamska, M. Lynch \& J. Wajcman (Eds.), The Handbook of Science and Technology Studies (Third Edition ed., pp. 353-77). Cambridge, MA: MIT Press.

Hilgartner, S. (1995). Biomolecular Databases. New Communication Regimes for Biology. Science Communication, 17(2): 240-63.

Hilgartner, S., \& Brandt-Rauf, S. I. (1994). Data access, ownership, and control: toward empirical studies of access practices. Knowledge: Creation, Diffusion, Utilization, 15(4): 355-72.

Hill, G. E., Mennill, D. J., Rolek, B. W., Hicks, T. L., \& Swiston, K. A. (2006). Evidence Suggesting that Ivory-billed Woodpeckers (Campephilus principalis) Exist in Florida. Avian Conservation and Ecology, 1(3): 2.

Hine, C. (2006). Databases as Scientific Instruments and Their Role in the Ordering of Scientific Work. Social Studies of Science, 36(2): 269-98.

Hochman, B. (2010). Hearing Lost, Hearing Found: George Washington Cable and the Phono-Ethnographic Ear. American Literature, 82(3): 519-51.

Hoffmann, B. (1908). Kunst und Vogelgesang in ibren Wechselseitigen beziehungen vom naturwissenschaftlich-musikalischen Standpunkte. Quelle \& Meyer.

Höhler, S. (2002). Depth Records and Ocean Volumes: Ocean Profiling by Sounding Technology, 1850-1930. History and Technology, 18(2): 119-54.

Höhler, S. (2003). A Sound Survey: The Technological Perception of Ocean Depth, 1850-1930. Paper presented at the Transforming Spaces. The Topological Turn in Technology Studies Conference.

Hold, T. (1970). The Notation of Bird-Song: A Review and a Recommendation. The Ibis, 112(2): 151-72.

Hornbostel, E. v. (1911). Musikpsychologische Bemerkungen ueber Vogelgesang. Zeitschrift der Internationalen Musikgesellschaft, 12: 117-28

Horning, S. S. (2002). Chasing Sound: The Culture and Technology of Recording Studios in America. Case Western Reserve. 
House, N. v. (2002). Digital Libraries and Practices of Trust: Networked Biodiversity Information. Social Epistemology, 16(1): 99-114.

Hulse, S. H. (2002). Auditory scene analysis in animal communication. Advances in the Study of Behaviour, 31: 163-200.

Hunt, R. (1922). Evidence of Musical 'Taste' in the Brown Towhee. The Condor, 24(6), 193-203.

Huxley, J., \& Koch, L. (1938). Animal Language. Country Life Ltd.

Huxley, J. S. (1916). Bird-watching and biological science. Some Observations on the Study of Courtship in Birds. The Auk, 33(2): 142-61.

Ihde, D. (1976). Listening and Voice: A Phenomenology of Sound. Ohio: Ohio University Press.

Ingold, T. (2000). The Perception of the Environment. Essays on livelihood, dwelling and skill. London/New York: Routledge.

Ingold, T. (2007). Lines: A Brief History. New York: Routledge.

Jairazbhoy, N. A. (1977). The 'Objective' and Subjective View in Music Transcription. Ethnomusicology 21(2): 263-73.

Johnson, K. (2004). The Ibis: Transformations in a Twentieth Century British Natural History Journal. Journal of the History of Biology, 37(3): 515-55.

Jones, C. D., Troy, J. R., \& Pomara, L. Y. (2007). Similarities Between Campephilus Woodpecker Double Raps and Mechanical Sounds Produced by Duck Flocks. The Wilson Journal of Ornithology, 119(2): 259-62.

Judd, S. (1899). Graphophone Demonstration of a Brown Thrasher's Song. The Auk, 16(1): 52-3.

Junker, T. (2003). Ornithology and the genesis of the Synthetic Theory of Evolution. Avian Science, 3(2/3): 65-73.

Kahn, D. (1999). Noise, Water, Meat: A bistory of sound in the arts. Cambridge MA, London: MIT Press.

Kahn, D. (2002). Concerning the Line. In B. Clarke \& L. Dalrymple Henderson (Eds.), From Energy to Information: Representation in Science and Technology, Art, and Literature (pp. 178-194). Stanford, CA: Stanford University Press

Kaiser, D. (2000). Stick-Figure Realism: Conventions, Reification, and the Persistence of Feynman Diagrams, 1948-1964. Representations, 70: 49-86.

Kaiser, D. (2005a). Drawing Theories Apart. The Dispersion of Feynman Diagrams in Postwar Physics. Chicago/London: University of Chicago Press.

Kaiser, D. (Ed.). (2005b). Pedagogy and the Practice of Science. Historical and Contemporary Perspectives. Cambridge, MA: The MIT Press.

Kellogg. (1938). A study of bird sound recording. Cornell University Ithaca, NY.

Kellogg. (1962a). Bird-Sound Studies at Cornell. The Living Bird: Annual of the Cornell Laboratory of Omithology, 1: 37-48.

Kellogg, E. W. (1955). History of Sound Motion Pictures. Journal of the Society for Motion Picture and Television Engineers. 64: 291-304.

Kellogg, P. P. (1950). Recording Sound in Nature. In J. Tall (Ed.), Techniques of Magnetic Recording (1958 ed.). New York: The MacMillan Company. 
Kellogg, P. P. (1962b). Bird-sound studies at Cornell. Living Bird, 1: 37-48.

Kellogg, P. P. (1962c). Vocalizations of the Black Rail (Laterallus Jamaicensis) and the Yellow Rail (Coturnicops Noveboracensis). The Auk, 79(4): 698-701.

Kellogg, P. P., \& Stein, R. C. (1953). Audio-spectrographic analysis of the songs of the Alder Flycatcher. The Wilson Bulletin, 65(2): 75-80.

Kevles, D. J. (1992). Huxley and the Popularization of Science. In K. C. Waters \& A. V. Helden (Eds.), Julian Huxley. Biologist and Statesman of Science. Houston, TX: Rice University Press.

Kirkman, F. B. (1910). The Meaning of Birds' Songs. British Birds, 3(4): 121.

Kivy, P. (1959). Charles Darwin on Music. Journal of the American Musicological Society, $12(1): 42-8$.

Klein, U. (2001). Paper tools in experimental cultures. Studies In History and Philosophy of Science Part A, 32(2): 265-302.

Knorr-Cetina, K. (1992). The Couch, the Cathedral, and the Laboratory: On the Relationship between Experiment and Laboratory in Science. In A. Pickering (Ed.), Science as Practice and Culture (pp. 113-138). Chicago: University of Chicago Press.

Knorr-Cetina, K. (1999). Epistemic Cultures. How the Sciences Make Knowledge. Cambridge, MA: Harvard University Press.

Koch, L. (1955). Memoirs of a Birdman. Boston, MA: Charles T. Branford.

Koenig, W., Dunn, H. K., \& Lacy, L. Y. (1946). The Sound Spectrograph. The Journal of the Acoustical Society of America, 15(1): 19-49.

Kohler, R. E. (1994). Lords of the Fly. Drosophila Genetics and the Experimental Life. Chicago: University of Chicago Press.

Kohler, R. E. (2002a). Labscapes: Naturalizing the Lab. History of Science, 40(4): 473501.

Kohler, R. E. (2002b). Landscapes and Labscapes. Exploring the Lab-Field Border in Biology. Chicago: University of Chicago Press.

Kohler, R. E. (2002c). Place and Practice in Field Biology. History of Science, 40(2): 189-210.

Kohler, R. E. (2006). All Creatures. Naturalists, Collectors, and Biodiversity, 1850-1950. Princeton: Princetone University Press.

Konishi, M. (1964). Song variation in a population of Oregon juncos. The Condor, 66(5): 423-36.

Krebs, S. (2012). "Sobbing, whining, rumbling": listening to automobiles as social practice. In T. Pinch \& K. Bijsterveld (Eds.), The Oxford Handbook of Sound Studies (pp. 79-101). Oxford: Oxford University Press.

Kroodsma, D. E. (2007). The Singing Life of Birds. The Art and Science of Listening to Birdsong. Boston/New York: Houghton Mifflin Company.

Kroodsma, D. E., Budney, G. F., Grotke, R. W., Vielliard, J., Ranft, R., \& Veprintseva, O. D. (1996). Natural Sound Archives. In D. E. Kroodsma \& E. H. Miller (Eds.), Ecology and evolution of acoustic communication among birds. New York: Cornell University Press. 
Kroodsma, D. E., \& Miller, E. H. (1980). Winter wren singing behavior: A pinnacle of song complexity. The Condor, 82(4): 357-65.

Kuklick, H., \& Kohler, R. E. (Eds.). (1996). Science in the Field. Osiris (11).

Kursell, J. (2003). Schallkunst. Eine Literaturgeschichte der Musik in der frühen russischen Avantgarde (Vol. 59). München: Wiener Slawistischer Almanach.

Kursell, J. (2012). A Gray Box: The Phonograph in Laboratory Experiments and Fieldwork, 1900-1920. In T. Pinch \& K. Bijsterveld (Eds.), The Oxford Handbook of Sound Studies (pp. 176-200). Oxford: Oxford University Press.

Kwa, C. (2008). Painting and Photographing Landscapes: Pictorial Conventions and Gestalts. Configurations, 16(1): 57-75.

Lachmund, J. (1999). Making Sense of Sound: Auscultation and Lung Sound Codification in Nineteenth-Century French and German Medicine. Science, Technology \& Human V alues, 24(4): 419-50.

Lachmund, J. (2003). Exploring the City of Rubble. Botanical Fieldwork in Bombed Cities in Germany after World War II. Osiris (18): 234-54.

LaFollette, M. C. (2008). Science on the air: popularizers and personalities on radio and early television. Chicago: University of Chicago Press.

Langemann, U., Gauger, B., \& Klump, G. M. (1998). Auditory sensitivity in the great tit: Perception of signals in the presence and absence of noise. Animal Behaviour, 56(3): 763-9.

Lanyon, W., \& Fish, W. (1958). Geographical Variation in the Vocalization of the Western Meadowlark. The Condor, 60(5): 339-41.

Latour, B. (1986). Visualization and Cognition: Thinking with Eyes and Hands. Knowledge and Society: Studies in the Sociology of Culture Past and Present 6(1): 1-40.

Latour, B. (1997). De Berlijnse sleutel en andere lessen van een liefhebber van wetenschap en techniek (R. Hofstede \& H. v. d. Kooy, Trans.). Amsterdam: Van Gennep.

Latour, B., \& Woolgar, S. (1986). Laboratory Life: The Construction of Scientific Facts. Princeton, NJ: Princeton University Press.

LaVallee, A. (2007). Why Birdwatchers Now Carry iPods And Laser Pointers; Devices Help Spot, Call, Identify and Spread News; The Noise of Wireless Alerts. The Wall Street Journal.

Law, J., \& Lynch, M. (1988). Lists, field guides and the descriptive organization of seeing: birdwatching as an exemplary observational activity. Human Studies, 11(2): 271-303.

Lemon, R. E. (1968). The Relation between Organization and Function of Song in Cardinals. Behaviour, 32(1/3): 158-78.

Lemon, R. E., \& Chatfield, C. (1971). Organization of Song in Cardinals. Animal Behaviour, 19(1): 1-17.

Lenoir, T. (Ed.). (1998). Inscribing Science. Scientific texts and the materiality of communication. Stanford: Stanford University Press.

Levin, D. M. (1993). Modernity and the Hegemony of Vision. Berkeley: University of California Press. 
Levin, T. Y. (2006). 'Tones from out of Nowhere': Rudolph Pfenninger and the Archaeology of Synthetic Sound. In W. Hui Kyong Chun \& T. Keenan (Eds.), New Media, Old Media: A History and Theory Reader (pp. 45-81). New York: Routledge.

Liberman, A. M., \& Cooper, F. S. (1972). In search of the acoustic cues. In A. Valdman (Ed.), Papers on Linguistics and Phonetics in Memory of Pierre Delattre (pp. 329-38). The Hague: Mouton.

Lutts, R. H. (1990). The nature fakers: wildlife, science and sentiment. Charlottesville: University Press of Virginia.

Lynch, M. (1985). Discipline and the Material Form of Images: An Analysis of Scientific Visibility. Social Studies of Science, 15(1): 37-66.

Lynch, M. (1988). The Externalized Retina: Selection and Mathematization in the Visual Documentation of Objects in the Life Sciences. Human Studies, 11(2/3): 201-34.

Lynch, M. (2011). Credibility, Evidence, and Discovery: The Case of the Ivorybilled Woodpecker. Ethnographic Studies, 12(1): 78-105.

Lynch, M., \& Woolgar, S. (1988). Representations in Scientific Practice. Human Studies, $11(2 / 3)$.

MacDonald, H. (2002). What Makes You a Scientists Is the Way You Look at Things: Ornithology and the Observer. Studies in History and Philosophy of Biological and Biomedical Sciences, 33(1): 53-77.

Margoschis, R. (1977). Recording Natural History Sounds. Herts, Print and Press.

Marler, P. (1952). Variation in the Song of the Chaffinch 'Fringilla Coelebs'. The Ibis, 94(3): 458-72.

Marler, P. (1956). The Voice of the Chaffinch and Its Function as a Language. The Ibis, 98(2): 231-61.

Marler, P. (1959). Developments in the study of animal communication. In P. R. Bell (Ed.), Darwin's Biological Work (pp. 150-206). Cambridge: Cambridge University Press.

Marler, P. (1960). Bird Songs and Mate Selection. In W. Lanyon \& W. N. Tavolga (Eds.), Animal Sounds and Communication (pp. 349-67). Washington D.C.: American Institute of Biological Sciences.

Marler, P. (1985). Hark Ye to the Birds: Autobiographical Marginalia. In D. A. Dewsbury (Ed.), Studying Animal Behavior: Autobiographies of the Founders (pp. 315-345). Chicago: University of Chicago Press.

Marler, P. (2004). Science and birdsong: the good old days. In P. Marler \& H. Slabbekoorn (Eds.), Nature's Music. The Science of Birdsong (pp. 1-38). Amsterdam et al.: Elsevier Academic Press.

Marler, P., \& Isaac, D. (1960a). Physical Analysis of a Simple Bird Song as Exemplified by the Chipping Sparrow. The Condor, 62(2): 124-35.

Marler, P., \& Isaac, D. (1960b). Song Variation in a Population of Brown Towhees. The Condor, 62(4): 272-83. 
Marler, P., \& Mundinger, P. C. (1975). Vocalizations, social organization and breeding biology of the twite, acanthus flavirostris. The Ibis, 117(1): 2-17.

Marler, P., \& Slabbekoorn, H. (Eds.). (2004). Nature's Music. The Science of Birdsong. Amsterdam et al: Elsevier Academic Press.

Marler, P., \& Tamura, M. (1962). Song "Dialects" in three populations of whitecrowned sparrows. The Condor, 64(5): 368-77.

Marshall Jr., J. T. (1964). Voice in Communication and Relationships among Brown Towhees. The Condor, 66(5): 345-56.

Marshall Jr., J. T. (1977). Audiospectrograms with pitch scale: a universal 'language' for representing bird songs graphically. The Auk, 94(1): 150-2.

Mathews, F. S. (1904). Field Book of Wild Birds and Their Music. A description of the character and music of birds, intended to assist in the identification of species common in the United States East of the Rocky Mountains. New York \& London: G. P. Putnam's sons.

Matless, D. (2005). Sonic geography in a nature region. Social \& Cultural Geography, 6(5): 745-66.

Mayfield, H. (1957). Proceedings of the Seventy-Fourth Stated Meeting of the American Ornithologists' Union. The Auk, 74(1): 79-89.

Mayfield, H. (1979). Commentary. The Amateur in Ornithology. The Auk, 96(1): 168-71.

Mayr, E. (1942). Systematics and the Origin of Species. New York Columbia University Press.

McCain, K. W. (1991). Communication, Competition, and Secrecy: The Production and Dissemination of Research-Related Information in Genetics. Science, Technology \& Human Values, 16(4): 491-516.

McCray, W. P. (2000). Large Telescopes and the Moral Economy of Recent Astronomy. Social Studies of Science, 30(5): 685-711.

Mearns, B., \& Mearns, R. (1998). The Bird Collectors. London: Academic Press.

Merton, R. (1971). The Normative Structure of Science. In N. W. Storer (Ed.), The Sociology of Science (pp. 267-78). Chicago, IL: University of Chicago Press.

Meyer, M. (2010). Caring for Weak Ties. The Natural History Museum as a Place of Encounter Between Amateur and Professional Science. Sociological Research Online, 15(2).

Miligan, M. (1966). Vocal responses of white-crowned sparrows to recorded songs of their own and another species. Animal Behaviour, 14(2/3): 356-61.

Miller, E. H. (1980). Commentary: Sound Spectrographic Analysis. The Condor, 82(2): 234.

Miller, O. T. (1894). Popular vs. Scientific Ornithology. The Auk, 11(1): 85-6.

Mills, M. (2010). Deaf Jam. From Inscription to Reproduction to Information. Social Text, 28 (1): 35-58.

Mirowski, P., \& Sent, E.-M. (Eds.). (2002). Science Bought and Sold: Essays in the Economics of Science. Chicago: University of Chicago Press. 
Mitman, G. (1996). "When Nature is the Zoo": Vision and Power in the Art and Science of Natural History. Osiris 11: 117-43.

Mitman, G. (1999). Reel Nature. America's Romance with Wildlife on Film. Cambridge, London: Harvard University Press.

Mitroff, I. I. (1974). Norms and Counter-Norms in a Select Group of the Apollo Moon Scientists: A Case Study of the Ambivalence of Scientists. American Sociological Review, 39(4): 579-95.

Mody, C. C. M. (2005). The Sounds of Science: Listening to Laboratory Practice. Science, Technology \& Human Values, 30(2): 175-98.

Mody, C. C. M. (2006). Corporations, Universities, and Instrumental Communities. Commercializing Probe Microscopy, 1981-1996. Technology and Culture, 47(1): 56-80.

Mody, C. C. M. (2011). Instrumental Community: Probe Microscopy and the Path to Nanotechnology. Cambridge, MA: MIT Press.

Moore, R. T. (1915). Methods of Recording Bird Songs. The Auk, 32(4): 535-8.

Moreau, R. E. (1959). The Centenarian 'Ibis'. The Ibis, 101(1): 19-38.

Morton, D. (2000). Off the Record: The Technology and Culture of Sound Recording in America. New Jersey: Rutgers University Press.

Morton, D. (2004). Sound Recording: The Life Story of a Technology. Westport, CT: Greenwood Press.

Morton, E. S. (1975). Ecological sources of selection on avian sounds. The American Naturalist, 109(965): 17-34.

Moss, S. (2004). A Bird in the Bush: A Social History of Birdwatching. London: Aurum.

Mundy, R. (2009). Birdsong and the Image of Evolution. Society and Animals, 17(3): 206-23.

Mundy, R. (2010). Nature's Music: Birds, Beasts, and Evolutionary Listening in the Twentieth Century (PhD dissertation). New York University New York.

Murie, O. J. (1962). Why do birds sing? The Wilson Bulletin, 74(2): 177-82.

Murray, F. (2010). The Oncomouse That Roared: Hybrid Exchange Strategies as a Source of Distinction at the Boundary of Overlapping Institutions. The American Journal of Sociology, 116(2): 341-88.

n.a. (1905). Some April and May work suggested. The Wilson Bulletin, 50: 22.

Nelkin, D. (1984). Science as intellectual property. Washington, DC: American Association for the Advancement of Science.

Nelson, D. A., \& Marler, P. (1990). The perception of birdsong and an ecological concept of signal space. In M. A. Berkley \& W. C. Stebbins (Eds.), Comparative Perception Volume II: Complex Signals (pp. 443-78). New York: John Wiley \& Sons.

Nicholson, M., \& Koch, L. (1937a). More Songs of Wild Birds. London: H. F. \& G. Witherby, Ltd.

Nicholson, M., \& Koch, L. (1937b). Songs of Wild Birds. London: H. F. \& G. Witherby, Ltd.

Niethammer, G. (1955). Jagd auf Vogelstimmen. Journal für Ornithologie, 96(1): 115-8. 
North, M. E. W. (1950). Transcribing bird-song. The Ibis, 92(1): 99-114.

Nyhart, L. K. (1991). Writing Zoologically: the Zeitschrift für wissenschaftliche Zoologie and the Zoological Community in late Nineteenth-Century Germany. In P. Dear (Ed.), The Literary Structure of Scientific Argument: Historical Studies (pp. 43-71). Philadelphia: University of Pennsylvania Press.

Nyhart, L. K. (2009). Modern Nature: The Rise of the Biological Perspective in Germany. Chicago: University of Chicago Press.

Olds, W. B. (1914). Twenty-five Bird Songs for Children. London, New York \& Boston: G. Schirmer.

Oldys, H. (1904). The rhytmical song of the Wood Pewee. The Auk, 21(2): 270-4.

Oldys, H. (1913). A remarkable Hermit Thrush song. The Auk, 30(4): 538-41.

Oldys, H. (1916). Rhythmical Singing of Veeries. The Auk, 33(1): 17-21.

Orr, O. H. j. (1992). Saving American Birds: T. Gilbert Pearson and the founding of the Audubon Movement. Gainesville, FL: University Press of Florida.

Ouellette, J. (2012). Your Birdsong Stays on My Mind. Scientific American, 306, 26.

Pantalony, D. (2004). Seeing a Voice: Rudolph Koenig's Instruments for Studying Vowel Sounds. The American Journal of Psychology, 117(3): 425-42.

Perlman, M. (2004). Golden Ears and Meter Readers. Social Studies of Science, 34(5): 783-807.

Pinch, T., \& Bijsterveld, K. (2004). Sound studies: New technologies and music.. Social Studies of Science, 34(5): 635-48.

Pinch, T., \& Bijsterveld, K. (2012a). New Keys to the World of Sound. In T. Pinch \& K. Bijsterveld (Eds.), The Oxford Handbook of Sound Studies (pp. 3-35). Oxford: Oxford University Press.

Pinch, T., \& Bijsterveld, K. (Eds.). (2012b). Oxford Handbook for Sound Studies. Oxford: Oxford University Press.

Porcello, T. (2004). Speaking of Sound: Language and the Professionalization of Sound-Recording Engineers. Social Studies of Science, 34(5): 733-58.

Potter, R. K. (1945). Visible Patterns of Sound. Science, 102(2654): 463-70.

Potter, R. K., Kopp, G. A., \& Green, H. C. (1947). Visible Speech. London: Macmillan and Co.

Poulsen, H. (1951). Inheritance and Learning in the Song of the Chaffinch. Behaviour 3(3): 216-28.

Pryer, A. (2002). Graphic notation. In A. Latham (Ed.), The Oxford companion to music. Oxford: Oxford University Press.

Pulling, M. J. L. (1949). The development of mobile recording technique. BBC Quarterly, 4(3): 179-92.

Purves, F. (1962). Bird Song Recording. London: The Focal Press.

Radick, G. (2000). Morgan's canon, Garner's phonograph, and the evolutionary origins of language and reason. British Journal for the History of Science, 33(1): 323.

Radick, G. (2007). The Simian Tongue. The Long Debate about Animal Language. Chicago \& London: University of Chicago Press. 
Ramseyer, U. J. (1908). Unsere Singvögel. Ihr Gesang, Leben und Lieben. Narau: Emil Wirz vorm. J. J. Chriften.

Ranft, R. (2004). Natural sound archives: past, present and future. Annals of the Brazilian Academy of Sciences, 76(4): 455-65.

Rasmussen, N. (2004). The Moral Economy of the Drug Company-Medical Scientist Collaboration in Interwar America. Social Studies of Science, 34(2): 161-85.

Rees, A. (2005). A Place that Answers Questions: Primatological Field Sites and the Making of Authentic Observations. Studies in History and Philosophy of Biological and Biomedical Sciences, 37(2): 311-33.

Rehding, A. (2000). The Quest for the Origins of Music in Germany Circa 1900. Journal of the American Musicological Society, 53(2): 345-85.

Rice, T. (2008). "Beautiful Murmurs": Stethoscopic Listening and Acoustic Objectification. The Senses and Society, 3(3): 293-306.

Ridgway, R. (1901). The Birds of North and Middle America. Bulletin of the United States National Museum, 50.

Rieger, S. (2009). Schall und Rauch. Eine Mediengeschichte der Kurve. Frankfurt am Main: Suhrkamp Verlag.

Ritvo, H. (1989). The Animal Estate. The English and Other Creatures in the Victorian Age. Cambridge, MA: Harvard University Press.

Roberts, L. (1995). The Death of the Sensuous Chemist. The 'New' Chemistry and the Transformation of Sensuous Technology. Studies in the History and Philosophy of Science, 26(4): 503-29.

Roberts, L., Schaffer, S., \& Dear, P. (Eds.). (2007). The mindful hand. Inquiry and invention from the late Renaissance to early industrialisation. Amsterdam: KNAW.

Roosth, S. (2009). Screaming Yeast: Sonocytology, Cytoplasmic Milieus, and Cellular Subjects. Critical Inquiry, 35(2): 332-50.

Roth, W.-M. (2003). Toward an Anthropology of Graphing.Semiotic and Activity-Theoretic Perspectives. Dordrecht: Kluwer Academic Publishers.

Roth, W.-M., \& Bowen, G. M. (1999). Digitizing Lizards: The Topology of 'Vision' in Ecological Fieldwork. Social Studies of Science, 29(5): 719-64.

Rowan, W. M. (1925). A practical method of recording bird-calls. British Birds, 18(1): 14-8.

Rudwick, M. (1976). The Emergence of a Visual Language for Geological Science, 1760-1840. History of Science, 14: 149-95.

Ryan, M. J., \& Brenowitz, E. A. (1985). The Role of Body Size, Phylogeny, and Ambient Noise in the Evolution of Bird Song. The American Naturalist, 126(1): 87-100.

Sage, J. H. (1899). Sixteenth Congress of the A. O. U. The Auk, 16(1): 51-5.

Saunders, A. A. (1915). Some Suggestions for Better Methods of Recording and Studying Bird Songs. The Auk, 32(2): 173-83.

Saunders, A. A. (1916). Correspondence 'Graphic Representation of Bird Song'. The Auk, 33(2): 228-30.

Saunders, A. A. (1922). The Song of the Field Sparrow. The Auk, 39(3): 386-99. 
Saunders, A. A. (1924). The Study of Bird Sounds. The Condor, 26(6): 209-13.

Saunders, A. A. (1929). Bird song. Albany: University of the State of New York.

Saunders, A. A. (1955). An Analysis of the Songs of Meadowlarks. The Wilson Bulletin, 67(4): 303-4.

Saunders, A. A. (1961). The songs and calls of the Wood Thrush. The Auk, 78(4): 595-606.

Saunders, W. E. (1934). Losing the Bird Songs. The Auk, 51(4): 503-6.

Schafer, R. M. (1977). The soundscape. Our sonic environment and the tuning of the world. Rochester: Destiny Books.

Schalow, H. (1911). Verhandlungen des V. Internationalen Ornithologen-Kongresses, Berlin.

Schmidgen, H. (2003). Time and noise: the stable surroundings of reaction experiments, 1860-1890. Studies in History and Philosophy of Biological and Biomedical Sciences, 34(2): 237-75.

Schmidgen, H. (2008). Silence in the Laboratory: The History of Soundproof Rooms. In J. Kursell (Ed.), Sounds of Science - Shall im Labor (pp. 47-62). Berlin: Max Planck Institute for the History of Science.

Schmitt, C., \& Stadler, H. (1913). Studien über Vogelstimmen. Journal für Omithologie, 61(2): 383-94.

Schmitt, C., \& Stadler, H. (1919). Die Vogelsprache. Eine Anleitung zu ibrer Erkennung und Erforschung. Stuttgart: Frankh'sche Verlagshandlung.

Schmitt, P. J. (1990). Back to nature: the Arcadian myth in urban America. Baltimore: John Hopkins University.

Science: Visible Bird Song. (1953, July 20). Time.

Secord, A. (2002). Botany on a plate: pleasure and the power of pictures in promoting early nineteenth-century scientific knowledge. Isis, 93(1): 28-57.

Secord, J. A. (2004). Knowledge in Transit. Isis, 95(4): 654-72.

Sellar, P. J. (1976). Sound recording and the birdwatcher. British Birds, 69(6): 202-15.

Shapin, S. (1984). Pump and circumstance: Robert Boyle's literary technology. Social Studies of Science, 14(4): 481-520.

Shapin, S. (1988). The House of Experiment in Seventeenth-Century England. Isis, 79(3): 373-404.

Shapin, S. (1989). The Invisible Technician. American Scientist, 77(6): 554-63.

Shapin, S. (1994). A Social History of Truth: Civility and Science in Seventeenth-Century England. Chicago IL: University of Chicago Press.

Shapin, S. (1998). Placing the View from Nowhere: Historical and Sociological Problems in the Location of Science. Transactions of the Institute of British Geographers, 23(1): 5-12.

Shelemay, K. K. (1991). Recording Technology, the Record Industry, and Ethnomusicological Scholarship. In B. Nettl (Ed.), Comparative Musicology and Anthropology of Music: Essays on the History of Ethnomusicology (pp. 277-92). Chicago \& London: University of Chicago. 
Shiovitz, K. A. (1975). The Process of Species-Specific Song Recognition by the Indigo Bunting, Passerina cyanea, and Its Relationship to the Organization of Avian Acoustical Behavior. Behaviour, 55(1/2): 128-79.

Simms, E., \& Wade, G. F. (1953). Recent Advances in the Recording of BirdSongs. British Birds, 46(6): 200-9.

Slabbekoorn, H. (2004). Singing in the wild: the ecology of birdsong. In P. Marler, \& Slabbekoorn, H. (Ed.), Nature's Music. The Science of Birdsong (pp. 178-205). Amsterdam et al.: Elsevier Academic Press.

Slabbekoorn, H. (2009). Geschiedenis van de Bioakoestiek in technologisch perspectief. Tijdschrift voor Mediageschiedenis 12(2): 205-32.

Slabbekoorn, H., \& Peet, M. (2003). Birds sing at a higher pitch in urban noise. Nature, 424(6946): 267.

Slater, P. J. B., \& Ince, S. A. (1979). Cultural Evolution in Chaffinch Song. Behaviour, 71(1/2): 146-66.

Smith, M. M. (2012). The Garden in the Machine: Listening to Early American Industrialization. In T. Pinch \& K. Bijsterveld (Eds.), The Oxford Handbook of Sound Studies (pp. 39-57). Oxford: Oxford University Press

Stangl, B. (2000). Ethnologie im Ohr: die Wirkungsgeschichte des Phonographen. Vienna: WUV Universitätsverlag.

Star, S. L., \& Griesemer, J. R. (1989). Institutional Ecology, Translations and Boundary Objects: Amateurs and Professionals in Berkeley's Museum of Vertebrate Zoology, 1907-39. Social Studies of Sciences, 19(3): 387-420.

Stein, R. C. (1956). A Comparative Study of 'Advertising Song' in the Hylocichla Thrushes. The Auk, 73(4): 503-12.

Steinberg, M. K. (2008). Stalking the ghost bird: the elusive ivory-billed woodpecker in Louisiana. Baton Rouge: Louisiana State University Press.

Sterne. (2003). The Audible Past. Cultural origins of sound reproduction. Durham: Duke University Press.

Sterne, J. (2006a). The Death and Life of Digital Audio. International Science Review, 31(4): 338-48.

Sterne, J. (2006b). The mp3 as cultural artifact. New Media \& Society, 8(5): 825-42.

Stillwell, N. (1964). Bird Song. Adventures and Techniques in Recording The Songs of American Birds. New York: Doubleday \& Company, Inc.

Stone, W. (1913). Notes and News. The Auk, 30(3): 472-4.

Strong, R. M. (1918). The Description of the Voice of Birds. The Auk, 35(2): 133-5.

Stubbs, F. J. (1910). The Meaning of Birds' Songs. British Birds, 3(5): 155-7.

Stumpf, C. (1911). Die Anfänge der Musik. Leipzig: Verlag van Johann Ambrosius Barth.

Summers, E. (1916). Notation of Bird Songs and Notes. The Auk, 33(1): 78-80.

Supper, A. (2012). Lobbying for the Ear. The Sonification of Scientific Data and the Struggles for its Academic Legitimacy. Maastricht University Maastricht.

Tall, J. (1958). Techniques of Magnetic Recording. New York: Macmillan Com-pany. 
Taruskin, R. (2005). The Oxford History of Western Music. Volume 5, The Late Twentieth Century. Oxford: Oxford University Press.

Thielcke, G. (1961). Ergebnisse der Vogelstimmen-Analyse. Journal für Ornithologie, 102(3): 285-300.

Thomas, M. (2005). Are Animals Just Noisy Machines?: Louis Boutan and the CoInvention of Animal and Child Psychology in the French Third Republic. Journal of the History of Biology, 38(3): 425-60.

Thompson, E. (1995). Machines, Music, and the Quest for Fidelity: Marketing the Edison Phonograph in America, 1877-1925. The Musical Quarterly, 79(1): 13171.

Thompson, E. (1997). Dead Rooms and Live Wires. Harvard, Hollywood, and the Deconstruction of Architectural Acoustics, 1900-1930. Isis, 88(4): 597-626.

Thompson, E. (2002). The Soundscape of Modernity: architectural acoustics and the culture of listening in America 1900-1933. Cambridge: MIT Press.

Thompson, W. L. (1970). Song variation in a population of indigo buntings. The Auk, 87(1): 58-71.

Thompson, W. L. (1979). Suggestions for preparing audiospectrograms for publication. The Condor, 81(2): 220-1.

Thorpe, W. H. (1951). The learning abilities of birds. The Ibis, 93(2): 252-96.

Thorpe, W. H. (1954). The Process of Song-Learning in the Chaffinch as Studies by Means of the Sound Spectrograph. Nature 173: 465-9.

Thorpe, W. H. (1958). The Learning of Song Patterns by Birds, with Especial Reference to the Songs of the Chaffinch 'Fringilla Coelebs'. The Ibis, 100(4): 53570.

Thorpe, W. H. (1961a). Bird-Song. The Biology of Vocal Communication and Expression in Birds. Cambridge Cambridge University Press.

Thorpe, W. H. (1961b). The Songs of Some Families of the Passeriformes. II. The Songs of the Buntings (Emberizidae). The Ibis, 103a: 246-59.

Thorpe, W. H. (1966). Ritualization in Ontogeny. II. Ritualization in the Individual Development of Bird Song. Philosophical Transactions of the Royal Society of London. Series B. Biological Sciences, 251(772): 351-8.

Thorpe, W. H. (1968). Obituary. Myles Edward Wentworth North, 1908-1967. The Ibis, 110(3): 364-5.

Thorpe, W. H., Hall-Craggs, J., Hooker, B., Hooker, T., \& Hutchison, R. E. (1972). Duetting and Antiphonal Song in Birds: Its Extent and Significance. Behaviour, 18(supplement): 1-197.

Thorpe, W. H., \& Hinde, R. A. (1957). An Inexpensive Type of Sound-proof Room Suitable for Zoological Research. Experimental Biology, 33(4): 750-5.

Thorpe, W. H., \& Lade, B. I. (1961). The Songs of Some Families of the Passeriformes. I. Introduction: The Analysis of Bird Songs and Their Expression in Graphic Notation. The Ibis, 103(2): 231-45. 
Tillmann, H. G. (1995). Early Modern Instrumental Phonetics. In E. F. K. Koerner \& R. E. Asher (Eds.), Concise History of the Language Sciences: From Sumerians to the Cognitivists. Oxford: Pergamon.

Tipp, C. (2011a). Listening to the Nightingale Song. Brio: journal of LAML, 48(2): 1521.

Tipp, C. (2011b). Margaret McKee: the California Mocking Bird. For the Record, 39(September): 392-6.

Tipp, C. (2011c). An Overview of Early Commercial Wildlife Recordings at the British Library. IAS A Journal, 37(July): 47-54.

Toogood, M. (2011). Modern observations: new ornithology and the science of ourselves, 1920-1940. Journal of Historical Geography 37(3): 348-57.

Tyler, W. M. (1916). The call-notes of some nocturnal migrating birds. The Auk, 33(2): 132-41.

Vaughan, D. (2004). Theorizing disaster. Analogy, historical ethnography, and the Challenger accident. Ethnography, 5(3): 315-47.

Vetter, J. (2004). Science along the Railroad: Expanding Field Work in the US Central West. Annals of Science, 61(2): 187-211.

Vetter, J. (Ed.). (2011). Knowing Global Environments: New Historical Perspectives on the Field Sciences. New Brunswick: Rutgers University Press.

Voigt, A. (1913). Excursionsbuch zum Studium der Vogelstimmen. Praktische Anleitung zum Bestimmen der Vögel nach ihrem Gesange von prof. dr. A Voigt (6th ed.). Leipzig: Quelle u. Meyer.

Wachelder, J. (2009). Vogelafbeeldingen en vogels kijken in de negentiende en twintigste eeuw. Tijdschrift voor Mediageschiedenis, 12(2): 187-204.

Wallaschek, R. (1893). Primitive Music. New York: Longman, Green and Co.

Walters, J. R., \& Crist, E. L. (2005). Rediscovering the King of Woodpeckers: Exploring the Implications. Avian Conservation and Ecology, 1(1): 6-12.

Warren, P. S., Katti, M., Ermann, M., \& Brazel, A. (2006). Urban bioacoustics: it's not just noise. Animal Behaviour, 71(3): 491-502.

Warwick, A. (2003). Masters of Theory: Cambridge and the rise of mathematical physics. Chicago: University of Chicago Press.

Waters, K. C., \& Helden, A. V. (Eds.). (1992). Julian Huxley. Biologist and Statesman of Science. Houston, TX: Rice University Press.

Watson, G. P. L. (2010). Multiple Acts of Birding: The Education, Ethics and Ontology of Bird Watching in Ontario. Toronto: York University.

Weeden, J. S., \& Falls, J. B. (1959). Differential responses of male ovenbirds to recorded songs of neighboring and more distant individuals. The Auk, 76(3): 343-51.

Wheeler, W. C., \& Nichols, J. T. (1924). The Song of the Song Sparrow. The Auk, 41(3): 444-51.

White, S. J., \& White, R. E. C. (1970). Individual Voice Production in Gannets. Behaviour, 37(1/2): 40-54. 
Wiley, R. H., \& Richards, D. G. (1982). Adaptations for acoustic communication in birds, Sound transmission and signal detection. In D. E. Kroodsma \& E. H. Miller (Eds.), Acoustic Communication in Birds, Vol 1. Production, Perception, and Design Features of Sounds (pp. 132-81). New York: Academic Press.

Williams, J. J. (1902). A Study of Bird Songs. Chapter I. Preparatory Study of Bird Songs. The Condor, 4(1): 12-4.

Winn, W. (2009). 'Proof in Pictures: Visual Evidence and Meaning Making in the Ivory-Billed Woodpecker Controversy. Journal of Technical Writing and Communication, 39(4): 351-79.

Wise, M. N. (2006). Making Visible. Isis, 97(1): 75-82.

Witchell, C. A. (1896). The Evolution of Bird-Song with Observations on the influence of beredity and imitation. London: Adam \& Charles Black.

Zimmerman, A. S. (2008). New knowledge from old data. The role of standards in the sharing and reuse of ecological data. Science, Technology \& Human Values, 33(5): 631-52.

Zon, B. (2007). Representing non-Western music in nineteenth-century Britain. Rochester, NY: University of Rochester Press.

Zuckerman, H. A. (1988). Intellectual Property and Diverse Rights of Ownership in Science. Science, Technology and Human Values, 13(1/2): 7-16. 



\section{Samenvatting}

Vraag een ervaren vogelaar naar de zang van de vink en de kans is groot dat hij een onbegrijpelijke serie klanken voortbrengt: Chip-chip-chip-chwee-chwee-tissi-chooeeo, niet te verwarren met het Chippoo-it tio-tew tutee-o wee-ploo-ploo tu-itty van de zanglijster. Elke vogel zingt zijn eigen lied, wil het cliché, en sinds het einde van de negentiende eeuw heeft de beschrijving van dat lied gestaag aan populariteit gewonnen. Niet alleen onder vogelaars en liefhebbers, die soorten in het veld vaak aan hun geluid herkenden, maar ook onder onderzoekers die aan de hand van vogelgeluid belangrijke biologische vraagstukken over de evolutie van soorten, de ontwikkeling van gedrag, en de rol van communicatie bij dieren probeerden te beantwoorden. De studie van vogelgeluid heeft zich sindsdien tot een omvangrijk en interdisciplinair veld ontwikkeld. Maar met deze wetenschappelijke interesse in vogelgeluid werd ook de specifieke manier waarop vogelgeluid beschreven kan worden van groot belang. Hoe kon de impressie van een vaak zo vluchtig geluid tenslotte accuraat, duidelijk en betrouwbaar worden vastgelegd?

In dit proefschrift analyseer ik hoe in de twintigste eeuw de geluidsopname als wetenschappelijk instrument in de studie van vogelgedrag werd ingezet. Daarmee sluit ik aan bij een lange traditie binnen het wetenschaps- en technologieonderzoek. Daarin staat de verhouding tussen lichamelijke waarneming, wetenschappelijke representatie en kennis centraal. Lang benadrukte men daarin voornamelijk visuele waarneming, vaardigheden en instrumenten. Tegelijkertijd benadrukt recent werk dat de wetenschap niet uitsluitend een visueel georiënteerde praktijk is. Ook andere zintuigen dan het zien kunnen een belangrijke rol spelen in de ontwikkeling van wetenschappelijk inzicht, al hebben die tegenwoordig niet de vanzelfsprekend wetenschappelijke status als het zien. Dit proefschrift onderzoekt daarom hoe auditieve ervaringen gerepresenteerd en gelegitimeerd werden binnen de wetenschappelijke praktijk. Daartoe behandelt dit proefschrift drie centrale vragen. Hoe hebben onderzoekers hun luisterend oor ingezet in hun wetenschappelijk werk en met behulp van welke instrumenten deden zij dat? Wat is de relevantie geweest van deze luisterpraktijken voor kennisvergaring, welke vragen riepen zij op en welke nieuwe kennis werd ermee verworven? En tot slot: Hoe hebben onderzoekers deze manieren van luisteren en opnemen proberen te legitimeren als deel van een wetenschappelijke praktijk en van hun professionele autoriteit?

Ik doe dit door de ontwikkeling van luister- en opnamepraktijken te bestuderen in de ornithologie tussen 1880 en 1980, in de Verenigde Staten, Groot Brittan- 
nië en Duitsland. Dat doe ik aan de hand van historisch bronnenonderzoek, door middel van een kwalitatieve analyse van primaire bronnen zoals correspondentie, aantekeningen, artikelen, handboeken en interviews. Daarbij gaat het me niet zozeer om een systematische vergelijking van wat in deze landen gebeurde, maar om de technologieën en technieken waarmee onderzoekers gezamenlijk, en vaak internationaal, invulling hebben gegeven aan het wetenschappelijke luisteren. Ik doe dit zowel diachroon als thematisch. Waar dit proefschrift als geheel de ontwikkeling van het wetenschappelijke luisteren en zijn autoriteit traceert, plaatst ieder hoofdstuk afzonderlijk een technologische innovatie centraal. Aan de hand van notaties van geluid, de elektrische grammofoon en microfoon, de magnetische bandrecorder en de geluidsspectrograaf diep ik steeds een andere inhoudelijke kwestie uit met betrekking tot de wetenschappelijke rol van veldopnamen.

Zo laat ik zien dat geluidsopnamen meer zijn dan simpele geluidsregistraties. Het maken van een opname veronderstelt niet alleen een opvatting van wat luisteren is, maar ook van wat die opname de onderzoeker zou moeten brengen of, anders gezegd, een idee over wat de rol van de opname in de wetenschappelijke praktijk zou moeten zijn. In de ornithologie werden die rollen bepaald door zowel de specifieke eigenschappen van veldonderzoek als de culturele betekenis van geluidsopnamen zelf. Vogels zijn tenslotte een wijdverspreid, toegankelijk en tot de verbeelding sprekend onderzoeksobject. Om die redenen werd vogelgeluid niet alleen geregistreerd en bestudeerd door specialisten binnen de biologie, maar ook door amateurs, geluidsjagers, musici en componisten, radiomedewerkers, filmproducenten en hun teams van opnametechnici en -assistenten. Voor de studie van vogelgeluid in het veld rekenden biologen dan ook vaak op de kennis, kunde en opnamen van deze mensen. Deze laatsten hadden echter vaak ook hun eigen ideeën over hoe natuurgetrouwe geluidsopnamen gemaakt, beschreven en gebruikt moesten worden. In de volgende alinea's bespreek ik per hoofdstuk hoe onderzoekers deze zeer uiteenlopende ideeën en eisen in overeenstemming probeerden te brengen met hun eigen toepassingen en idealen van wetenschappelijke objectiviteit.

In hoofdstuk 2 beschrijf ik de periode tussen 1880 en 1930. Tegen het einde van de negentiende eeuw trok een groeiende groep recreanten en onderzoekers het veld in om voor het eerst echt naar vogels te luisteren. Ornithologen hadden zich tot dan toe gericht op het verzamelen van opgezette dieren en het bestuderen van hun uiterlijke kenmerken. De onderzoeker nieuwe stijl, veelal amateur naturalisten, probeerden daarentegen de levensgeschiedenis en het gedrag van wilde vogels, waaronder hun zang, in kaart te brengen. Ik laat zien dat deze onderzoekers twee technieken ontwikkelden om dat geluid vast te leggen. Elk van deze technieken veronderstelde een specifiek begrip van wetenschappelijk luisteren. Eén groep van veldonderzoekers werkte met een vorm van notatie die we uit de klassieke muziek kennen. Wie het muzieknotenschrift methodisch en precies gebruikte, luisterde naar de mening van deze onderzoekers werkelijk wetenschappelijk. Een groep van critici verwierp deze muzieknotatie echter als te esthetiserend, subjectief en complex om door de ongeoefende luisteraar toegepast te worden. Zij verkozen het 
gebruik van een grafisch diagram dat door zijn vermeende transparantie en eenvoud door een brede groep van luisteraars zonder muzikale vaardigheden gebruikt zou kunnen worden. Aan de hand van deze tegenstelling laat ik zien dat ornithologen schipperden tussen de uitwerking van een gemeenschappelijke manier van notatie enerzijds, en de lokale interesses en vaardigheden van veldmedewerkers anderzijds. Om de wetenschappelijke veldopname-praktijk beter te begrijpen is het daarom belangrijk te weten dat van deze notaties niet alleen verwacht werd dat ze ingezet konden worden als wetenschappelijk bewijs, of als inscriptie in termen van het wetenschaps-en techniekonderzoek. Geluidsopnamen dienden er namelijk niet alleen voor om vogelgeluid te bestuderen, maar ook om het te onthouden en te onderwijzen, en zelfs om leken te enthousiasmeren. Deze functies heb ik respectievelijk mimetisch, mnemonisch, didactisch en verleidelijk genoemd.

In hoofdstuk 3 neem ik de draad op rond 1930, wanneer mechanische opname-instrumenten voor het eerst hun opwachting makten in het veldonderzoek naar vogelgeluid. Deze opnamen leken aanvankelijk alle vier genoemde functies te verenigen. Bovendien, zo was de gedachte, zou de techniek helpen om subjectieve idealiseringen en theoretische projecties te omzeilen. Maar de elektrische grammofoon en microfoon deden meer dan dat; ze leken het gemiddelde menselijke oor ook te 'ontmaskeren' als een bijzonder gebrekkig, selectief en bedrieglijk instrument. Deze nieuwe instrumenten bleken bijvoorbeeld extreem korte noten en hoge tonen te registreren die zelfs een geschoolde en aandachtige luisteraar niet eenvoudig waarnam. Ornithologen schreven daarom een grotere objectiviteit toe aan dergelijke mechanische instrumenten. Door de kosten van de apparatuur en de technische complexiteit ervan bleven deze instrumenten echter lang voorbehouden aan een selecte groep van prominente ornithologen die samenwerkten met uitgevers, filmproducenten en organisaties zoals de BBC. Bovendien riepen zulke instrumenten ook opnieuw een praktisch en epistemologisch probleem op. Zij attendeerden de luisteraar namelijk op het lawaai van motoren, wind of andere vogels. Dat was voorheen onopgemerkt gebleven, maar bemoeilijkte nu het opnemen van een bruikbaar, helder, natuurgetrouw en "objectief” geluid. Aan de hand van een vergelijking tussen veldopname-praktijken van ornithologen en opnametechnici in de Verenigde Staten en in Groot- Brittannië laat ik zien dat de onderzoekers dit op verschillende manieren oplosten. Ornithologen aan de Amerikaanse Cornell University ontwikkelden bij voorbeeld een paraboolmicrofoon waarmee vogelgeluid selectief versterkt kon worden. Met deze luistertechniek slaagden zij erin ongewenst lawaai gemakkelijker te filteren en een breed geluidspanorama te verdelen in individuele geluidsopnamen die in het laboratorium vervolgens gemakkelijker te analyseren bleken. De paraboolmicrofoon maakte bovendien een bepaalde gerichtheid en afstandelijkheid in de opname mogelijk, die normaal gesproken als kenmerken van de visuele waarneming werden beschouwd. Dit proces, waarbij geluidspanorama's systematisch tot beheersbare onderzoeksobjecten worden bewerkt, heb ik de laboratorisering van het veld genoemd. 
In hoofdstuk 4 laat ik zien hoe het luisteren met mechanische instrumenten ook voor een grotere groep vogelonderzoekers en -liefhebbers binnen bereik kwam. Vanaf de late jaren '40 voorzag de magnetische bandrecorder in een alternatief voor de grammofoon dat goedkoper, mobieler en gemakkelijker te hanteren was. Vanaf 1950 experimenteerden steeds meer biologen met het gebruik van geluidsopnamen in hun werk, en lijfden zij bovendien een groeiende groep geluidsjagers en radiomakers in om vogelgeluid in het veld te verzamelen. Om werkelijk waardevol te zijn voor wetenschappelijk onderzoek, dienden deze opnamen op een specifieke manier gemaakt, geïdentificeerd en geannoteerd te worden door geoefende en betrouwbare veldmedewerkers. Ik laat zien dat ornithologen zich van de medewerking en kunde van deze veldmedewerkers verzekerden door de culturele betekenis van de geluidsopnamen serieus te nemen, en daarmee de monetaire, sociale en symbolische waarde van die opnamen buiten het wetenschappelijke domein. Geluidsopnamen brachten onderzoekers namelijk op verschillende manieren geld of erkenning op. Het eigendomsrecht op geluidsopnamen liet onderzoekers bij voorbeeld toe opnamen niet alleen vrij te geven als gemeenschappelijk gedeeld wetenschappelijk materiaal, maar deze ook commercieel aan te bieden aan radiomakers of te verkopen via grammofoonplaten. Kennis van vogelgeluiden kon daarmee op veel grotere schaal verspreid worden. Met de opbrengst werden expedities en de uitgaven van een groep geluidsjagers gefinancierd die op hun beurt opnieuw wetenschappelijk waardevolle opnames verzamelden. Het auteurschap van zo een opname bracht de geluidsjager erkenning, maar veronderstelde ook verantwoordelijkheid voor de betrouwbaarheid ervan. Essentieel is dat het niet zozeer de economische uitwisseling was die deze samenwerking zo succesvol maakte, maar dat wetenschappers met die uitwisseling ook een normatief kader schiepen. Ik laat zien dat veldmedewerkers binnen dat kader niet alleen uit een specifiek eigenbelang samenwerkten, maar ook uit verantwoordelijkheid en erkentelijkheid aan wetenschappelijk onderzoek bijdroegen. Opvallend is dan ook dat de commerciële aspecten van de omgang met geluidsopnamen de wetenschappelijkheid ervan niet ondermijnden maar juist mogelijk maakten. Dit morele kader, dat ik een morele economie heb genoemd, laat bovendien opnieuw zien hoe opnamen verschillende rollen speelden in de verspreiding van een gemeenschappelijke manier van luisteren.

Hoofdstuk 5 gaat niet over het maken van opnamen van vogelgeluid in het veld maar hun analyse in het laboratorium. Vanaf de vroege jaren '50 gebruikten biologen daarvoor een geluids-spectrograaf, een apparaat dat de spectrale samenstelling van een geluid analyseert en dat vervolgens visueel representeert. Het instrument werd oorspronkelijk ontwikkeld door Bell Laboratories ter ondersteuning van de communicatie van doven, maar werd al snel omarmd als een standaard die een 'mechanisch objectieve' analyse en representatie van vogelgeluid mogelijk zou maken. De spectrograaf, zo was gedachte, bracht een waterscheiding aan tussen objectieve analyse en subjectieve ervaring van geluid. Ik laat echter zien dat de lichamelijke ervaring van geluid niettemin een opmerkelijke rol bleef spelen. Zo ondervonden gebruikers al snel dat de gedetailleerde afbeelding van een geluid- 
spectrografische representatie, een spectrogram, een goed begrip van het geluid soms juist bemoeilijkte. In het herkennen van structuren en patronen in vogelgeluid, bijvoorbeeld, bleek de intuitie van een ervaren luisteraar nog altijd een toegevoegde waarde te hebben. De rol van het geoefende oor van de wetenschapper bleef echter wel beperkt tot het differentiëren tussen geluiden. Ik laat bij voorbeeld zien dat biologen met behulp van muzieknotatie de geluidsstructuren in het spectrogram op een andere manier begrijpelijk wilden maken. Zulke initiatieven werden echter niet breed omarmd omdat critici meenden dat met de muzieknotatie ook de subjectieve ervaring van geluid weer werd binnengebracht. Het geoefende luisteren stond dan ook vooral in functie van de geluidspectrografische representatie. Aan de hand van het concept inscriptie laat ik zien hoe zulke spectrogrammen gebruikt werden om geluid tot een zo bewijskrachtig mogelijke representatie te maken. Door geluidsopnamen te combineren met een reeks van grafische en numerieke representaties bereikte de wetenschapper namelijk in toenemende mate over het geluid. Dit hoofdstuk toont aan dat om de mechanismen van wetenschappelijke representatie beter te begrijpen we niet alleen aandacht moeten hebben voor de context waarin deze representaties gebruikt worden en de rollen die ze daarin aannemen. Het is belangrijk ook aandacht te hebben voor de lichamelijke en zintuiglijke praktijken waarin aan deze representaties betekenis wordt verleend.

In het concluderende hoofdstuk 6 laat ik zien hoe de manier waarop wetenschappers op hun luisterend oor vertrouwden over de tijd heen veranderd is. Het menselijk oor werd in toenemende mate gediskwalificeerd als een gebrekkig, selectief en subjectief instrument. Tegelijkertijd werd de autoriteit van het individuele luisteren gedeeltelijk overgedragen aan het gestandaardiseerde en vermeend 'mechanisch objectieve' oor van het opname-instrument en aan allerhande grafische en numerieke representaties. Op die manier verschoof de analyse van vogelgeluid van het veld naar het laboratorium. Maar hoewel het aandeel van het geoefende oor niet altijd expliciet benoemd werd, viel het nooit helemaal uit te sluiten, noch in de analyse, noch in het veldwerk. Auditieve informatie kon dan wel in detail visueel worden weergegeven, maar het was het oor dat die informatie van essentiële context voorzag: welke vogelsoort bracht het geluid voort, met welk gedrag hing het samen en welke informatie leek het te communiceren? Die informatie was vaak juist afhankelijk van de kennis van een waarnemer, die eveneens verspreid en gestandardiseerd diende te worden. Naast hun mimetische rol in wetenschappelijke studie konden de mnemonische, didactische en zelfs verleidelijke functies van geluidsopnames er voor zorgen dat luisteraars op verschillende manieren aandacht ontwikkelden voor de specifieke samenstelling van vogelgeluid.

Dit proefschrift laat dan ook zien dat het wetenschappelijk luisteren niet uitsluitend door de mechanische opname werd gelegitimeerd, maar dat deze het wetenschappelijk luisteren wel ondersteunde en er op nieuwe manieren vorm aan gaf. Omdat de analyse van vogelgeluid in toenemende mate met behulp van mechanische instrumenten gebeurde, verschoof ook de vraagstelling en de focus van veel onderzoek naar vogelgeluid. De studie van vogelgeluid benadrukte aanvankelijk 
voornamelijk herkenning in het veld, en de veelal uitgesponnen melodische structuren van vogelgeluid. Door de mogelijkheid geluiden van verschillende locaties efficiënter samen te brengen en deze in detail te beschouwen werden juist subtiele (en vaak voor het oor onmerkbare) variaties in de geluidsstructuur van kortere fragmenten belangrijker. Dergelijke variaties vormden op hun beurt de basis voor een keur aan nieuwe vragen naar de mechanismen waarop vogelgeluid geleerd werd, zich aan zijn omgeving aanpaste, en hoe dankzij deze variaties individuele vogels of populaties zich tot elkaar verhielden.

Tenslotte laat dit proefschrift zien dat de legitimatie van geluidsopnames begrepen kan worden aan de hand van de vele conversies die zij ondergingen, tussen verschillende media, tussen verschillende sociale en professionele contexten, en tussen zintuiglijke modi. Daarmee draagt deze studie ook bij aan het veld van wetenschaps- en technologieonderzoek. Dat doet het ten eerste door nadrukkelijk te wijzen op het zintuiglijk multimodale karakter van wetenschappelijke waarneming en representatie. De manier waarop het luisteren wordt vormgegeven en gelegitimeerd blijkt in bepaalde gevallen (bij voorbeeld via de paraboolmicrofoon) overeen te komen met de manier waarop visuele observatie wordt geordend. Bovendien blijken visuele representaties niet altijd op zichzelf te staan; hun interpretatie kan door andere zintuiglijke ervaringen, zoals het luisteren, worden gevoed. Maar die ervaringen moeten op hun beurt ook aangeleerd worden, en waarvoor de mnemonische, didactische en verleidelijke rollen van de geluidsopname van groot belang zijn - rollen die in het wetenschaps- en techniekonderzoek naar de rol van instrumenten nog wel eens over het hoofd worden gezien. Tenslotte geeft dit proefschrift ook inzicht in de culturele waarde van geluidsopnamen, en de soms poreuze grenzen tussen wetenschap en de cultuur waarin zij zich ontwikkelt. Geluidsopnames werden niet alleen in wetenschappelijke bewijsvoering ingezet, maar verwierven tegelijkertijd ook tal van andere commerciële of symbolische waarden die, soms paradoxaal, op hun beurt opnieuw hun wetenschappelijke gebruik ondersteunden. Op die manier hielpen zij eveneens om de kennis en zintuigelijke ervaring van vogelgeluid te delen, te bediscussiëren, te standaardiseren, te onthouden, en te populariseren. 


\section{Curriculum Vitae}

Joeri Bruyninckx (Genk, 1985) studied a BA in Arts \& Culture at Maastricht University, The Netherlands. He was an intern junior researcher at the Kungliga Tekniska Högskolan in Stockholm, and earned a Master of Philosophy degree with distinction in the Cultures of Arts, Science and Technology program at Maastricht University in 2008. His Master thesis explored the role of sound recording in ornithology, and was awarded with the Maastricht University Science Foundation Student Prize. Between 2008 and 2012 he was employed by the Faculty of Arts and Social Sciences at the same university, where he taught and investigated this theme in more detail in a $\mathrm{PhD}$ project and as a member of the NWO-funded project group 'Sonic Skills: Sound and Listening in the Development of Science, Technology and Medicine (1920-now)'. As part of his $\mathrm{PhD}$ work, he was enrolled in the graduate training program of the Netherlands Graduate Research School of Science, Technology and Modern Culture (WTMC). In the autumn of 2010, he also was a visiting pre-doctoral student at the Science and Technology Studies department at Cornell University. For a chapter contribution to the Oxford Handbook of Sound Studies based on this dissertation, he was awarded the 2012 Nicholas C. Mullins prize by the Society for Social Studies of Science. He has taken up a postdoctoral position at the Faculty of Arts \& Social Sciences at Maastricht University, focusing his research on the intersections between science \& technology studies and the senses. 